Keila Modesto Tramonte

Estudo da disponibilidade de metais em sedimentos do Sistema Cananéia-Iguape

Tese apresentada ao Instituto Oceanográfico da Universidade de São Paulo, como parte dos requisitos para obtenção do título de Doutor em Ciências, Programa de Oceanografia, área de Oceanografia Química

Orientador:

Prof. Dr. Rubens Cesar Lopes Figueira

São Paulo

2014 

Universidade de São Paulo Instituto Oceanográfico

\title{
Estudo da disponibilidade de metais em sedimentos do Sistema Cananéia-Iguape
}

\author{
Keila Modesto Tramonte
}

Tese apresentada ao Instituto Oceanográfico da Universidade de São Paulo, como parte dos requisitos para obtenção do título de Doutor em Ciências, Programa de Oceanografia, área de Oceanografia Química.

(versão corrigida)

Julgada e Aprovada em 26/11/2014

Prof. Dr. Rubens Cesar Lopes Figueira

Conceito

Prof. Dr. Renato Rodrigues Neto

Conceito

Prof. Dr. Marcelo Luiz Martins Pompêo

Conceito

Profa. Dra. Márcia Caruso Bícego

Conceito

Prof. Dr. Michel Michaelovitch de Mahiques

Conceito 
Ao meu pai, Rogério Tramonte (in memoriam), que me ensinou que as adversidades ao longo do caminho são também valiosas oportunidades de evolução. $\mathcal{N a ̃ o}$ me esqueço, um só dia, de tuas lições do bem... 


\section{AGRADECIMENTOS}

Ao Prof. Dr. Rubens Cesar Lopes Figueira, pela oportunidade, pela acolfida, pelos ensinamentos, pela confiança, pela amizade, pela paciência e compreensão em momentos dificeis. Obrigada por tudo!

À Profa. Dra. Márcia Caruso Bícego e ao Prof. Dr. Renato Rodrigues $\mathcal{N}$ eto pelas contribuições durante o exame de Qualificação.

À Dra. Andreza Portella Ribeiro, pela amizade e pelo apoio no desenvolvimento deste trabalho, principalmente, quanto ao "desvendando os mistérios do ICP-OES".

Ao meu esposo Marcello Oliveira Franco, amigo e companheiro de todas as horas, que sempre me incentivou e não mediu esforços para ajudar na conquista dos meus objetivos.

Ao Conselho $\mathcal{N a c i o n a l}$ de Desenvolvimento Científico e Tecnológico (CNPPq) pela concessão da bolsa de doutorado.

Aos colegas do LaQIMMar, pela ajuda e agradável convivência ao longo desses anos, com especial agradecimento:

Ao Paulo Alves de Lima Ferreira, pelas dicas de oceanografia, estatística e tudo mais. Muito obrigada!

À Miriam Fernanda Batista, pela grande ajuda nos procedimentos de laboratório.

Ao Alexandre Barbosa Salaroli, pelo auxílio nas inúmeras análises de metais.

À equipe do Laboratório de Sedimentologia do Instituto Oceanográfico da Universidade de São Paulo, pelas análises granulométricas.

Aos funcionários da biblioteca e da secretária de pós-graduação do Instituto Oceanográfico da Vniversidade de São Paulo, sempre gentis e solícitos.

E, finalmente, o meu agradecimento a Deus e aos mensageiros celestiais, por tudo, principalmente, pelo amparo nas dificuldades. 


\section{SUMÁRIO}

ÍNDICE DE FIGURAS..........................................................................

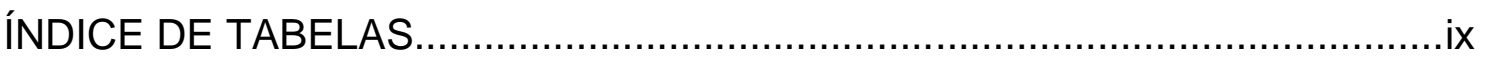

RESUMO

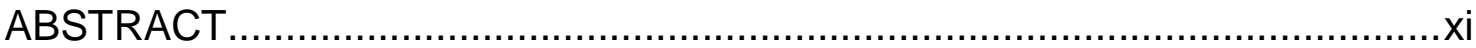

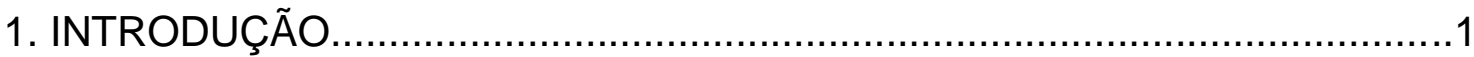

1.1 Metais em sedimentos aquáticos.................................................

1.1.1 Características físico-químicas dos sedimentos...........................4

1.1.2 Remobilização de metais em sedimentos.....................................

1.2 Extração sequencial de metais em sedimentos..............................11

1.3 A contribuição das atividades de mineração no enriquecimento de metais no Sistema Cananéia-Iguape...........................................15

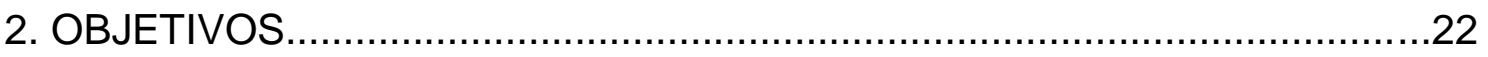

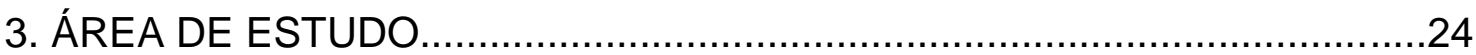

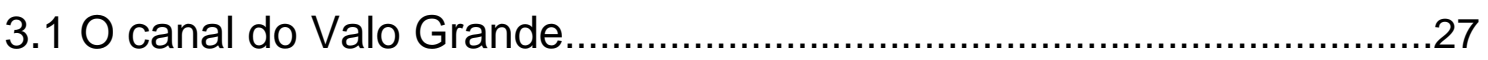

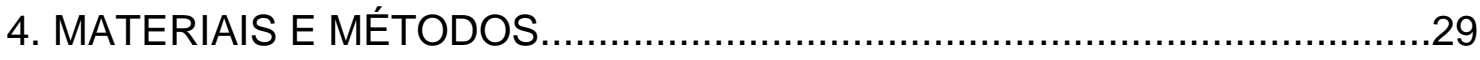

4.1 Coleta e preparação das amostras.............................................29

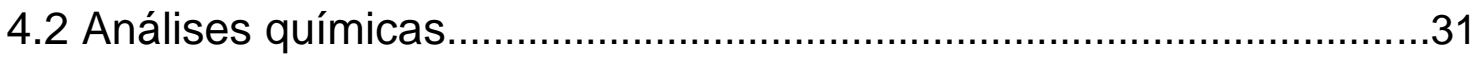

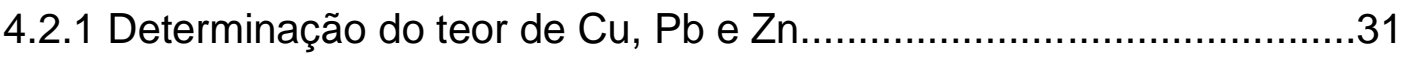

4.2.1.1 Extração sequencial de metais...........................................31 


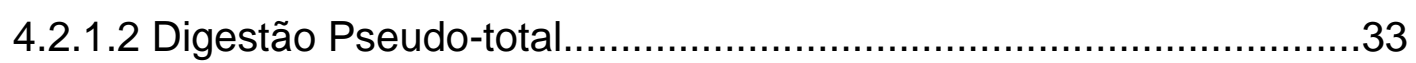

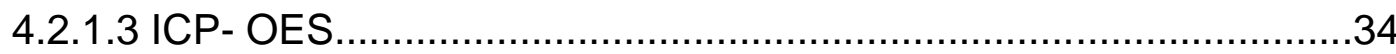

4.2.2 Carbono Orgânico Total (COT)......................................................36

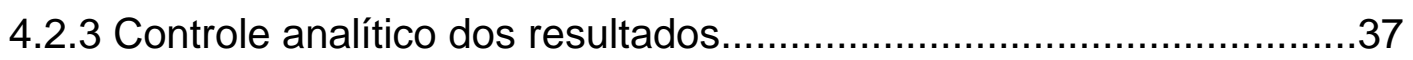

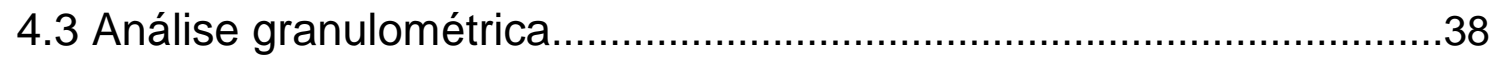

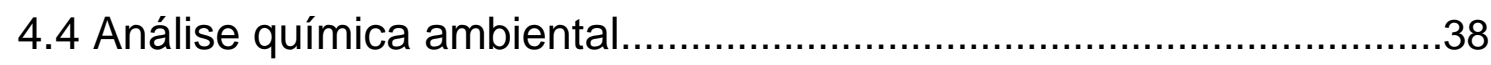

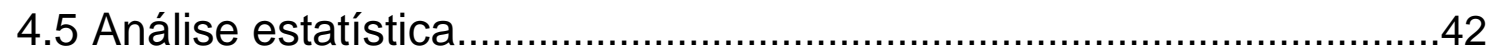

4.6 Histórico da inserção antrópica de $\mathrm{Cu}, \mathrm{Pb}$ e Zn no Sistema CananéiaIguape durante o período de atividades de mineração no Vale do

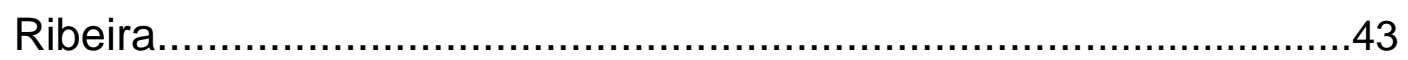

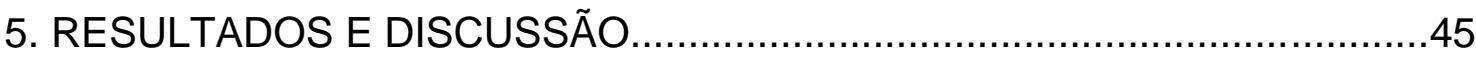

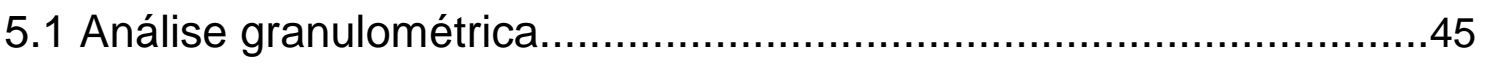

5.2 Análise de Carbono Orgânico Total (COT).........................................51

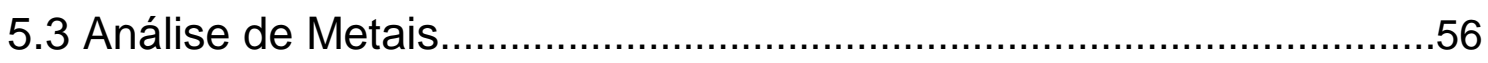

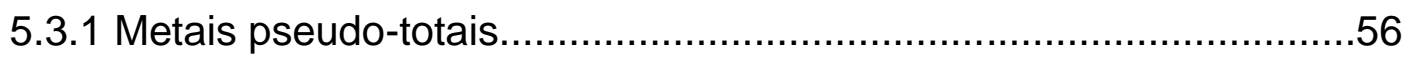

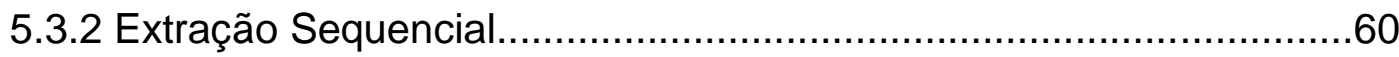

5.3.2.1 Somatório das frações ( 5 F1 a F3) ...........................................67

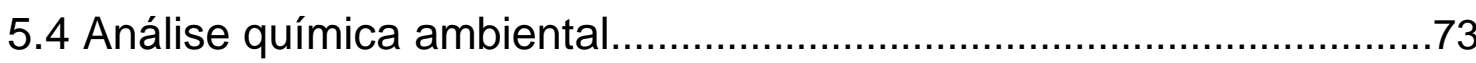

5.4.1 Grau de contaminação dos sedimentos.............................................73

5.4.2 Análise do potencial de mobilidade.............................................78

5.4.3 Risk Assessment Code (RAC)...................................................80 
5.4.4 Comparação do teor disponível de $\mathrm{Cu}, \mathrm{Pb}$ e $\mathrm{Zn}$ entre o Sistema Cananéia-Iguape e outras regiões afetadas por atividades de mineração .86

5.5 Análises estatísticas. .90

5.5.1 Coeficiente de correlação de Pearson. .90

5.5.1.1 Teor disponível ( $\Sigma$ F1 a F3) e parcial de $\mathrm{Cu}, \mathrm{Pb}$ e $\mathrm{Zn}$ (método ISO 11466) .90

5.5.1.2 Teor parcial de $\mathrm{Cu}, \mathrm{Pb}$ e $\mathrm{Zn}$ (métodos ISO 11466 e US EPA 3050B). .92

5.5.2 Matriz de correlação. 94

5.5.3 Análise de Agrupamento. .96

5.6 Histórico da inserção antrópica de $\mathrm{Cu}, \mathrm{Pb}$ e Zn no Sistema CananéiaIguape durante o período de atividades de mineração no Vale do Ribeira. 100

5.6.1 Extração sequencial: teor disponível de $\mathrm{Cu}, \mathrm{Pb}$ e Zn 100

5.6.2 Grau de contaminação dos sedimentos 105

5.6.3 Geocronologia da camada superior sedimentar dos testemunhos...111

6. CONCLUSÕES 116

7. REFERÊNCIAS BIBLIOGRÁFICAS 119

ANEXOS. 136 


\section{ÍNDICE DE FIGURAS}

Figura 1. Localização da área de estudo; Sistema Cananéia-Iguape. .24

Figura 2. Representação gráfica das estações amostrais superficiais e dos testemunhos ao longo do Sistema Cananéia-Iguape. .30

Figura 3. Fluxograma do esquema de extração sequencial de metais com base no protocolo desenvolvido e otimizado do Programa BCR. 32

Figura 4. Diâmetro médio, em $\phi$, das amostras de sedimento superficial coletadas ao longo do Sistema Cananéia-Iguape. 46

Figura 5. Areia, silte e argila, em \%, das amostras de sedimento superficial coletadas ao longo do Sistema Cananéia-Iguape

Figura 6. Representação dos percentuais de lama junto às estações amostrais ao longo do Sistema Cananéia-Iguape

Figura 7. Representação dos percentuais de lama, junto às estações amostrais, nas regiões Iguape-Valo Grande, Mar Pequeno e Mar de Cananéia. .51

Figura 8. COT, em \%, nas amostras de sedimento superficial coletadas ao longo do Sistema Cananéia-Iguape .52

Figura 9. Representação dos percentuais de COT junto às estações amostrais ao longo do Sistema Cananéia-Iguape .53

Figura 10. Representação dos percentuais de COT, junto às estações amostrais, nas regiões Iguape-Valo Grande, Mar Pequeno e Mar de Cananéia.

Figura 11. Teor parcial de $\mathrm{Cu}$, em $\mathrm{mg} \mathrm{kg}^{-1}$, nas amostras superficiais ao longo do Sistema Cananéia-Iguape 
Figura 12. Teor parcial de $\mathrm{Pb}$, em $\mathrm{mg} \mathrm{kg}^{-1}$, nas amostras superficiais ao longo do Sistema Cananéia-Iguape. .58

Figura 13. Teor parcial de $\mathrm{Zn}$, em $\mathrm{mg} \mathrm{kg}^{-1}$, nas amostras superficiais ao longo do Sistema Cananéia-Iguape. .59

Figura 14. Teor de $\mathrm{Cu}$, em $\mathrm{mg} \mathrm{kg}^{-1}$, associado às frações disponíveis nas amostras de sedimento superficial ao longo do Sistema CananéiaIguape. .64

Figura 15. Teor de $\mathrm{Pb}$, em $\mathrm{mg} \mathrm{kg}^{-1}$, associado às frações disponíveis nas amostras de sedimento superficial ao longo do Sistema CananéiaIguape. .65

Figura 16. Teor de $\mathrm{Zn}$, em $\mathrm{mg} \mathrm{kg}^{-1}$, associado às frações disponíveis nas amostras de sedimento superficial ao longo do Sistema CananéiaIguape. .66

Figura 17. Teor disponível de $\mathrm{Cu}$, em $\mathrm{mg} \mathrm{kg}^{-1}$, nas estações amostrais ao longo do Sistema Cananeia-Iguape.

Figura 18. Teor disponível de $\mathrm{Pb}$, em $\mathrm{mg} \mathrm{kg}^{-1}$, nas estações amostrais ao longo do Sistema Cananeia-Iguape .68

Figura 19. Teor disponível de $\mathrm{Zn}$, em mg kg${ }^{-1}$, nas estações amostrais ao longo do Sistema Cananeia-Iguape. 68

Figura 20. Teor disponível de $\mathrm{Cu}, \mathrm{Pb}$ e $\mathrm{Zn}$, em $\mathrm{mg} \mathrm{kg}^{-1}$, juntos às estações amostrais nas regiões Iguape-Valo Grande, Mar Pequeno e Mar de Cananéia .72

Figura 21. Teor disponível e valores de comparação do $\mathrm{Cu}$, em $\mathrm{mg} \mathrm{kg}^{-1}$, em amostras superficiais ao longo do Sistema CananéiaIguape. .75 
Figura 22. Teor disponível e valores de comparação do $\mathrm{Pb}$, em $\mathrm{mg} \mathrm{kg}^{-1}$, em amostras superficiais ao longo do Sistema CananéiaIguape .76

Figura 23. Teor disponível e valores de comparação do $\mathrm{Zn}$, em $\mathrm{mg} \mathrm{kg}^{-1}$, em amostras superficiais ao longo do Sistema CananéiaIguape. .77

Figura 24. Potencial de mobilidade do $\mathrm{Cu}, \mathrm{Pb}$ e $\mathrm{Zn}$ nas regiões Iguape-Valo Grande, Mar Pequeno e Mar de Cananéia .79

Figura 25. Risk Assessment Code (RAC) para $\mathrm{Cu}, \mathrm{Pb}$ e $\mathrm{Zn}$ na região IguapeValo Grande. .82

Figura 26. Risk Assessment Code (RAC) para $\mathrm{Cu}, \mathrm{Pb}$ e $\mathrm{Zn}$ na região do Mar Pequeno .83

Figura 27. Risk Assessment Code (RAC) para $\mathrm{Cu}, \mathrm{Pb}$ e $\mathrm{Zn}$ na região do Mar de Cananéia. 84

Figura 28. Risk Assessment Code (RAC) para $\mathrm{Cu}, \mathrm{Pb}$ e $\mathrm{Zn}$ no Sistema Cananéia-lguape. .85

Figura 29. Gráfico de dispersão entre teor disponível e teor parcial de Cu.......90

Figura 30. Gráfico de dispersão entre teor disponível e teor parcial de Pb.......91

Figura 31. Gráfico de dispersão entre teor disponível e teor parcial de Zn......91

Figura 32. Gráfico de dispersão do teor parcial de Cu obtido pelos métodos de digestão ISO 11466 e US EPA 3050B.

Figura 33. Gráfico de dispersão do teor parcial de $\mathrm{Pb}$ obtido pelos métodos de digestão ISO 11466 e US EPA 3050B. .93

Figura 34. Gráfico de dispersão do teor parcial de Zn obtido pelos métodos de digestão ISO 11466 e US EPA 3050B. 
Figura 35. Dendrograma com os agrupamentos entre teor disponível de $\mathrm{Cu}, \mathrm{Pb}$ e Zn, lama e COT em amostras superficiais do Sistema CananéiaIguape .99

Figura 36. Teor de $\mathrm{Cu}$, em $\mathrm{mg} \mathrm{kg}^{-1}$, associado às frações móveis nas amostras de sedimento dos testemunhos CAN 02, 04, 05, 07 e 10, coletados ao longo do Sistema Cananéia-Iguape. 102

Figura 37. Teor de $\mathrm{Pb}$, em $\mathrm{mg} \mathrm{kg}^{-1}$, associado às frações móveis nas amostras de sedimento dos testemunhos CAN 02, 04, 05, 07 e 10, coletados ao longo do Sistema Cananéia-Iguape. 103

Figura 38. Teor de $\mathrm{Zn}$, em $\mathrm{mg} \mathrm{kg}^{-1}$, associado às frações móveis nas amostras de sedimento dos testemunhos CAN 02, 04, 05, 07 e 10, coletados ao longo do Cananéia-Iguape. .104

Figura 39. Teor disponível e valores de comparação do $\mathrm{Cu}$, em $\mathrm{mg} \mathrm{kg}^{-1}$, em amostras de testemunhos coletados ao longo do Sistema Cananéia-Iguape. 108

Figura 40. Teor disponível e valores de comparação do $\mathrm{Pb}$, em $\mathrm{mg} \mathrm{kg}^{-1}$, em amostras de testemunhos coletados ao longo do Sistema Cananéia-Iguape. 109

Figura 41. Teor disponível e valores de comparação do $\mathrm{Zn}$, em $\mathrm{mg} \mathrm{kg}^{-1}$, em amostras de testemunhos coletados ao longo do Sistema Cananéia-Iguape. 110

Figura 42. Idade (ano) e teor disponível de $\mathrm{Cu}, \mathrm{Pb}$ e $\mathrm{Zn}$, em $\mathrm{mg} \mathrm{kg}^{-1}$, das amostras do testemunho CAN 02. 113

Figura 43. Idade (ano) e teor disponível de $\mathrm{Cu}, \mathrm{Pb}$ e $\mathrm{Zn}$, em mg kg-1, das amostras do testemunho CAN 04. 113

Figura 44. Idade (ano) e teor disponível de $\mathrm{Cu}, \mathrm{Pb}$ e $\mathrm{Zn}$, em mg kg-1, das amostras do testemunho CAN 05. 
Figura 45. Idade (ano) e teor disponível de $\mathrm{Cu}, \mathrm{Pb}$ e $\mathrm{Zn}$, em $\mathrm{mg} \mathrm{kg}^{-1}$, das amostras do testemunho CAN 07............................................114

Figura 46. Idade (ano) e teor disponível de $\mathrm{Cu}, \mathrm{Pb}$ e $\mathrm{Zn}$, em $\mathrm{mg} \mathrm{kg}^{-1}$, das amostras do testemunho CAN 10..............................................115 


\section{ÍNDICE DE TABELAS}

Tabela 1. Mobilidade relativa e disponibilidade de metais

Tabela 2. Frações e reagentes do protocolo de extração sequencial de TESSIER

Tabela 3. Posição e comprimento dos testemunhos. 29

Tabela 4. Comprimentos de onda e limites de quantificação .35

Tabela 5. Recuperação do material de referência CRM 701 (Taxa de recuperação + DPR, $n=4)$ 37

Tabela 6. Concentração de metais $\left(\mathrm{mg} \mathrm{kg}^{-1}\right)$ : valores Canadenses, regionais e composição média nos folhelhos

Tabela 7. Taxa de sedimentação dos testemunhos .44

Tabela 8. Comparação do teor disponível de $\mathrm{Cu}, \mathrm{Pb}$ e $\mathrm{Zn}$ entre o Sistema Cananéia-Iguape e outras regiões afetadas por atividades de exploração mineral e afins .88

Tabela 9. Matriz de correlação entre os resultados de metais, lama e COT das amostras superficiais do Sistema Cananéia-Iguape. 95 


\section{ESTUDO DA DISPONIBILIDADE DE METAIS EM SEDIMENTOS DO SISTEMA CANANÉIA-IGUAPE}

\section{Keila Modesto Tramonte}

\section{RESUMO}

O Sistema Cananéia-Iguape sofreu importantes alterações ambientais devido à abertura do canal do Valo Grande que o conectou ao rio Ribeira de Iguape. Com a intensa atividade de mineração ocorrida no Vale do Ribeira, a bacia do rio Ribeira foi afetada, atingindo o Sistema através desse canal. Diante desse cenário, o principal objetivo deste estudo foi avaliar a disponibilidade de $\mathrm{Cu}, \mathrm{Pb}$ e Zn no Sistema Cananéia-Iguape, a partir do teor associado aos principais componentes dos sedimentos. Para estimar a contaminação química, o teor desses elementos foi comparado aos limites canadenses (ISQG e PEL), ao teor na região em período que antecedeu à intensa atividade de mineração e a valores de background (composição média dos folhelhos). Considerando-se os resultados de $\mathrm{Cu}$ e $\mathrm{Zn}$, estima-se que em caso de remobilização, possivelmente, não representariam perigo às comunidades bióticas. Entretanto, o teor disponível de $\mathrm{Pb}$ excedeu os valores de comparação em várias estações, sugerindo atenção quanto à sua biodisponibilidade. Em geral, a região que mais favoreceu o acúmulo de metais foi o Mar Pequeno, provavelmente, devido às condições oceanográficas. Dados de geoquímica e de geocronologia de testemunhos possibilitaram reconhecer a inserção antrópica do $\mathrm{Pb}$ no Sistema durante o período de mineração.

Palavras-chave: Sistema Cananéia-Iguape, mineração, extração sequencial, metais, sedimento. 


\title{
STUDY OF THE AVAILABILITY OF METALS IN SEDIMENTS IN THE CANANÉIA-IGUAPE SYSTEM
}

\section{Keila Modesto Tramonte}

\begin{abstract}
The Cananéia-Iguape System suffered important changes due to the opening of Valo Grande Channel, which connect this System to the Ribeira de Iguape River. The mining activities in the Ribeira Valley affected the river basin, reaching this System through Valo Grande. The main goal of this study was to evaluate the availability of $\mathrm{Cu}, \mathrm{Pb}$ and $\mathrm{Zn}$ in the Cananéia-Iguape System, based on the content associated with the main components of the sediments. In order to estimate chemical contamination, the content of these elements was compared to Canadians limits (ISQG and PEL), to the content of these metals in the region in period preceding to the intense mining activity and to the background values (shale average composition). The results for $\mathrm{Cu}$ and $\mathrm{Zn}$ indicated that in case of remobilization, they possibly would not represent a hazard to the biotic communities. However, the available content for $\mathrm{Pb}$ exceeded the comparative values at various stations, suggesting attention regarding its bioavailability. In general, the region that favored the most the accumulation of metals was Mar Pequeno, possibly due to oceanographic conditions. Data regarding geochemistry and geochronology of cores enable the observation of the insertion the $\mathrm{Pb}$ anthropogenic in the System during the mining period.
\end{abstract}

Keywords: Cananéia-Iguape System, mining, sequential extraction, metals, sediment. 


\section{INTRODUÇÃO}

O Sistema Cananéia-Iguape está localizado no extremo sul do estado de São Paulo e consiste em um complexo de canais estuarinos e lagunares. Essa região, reconhecida como Reserva da Biosfera pela Organização das Nações Unidas para a Educação, Ciência e Cultura - UNESCO (MAHIQUES et al., 2013), sofreu impacto ambiental significativo desde a abertura do canal do Valo Grande. Este canal, construído por volta de 1852 (GEOBRÁS, 1966), conectou o rio Ribeira de Iguape ao Sistema Cananéia-Iguape; sua abertura teve como objetivo interligar o porto do Ribeira a Iguape, estratégia que na época favorecia a economia da região. Com a intensa atividade de mineração ocorrida no Vale do Ribeira entre as décadas de 40 e 90, a bacia do rio Ribeira foi afetada atingindo o Sistema Cananéia-Iguape através do canal do Valo Grande. Diante deste cenário, tornou-se importante estudar a disponibilidade de metais nessa região, a fim de estimar o teor móvel dos elementos e o comportamento destes quanto à remobilização.

O estudo de metais em sedimentos tem sido um tema relevante em pesquisas ambientais, visto que são considerados, além de um reservatório de espécies químicas, compartimentos aquáticos ativos que desempenham importante papel na redistribuição dessas espécies à biota (COTTA, REZENDE e PIOVANI, 2006; CUONG e OBBARD, 2006). Contudo, conhecer a concentração total de metais em sedimentos, embora seja importante em termos de poluição global, não é suficiente para estimar os efeitos biológicos (ARAIN et al., 2009); pois, utilizá-la para avaliar os efeitos potenciais de contaminação, é sugerir que todas as formas de um determinado metal 
apresentam igual impacto sobre o ambiente, sendo tal suposição insustentável (TESSIER, CAMPBELL e BISSON,1979).

Portanto, para estudar a disponibilidade de metais no Sistema Cananéia-Iguape, optou-se por utilizar procedimento de extração sequencial. Foi adotado o método proposto e otimizado pela European Community Bureau of Reference (BCR), atual Standards, Measurements and Testing Programme (SM\&T), que estabelece três frações distintas reconhecidas como solúvel em ácido, redutível e oxidável. Os metais associados a essas frações são liberados, sequencialmente, pela ação química de reagentes específicos para cada fase, simulando a remobilização de metais em sedimentos quando há variação das condições ambientais.

É oportuno esclarecer que o termo disponibilidade aqui utilizado está relacionado à possibilidade de remobilização dos metais no ambiente e não reflete a biodisponibilidade destes. Biodisponibilidade costuma ser operacionalmente definida como resultados de experimentos de toxicidade e, como não há método universalmente aceito para sua determinação, o conceito permanece sujeito a muitas interpretações e argumentações (HOROWITZ, 1985).

\subsection{Metais em sedimentos aquáticos}

Os metais em ambientes aquáticos podem ser de origem natural em decorrência de diversos processos como, por exemplo, intemperismo do solo e das rochas, erosão e erupções vulcânicas; ou ainda, de origem antrópica, quando presentes em efluentes industriais, em resíduos de atividades de 
mineração e refino e na drenagem agrícola, entre outros (DAVUTLUOGLU et al., 2011). As rochas e os solos são as principais fontes naturais de metais pesados no meio ambiente, os quais foram incorporados como elementos traço na estrutura cristalina de minerais primários, formados durante o resfriamento do magma (BRADL, 2005).

Embora os metais sejam constituintes naturais dos ambientes aquáticos, estudos têm revelado um aumento significativo no teor desses elementos, em razão de atividades humanas. Nesses ambientes, a maioria dos compostos químicos de origem antrópica e materiais residuais, eventualmente, acumulam-se em sedimentos (US EPA, 2000). Estima-se que mais de $90 \%$ da carga de metais pesados em sistemas aquáticos esteja ligada a particulados, como material em suspensão e sedimentos (CALMANO, HONG e FÖRSTNER,1993).

Os sedimentos têm sido considerados parte integral e dinâmica das bacias hidrográficas, estuários e zonas costeiras (FÖRSTNER, 2004), fornecendo habitat para diversos organismos aquáticos e funcionando como os principais repositórios da maioria das substâncias químicas persistentes introduzidas nas águas superficiais (US EPA, 2000). A investigação sobre metais nestes compartimentos têm crescido, não apenas com foco em ambientes de deposição de espécies químicas, mas também com outros interesses. Segundo FÖRSTNER (2004), os sedimentos aquáticos podem apresentar funções como vigilância (efeito memória); monitoramento da qualidade biológica e química; prognósticos para os riscos de remobilização e depósitos subaquosos. 


\subsubsection{Características físico-químicas dos sedimentos}

De acordo com BAIRD (2002), os sedimentos são definidos como camadas de partículas minerais e orgânicas, com frequência finamente granuladas, que estão junto à parte inferior dos corpos de água natural. As partículas que formam os sedimentos originam-se da ação do intemperismo e da erosão de rochas, das atividades de organismos, de erupções vulcânicas, de processos químicos que ocorrem na água e, até mesmo, do espaço, tendo como fonte a poeira interplanetária e os impactos de grandes asteróides e cometas (GARRISON, 2010).

Sedimentos marinhos, geralmente, são classificados pela origem da maioria de suas partículas. Nas fontes extrabaciais ou alóctones os sedimentos são de natureza terrígena, incluindo, os sedimentos cosmogênicos; nas fontes intrabaciais ou autóctones, os sedimentos são decorrentes de precipitações entre a água do mar e compostos químicos orgânicos e inorgânicos, envolvendo inclusive a autigênese (PONZI, 2004).

A granulometria também é utilizada para classificar os sedimentos, que de acordo com o tamanho do grão, basicamente, costumam ser agrupados em sedimentos grossos ou finos (lama). O primeiro grupo é constituído por areia e cascalho, e o segundo, por argila e silte (PONZI, 2004); dentre essas quatro partículas, a argila apresenta o menor diâmetro, inferior a 0,004 mm, segundo a escala de WENTWORTH (1922).

Geralmente, quanto menor o tamanho das partículas, mais fácil será o transporte por correntes e ondas; os grãos grossos são movidos apenas por 
fluxos turbulentos, tendendo a não se deslocarem para muito longe, já a argila poderá permanecer suspensa por longos períodos e ser levada por grandes distâncias antes da deposição (GARRISON, 2010).

O tamanho do grão, normalmente, influência no acúmulo dos contaminantes, uma vez que o enriquecimento da maioria dos componentes ativos da superfície do sedimento ocorre nas frações de grão fino (FÖRSTNER, 2004), em razão da área superficial. Estudos mostraram que partículas de areia apresentam área superficial na ordem de dezenas a centenas de $\mathrm{cm}^{2} \mathrm{~g}^{-1}$, partículas de silte na ordem de centenas a milhares de $\mathrm{cm}^{2} \mathrm{~g}^{-1}$ e partículas de argila na ordem de dezenas de $\mathrm{m}^{2} \mathrm{~g}^{-1}$ (JACKSON, 1979 apud HOROWITZ, 1985).

Enquanto o particionamento físico do sedimento ocorre pela separação de uma amostra em diversas categorias como o tamanho do grão, a área superficial, propriedades mineralógicas e outras; o particionamento químico ocorre em função da separação dos metais traço de acordo com as suas associações a outros componentes existentes no sedimento, e ainda, pelo tipo de ligação existente entre eles (HOROWITZ, 1985). A retenção de íons metálicos em fases sólidas poderá ocorrer por meio de diferentes mecanismos, conforme informações apresentadas a seguir.

O processo de adsorção, considerado o principal mecanismo de retenção de metais nas superfícies, envolve a condensação de átomos, íons ou moléculas na superfície de outra substância; a adsorção poderá ocorrer com ou sem a troca iônica, que por sua vez, é um processo que caracteriza-se pela adsorção de cátions em solução e a equivalente liberação de outros cátions 
(HOROWITZ, 1985). Contudo, ambos os processos, adsorção e troca iônica, ocorrem em substâncias de granulação fina com grande superfície de área (FÖRSTNER, 1979).

Muitos materiais que são componentes comuns dos sedimentos como os argilominerais, hidróxidos de Fe (ferro), óxidos de Mn (manganês) e matéria orgânica são capazes de realizar a troca iônica (HOROWITZ, 1985). Os argilominerais desempenham importante função na acumulação, sorção/dessorção, bem como, em processos de troca de metais (RYBICKA, CALMANO e BREEGER, 1995), porém, o seu principal papel não é na adsorção direta de elementos traço e sim na sua atuação como substrato mecânico, para a precipitação e floculação de matéria orgânica e de minerais secundários, como hidróxidos de Fe e óxidos de Mn (FÖRSTNER, 2004).

Os ciclos redox do $\mathrm{Mn}$ e $\mathrm{Fe}$ exercem importante influência no enriquecimento de metais traço em sistemas subóxido-anóxico, pois, podem desencadear e/ou acelerar a transferência desses elementos da água do mar para o sedimento, bem como, sua remobilização diagenética nos sedimentos (TRIBOVILLARD et al., 2006). Os oxi-hidróxidos de Fe e Mn apresentam alta capacidade de adsorção de íons metálicos, fosfatos, silicatos, arsenatos e selenatos, porém, suas sequências redox são meio de trânsito entre a espécie metálica oxidada e facilmente precipitável, e a espécie metálica reduzida e facilmente solúvel (MELLADO e GALVÍN, 1999).

A matéria orgânica presente nos solos, turfas e sedimentos consiste em uma mistura de produtos resultantes da degradação química e biológica de resíduos vegetais e animais, e da atividade de síntese de micro-organismos, 
sendo chamada de húmus, substâncias húmicas e substâncias não húmicas (ROCHA e ROSA, 2003). Importante característica das substâncias húmicas é a habilidade em formar complexos, solúveis e insolúveis em água, com íons metálicos e oxi-hidróxidos, além de interagir com argilominerais e compostos orgânicos (SCHNITZER, 1978). Essas substâncias geralmente possuem, em média, $35 \%$ de oxigênio e entre 1 e $2 \%$ de nitrogênio e enxofre em suas estruturas, sendo o oxigênio predominante na forma de grupos carboxílicos e fenólicos (ROCHA e ROSA, 2003).

Os sulfetos são comuns em sedimentos de água doce e marinhas, sendo predominantes na forma de enxofre em sedimentos anaeróbios (CALMANO, AHLF e FÖRSTNER, 1996). Nos ambientes reduzidos da maioria dos sedimentos subsuperficias estuarinos, os sulfetos dominam 0 particionamento de metal, enquanto que, os óxidos de Fe e Mn, bem como, vários materiais orgânicos são importantes substratos para ligações de metais sob condições óxicas (BOURGOIN, RISKB e AITKEN, 1991). A habilidade dos sulfetos em complexar íons metálicos é bem conhecida e, inclusive, pode explicar a falta de toxicidade, até mesmo quando altas concentrações de metais estão presentes em alguns sedimentos (CALMANO, AHLF e FÖRSTNER, 1996).

Além desses mecanismos, é importante citar o processo de substituição isomórfica. Trata-se da incorporação de metais em cristais minerais e envolve a troca de um elemento por outro que está em uma estrutura cristalina, sendo regido pela carga e pelo raio atômico (HOROWITZ, 1985). 


\subsubsection{Remobilização de metais em sedimentos}

Contaminantes não são, necessariamente, fixos permanentemente aos sedimentos (CALMANO, AHLF e FÖRSTNER, 1996; ZOUMIS et al., 2001). A mobilidade, a biodisponibilidade e a toxicidade dos metais pesados no ambiente dependem fortemente de suas formas químicas específicas ou do tipo de ligação (QUEVAUVILLER, 1998; PUEYO et al., 2001; KELDERMAN e OSMAN, 2007), que por sua vez, são controladas pelas características físicoquímicas e biológicas do sistema (SAKAN et al., 2009).

A transferência direta de substâncias químicas dos sedimentos para os organismos é considerada a principal rota de exposição para muitas espécies (ZOUMIS et al., 2001) e, embora a captação de metais pesados ocorra principalmente em fases dissolvidas, a interação com fases sólidas deve ser considerada com seus processos mecânicos e químicos como bioturbação, sorção e dessorção, difusão e mobilização (CALMANO e FÖRSTNER, 1983).

As formas químicas dos metais diferem na sua capacidade de transferência e biodisponibilidade no ecossistema; os metais dissolvidos ou fracamente adsorvidos podem estar facilmente disponíveis para as plantas e organismos aquáticos, enquanto os metais ligados à rede cristalina estrutural de minerais primários e secundários, não estão disponíveis para a biota, a menos que haja intemperismo geoquímico (CALMANO, HONG e FÖRSTNER,1993). Quando os sedimentos não sofrem ação antrópica, os metais traço estão ligados, principalmente, aos silicatos e aos minerais primários e, portanto, com baixo grau de mobilidade; entretanto, elementos incorporados de forma antrópica, estão ligados a outras fases do sedimento, 
como carbonatos, óxidos, hidróxidos e sulfetos, apresentando maior mobilidade (PEREIRA et al., 2007). De acordo com FÖRSTNER (1981), a mobilização dos metais pesados de material suspenso e sedimentos pode ser causada, principalmente, por quatro tipos de alterações químicas nas águas:

1- Elevada concentração salina, pela qual os cátions de metais alcalinos e alcalino-terrosos podem competir com os íons metálicos sorvidos em partículas sólidas.

2 - Mudanças da condição redox, levando à dissolução parcial ou completa de hidróxidos de $\mathrm{Fe}$ e $\mathrm{Mn}$, além da liberação de parte dos metais pesados incorporados ou sorvidos.

3 - Queda do pH, permitindo a dissolução de carbonatos e hidróxidos, bem como, aumentando a dessorção dos cátions metálicos devido à competição com íons $\mathrm{H}^{+}$.

4 - Aumento do uso de agentes complexantes naturais e sintéticos, os quais podem formar complexos metálicos solúveis de alta estabilidade com metais pesados adsorvidos em partículas sólidas.

Segundo CALMANO, HONG e FÖRSTNER (1993), as transformações dos tipos de ligação dos metais pesados nos sedimentos incluem, principalmente, os seguintes processos: sorção e dessorção; formação e dissolução de metais ligados a carbonato; formação e decomposição de compostos complexos organometálicos solúveis e insolúveis; formação e dissolução de hidróxidos e oxi-hidratos; sorção e co-precipitação de metais por 
óxidos de Fe/Mn; precipitação de sulfetos metálicos em ambientes de forte redução e dissolução na conversão a sulfatos sob condições óxicas.

A dissolução redutiva do Mn (IV) e Fe (III) para Mn (II) e Fe (II), respectivamente, está associada com um aumento na solubilidade e mobilidade desses elementos na água intersticial subóxica (OTERO et al., 2009). A mudança das condições redox, usualmente causada pelo aumento de nutrientes e deficiência de oxigênio nos sedimentos, permite a dissolução inicial do óxido hidratado de Mn seguido pelos componentes de Fe e, uma vez que esses metais são solúveis em seus estados divalentes, qualquer co-precipitado com revestimento metálico poderá ser parcialmente remobilizado (FÖRSTNER, 1979). Quando o oxigênio esgota-se, os micro-organismos continuam a decomposição da matéria orgânica utilizando outros oxidantes disponíveis. Segundo FROELICH et al. (1979) os oxidantes são consumidos na seguinte ordem: oxigênio > óxido de $\mathrm{Mn} \sim$ nitrato > óxido de $\mathrm{Fe}>$ sulfato.

De acordo com CALMANO e FÖRSTNER (2004), os processos redox periódicos também podem induzir ao aumento ou diminuição no potencial de produção ácida ou $\mathrm{pH}$; em um sistema água/sedimento fechado, os íons $\mathrm{H}^{+}$ produzidos durante a oxidação serão consumidos pela redução seguinte tornando os processos reversíveis, enquanto em sistema aberto, o potencial de produção ácida dependerá das propriedades do sistema e das reações do processo.

A interpretação da mobilidade e, consequente, disponibilidade dos metais em função de associações químicas está sintetizada na Tabela 1 adaptada de SALOMONS (1995). 
Tabela 1. Mobilidade relativa e disponibilidade de metais

\begin{tabular}{|c|c|}
\hline $\begin{array}{l}\text { Espécies metálicas e } \\
\text { associações }\end{array}$ & Mobilidade \\
\hline Cátions trocáveis & $\begin{array}{l}\text { Alta. Alteração na composição catiônica } \\
\text { poderá causar a liberação do metal devido à } \\
\text { troca iônica. }\end{array}$ \\
\hline $\begin{array}{l}\text { Compostos metálicos associados } \\
\text { com hidróxidos de Fe e Mn }\end{array}$ & $\begin{array}{l}\text { Média. Alteração nas condições redox } \\
\text { (condições de redução) poderá causar a } \\
\text { liberação do metal. Se houver sulfeto poderá } \\
\text { formar sulfeto metálico insolúvel. }\end{array}$ \\
\hline $\begin{array}{l}\text { Metais ligados ou fixos em } \\
\text { substâncias orgânicas } \\
\text { Metais associados à fase sulfídica }\end{array}$ & $\begin{array}{l}\text { Média. Ocorre após a decomposição da } \\
\text { matéria orgânica. Fortemente dependente } \\
\text { das condições ambientais. Em condições } \\
\text { óxicas ocorre a oxidação de sulfetos. }\end{array}$ \\
\hline $\begin{array}{l}\text { Metais ligados ou fixos em partículas } \\
\text { minerais }\end{array}$ & $\begin{array}{l}\text { Baixa. Ocorre após intemperismo e/ou } \\
\text { decomposição. }\end{array}$ \\
\hline
\end{tabular}

Fonte: Adaptado de SALOMONS (1995).

\subsection{Extração sequencial de metais em sedimentos}

Métodos de extração sequencial comumente são aplicados em estudos ambientais para avaliar a disponibilidade ou mobilidade dos metais. Esses procedimentos fornecem informações detalhadas sobre a origem, modo de ocorrência, disponibilidade biológica e físico-química, mobilização e transporte de metais traço (ISHIKAWA et al., 2009; PASSOS et al., 2010). A principal vantagem da extração sequencial em relação ao uso de extratores simples é a especificidade de cada fase, que ocorre em razão da diferente natureza química de cada reagente e das etapas em ordem crescente de reatividade (RAO, SAHUQUILLO e LOPEZ SANCHEZ, 2008). 
Nesses procedimentos a amostra é tratada com uma sequência de reagentes, cada um específico para extrair os metais associados a uma determinada fase do sedimento. Os reagentes, sequencialmente adicionados, apresentam ação química mais drástica e de diferente natureza que o anterior, sendo classificados em concentrados de eletrólitos inertes, ácidos fracos, agentes redutores, agentes complexantes, agentes oxidantes e ácidos minerais fortes (LIMA et al., 2001).

As frações obtidas nesses esquemas estão relacionadas aos metais trocáveis; metais associados, principalmente, a carbonatos; metais liberados em condições redutíveis como aqueles ligados a óxi-hidróxidos de Fe e Mn; metais ligados a componentes oxidáveis como matéria orgânica e sulfetos e metais ligados à fração residual (RAURET, 1998).

Nos procedimentos de extração sequencial presume-se uma diminuição da disponibilidade do elemento durante a sequência de extração; a primeira fração é bastante instável e, portanto, facilmente disponível para a absorção pelas plantas; já na última fração, os elementos apresentam baixa mobilidade e baixa probabilidade de solubilização em condições naturais (ABOLINO et al., 2011).

Dentre os esquemas de extração sequencial disponíveis, são aplicados principalmente o método de TESSIER e o protocolo desenvolvido pela Community Bureau of Reference - BCR, atualmente, Standards, Measurements and Testing Programme - SM\&T (GONZÁLEZ, 2005; RAO, SAHUQUILLO e LOPEZ SANCHEZ, 2008; ABOLLINO et al., 2011). 
O método de TESSIER foi o primeiro procedimento analítico completo elaborado para extração sequencial de metais (ANJOS, 2003). Nesse esquema foram selecionadas cinco frações consideradas susceptíveis a diversas condições ambientais e o reagente específico para cada fração, conforme indicado na Tabela 2.

Tabela 2. Frações e reagentes do protocolo de extração sequencial de TESSIER

\begin{tabular}{|c|c|}
\hline Frações & Reagentes \\
\hline 1: metais trocáveis & $\mathrm{MgCl}_{2}(1 \mathrm{M} ; \mathrm{pH} 7)$ ou $\mathrm{NaOAc}(1 \mathrm{M} ; \mathrm{pH} 8,2)$ \\
\hline $\begin{array}{c}\text { 2: metais associados a } \\
\text { carbonatos }\end{array}$ & $\mathrm{NaOAc}(1 \mathrm{M} ; \mathrm{pH} 5$ com HOAc $)$ \\
\hline $\begin{array}{c}\text { 3: metais associados aos } \\
\text { óxidos de Fe e Mn }\end{array}$ & $\begin{array}{c}\mathrm{Na}_{2} \mathrm{~S}_{2} \mathrm{O}_{4}(0,3 \mathrm{M})+\text { Na-citrato }(0,175 \mathrm{M})+ \\
\text { H-citrato }(0,025 \mathrm{M}) \text { ou } \\
\mathrm{NH}_{2} \mathrm{OH} . \mathrm{HCl}(0,04 \mathrm{M} \text { em } 25 \% \text { HOAc }(\mathrm{v} / \mathrm{v}))\end{array}$ \\
\hline $\begin{array}{c}\text { 4: metais associados a } \\
\text { matéria orgânica }\end{array}$ & $\begin{array}{c}\mathrm{HNO}_{3}(0,02 \mathrm{M}), \mathrm{H}_{2} \mathrm{O}_{2}(30 \%) \mathrm{e} \\
\mathrm{NH}_{4} \mathrm{OAc}\left(3,2 \mathrm{M} \text { em } 20 \% \mathrm{HNO}_{3}(\mathrm{v} / \mathrm{v})\right)\end{array}$ \\
\hline 5: metais na fase residual & $\mathrm{HF}-\mathrm{HClO}_{4}$ \\
\hline
\end{tabular}

Fonte: Adaptado de TESSIER, CAMPBELL e BISSON (1979)

O método de TESSIER apresenta grande importância no campo da extração sequencial, pois a maioria dos protocolos desenvolvidos baseia-se neste método ou em modificações do mesmo (LÓPEZ JULIÁN e MANDADO COLLADO, 2002). Observa-se que, em geral, os métodos de extração sequencial diferem no número de frações ou fases, nos reagentes específicos para cada fração e nos procedimentos operacionais (BÁSCONES, 2003). Esquemas particulares adaptados a casos especiais como o fracionamento de 
metais no lodo de esgoto e o método para estudo de enxofre em solo, têm sido desenvolvido a partir dos procedimentos clássicos de extração sequencial (GLEYZES, TELLIER e ASTRUC, 2002). A variação de extratores tem se intensificado em função da especificidade do solo e sedimento, tipo de resíduos tóxicos e condições ambientais (ANJOS, 2003). BÁSCONES (2003) analisou diversos procedimentos de extração sequencial disponíveis na literatura e fez as seguintes observações:

- As fases importantes na adsorção de metais são óxidos, sulfetos e matéria orgânica.

- As frações obtidas nos esquemas são metais trocáveis, metais ligados a carbonatos, aos óxidos de Fe e Mn, a matéria orgânica/sulfetos e a fase residual.

- Os extratores são aplicados em ordem determinada e agrupam-se em sais não tamponados, ácidos fracos, redutores reativos, oxidantes reativos e ácidos fortes.

- A maior parte dos extratores não são totalmente seletivos e efetivos.

O procedimento BCR da Comunidade Europeia foi desenvolvido em razão da necessidade de se estabelecer esquemas comuns para extração de metais traço em solo e sedimentos (RAURET, 1998). A falta de uniformidade entre os métodos não permitia a comparação dos resultados e, a fim de resolver esta situação, a Comissão Europeia através do Programa BCR e seu sucessor, lançou um projeto de colaboração visando projetar um esquema com três etapas de extração sequencial, testar o esquema selecionado em estudos interlaboratoriais e certificar o teor de elemento traço extraído de um sedimento 
para referência (RAURET et al., 1999). As três etapas estabelecidas pelo método BCR estão relacionadas, sucessivamente, com a extração dos metais associados às fases solúvel em ácido, redutível e oxidável. Nesse procedimento utiliza-se, sequencialmente, ácido acético; cloridrato de hidroxilamina; peróxido de hidrogênio e acetato de amônio (PUEYO et al., 2001). O procedimento detalhado está descrito em metodologias (Capítulo 4).

Dois materiais de referência foram certificados para a metodologia BCR, o CRM 601 e o CRM 701, ambos são sedimentos (ŽEMBERYOVÁ, BORTEKOVÁ, HAGAROVÁ, 2006). O CRM 601 foi coletado no lago Flumendosa em Sardenha na Itália (SAHUQUILLO et al., 1999) e, o CRM 701, no lago Orta em Piemonte, também na Itália (PUEYO et al., 2001).

Em razão de algumas dificuldades com o esquema BCR (SAHUQUILLO et al., 1999; PUEYO et al., 2001), o protocolo original foi revisado gerando um procedimento de três etapas otimizado. As três etapas do procedimento original foram utilizadas na certificação do teor extraível de Cd, $\mathrm{Cr}, \mathrm{Cu}, \mathrm{Ni}, \mathrm{Pb}$ e $\mathrm{Zn}$ do material CRM 601 (PUEYO et al., 2001). Com a modificação do procedimento em 2001, o novo material de referência, CRM 701, foi divulgado (PUEYO et al., 2001, HORVÁTH et al., 2010).

\subsection{A contribuição das atividades de mineração no enriquecimento de metais no Sistema Cananéia-Iguape}

Atividades de mineração têm provocado significativas alterações ambientais ao longo do tempo. Exemplos destes impactos são as minas de chumbo, exploradas desde antes da ascensão das culturas greco-romana, em 
minas situadas ao norte da ilha Bretã e na Espanha, que chegaram até os nossos tempos, na forma de solo, rios e estuários contaminados (MORAES, 1997). No Vale do Ribeira, localizado entre os estados de São Paulo e Paraná, ocorreu intensa atividade de mineração até meados da década de 90 . De acordo com documento da GEOBRÁS (1966), o Vale do Rio Ribeira de Iguape, como era chamado, era rico em jazidas minerais, como calcários, galena, antimônio, chumbo, ferro, prata, e até mesmo ouro, que no tempo do império era intensamente extraído, chegando a ser utilizado nas transações locais na forma de ouro em pó. Essa região apresenta extenso histórico de mineração, comportando diversas minas durante décadas (Panelas, Perau, Rocha, Furnas, Canoas, Barrinhas e outras) e uma refinaria (Plumbum), fontes potenciais para a contaminação ambiental (SILVA, 1997).

Os processos de beneficiamento e fundição dos minérios nessa região foram quase sempre rudimentares, não havendo controle sobre os consequentes impactos no ambiente (GUIMARÃES e SíGOLO, 2008). A usina Plumbum, pertencente ao grupo Trevo, funcionou no período de 1945 a 1995 e operava o beneficiamento e refino dos minérios de chumbo, produzidos nas minas da região ou importados de outros países (DI GIULIO, PEREIRA e FIGUEIREDO, 2008). Nesse período, foram processadas aproximadamente 3 milhões de toneladas de minério de chumbo e, com base nessa quantidade, pode-se estimar que a Plumbum processou, em média, 60 mil toneladas de minério de chumbo por ano, durante o período de funcionamento no Vale do Ribeira (PARANÁ, 2008). A escória foi lançada durante 40 anos nas águas do rio Ribeira até o surgimento da lei de proteção ambiental na década de 90, quando o material passou a ser depositado no solo sem tratamento ou 
proteção até 1995; sendo removido apenas em 2007 (GUIMARÃES e SíGOLO, 2008). Quando a mineradora encerrou suas atividades em 1995, deixou a céu aberto milhares de toneladas de resíduos do beneficiamento de chumbo, bem como as instalações e as minas abandonadas por muitos anos, sem quaisquer trabalhos de recuperação ambiental (PARANÁ, 2008).

Diversos estudos em sedimentos, realizados desde a década de 80 , evidenciaram que a bacia do rio Ribeira foi afetada pelas atividades de mineração e metalurgia (e.g. TESSLER, SUGUIO e ROBILOTTA, 1987; MORAES, 1997; SILVA, 1997; CORSI, 1999; GUIMARÃES e SÍGOLO, 2008), conforme relatos a seguir.

TESSLER, SUGUIO e ROBILOTTA (1987) analisaram teores de alguns metais em sedimentos pelíticos da superfície de fundo da região lagunar Cananéia-Iguape e determinaram de 1,4 a 105,8 $\mathrm{mg} \mathrm{g}^{-1}$ de zinco, $<0,05$ a $292,4 \mu \mathrm{g} \mathrm{g}^{-1}$ de cobre e $<0,30$ a $246,8 \mu \mathrm{g} \mathrm{g}^{-1}$ de chumbo, provavelmente supridos, principalmente, pelo rio Ribeira de Iguape, que atinge a área lagunar através do canal do Valo Grande. Ainda segundo esses autores, o alto teor de chumbo poderia, eventualmente, ser atribuído à contaminação por empresas mineradoras que extraíam este metal no Alto Vale do Ribeira.

MORAES (1997) determinou as razões isotópicas de chumbo em amostras de estações distribuídas desde a região logo a montante da cidade de Ribeira-SP até a do Mar Pequeno, no Complexo estuarino lagunar de Iguape e Cananéia, e os resultados indicaram que as razões isotópicas dos sedimentos sobrepuseram-se ao campo das galenas das jazidas do tipo Panelas, mostrando que as atividades de extração e beneficiamento dos seus 
minérios foram as que mais contribuíram para a contaminação, por chumbo, dos sedimentos do rio Ribeira de Iguape.

SILVA (1997) estudou o impacto ambiental do arsênio no Vale do Ribeira (SP-PR) analisando sedimentos de corrente, coluna de sedimentos e água superficial, além de rejeitos de mineração, e os resultados evidenciaram o impacto do arsênio nos sedimentos de corrente do rio Ribeira de Iguape com concentrações mais elevadas nas áreas de mineração; a contaminação dos sedimentos mais recentes da coluna de sedimentos indicaram fonte antrópica como causa provável.

Os estudos de CORSI (1999) mostraram que as minas Perau e Barrinha forneciam os teores mais altos de chumbo e cobre para o ribeirão Grande e, consequentemente, para o rio Ribeira de Iguape; o transporte ocorria, principalmente, via sedimento de corrente, sendo esses metais carreados para o rio no período das chuvas.

Estudo realizado por FIGUEIREDO, CAPITANI e GITAHY (2004), mostrou que as populações do Alto Vale do Ribeira convivem com várias fontes de contaminação ambiental, em especial de chumbo e arsênio. Ainda de acordo esses autores, estudos de qualidade ambiental indicaram a atividade industrial de refino e mineração como a principal fonte de poluição, sendo as emissões de metais para atmosfera e a, subsequente, deposição dos particulados, responsáveis pela contaminação dos solos em áreas habitadas por essas populações. 
GUIMARÃES e SÍGOLO (2008) concluíram que parte importante de metais pesados como chumbo, cobre e zinco, lançados como resíduos no rio Ribeira de Iguape durante a fundição do minério na região do Alto Vale do Ribeira, encontra-se depositada nos sedimentos e que uma parcela desses metais está sendo mobilizada junto aos sedimentos em suspensão, migrando ao longo do curso rio até a foz, sistema estuarino lagunar; a comprovação dáse pela presença de escória nos sedimentos e teores elevados dos diversos metais analisados.

Os resíduos sólidos da Plumbum, lançados diretamente no rio Ribeira, sem tratamento, correspondem a 5,5 toneladas/ano de rejeitos, contendo arsênio, bário, cádmio, chumbo, cobre, cromo e zinco (CASSIANO, 2001 apud PARANÁ, 2008). De acordo com dados do relatório de qualidade das águas interiores do estado de São Paulo (CETESB, 2001), no ano de 2000 o rio Ribeira apresentou não conformidades referentes ao cobre e ao chumbo no trecho de Registro e, referente ao cádmio, no trecho de Apiaí. Esse relatório informou também que o trecho do rio Ribeira em Apiaí fica próximo às empresas mineradoras e, ainda que, aparentemente, estas não fossem fontes expressivas de contaminação, na época das chuvas poderia haver transporte de resíduos de mineração, contaminantes do solo.

Segundo o relatório de qualidade das águas interiores do estado de São Paulo do ano de 2007 (CETESB, 2008), foram observadas concentrações de arsênio, chumbo, cromo, níquel e zinco entre TEL (Threshold Effect Level - teor abaixo do qual são raros os efeitos deletérios para os organismos bentônicos) e PEL (Probable Effect Leve - teor acima do qual é frequentemente esperado 
efeito adverso para os organismos bentônicos) em sedimentos do rio Ribeira de Iguape, destacando-se a presença de chumbo e sua capacidade de bioacumulação. Esse mesmo relatório informou que em relação ao controle de fontes de chumbo e outros metais, no período de 2000 a 2004, por exigência da Companhia Ambiental do Estado de São Paulo - CETESB, a empresa Cia Argentífera de Furnas - CAF ou Plumbum realizou obras de contenção, remoção e disposição de rejeitos da mineração de chumbo, para evitar a contaminação das águas superficiais e subterrâneas da bacia do rio Ribeira; porém, com o escorregamento ocorrido no morro acima do local em 2006, toda essa área ficou soterrada e, apesar das ações de controle conduzidas no estado de São Paulo, o chumbo ainda ocorria na bacia.

Em 2011, o relatório de qualidade das águas superficiais no estado de São Paulo mostrou que o sedimento do rio Ribeira foi classificado com qualidade química péssima, pois apresentou concentrações acima do PEL para chumbo $\left(93,2 \mathrm{mg} \mathrm{kg}^{-1}\right)$, além de concentrações acima do TEL para arsênio $\left(6,15 \mathrm{mg} \mathrm{kg}^{-1}\right)$, mercúrio $\left(0,21 \mathrm{mg} \mathrm{kg}^{-1}\right)$ e zinco (137 $\left.\mathrm{mg} \mathrm{kg}^{-1}\right)$ (CETESB, 2012). Entretanto, o relatório de 2012 indicou que o rio Ribeira apresentou qualidade química regular, com a presença de arsênio e chumbo em concentrações acima do TEL, tendo melhorado sua classificação em relação a 2011 (CETESB, 2013).

A bacia hidrográfica do rio Ribeira de Iguape ocupa uma área aproximada de $25.000 \mathrm{~km}^{2}$, sendo $61 \%$ pertencente ao território do estado de São Paulo e o restante ao do Paraná; as cabeceiras situam-se na porção nordeste do estado do Paraná e sua foz no litoral extremo sul do estado de São Paulo (MORAES, 1997). A vazão do rio Ribeira em seu menor curso varia de 
300 até $1.200 \mathrm{~m}^{3}$ ou mais, sendo essa variação fortemente controlada pelo regime climático (MAHIQUES et al., 2013). O rio Ribeira nasce no estado do Paraná e somente passa a ser denominado Ribeira de lguape após a confluência com o rio Juquiá, seu principal afluente no estado de São Paulo (CETESB, 2002). O rio Ribeira de Iguape, com aporte através do canal do Valo Grande, é um dos principais contribuintes de água doce e de sedimentos em suspensão para o Sistema Cananéia-lguape e, portanto, dá-se a contribuição das atividades de mineração no enriquecimento de metais nessa região. Estudo realizado por MAHIQUES et al. (2013), apresentou o registro de 150 anos de inserção antrópica de metais nesse Sistema revelando que os mais elevados níveis de contaminação, especialmente para o chumbo, ocorreram entre as décadas de 40 e 90, período referente à intensa mineração industrial.

É importante destacar que o Sistema Cananéia-Iguape situa-se entre os mais complexos, biodiversos e preservados ecossistemas de transições, entre os ambientes continental e marinho, existentes no planeta (MORAES, 1997). Os canais estuarinos e lagunares dessa região são cercados por vegetação de mangue abundante, que abriga ostras e mexilhões, sendo como um todo importante para o crescimento ou residência de espécies valiosas economicamente (MAHIQUES et al., 2013). Se comparadas às águas dos rios e oceanos adjacentes, as águas estuarinas são biologicamente mais produtivas em razão de características hidrodinâmicas da circulação, que favorecem a retenção de nutrientes, algas e outras plantas, estimulando a produtividade (MARTINS, 2005). No entanto, por ser uma região parcialmente fechada, o estuário sofre os efeitos da poluição, que podem ser nocivos tanto às comunidades bióticas, como à saúde pública através da cadeia alimentar. 


\section{OBJETIVOS}

O principal objetivo deste trabalho foi avaliar a disponibilidade de cobre $(\mathrm{Cu})$, chumbo $(\mathrm{Pb})$ e zinco $(\mathrm{Zn})$ no Sistema Cananéia-Iguape, a partir do teor associado à frações móveis nos sedimentos e do comportamento destes metais quanto à remobilização; a fim de constituir-se em importante ferramenta para estudos relativos às comunidades bióticas e ao monitoramento da poluição química na região.

Para atingir o objetivo, este estudo teve como principais ações:

- Estabelecer o método para extração sequencial de metais com base no protocolo desenvolvido e otimizado pelo Programa BCR e aplicar a metodologia em material de referência (CRM 701 do IRMM - Institute for Reference Materials and Measurements), para verificação da precisão e exatidão da técnica estabelecida.

- Determinar o teor disponível e o teor pseudo-total de $\mathrm{Cu}, \mathrm{Pb}$ e $\mathrm{Zn}$ em amostras de sedimento superficial do Sistema Cananéia-Iguape.

- Analisar a correlação entre o acúmulo de metais, composição granulométrica e teor de carbono orgânico total nas amostras de sedimento superficial.

- Analisar as condições oceanográficas que favoreceram o acúmulo desses elementos na região.

- Avaliar o grau de contaminação química da região tendo como referência valores estabelecidos para $\mathrm{Cu}, \mathrm{Pb}$ e $\mathrm{Zn}$ em guia de qualidade de sedimento, valores regionais em período que antecedeu a intensa atividade de mineração industrial no Vale do Ribeira e valores de 
background (composição média dos folhelhos).

- Analisar o risco de remobilização desses metais aplicando o critério de avaliação de risco RAC (Risk Assessment Codes).

- Avaliar a inserção antrópica de $\mathrm{Cu}, \mathrm{Pb}$ e $\mathrm{Zn}$ na região durante o período de intensa atividade de mineração no Vale do Ribeira, a partir de dados de geoquímica e geocronologia de amostras de testemunhos. 


\section{3. ÁREA DE ESTUDO}

A área de estudo corresponde ao Sistema Cananéia-Iguape, localizado no extremo sul do estado de São Paulo, entre as latitudes 2440'S e 250.5'S e longitudes $47^{\circ} 25^{\prime} \mathrm{W}$ e $48^{\circ} 00^{\prime} \mathrm{W}$ (Figura 1), fazendo divisa com o estado do Paraná. Esse Sistema apresenta cerca de $100 \mathrm{~km}$ de extensão (BERNARDES e MIRANDA, 2001), sendo composto por um complexo de canais que circundam as Ilhas do Cardoso, de Cananéia, Comprida e a cidade de Iguape. Iguape é considerada uma ilha artificial, originada em razão da abertura do canal do Valo Grande que liga o rio Ribeira ao Mar Pequeno (GEOBRÁS, 1966).

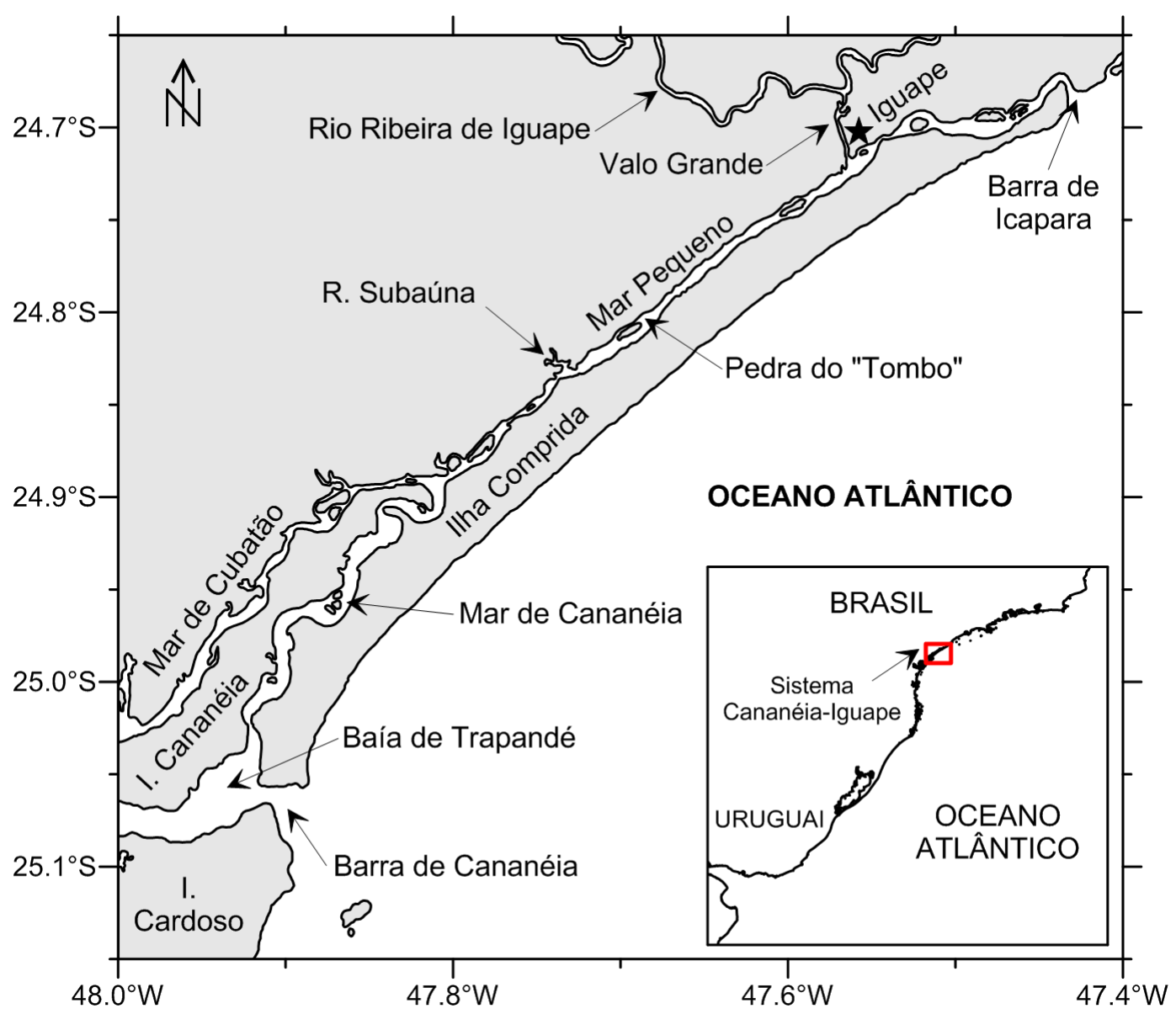

Figura 1. Localização da área de estudo; Sistema Cananéia-Iguape 
O Sistema Cananéia-Iguape é separado do oceano pela llha Comprida com aproximadamente $70 \mathrm{~km}$ de extensão, tendo como limites, ao norte e ao sul, pontões do embasamento cristalino; nas porções central e sul está a llha de Cananéia, separada do continente pelo canal Mar de Cubatão, e da Ilha Comprida, pelo canal Mar de Cananéia (TESSLER e SOUZA, 1998). O canal Mar de Cananéia, em continuidade com o Mar Pequeno, é o principal canal do Sistema, apresentando formação sinuosa, com comprimento de aproximadamente $75 \mathrm{~km}$ que se estende entre as Barras de Cananéia e Icapara (BÉRGAMO, 2000). A llha de Cananéia possui extensão aproximada de $27 \mathrm{~km}$, com largura que varia entre 1 e $5 \mathrm{~km}$; os canais que a circundam possuem larguras entre 1 e $3 \mathrm{~km}$ e profundidades que atingem, no máximo, $20 \mathrm{~m}$, com média de aproximadamente $6 \mathrm{~m}$ (TESSLER e SOUZA, 1998). A principal comunicação do Sistema com a região costeira é através das Barras de Cananéia e de Icapara, próximo à cidade de Iguape (BERNARDES e MIRANDA, 2001).

O Sistema Cananéia-Iguape, localizado a S-SE da desembocadura do rio Ribeira de lguape, recebe águas marinhas através das desembocaduras fluviais e lagunares, e águas continentais e insulares, por meio de inúmeros rios que ali desembocam (TESSLER, 2001). Os cursos de água que desembocam nos canais lagunares são rios que se localizam no continente e na ilha do Cardoso e canais de maré de água salobra das ilhas circunvizinhas (TESSLER, 1982). A água doce que chega ao Sistema é proveniente de uma bacia de drenagem formada pelos rios Ribeira de Iguape, Taquari, Mandira, das Minas, Itapitangui e um grande número de gamboas, sendo o rio Ribeira de 
Iguape o responsável pela principal fonte de água doce do Sistema, através do canal do Valo Grande, que o interliga ao Mar Pequeno (BÉRGAMO, 2000).

A circulação do Sistema é dirigida, principalmente, pela ação da onda de maré que entra pelas Barras de Cananéia e de Icapara, e pela contribuição de água doce dos rios, além da influência do vento (MIYAO, NISHIHARA e SARTI, 1986). A maré observada na Base de Cananéia e em Subaúna, próximo à Pedra do Tombo, apresenta predominância semidiurna (MIYAO e HARARI, 1989). Segundo TESSLER (2001), os ciclos de maré, associados às descargas dos rios e precipitação atmosférica, causam grande variação na amplitude da salinidade ao longo do Sistema Cananéia-Iguape. A ação da maré nesse Sistema é a principal responsável pelos processos de mistura e trocas entre o oceano e o estuário, sendo um agente efetivo no processo de transporte de sedimentos e na renovação das águas estuarinas. (MIYAO e HARARI, 1989).

BARCELLOS et al. (2005) verificaram que a salinidade de fundo da região varia de 0,05 a 34,92; os maiores valores estão concentrados na região da Barra de Cananéia, decrescendo em direção ao norte e atingindo os menores valores defronte a desembocadura do Valo Grande, para aumentar novamente em direção à Barra de Icapara. Estudos realizados por MALUF (2009) em estações amostrais entre Cananéia e Iguape, indicaram que a salinidade na superfície variou entre 0,04 e 28,79, e no fundo, entre 0,04 e 30,94 .

O clima do Sistema Cananéia-Iguape é subtropical, com umidade relativa do ar de aproximadamente $87 \%$ e pluviosidade maior que $200 \mathrm{~mm}$ de 
dezembro a abril e, em torno de $80 \mathrm{~mm}$, de maio a novembro (ICMBio, 2008). De acordo com KUMPERA (2007), a Base de apoio à pesquisa do Instituto Oceanográfico da Universidade de São Paulo em Cananéia possui uma estação meteorológica, com registros desde 1956, e uma série temporal de 30 anos aponta média pluvial anual superior a $2.248 \mathrm{~mm}$, sendo o mês de março o mais chuvoso $(328 \mathrm{~mm})$ e o de agosto o mais seco $(80 \mathrm{~mm})$; o período das chuvas e de estiagem se estende de dezembro a abril e de maio a novembro, respectivamente.

Devido às características climáticas e geomorfológicas da região, a cobertura vegetal é marcada por restingas e mangues nas margens de corpos de águas mixohalinas e pela vegetação de dunas da Mata Atlântica nas áreas mais altas (MAHIQUES et al., 2009).

\subsection{O canal do Valo Grande}

O canal artificial do Valo Grande foi construído entre os anos de 1827 e 1852 (GEOBRÁS, 1966), sendo inicialmente chamado de Valo do Rocio (BERNADES e MIRANDA, 2001; MAHIQUES et al., 2009). A finalidade deste canal foi reduzir a distância e os custos para transportar os produtos agrícolas da zona rural ao principal porto de exportação da região (MAHIQUES et al., 2009). Naquela época, a abertura de um canal que permitisse a comunicação direta por água entre o porto da Ribeira e Iguape apresentava aspectos de um grande negócio, com enormes possibilidades financeiras em virtude do grande tráfego fluvial existente e a importância econômica de todo o chamado Vale da Ribeira do Iguape (GEOBRÁS, 1966). 
O canal artificial, com aproximadamente $4 \mathrm{~km}$ de extensão, escavado a profundidades inferiores a $2 \mathrm{~m}$ e largura em torno de $4,4 \mathrm{~m}$, foi rapidamente erodido pelo curso fluvial (TESSLER, 2001). De acordo com dados da GEOBRÁS (1966), após quase 130 anos, o canal apresentava larguras que atingiram até $235 \mathrm{~m}$, ou seja, mais de 50 vezes a primitiva dimensão.

O porto de Iguape, localizado no Mar Pequeno, após a abertura do canal Valo Grande foi influenciado pela descarga fluvial do rio Ribeira de Iguape, ao qual se associa um processo de assoreamento acelerado, não apenas dos sedimentos em suspensão, carreados pelo rio, mas também de sedimentos arenosos carreados por tração, a partir da pronunciada erosão das margens do Valo (TESSLER, 2001). Em agosto de 1978, o canal, com cerca de $250 \mathrm{~m}$ de largura e $7 \mathrm{~m}$ de profundidade, foi fechado pela construção de uma barragem até 1983, quando houve o seu rompimento (TESSLER e SOUZA, 1998). Após a abertura do canal cerca de $60 \%$ do fluxo fluvial foi direcionado para o Valo Grande e, consequentemente, para o Sistema lagunar, conduzindo a um drástico decréscimo na salinidade (MAHIQUES et al., 2009). Além de água doce, o rio Ribeira de Iguape, também descarrega no Sistema elevada carga de sedimentos finos em suspensão (TESSLER e SOUZA, 1998), enriquecidos com metais, em razão da intensa atividade de mineração na região até meados dos anos 90, que afetou a bacia do rio Ribeira, conforme histórico apresentado no Capítulo 1 deste trabalho. A abertura do canal do Valo Grande afetou as características físico-químicas e a deposição de sedimentos nessa região (MAHIQUES et al., 2013). 


\section{MATERIAIS E MÉTODOS}

\subsection{Coleta e preparação das amostras}

Foram utilizadas 64 amostras de sedimento superficial e 30 amostras de sedimento de 5 testemunhos, com profundidade entre 0 e $50 \mathrm{~cm}$, todos coletados ao longo do Sistema Cananéia-Iguape. As amostras superficiais foram coletadas no início de março de 2011, com um amostrador do tipo Van Veen. Os testemunhos, CAN (02, 04, 05, 07 e 10), com comprimento entre 1,27 a 2,00 m, foram coletados em 2008 com um Rossfelder VT-1 vibracorer. Esses testemunhos são parte do projeto "Registro geológico da atividade antrópica no Sistema estuarino-lagunar de Cananéia-lguape" (Processo FAPESP 06/043442). As localizações das estações superficiais e dos testemunhos estão representadas na Figura 2. As coordenadas e profundidades das amostras superficiais estão em Anexos e, a posição e o comprimento dos testemunhos, na Tabela 3. Em laboratório, as amostras foram liofilizadas, maceradas e acondicionadas em recipientes plásticos até a utilização. Os testemunhos foram seccionados continuamente a intervalos de $2 \mathrm{~cm}$, com exceção de CAN 04 que foi seccionado a cada $1 \mathrm{~cm}$.

Tabela 3. Posição e comprimento dos testemunhos

\begin{tabular}{c|c|c|c}
\hline Testemunho & Latitude (S) & Longitude (W) & Comprimento (m) \\
\hline CAN 02 & $24^{\circ} 42.477$ & $47^{\circ} 32.787$ & 1,44 \\
\hline CAN 04 & $24^{\circ} 43.418$ & $47^{\circ} 33.858$ & 1,50 \\
\hline CAN 05 & $24^{\circ} 45.245$ & $47^{\circ} 37.370$ & 2,00 \\
\hline CAN 07 & $24^{\circ} 48.895$ & $47^{\circ} 41.612$ & 1,27 \\
\hline CAN 10 & $24^{\circ} 53.330$ & $47^{\circ} 48.700$ & 1,53 \\
\hline
\end{tabular}




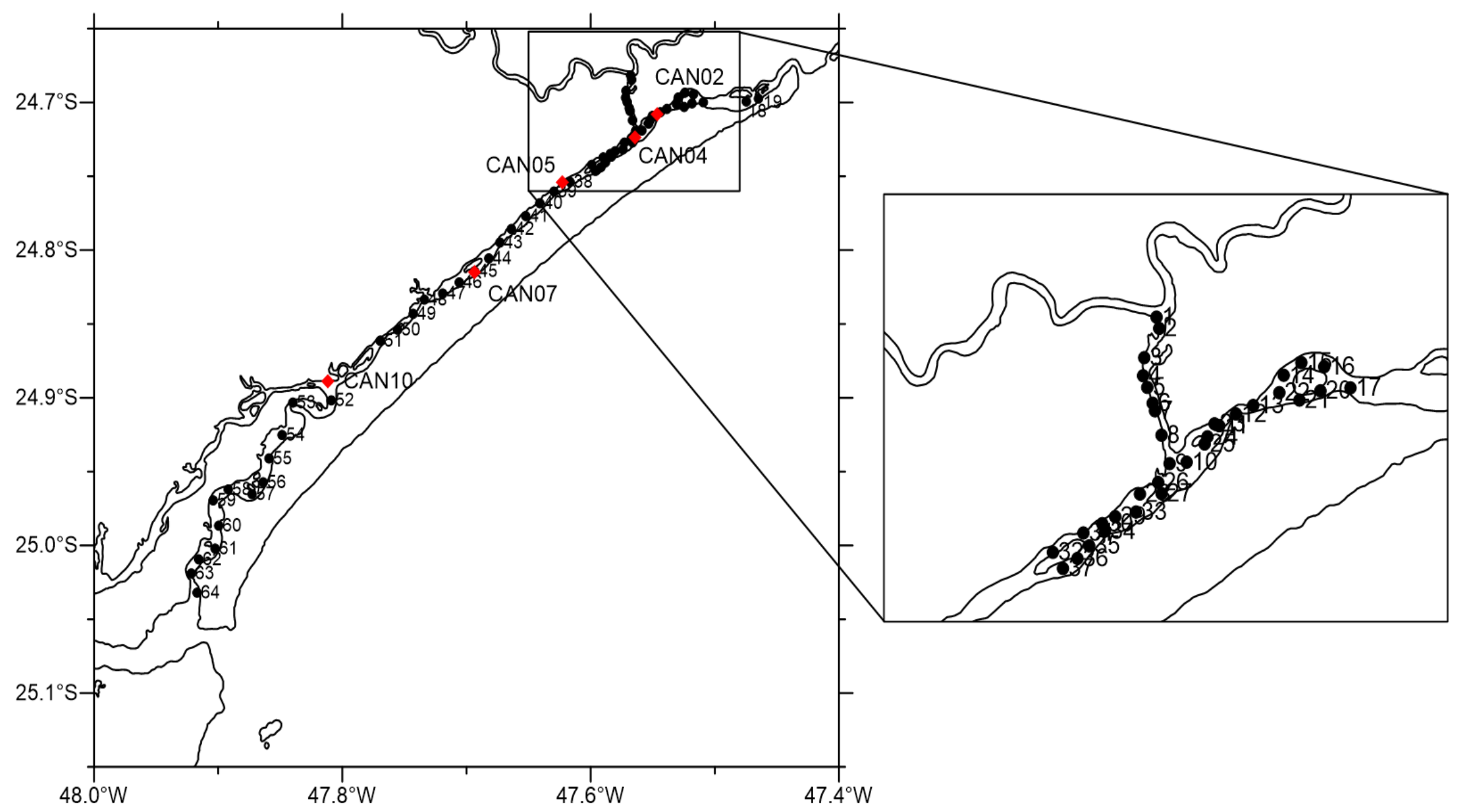

Figura 2. Representação gráfica das estações amostrais superficiais e dos testemunhos ao longo do Sistema Cananéia-Iguape. 


\subsection{Análises químicas}

\subsubsection{Determinação do teor de $\mathrm{Cu}, \mathrm{Pb}$ e $\mathrm{Zn}$}

Foram determinados o teor de $\mathrm{Cu}, \mathrm{Pb}$ e $\mathrm{Zn}$ nas frações geoquímicas móveis ou disponíveis, bem como o teor pseudo-total desses elementos nas amostras de sedimento. Para a quantificação dos metais foi utilizada a técnica de espectrometria de emissão ótica com plasma indutivamente acoplado (ICPOES).

\subsubsection{Extração sequencial de metais}

Para determinação do teor de $\mathrm{Cu}, \mathrm{Pb}$ e $\mathrm{Zn}$ nas frações disponíveis foi utilizado procedimento de extração sequencial com base no protocolo desenvolvido e otimizado do Programa BCR. Abaixo segue a síntese do procedimento com base no método descrito em PUEYO et al. (2001).

- Etapa 1: solúvel em ácido ( $\mathrm{F} 1)$ - Para cada $0,5 \mathrm{~g}$ de sedimento, $20 \mathrm{~mL}$ de ácido acético $0,11 \mathrm{~mol} \mathrm{~L}^{-1}$ foram adicionados. A suspensão foi agitada aproximadamente por 16 horas a temperatura ambiente e, posteriormente, centrifugada para separação do extrato e da fase sólida.

- Etapa 2: redutível (F2) - Para cada $0,5 \mathrm{~g}$ de amostra inicial, $20 \mathrm{~mL}$ de cloridrato de hidroxilamina $0,5 \mathrm{~mol} \mathrm{~L}^{-1}$ foram adicionados ao resíduo da etapa 1. A agitação e a separação ocorreram conforme descrito na etapa 1.

- Etapa 3: oxidável (F3) - Para cada $0,5 \mathrm{~g}$ de amostra inicial, $5 \mathrm{~mL}$ de peróxido de hidrogênio $(30 \% \mathrm{v} / \mathrm{v})$ foram adicionados ao resíduo da etapa 2. Inicialmente a extração ocorreu à temperatura ambiente e, em seguida, sob aquecimento, com incremento de outra porção de $5 \mathrm{~mL}$ de peróxido de hidrogênio. Após redução do volume e resfriamento da 
suspensão, adicionou-se $25 \mathrm{~mL}$ de acetato de amônio 1,0 mol L-1 $(\mathrm{pH} 2)$. A agitação e a separação ocorreram conforme descrito na etapa 1.

As extrações foram realizadas em alíquotas de sedimento seco. Os resíduos foram lavados com água Milli-Q, sob agitação, antes da utilização nas etapas subsequentes. $O$ extrato obtido em cada etapa foi armazenado, sob refrigeração, até o momento da análise. A Figura 3 apresenta o fluxograma do procedimento de extração sequencial descrito.

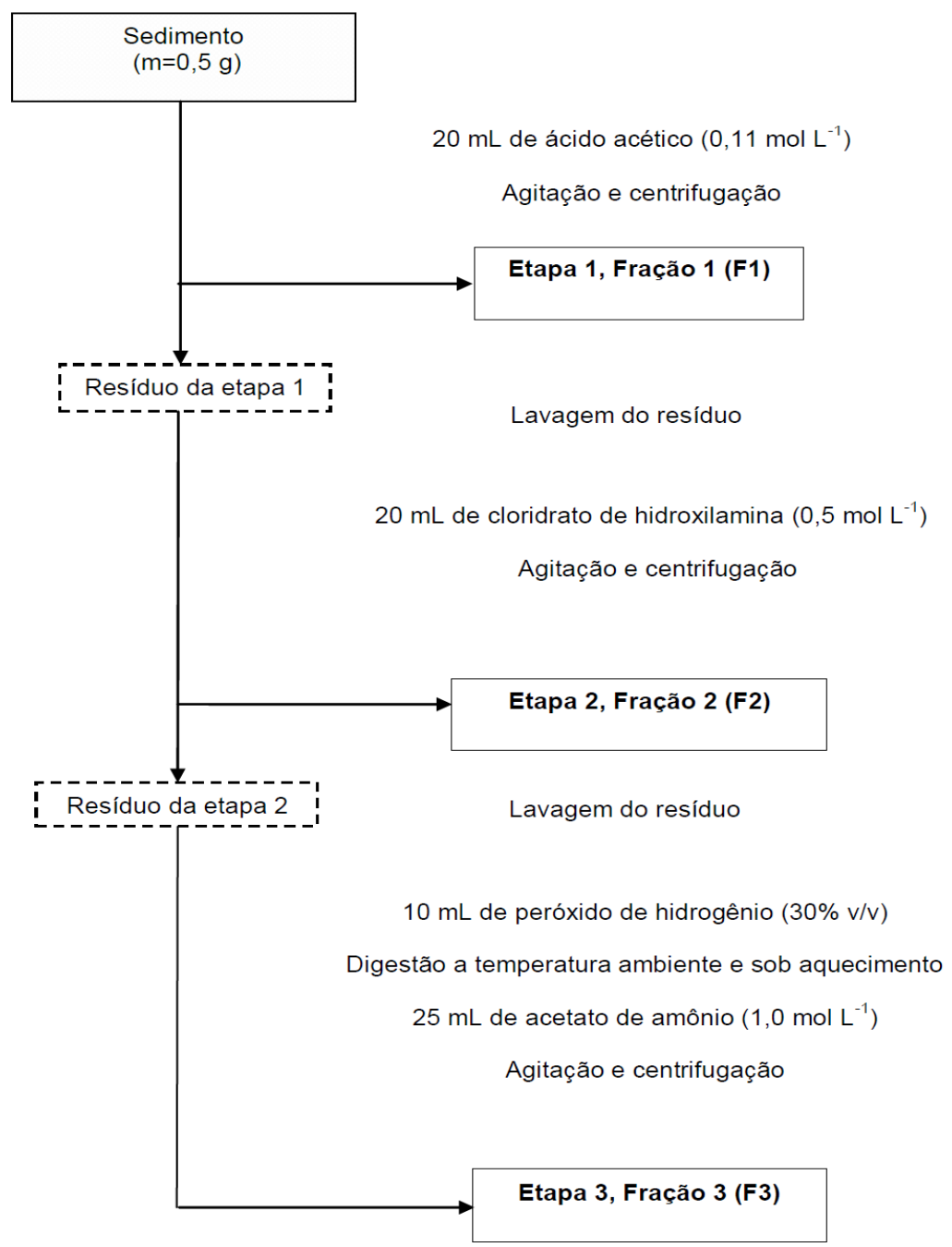

Figura 3. Fluxograma do esquema de extração sequencial de metais com base no protocolo desenvolvido e otimizado do Programa BCR. 


\subsubsection{Digestão Pseudo-total}

a) Procedimento recomendado pela Norma ISO 11466

O teor parcial de $\mathrm{Cu}, \mathrm{Pb}$ e $\mathrm{Zn}$ nas amostras foi extraído utilizando-se método de digestão com água régia com base no procedimento da Norma ISO 11466 (PUEYO et al., 2001). Em síntese, para 0,5 g de sedimento foram adicionados $5 \mathrm{~mL}$ de água régia (ácido clorídrico (37\%) e ácido nítrico (65\%) na proporção 3:1). A digestão ocorreu a frio por $16 \mathrm{~h}$ e, em seguida, a suspensão foi aquecida, em banho de água, por $2 \mathrm{~h}$ a $90^{\circ} \mathrm{C}$. Após o resfriamento a suspensão foi filtrada, o extrato foi avolumado e armazenado sob refrigeração, até o momento da análise.

b) Procedimento recomendado pelo método SW 846 US EPA 3050B

O teor parcial de $\mathrm{Cu}, \mathrm{Pb}$ e $\mathrm{Zn}$ também foi extraído utilizando-se procedimento de digestão ácida com base no método SW 846 US EPA 3050B (US EPA, 1996). Em síntese, $10 \mathrm{~mL}$ de $\mathrm{HNO}_{3}$ (1:1) foram adicionados a $2 \mathrm{~g}$ de sedimento seco, ficando sob aquecimento a $95^{\circ} \mathrm{C}$ por 15 minutos. Em seguida, adicionou-se $5 \mathrm{~mL}$ de $\mathrm{HNO}_{3}$ concentrado, prosseguindo com o aquecimento por mais 30 minutos. A operação foi repetida até a completa oxidação da amostra. Após o resfriamento da suspensão, adicionou-se $2 \mathrm{~mL}$ de água e 3 $\mathrm{mL}$ de $\mathrm{H}_{2} \mathrm{O}_{2}(30 \% \mathrm{v} / \mathrm{v})$, sob aquecimento. $\mathrm{O}$ procedimento continuou com a adição de $1 \mathrm{~mL}$ de $\mathrm{H}_{2} \mathrm{O}_{2}(30 \% \mathrm{v} / \mathrm{v})$, até a completa eliminação da matéria orgânica. Após essa etapa adicionou-se $10 \mathrm{~mL}$ de $\mathrm{HCl}$ concentrado e a suspensão foi mantida em aquecimento por 15 minutos. Após o resfriamento, a 
suspensão foi filtrada e o extrato foi avolumado e armazenado sob refrigeração até o momento da análise.

\subsubsection{ICP-OES}

A técnica de espectrometria de emissão ótica com plasma indutivamente acoplado foi utilizada para quantificação de $\mathrm{Cu}, \mathrm{Pb}$ e $\mathrm{Zn}$ nas amostras de sedimentos. O equipamento utilizado foi um ICP-OES modelo MPX 710-ES da Varian. O ICP-OES é uma das principais técnicas instrumentais na análise de materiais por ser multielementar, rápido e com sensibilidade adequada para a maioria dos metais comumente determinados, permitindo a análise em torno de setenta diferentes elementos químicos em nível de traço (DYMOTT, 1995). As aplicações analíticas ocorrem com base na emissão espontânea de fótons de átomos gasosos e íons gerados de amostras, que excitados termicamente emitem radiação de um determinado comprimento de onda, produzindo espectros atômicos ou iônicos específicos (WROBEL et al., 2007). DYMOTT (1995) descreveu os seguintes componentes básicos do ICP-OES:

- Sistema de tratamento da amostra: converte a solução em um aerossol capaz de ser excitado pela fonte.

- Fonte de plasma: excita os átomos na amostra para produzir um espectro de emissão característico dos elementos.

- Espectrômetro: coleta opticamente radiações do plasma e separa as linhas espectrais produzidas por diferentes elementos.

- Detector e processador do sinal: converte a intensidade da radiação medida em cada comprimento de onda em um resultado digital. 
A Tabela 4 apresenta os comprimentos de onda utilizados para leitura de $\mathrm{Cu}, \mathrm{Pb}$ e $\mathrm{Zn}$ nas amostras de sedimento, bem como, os limites de quantificação (LQ) determinados para esses elementos.

Tabela 4. Comprimentos de onda e limites de quantificação

\begin{tabular}{c|c|c}
\hline Elemento & Comprimento de Onda (nm) & $\mathbf{L Q}\left(\mathbf{m g ~ k g}^{-1}\right)$ \\
\hline $\mathrm{Cu}$ & 327,395 & 0,64 \\
\hline $\mathrm{Pb}$ & 283,305 e 220,353 & 1,90 \\
\hline $\mathrm{Zn}$ & 213,857 & 1,40 \\
\hline
\end{tabular}

Em relação ao $\mathrm{Pb}$, testes com o material de referência CRM 701 do IRMM - Institute for Reference Materials and Measurements revelaram que o comprimento de onda $283,305 \mathrm{~nm}$ é o mais indicado na quantificação desse elemento em baixas concentrações. Portanto, na fração solúvel em ácido, cuja maior parte dos resultados de $\mathrm{Pb}$ foi inferior ao seu $\mathrm{LQ}$, efetuou-se a leitura nas duas energias e optou-se pelos resultados obtidos com o comprimento de onda 283,305. Nas demais frações disponíveis e na digestão pseudo-total foi utilizado o comprimento de onda 220,353 nm. O material de referência CRM 701 foi o balizador para a escolha desses comprimentos de onda.

Para determinação dos $L Q$, inicialmente foram determinados os limites de detecção (LD) do $\mathrm{Cu}, \mathrm{Pb}$ e $\mathrm{Zn}$, considerando-se as definições do Code of Federal Regulations - CFR 40 (US CFR, 2011) e o fator de diluição do método. Os LD foram determinados por meio da análise de sete replicatas de soluções com concentrações conhecidas, preparadas a partir de soluções padrão. 0 desvio-padrão das sete medidas foi multiplicado pelo valor de t-Student para 
um nível de confiança de 99\%, resultando no LD. O LQ foi determinado considerando-se cinco vezes o LD.

O LD é definido como a concentração mínima de uma substância medida e declarada com $95 \%$ ou $99 \%$ de confiança de que a concentração do analito é maior que zero; o LQ é a menor concentração do analito que pode ser determinada com um nível aceitável de exatidão e precisão (INMETRO, 2007).

\subsubsection{Carbono Orgânico Total (COT)}

Para a determinação do COT foi utilizado o método modificado de WALKLEY-BLACK (GAUDETTE e FLIGHT, 1974), que se baseia na oxidação com dicromato de potássio $\left(\mathrm{K}_{2} \mathrm{Cr}_{2} \mathrm{O}_{7}\right)$ e ácido sulfúrico $\left(\mathrm{H}_{2} \mathrm{SO}_{4}\right)$ concentrado. A quantidade de $\mathrm{K}_{2} \mathrm{Cr}_{2} \mathrm{O}_{7}$ consumido na oxidação do carbonato orgânico é determinada titulando-se o excesso de $\mathrm{K}_{2} \mathrm{Cr}_{2} \mathrm{O}_{7}$ com sulfato ferroso amoniacal $\left(\mathrm{Fe}\left(\mathrm{NH}_{4}\right)_{2}\left(\mathrm{SO}_{4}\right)_{2} \cdot 6 \mathrm{H}_{2} \mathrm{O}\right)$. O resultado da análise é calculado pela Equação 1:

\section{Equação 1:}

Carbono Orgânico $(\%)=10 \times(1-T / S) \times[1,0 N \times(0,003) \times(100 / \mathrm{W})]$

Onde:

10 = volume do $\mathrm{K}_{2} \mathrm{Cr}_{2} \mathrm{O}_{7}(\mathrm{~mL})$

$\mathrm{T}=$ volume de $\mathrm{Fe}\left(\mathrm{NH}_{4}\right)_{2}\left(\mathrm{SO}_{4}\right)_{2} \cdot 6 \mathrm{H}_{2} \mathrm{O}$ consumido na amostra $(\mathrm{mL})$

$\mathrm{S}=$ volume de $\mathrm{Fe}\left(\mathrm{NH}_{4}\right)_{2}\left(\mathrm{SO}_{4}\right)_{2} \cdot 6 \mathrm{H}_{2} \mathrm{O}$ consumido no branco $(\mathrm{mL})$

$1,0 \mathrm{~N}=$ normalidade do $\mathrm{K}_{2} \mathrm{Cr}_{2} \mathrm{O}_{7}$

$0,003=12 / 4000=$ miliequivalente em peso de carbono

$\mathrm{W}=$ peso da amostra de sedimento $(0,2 \mathrm{a} 0,5 \mathrm{~g})$ 


\subsubsection{Controle analítico dos resultados}

A eficiência dos métodos de extração sequencial e digestão pseudototal (ISO 11466) foram avaliadas utilizando-se o material de referência CRM 701 do IRMM - Institute for Reference Materials and Measurements, que possui valores certificados para as frações disponíveis e valores informativos para análise direta do material integral com água régia. Em cada etapa de extração, as recuperações do $\mathrm{Cu}, \mathrm{Pb}$ e $\mathrm{Zn}$ foram calculadas, bem como, o desvio-padrão relativo (DPR) entre as concentrações medidas e os valores certificados/informativos (Tabela 5). O DPR ficou abaixo de 15\% para todos os elementos estudados neste trabalho. $\mathrm{Na}$ fração solúvel em ácido (F1) as recuperações variaram de 85 a 93\%, na redutível (F2) de 93 a 104\%, na oxidável (F3) de 89 a $116 \%$ e na digestão pseudo-total de 93 a 98\%. Os resultados estão próximos aos apresentados em outros trabalhos (PEREIRA et al., 2007; PASSOS et al., 2010) e refletem a eficiência dos métodos.

Tabela 5. Recuperação do material de referência CRM 701 (taxa de recuperação + DPR, $n=4)$

\begin{tabular}{c|c|c|c|c}
\hline Elemento & F1 (\%) & F2 (\%) & F3 (\%) & Pseudo-total (\%) \\
\hline $\mathrm{Cu}$ & $85 \pm 5$ & $93 \pm 9$ & $116 \pm 8$ & $98 \pm 1$ \\
\hline $\mathrm{Pb}$ & $93 \pm 14$ & $104 \pm 8$ & $110 \pm 11$ & $93 \pm 2$ \\
\hline $\mathrm{Zn}$ & $92 \pm 3$ & $103 \pm 9$ & $89 \pm 14$ & $97 \pm 1$ \\
\hline
\end{tabular}

O método para determinação de COT teve sua eficiência avaliada utilizando-se um padrão interno desenvolvido pelo Laboratório de Química Inorgânica Marinha (LaQIMar) do Instituto Oceanográfico da Universidade de São Paulo. Trata-se de uma amostra de sedimento marinho, cujo valor de COT 
foi determinado a partir de testes $(n=21)$ utilizando-se a técnica de Análise Elementar acoplada ao Espectrômetro de Massas de Razão Isotópica (EAIRMS). Esse padrão interno foi submetido ao procedimento modificado de WALKLEY-BLACK (GAUDETTE e FLIGHT, 1974), aplicado neste estudo, e os resultados dos experimentos ( $n=6)$ mostraram a eficiência do método com uma recuperação de $116 \%$ e DPR de $1 \%$.

\subsection{Análise granulométrica}

A análise granulométrica foi realizada no Laboratório de Sedimentologia do Instituto Oceanográfico da Universidade de São Paulo. A determinação do tamanho dos grãos foi feita por difração a laser em um equipamento Malvern 2000, com uso da técnica de espalhamento de luz laser de baixo ângulo. Foi utilizada a escala granulométrica de WENTWORTH (WENTWORTH, 1922) com os correspondentes valores de $\phi\left(-\log _{2}(\mathrm{~mm})\right)$. Os parâmetros estatísticos diâmetro médio e desvio padrão gráfico inclusivo foram determinados de acordo com FOLK e WARD (1957). O conteúdo de matéria orgânica e o carbonato biodetrítico foram previamente eliminados das amostras.

\subsection{Análise química ambiental}

O teor disponível de $\mathrm{Cu}, \mathrm{Pb}$ e $\mathrm{Zn}$ nos sedimentos foi estimado somandose o teor desses elementos nas três frações estabelecidas pelo método BCR ( $\Sigma$ F1 a F3), considerando-se que o metal associado a essas frações poderá ser remobilizado se houver alterações nas condições ambientais. Na composição do somatório, considerou-se apenas teor superior ao LQ determinado para 
cada elemento (Tabela 4). Para avaliar o grau de contaminação das amostras, o teor disponível de $\mathrm{Cu}, \mathrm{Pb}$ e $\mathrm{Zn}$ foi comparado aos valores estabelecidos para esses elementos em guia de qualidade de sedimento, bem como, a valores regionais e de background.

Neste trabalho, adotou-se como guia de qualidade de sedimento o Canadian Sediment Quality Guidelines for the Protection of Aquatic Life para sedimento marinho (CCME, 2001), que sugere dois limites com base nos efeitos dos elementos sobre a biota; o menor limite, ISQG (Interim Sediment Quality Guidelines) e, o maior limite, PEL (Probable Effect Level). Abaixo do ISQG, efeitos adversos raramente deverão ocorrer, enquanto acima do PEL, estes efeitos geralmente são esperados. A seguir estão relacionadas algumas informações referentes a obtenção desses valores descritas no Protocol for the Derivation of Canadian Sediment Quality Guidelines for the Protection of Aquatic Life (CCME, 1999):

- Guias de qualidade de sedimento para proteção da vida aquática são necessários para a avaliar a significância toxicológica de produtos químicos associados aos sedimentos; as diretrizes são derivadas da informação toxicológica disponível referente aos efeitos biológicos causados por esses produtos sobre os organismos aquáticos.

- Para cada produto químico, um funcional nível de efeito limiar (TEL) é calculado como a média geométrica da fração inferior a $15 \%$ da concentração dos dados de efeito e da fração de $50 \%$ da concentração dos dados de não efeito. Todas as informações relevantes sobre o comportamento do produto químico nos sedimentos e as informações 
toxicológicas disponíveis são avaliadas, a fim de recomendar o TEL como o ISQG.

- O peso da evidência dos dados toxicológicos compilados nas tabelas de orientação para cada substância química, deverá apoiar a hipótese de que o potencial para efeitos biológicos adversos de uma substância cresce com o aumento da concentração. Essa avaliação é facilitada pela derivação de um segundo valor de qualidade do sedimento, o PEL, que por sua vez é calculado como a média geométrica de $50 \%$ da concentração dos dados de efeito e $85 \%$ da concentração dos dados de não efeito.

Embora existam outros estudos relacionados a metais no Sistema Cananéia-Iguape, optou-se por utilizar o estudo de MAHIQUES et al. (2013) como referência regional, pois seus resultados permitiram estimar o teor de $\mathrm{Cu}$, $\mathrm{Pb}$ e $\mathrm{Zn}$ na região em período que antecedeu a intensa atividade de mineração. Esse estudo determinou a entrada antrópica de metais na região nos últimos 150 anos, através da análise de quatro testemunhos longos. Dentre esses testemunhos, optou-se pelos resultados de CAN 05, que está localizado no canal Mar Pequeno, aproximadamente a $7,5 \mathrm{~km}$ da foz do canal do Valo Grande, sendo marcado por sedimentação lamosa com teor de silte + argila variando de 70 a $80 \%$ a partir da profundidade de $130 \mathrm{~cm}$ até o topo do testemunho. Com base nos dados de metais e na taxa de sedimentação do testemunho CAN 05 (MAHIQUES et al., 2013), foi estimado o teor de $\mathrm{Cu}, \mathrm{Pb}$ e Zn em meados da década de 1920, época que antecedeu ao período de intensa de atividade de mineração. Como valor de background utilizou-se o teor de $\mathrm{Cu}, \mathrm{Pb}$ e $\mathrm{Zn}$ na composição média dos folhelhos (TUREKIAN e 
WEDEPOHL, 1961). Na Tabela 6 estão indicados os valores de $\mathrm{Cu}, \mathrm{Pb}$ e $\mathrm{Zn}$ estabelecidos no guia de qualidade de sedimento, bem como, os teores regionais e de background desses elementos.

Tabela 6. Concentração de metais $\left(\mathrm{mg} \mathrm{kg}^{-1}\right)$ : valores Canadenses, regionais e composição média nos folhelhos

\begin{tabular}{c|c|c|c|c}
\hline Metais & \multicolumn{2}{|l|}{ Sedimentos marinhos $^{\mathrm{a}}$} & $\begin{array}{c}\text { Valores } \\
\text { regionais }^{\mathrm{b}\left({ }^{*}\right)}\end{array}$ & $\begin{array}{c}\text { Composição } \\
\text { média nos } \\
\text { folhelhos }^{\mathrm{c}}\end{array}$ \\
& ISQG & $\mathbf{P E L}$ & & (background) $^{2}$ \\
\hline $\mathbf{C u}$ & 18,7 & 108 & 30,2 & 45 \\
\hline $\mathbf{P b}$ & 30,2 & 112 & 20,5 & 20 \\
\hline $\mathbf{Z n}$ & 124 & 271 & 90,1 & 95 \\
\hline
\end{tabular}

Fonte: ${ }^{a}$ CCME (2001); ' ${ }^{b} M A H I Q U E S$ et al., (2013); ' TUREKIAN e WEDEPOHL (1961)

* Teores na região em meados da década de 1920, estimados com base nos dados de metais e na taxa de sedimentação do testemunho CAN 05

Em relação ao $\mathrm{Cu}$, observou-se que o seu ISQG $\left(18,7 \mathrm{mg} \mathrm{kg}^{-1}\right)$, é inferior aos valores regional e de background. Em alguns casos, as diretrizes de orientação, baseadas toxicologicamente, podem ser menores do que as respectivas concentrações de ocorrência natural das substâncias em determinado local, por isso, a concentração de background regional nos sedimentos deve ser considerada (CCME, 1999).

$\mathrm{Na}$ análise química ambiental também aplicou-se o critério de avaliação de risco RAC (Risk Assessment Codes), ferramenta amplamente utilizada em análise de risco referente à remobilização de metais (e.g. JAIN, 2004; SINGH et al., 2005; GHREFAT e YUSUF, 2006; PASSOS et al., 2010; YAN et al., 
2010; ZAKIR e SHIKAZONO, 2011). Este critério de avaliação considera o percentual da fração de metais trocáveis e associados a carbonatos, visto que nessa fração os elementos estão fracamente ligados aos sedimentos e, portanto, apresentam maior risco de remobilização no sistema aquático (PASSOS et al., 2010). Neste estudo, em razão da aplicação do procedimento de extração sequencial com base no método $B C R$, o critério RAC foi aplicado utilizando-se o percentual do teor do elemento na fração solúvel em ácido (F1), em relação ao teor pseudo-total. De acordo com o RAC, se esse percentual for inferior a 1\% não há risco para o sistema aquático; entre 1 e 10\% apresenta baixo risco; entre 11 e $30 \%$ médio risco; entre 31 e $50 \%$ alto risco e se superior a 50\%, altíssimo risco (PERIN et al., 1985 apud JAIN, 2004). Neste trabalho, as amostras com teor inferior ao LQ do elemento na F1 foram consideradas sem risco para o Sistema em razão da baixa concentração.

\subsection{Análise estatística}

O grau de associação entre as variáveis foi medido pelo coeficiente de correlação de Pearson (r). O valor de $r$ varia entre -1 e 1 , sendo o sinal a indicação da direção positiva ou negativa do relacionamento, e o valor, a sugestão de força da relação entre as variáveis (FIGUEIREDO FILHO e SILVA JÚNIOR, 2009). Para verificar a associação entre diversas variáveis aplicou-se matriz de correlação. Nos testes de hipóteses, o nível de significância ( $\alpha$ ) estabelecido foi 0,05 , ou seja, um intervalo de confiança de $95 \%$.

Além dos tratamentos estatísticos elementares, aplicou-se análise multivariada para auxiliar na interpretação das inter-relações entre as variáveis. No tratamento do conjunto de dados, adotou-se a análise de agrupamento 
(Cluster, método hierárquico de agrupamento de Ward) entre teor disponível de $\mathrm{Cu}, \mathrm{Pb}$ e $\mathrm{Zn}$, resultados de granulometria e COT. Essa técnica agrupa os dados formando grupos homogêneos internamente e heterogêneos entre si (POSSOLI, 1984). Em razão de variáveis com diferentes unidades, os dados foram previamente padronizados.

\subsection{Histórico da inserção antrópica de $\mathrm{Cu}, \mathrm{Pb}$ e $\mathrm{Zn}$ no Sistema Cananéia-Iguape durante o período de atividades de mineração no Vale do Ribeira}

O estudo foi desenvolvido determinando-se o teor disponível desses elementos nas amostras de sedimentos dos testemunhos (Figura 2) e a idade dessas amostras, calculadas através da Equação 2. Esses dados de geoquímica e de geocronologia permitiram avaliar a inserção de $\mathrm{Cu}, \mathrm{Pb}$, e $\mathrm{Zn}$ na região, durante o período de intensa mineração no Vale do Ribeira. Considerando-se que em sedimentos não poluídos os metais estão associados, principalmente, aos silicatos e minerais primários, formando espécies relativamente imóveis (RAURET, 1998), pode-se inferir que o teor disponível tem indicativo de origem antrópica.

\section{Equação 2:}

Idade $=$ ano de coleta $-\left(\right.$ profundidade $(\mathrm{cm}) /$ taxa de sedimentação $\left.\left(\mathrm{cm} \mathrm{a}^{-1}\right)\right)$ 
As taxas de sedimentação (Tabela 7) foram determinadas por MAHIQUES et al. (2013) e FERREIRA (informação verbal) ${ }^{1}$, por espectrometria gama ${ }^{210} \mathrm{~Pb}$, analisando seu fotopico de $47 \mathrm{KeV}$, com um detector de $\mathrm{Ge}$ hiperpuro (EG\&G Ortec GMX 25190P).

Tabela 7. Taxa de sedimentação dos testemunhos

\begin{tabular}{c|c}
\hline Testemunho & ${\text { Taxa de sedimentação }\left(\mathbf{c m ~ a} \mathbf{~}^{-1}\right)}$ \\
\hline CAN 02 & $1,00 \pm 0,06^{\mathrm{a}}$ \\
\hline CAN 04 & $0,72 \pm 0,01^{\mathrm{a}}$ \\
\hline CAN 05 & $1,52 \pm 0,11^{\mathrm{a}}$ \\
\hline CAN 07 & $0,67 \pm 0,05^{\mathrm{a}}$ \\
\hline CAN 10 & $0,61 \pm 0,07^{\mathrm{b}}$ \\
\hline
\end{tabular}

Fonte: ${ }^{a}$ MAHIQUES et al., $2013 ;{ }^{b}$ FERREIRA (informação verbal) ${ }^{1}$ 


\section{RESULTADOS E DISCUSSÃO}

\subsection{Análise granulométrica}

A variação granulométrica do sedimento é um parâmetro importante neste estudo, visto que o tamanho da partícula interfere no acúmulo de metais, conforme mencionado no Capítulo 1.

De acordo com os parâmetros estatísticos de FOLK e WARD (1957), o diâmetro médio (Figura 4) variou de 1,96 a 6,62 ( $\phi$ ) e o desvio padrão gráfico inclusivo de 0,43 a 2,34 $(\phi)$, com grau de seleção dos sedimentos na seguinte ordem: pobremente selecionado ( $47 \%$ das amostras) $>$ muito pobremente selecionado (25\% das amostras) > moderadamente selecionado (19\% das amostras) > bem selecionado (9\% das amostras). As classes texturais predominantes nos sedimentos foram areia fina e areia muito fina, abrangendo juntas, aproximadamente, $69 \%$ das amostras.

As Figuras 5 e 6 apresentam, respectivamente, o teor de areia, silte e argila, em \%, nos sedimentos e a representação do teor de lama, em \%, junto às estações amostrais ao longo do Sistema Cananéia-Iguape. Os dados granulométricos estão disponíveis em Anexos. 


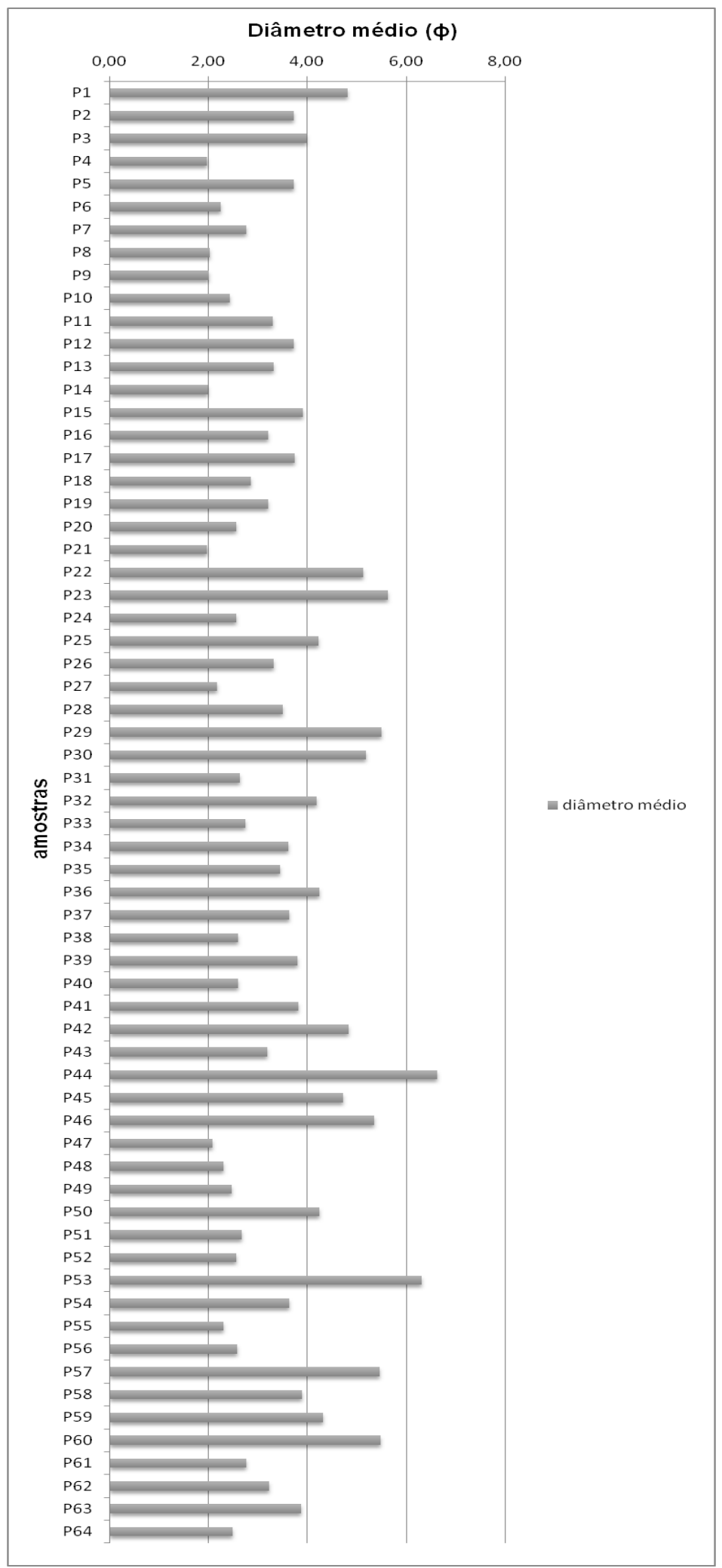

Figura 4. Diâmetro médio, em $\phi$, das amostras de sedimento superficial coletadas ao longo do Sistema Cananéia-Iguape. 


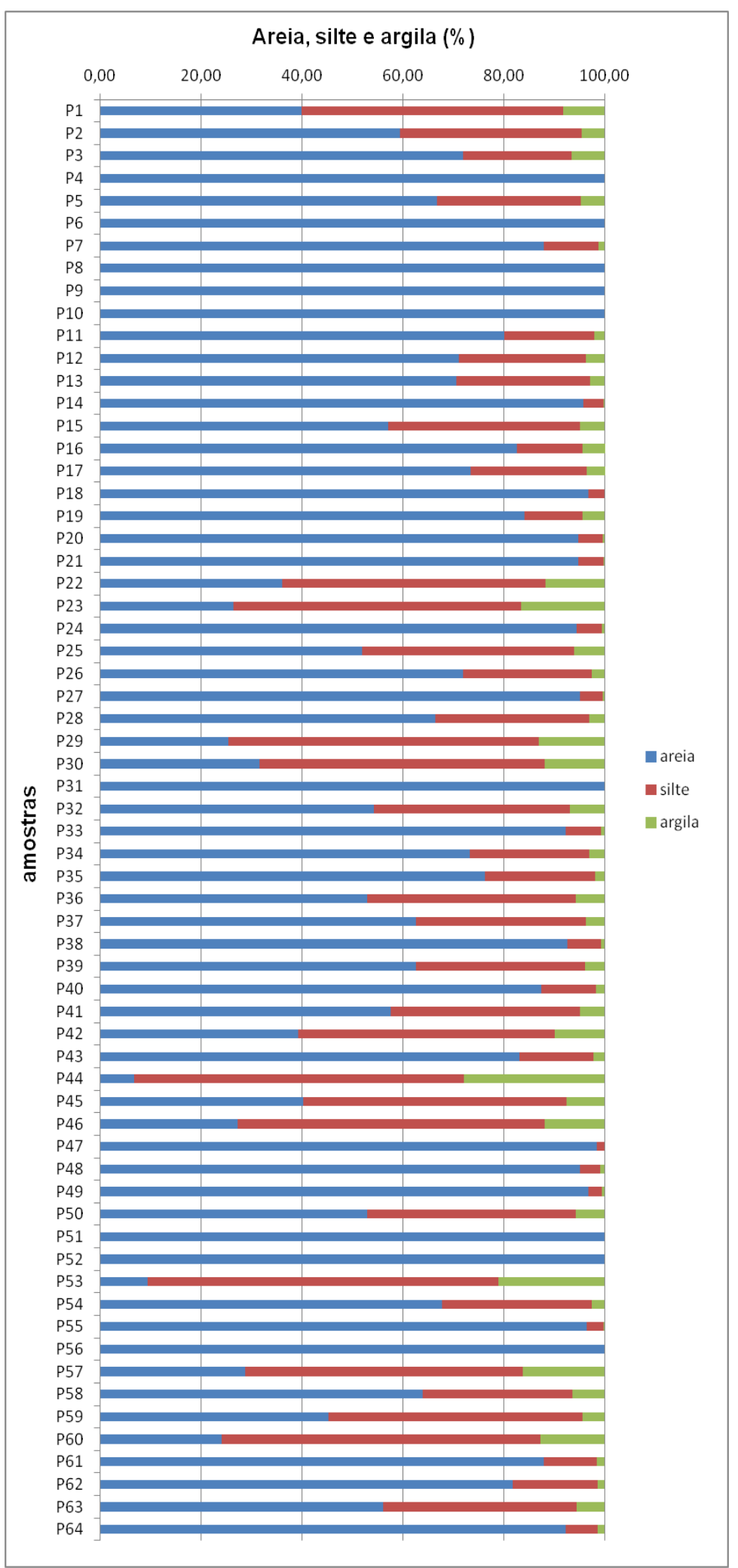

Figura 5. Areia, silte e argila, em \%, nas amostras de sedimento superficial coletadas ao longo do Sistema Cananéia-Iguape. 


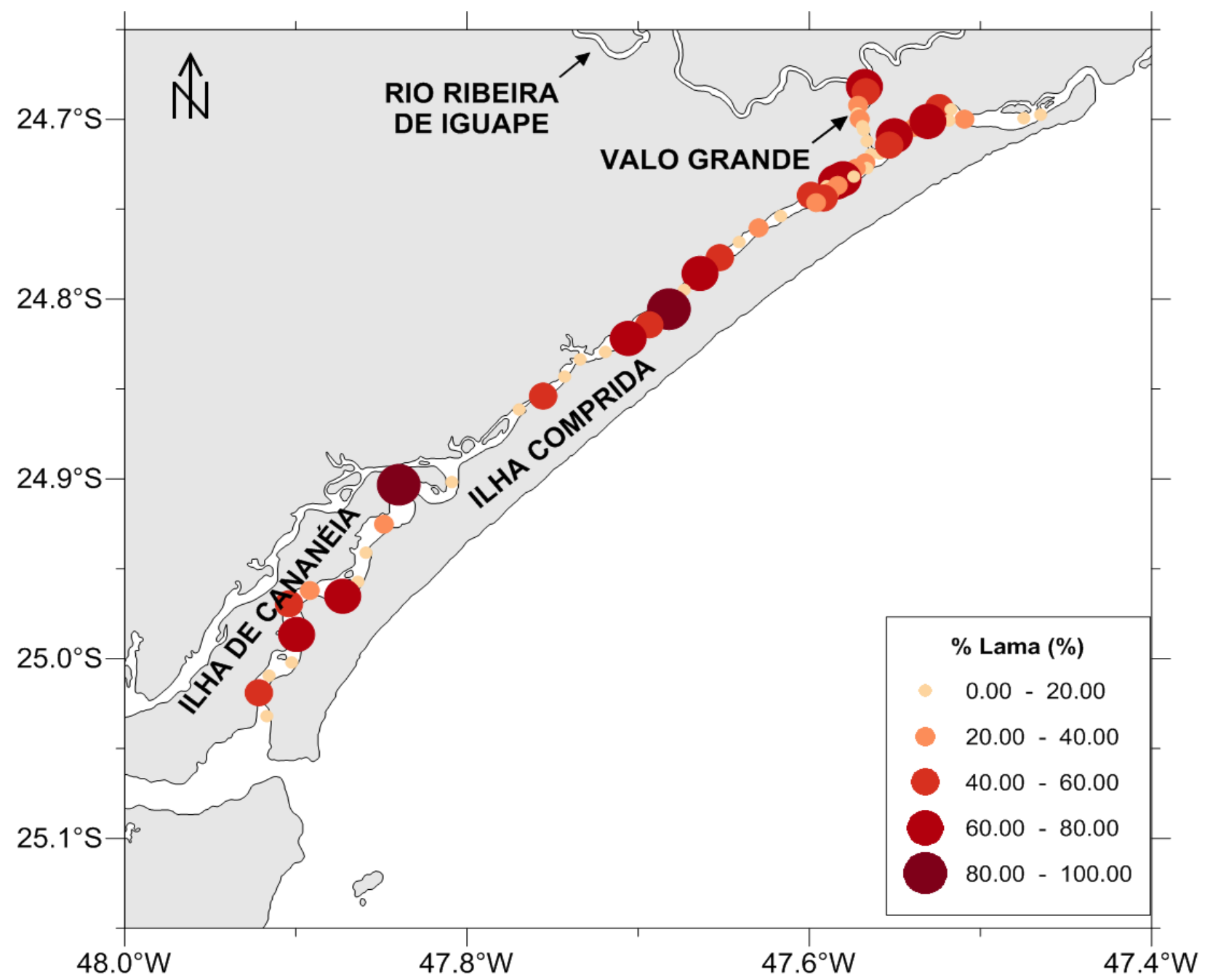

Figura 6. Representação dos percentuais de lama junto às estações amostrais ao longo do Sistema Cananéia-Iguape.

A fim de visualizar e melhor analisar a distribuição dos resultados, a área de estudo foi dividida em três regiões, considerando-se a proximidade geográfica entre as estações amostrais e a formação de pequenos grupos constituídos, no máximo, por 25 estações. As regiões foram denominadas de Iguape-Valo Grande, Mar Pequeno e Mar de Cananéia, conforme indicação na Figura 7. A região Iguape-Valo Grande é composta por 25 estações amostrais, P1 a P25 (Figura 2), localizadas ao longo do canal do Valo Grande e nas proximidades da cidade de Iguape. Na região do Mar Pequeno há 22 estações, 
P26 a P47 (Figura 2), distribuídas desde o início desse canal, até próximo à altura do rio Subaúna. A região do Mar de Cananéia é representada por 17 estações, P48 a P64 (Figura 2), localizadas no trecho que vai da altura do rio Subaúna até a Baía de Trapandé.

$\mathrm{Na}$ região Iguape-Valo Grande as amostras de sedimentos apresentaram, principalmente, areia muito fina e areia fina na sua composição. Em 56\% das amostras dessa região os percentuais de lama não ultrapassaram $20 \%$. Em apenas $24 \%$ das amostras os percentuais de lama foram superiores a $40 \%$, atingindo o valor máximo de $74 \%$. As estações com maiores percentuais estão localizadas próximo ao ponto de interligação entre o canal do Valo Grande e o rio Ribeira de Iguape, nas proximidades da cidade de Iguape e em direção à Barra de Icapara.

Na região do Mar Pequeno o principal componente dos sedimentos é areia muito fina, seguido de areia fina, silte grosso e médio. Em, aproximadamente, $41 \%$ das amostras dessa região os percentuais de lama ficaram acima de $40 \%$, atingindo o valor máximo de $93 \%$. As estações com percentuais de lama acima de 40\% estão localizadas, principalmente, no início do canal e nas proximidades da Pedra do Tombo. Esses resultados mostraram coerência com o estudo de TESSLER e SOUZA (1998), que indicou a ocorrência de sedimentos muito finos e mal selecionados entre o rio Subaúna e a foz do Valo Grande, além do predomínio de argilas siltosas e siltes argilosos a partir da Pedra do Tombo em direção à cidade de Iguape.

Na região do Mar de Cananéia os sedimentos apresentaram areia fina como principal componente. Aproximadamente 53\% das amostras dessa 
região apresentaram percentuais de lama inferiores a $20 \%$. Apenas em $35 \%$ das amostras os percentuais foram superiores a $40 \%$, atingindo o valor máximo de $91 \%$, em uma estação localizada nas proximidades da Ponta do Frade. Esses resultados também estão coerentes com as observações de TESSLER e SOUZA (1998), de que existe predomínio de sedimentos arenosos ao longo do canal Mar de Cananéia, com alterações em pequenas áreas, acentuando-se nas proximidades da cidade de Cananéia, onde há um afunilamento do canal e, principalmente, junto às ilhas do Boqueirão, na foz do córrego Jardim, onde regiões mais rasas causam circulação menos intensa. Ainda segundo esses autores, na Ponta do Frade, junto à margem da llha Comprida, fora do canal de circulação mais profundo, existe uma reentrância da margem do canal que possibilita a formação de uma zona de baixa energia, resultando na deposição de material muito fino. 


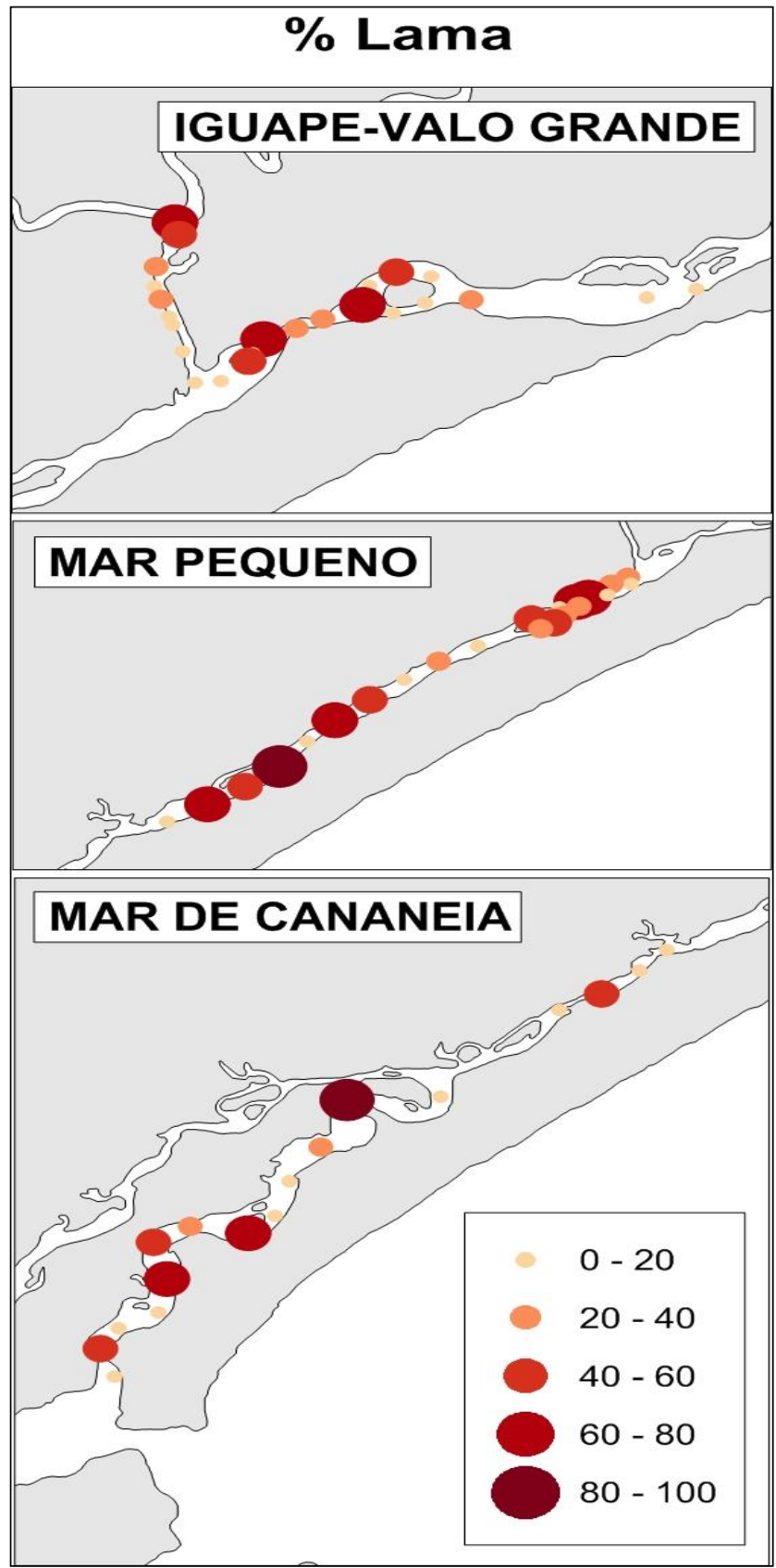

Figura 7. Representação dos percentuais de lama, junto às estações amostrais, nas regiões Iguape-Valo Grande, Mar Pequeno e Mar de Cananéia.

\subsection{Análise de Carbono Orgânico Total (COT)}

O COT é um dos parâmetros físico-químicos dos sedimentos considerados na adsorção (NAJI, ISMAIL A. e ISMAIL A. R., 2010), indicando a 
influência da matéria orgânica nesse processo. Portanto, trata-se de uma referência importante neste estudo e que contribuirá para melhor compreensão dos resultados de metais nos sedimentos. A Figura 8 mostra os resultados de COT (\%) nas amostras de sedimentos superficiais ao longo do Sistema Cananéia-Iguape.

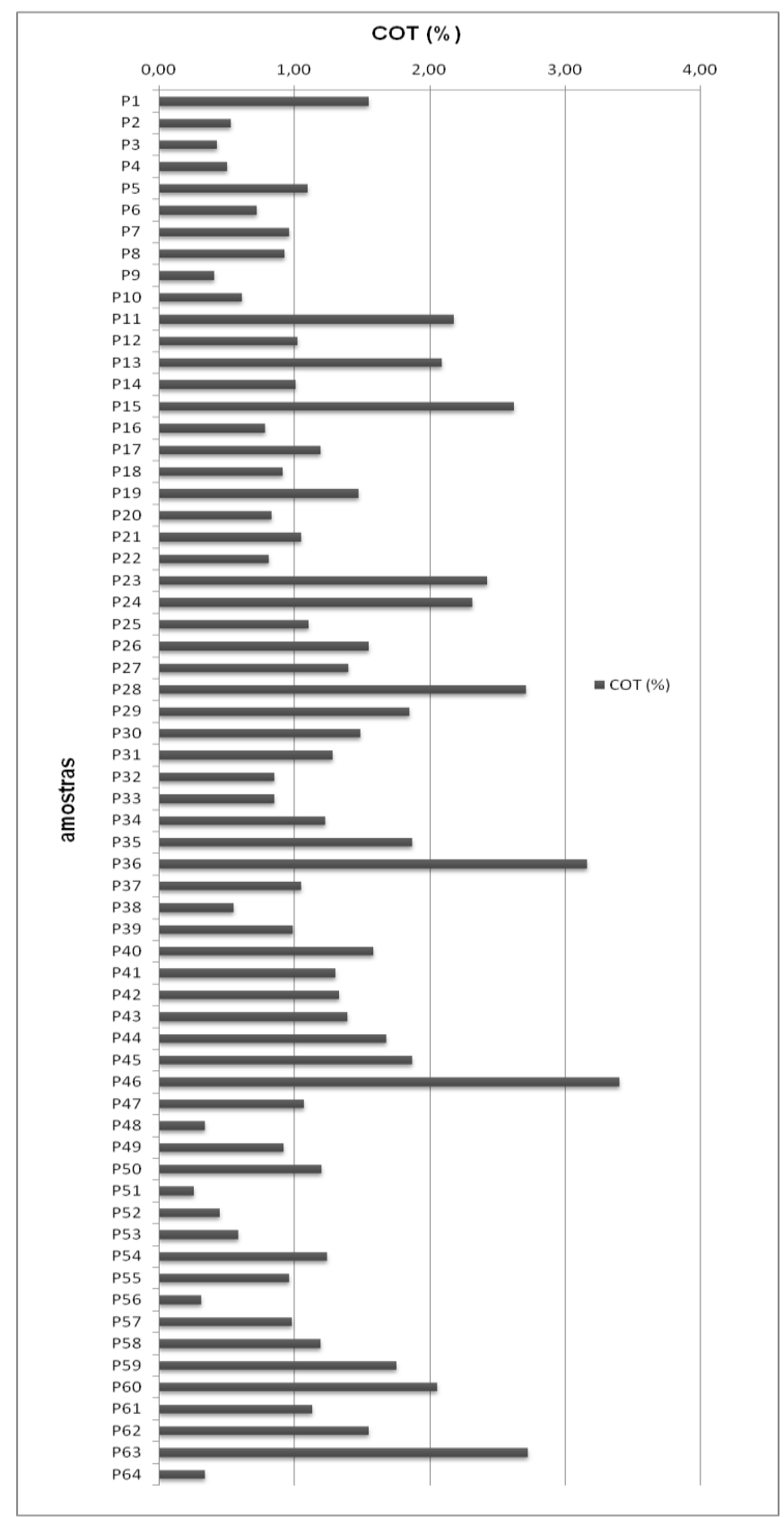

Figura 8. COT, em \%, nas amostras de sedimento superficial coletadas ao longo do Sistema Cananéia-Iguape. 
Os percentuais de COT variaram entre 0,26 a 3,40\%. Esses resultados estão disponíveis em Anexos. A Figura 9 mostra, representativamente, os valores de COT (\%) junto às estações amostrais ao longo do Sistema Cananéia-Iguape.

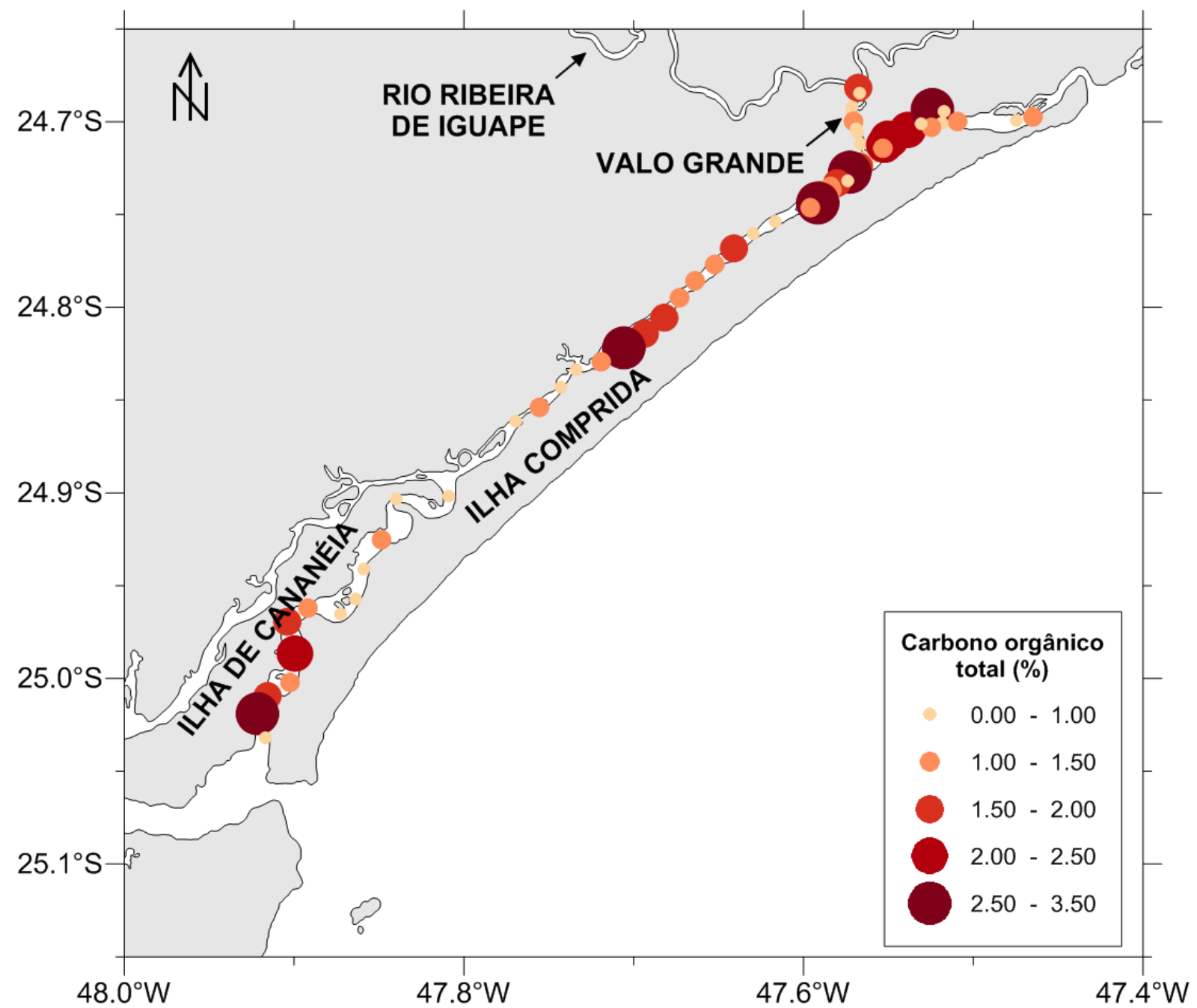

Figura 9. Representação dos percentuais de COT junto às estações amostrais ao longo do Sistema Cananéia-Iguape.

Analisando-se os percentuais de COT na área de estudo subdividida (Figura 10), observou-se que na região Iguape-Valo Grande $48 \%$ das amostras 
apresentaram percentuais de COT inferiores a $1,0 \%$. Apenas em $24 \%$ das amostras os percentuais foram superiores a 1,5\%, atingindo no máximo 2,6\%. As estações com maiores percentuais de COT estão localizadas próximo ao ponto de interligação entre o canal do Valo Grande e o rio Ribeira de Iguape, nas proximidades da cidade de Iguape e em direção à Barra de Icapara. É importante lembrar que nesses trechos também foram determinados os maiores percentuais de lama dessa região, conforme apresentado anteriormente.

Na região do Mar Pequeno apenas 18\% das amostras apresentaram percentuais de COT inferiores a 1,0\%; em $41 \%$ das amostras os valores foram superiores a $1,5 \%$, atingindo até $3,4 \%$. Os maiores percentuais de COT foram determinados, principalmente, no início desse canal, próximo à foz do canal do Valo Grande, e nas proximidades da Pedra do Tombo, assim como ocorreu com os maiores percentuais de lama dessa região.

Estudos realizados por BARCELLOS et al. (2009), também mostraram teores elevados de matéria orgânica em amostras do topo de testemunhos da região do Valo Grande e da Pedra do Tombo, considerando-se que o Valo Grande recebe grande quantidade de material sedimentar de origem terrígena, enquanto na região do tombo, as baixas condições hidrodinâmicas, induzidas pelo encontro de correntes de maré alta, resultam nas melhores condições para deposição de silte e argila dentro do Sistema Cananéia-Iguape.

Na região do Mar de Cananéia, aproximadamente, 53\% das amostras apresentaram percentuais de COT inferiores a 1,0\%. Em apenas, aproximadamente, $24 \%$ das amostras os percentuais foram superiores a $1,5 \%$, 
atingindo no máximo $2,7 \%$. Os maiores percentuais de COT no canal do Mar de Cananéia estão concentrados em um pequeno trecho em direção à baía de Trapandé. Esse trecho também apresentou algumas estações com considerável percentual de lama.

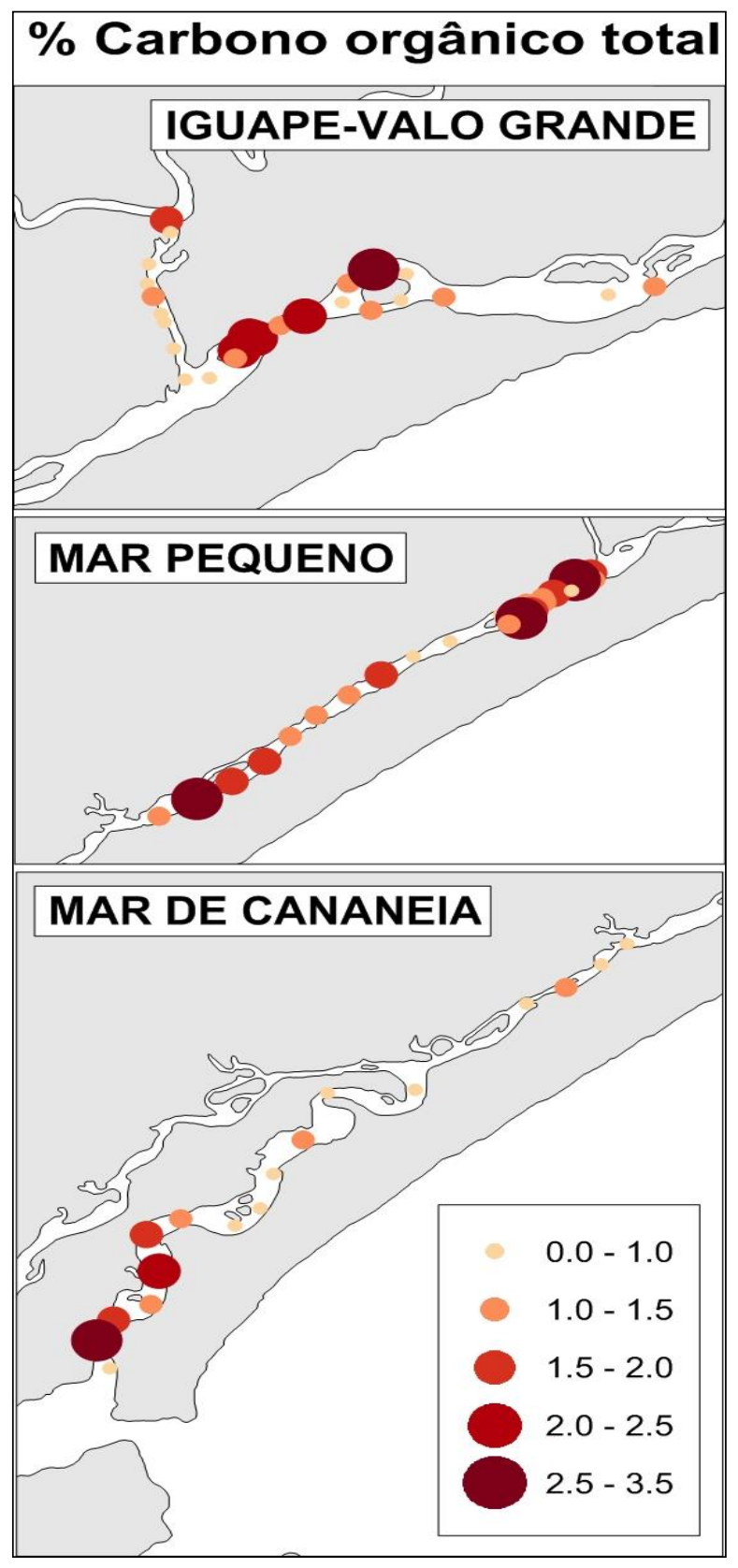

Figura 10. Representação dos percentuais de COT, junto às estações amostrais, nas regiões Iguape-Valo Grande, Mar Pequeno e Mar de Cananéia. 


\subsection{Análise de Metais}

\subsubsection{Metais pseudo-totais}

As amostras de sedimentos superficiais do Sistema Cananéia-Iguape foram submetidas ao procedimento de digestão pseudo-total com base no método recomendado pela Norma ISO 11466. Esses resultados foram utilizados na determinação do potencial de mobilidade dos metais e na aplicação do critério RAC. Considerando-se que o teor de $\mathrm{Cu}, \mathrm{Pb}$ e $\mathrm{Zn}$ extraído do material de referência (CRM 701) com água régia trata-se de um valor informativo, as amostras também foram digeridas com base no procedimento US EPA 3050B para comparação dos resultados. As Figuras de 11 a 13 mostram o teor parcial de $\mathrm{Cu}, \mathrm{Pb}$ e $\mathrm{Zn}$ obtidos nas duas metodologias. A ausência da indicação do teor do elemento significa que o valor determinado foi inferior ao seu LQ. De modo geral, observou-se que os teores parciais de $\mathrm{Cu}$, $\mathrm{Pb}$ e $\mathrm{Zn}$ nas amostras apresentaram a mesma tendência em ambos os métodos. Entretanto, em geral, a água régia mostrou ação mais efetiva, principalmente, para $\mathrm{Pb}$ e $\mathrm{Zn}$.

Utilizando-se o procedimento de digestão com base no método ISO 11466, verificou-se que o teor pseudo-total variou de 0,94 a $35,97 \mathrm{mg} \mathrm{kg}^{-1}$ para o $\mathrm{Cu}$, de 2,78 a 213,03 $\mathrm{mg} \mathrm{kg}^{-1}$ para o $\mathrm{Pb}$ e de 7,79 a $128,90 \mathrm{mg} \mathrm{kg}^{-1}$ para o $\mathrm{Zn}$. Os resultados de digestão pseudo-total desses elementos estão disponíveis em Anexos. 


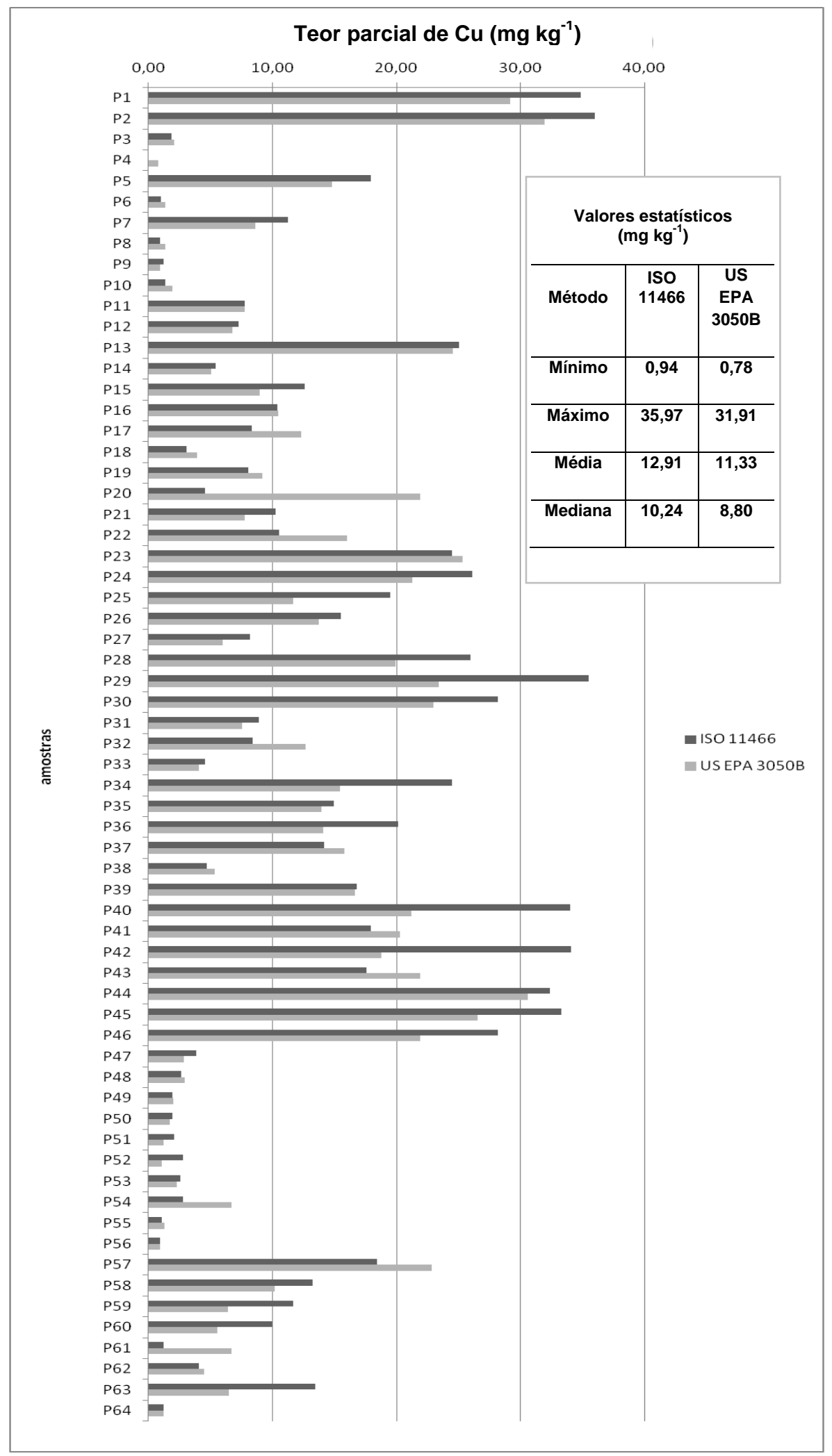

Figura 11. Teor parcial de $\mathrm{Cu}$, em $\mathrm{mg} \mathrm{kg}^{-1}$, nas amostras superficiais ao longo do Sistema Cananéia-Iguape. 


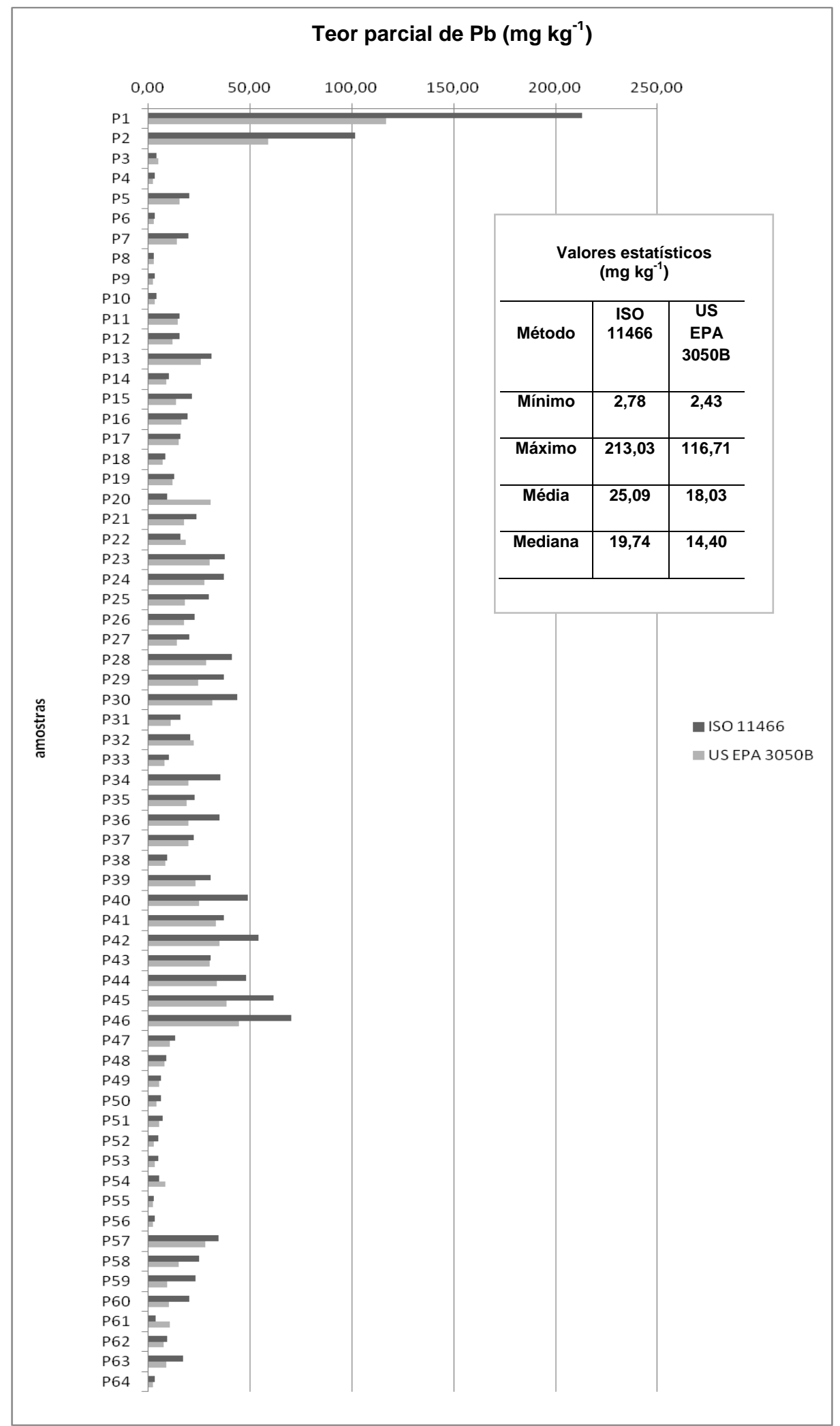

Figura 12. Teor parcial de $\mathrm{Pb}$, em $\mathrm{mg} \mathrm{kg}^{-1}$, nas amostras superficiais ao longo do Sistema Cananéia-Iguape. 


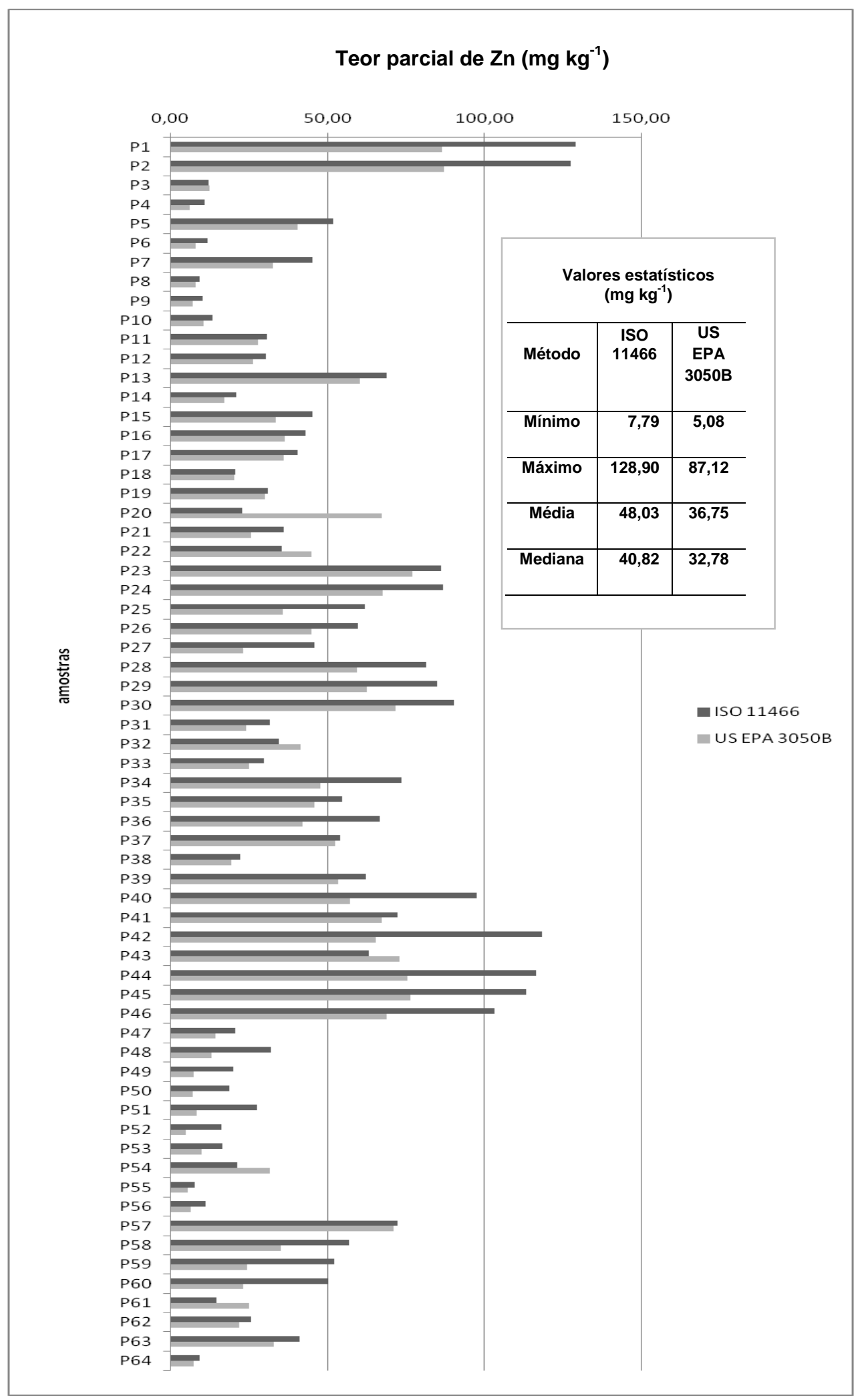

Figura 13. Teor parcial de $\mathrm{Zn}$, em $\mathrm{mg} \mathrm{kg}^{-1}$, nas amostras superficiais ao longo do Sistema Cananéia-Iguape. 


\subsubsection{Extração Sequencial}

O teor de $\mathrm{Cu}, \mathrm{Pb}$ e $\mathrm{Zn}$, associado às frações solúvel em ácido (F1), redutível (F2) e oxidável (F3), nos sedimentos superficiais do Sistema Cananéia-Iguape foi indicado, graficamente, nas Figuras de 14 a 16. Nas amostras em que não há indicação do teor do metal, em uma ou mais frações, significa que este foi inferior ao seu LQ. Os resultados de $\mathrm{Cu}, \mathrm{Pb}$ e $\mathrm{Zn}$ nas três frações estão disponíveis em Anexos.

$\mathrm{Na} F 1, \mathrm{Cu}, \mathrm{Pb}$ e $\mathrm{Zn}$ apresentaram, respectivamente, 45\%, 63\% e $11 \%$ das amostras com teor inferior ao seu LQ. Esses dados são importantes, principalmente, para $\mathrm{Pb}$ e $\mathrm{Cu}$ que detém os maiores percentuais, visto que, dentre as três frações, $\mathrm{F} 1$ é considerada a mais lábil e, portanto, apresenta o maior potencial de mobilidade ou disponibilidade no ambiente. O teor máximo determinado nessa fração foi $4,11 \mathrm{mg} \mathrm{kg}^{-1}$ para $\mathrm{Cu} ; 9,00 \mathrm{mg} \mathrm{kg}^{-1}$ para $\mathrm{Pb}$ e $30,82 \mathrm{mg} \mathrm{kg}^{-1}$ para $\mathrm{Zn}$. Os metais extraídos nessa fração são aqueles adsorvidos na superfície dos sedimentos por interação eletrostática relativamente fraca, metais que podem ser liberados por processos de troca iônica e, ainda, que podem ser co-precipitados com carbonatos; a remobilização desses elementos é controlada pela redução do pH e alterações na composição iônica (MARIN et al., 1997). Diversas investigações têm mostrado que o pH decresce durante a oxidação de sedimentos, sendo esse processo significante na remobilização de metais (FÖRSTNER, 2004). A acidificação de um sistema sedimento/água inicia-se após a produção de íons de hidrogênio durante a oxidação, que pode ocorrer, por exemplo, durante a dragagem ou ressuspensão de material, principalmente de granulação fina, 
contendo menos carbonato que o necessário para a neutralização de longo prazo (CALMANO e FÖRSTNER, 2004).

$\mathrm{Na} \mathrm{F} 2, \mathrm{Cu}, \mathrm{Pb}$ e $\mathrm{Zn}$ apresentaram, respectivamente, 23\%, 3\% e $6 \%$ das amostras com teor inferior ao seu LQ. O teor máximo determinado foi 8,15 $\mathrm{mg} \mathrm{kg}^{-1}$ para $\mathrm{Cu} ; 165,51 \mathrm{mg} \mathrm{kg}^{-1}$ para $\mathrm{Pb}$ e $32,81 \mathrm{mg} \mathrm{kg}^{-1}$ para Zn. Nessa fração são extraídos os metais associados aos óxidos de Fe e Mn. Esses metais são instáveis sob condições redutoras e alterações no potencial redox (Eh) podem induzir a dissolução desses óxidos, liberando os metais traço adsorvidos (MARIN et al., 1997). O pH e o Eh são parâmetros significantes para mobilização e transformação de metais (CALMANO, HONG e FÖRSTNER,1993; FÖRSTNER, 2004). Segundo TRIBOVILLARD et al. (2006), os metais traço adsorvidos em oxi-hidróxidos de Mn e Fe são exportados para o sedimento e depois liberados após a dissolução redutiva dos oxi-hidróxidos abaixo ou na interface água-sedimento, ficando disponíveis para novas reações; são influenciados por esses ciclos, principalmente, Ni, Cu, Zn, Co e $\mathrm{Pb}$ na forma de cátions (II), bem como, Mo, $\mathrm{V}$ e $\mathrm{Cr}$ nas respectivas espécies iônicas: $\mathrm{MoO}_{4}{ }^{2-}, \mathrm{VO}^{2+}$ e $\mathrm{Cr}(\mathrm{OH})_{2}{ }^{+}$. A proporção de metais pesados ligados aos óxidos de Fe e Mn é altamente variável e depende de mudanças ambientais como profundidade e reações redox com os sedimentos; o ciclo oxidaçãoredução varia sazonalmente, especialmente no verão, quando a concentração de oxigênio na interface água-sedimento, geralmente, diminui (ABD EL- AZIM e EL- MOSELHY, 2005). Correntes diárias de maré também causam mudanças periódicas no potencial redox dos sedimentos costeiros e estuarinos (CALMANO, HONG e FÖRSTNER,1993). 
Dentre os elementos estudados nesse trabalho, observou-se que em todas as amostras o $\mathrm{Pb}$ mostrou-se associado, principalmente, à F2, conforme pode ser visto claramente na Figura 15. Estudos realizados por CORSI (1999) na região do Vale do Ribeira $(\mathrm{PR})$, indicaram que o transporte de $\mathrm{Pb}$ nos sedimentos de corrente dá-se, principalmente, associado aos óxidos e hidróxidos de Fe e Mn. Resultados de extrações sequenciais em sedimentos de corrente no Vale do Ribeira (SP) obtidos por RODRIGUES (2008) também destacaram a associação do $\mathrm{Pb}$ aos oxi-hidróxidos de $\mathrm{Fe}$ e Mn.

$\mathrm{Na}$ F3, Cu e Pb apresentaram, respectivamente, 19\% e 34\% do total de amostras com teor inferior ao seu LQ. O teor máximo determinado foi 15,86 $\mathrm{mg} \mathrm{kg}^{-1}$ para $\mathrm{Cu} ; 17,06 \mathrm{mg} \mathrm{kg}^{-1}$ para $\mathrm{Pb}$ e $27,01 \mathrm{mg} \mathrm{kg}^{-1}$ para $\mathrm{Zn}$. Os metais extraídos na F3 são aqueles associados à matéria orgânica e aos sulfetos. A degradação da matéria orgânica sob condições oxidantes pode levar a liberação de metais traço solúveis associados a esse componente, bem como, associados aos sulfetos (MARIN et al., 1997). Tais condições podem ocorrer se o sedimento for ressuspenso por dragagem, correntes, inundações e marés, entre outros, fazendo com que partículas do sedimento entrem em contacto com a água rica em oxigênio (MORILLO, USERO e GRACIA, 2004). Estudos realizados por KELDERMAN e OSMAN (2007) em sedimentos poluídos de um canal em Delft (Holanda) indicaram que crescentes potenciais redox parecem ter efeitos marcantes sobre as formas de ligação de $\mathrm{Cu}, \mathrm{Zn}$ e $\mathrm{Pb}$; geralmente ocorre a oxidação de sulfetos metálicos, liberando os metais, que em parte serão novamente adsorvidos, especialmente, em ligações com as frações mais lábeis. A salinidade também pode interferir na associação entre metais e matéria orgânica. PEREIRA (2009), em seu estudo de especiação química do 
Cu em ambientes aquáticos, relatou que a concentração de ligantes naturais é reduzida com o aumento da salinidade, principalmente devido às macromoléculas orgânicas, tais como ácidos húmicos e fúlvicos, que tendem a flocular e precipitar com o aumento da força iônica da água.

Neste trabalho, observou-se que em, aproximadamente, $58 \%$ das amostras, o teor de $\mathrm{Cu}$ associado à $\mathrm{F} 3$ é maior do que nas demais frações. É sabido que o $\mathrm{Cu}$ pode facilmente formar complexos com a matéria orgânica, em razão da constante de estabilidade elevada dos compostos orgânicos de Cu (MORILLO, USERO e GRACIA, 2004). Além disso, sob condições anóxicas, compostos sólidos de metais pesados são geralmente estáveis, em particular as formas sulfídicas (CALMANO, HONG e FÖRSTNER,1993). 


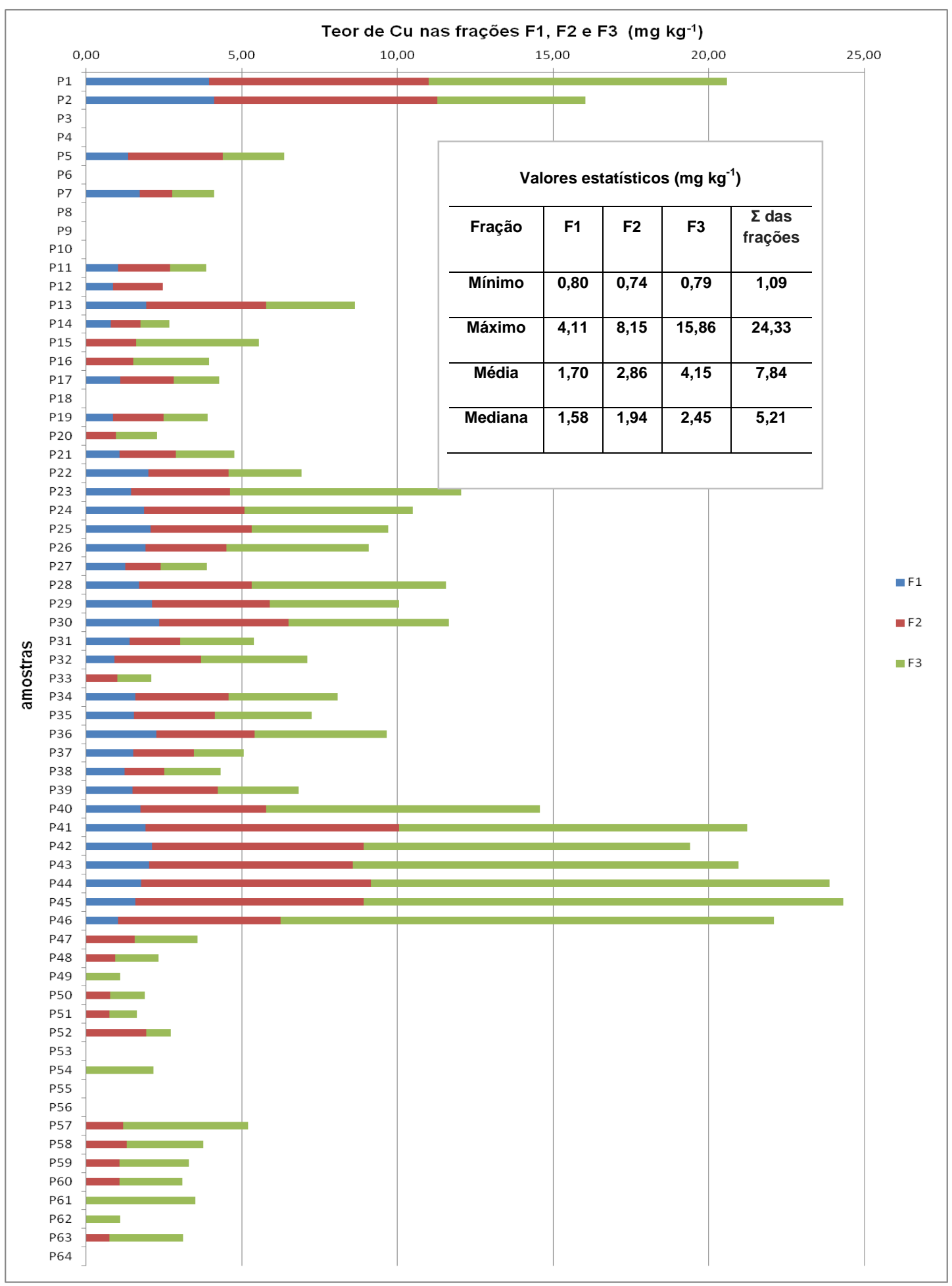

Figura 14. Teor de $\mathrm{Cu}$, em $\mathrm{mg} \mathrm{kg}^{-1}$, associado às frações disponíveis nas amostras de sedimento superficial ao longo do Sistema Cananéialguape. 


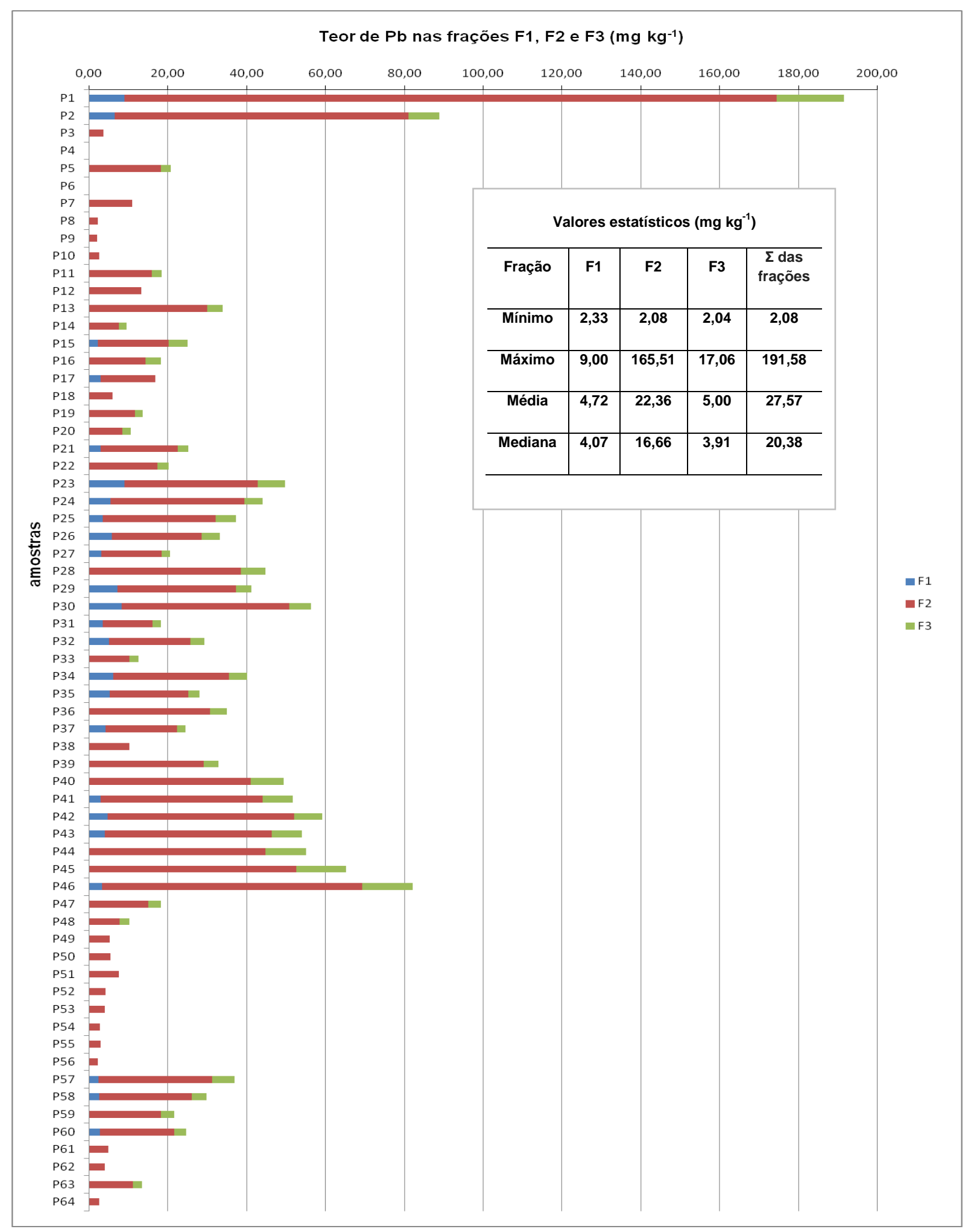

Figura 15. Teor de $\mathrm{Pb}$, em $\mathrm{mg} \mathrm{kg}^{-1}$, associado às frações disponíveis nas amostras de sedimento superficial ao longo do Sistema Cananéialguape. 


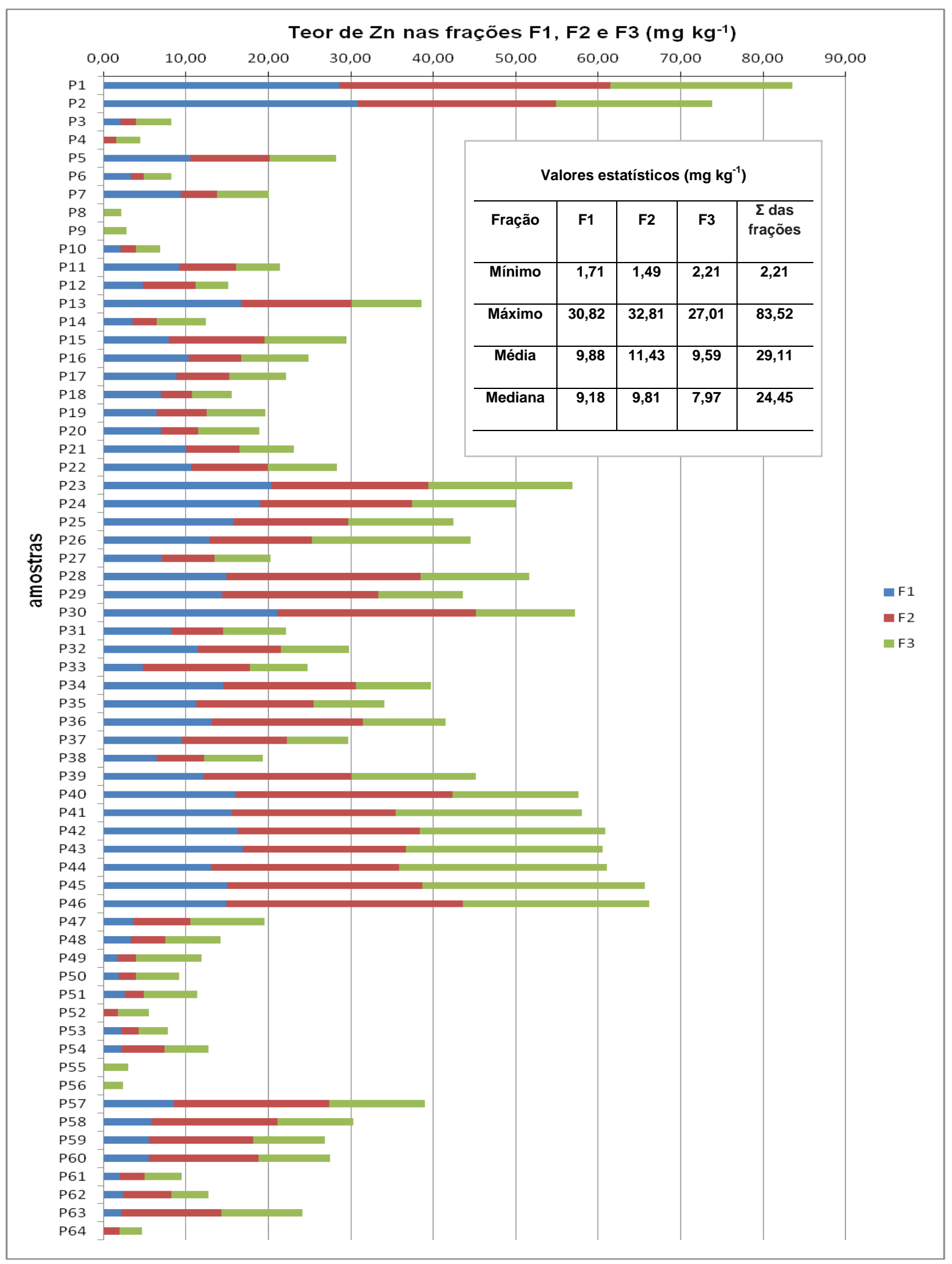

Figura 16. Teor de $\mathrm{Zn}$, em $\mathrm{mg} \mathrm{kg}^{-1}$, associado às frações disponíveis nas amostras de sedimento superficial ao longo do Sistema Cananéialguape. 


\subsubsection{Somatório das frações ( $\Sigma F 1$ a F3)}

Neste trabalho considerou-se como teor disponível de $\mathrm{Cu}, \mathrm{Pb}$ e $\mathrm{Zn}$ o somatório dos teores das frações F1, F2 e F3, que também pode ser visualizado nas Figuras de 14 a 16. A ausência da indicação do teor disponível de $\mathrm{Cu}$ e $\mathrm{Pb}$ em algumas amostras foi em razão da concentração ter sido inferior aos seus LQ nas três frações; isso ocorreu em $17 \%$ das amostras para o $\mathrm{Cu}$ e, em $3 \%$, para o $\mathrm{Pb}$. O teor máximo disponível foi $24,33 \mathrm{mg} \mathrm{kg}^{-1}$ para $\mathrm{Cu}, 191,58 \mathrm{mg} \mathrm{kg}^{-1}$ para $\mathrm{Pb}$ e $83,52 \mathrm{mg} \mathrm{kg}^{-1}$ para $\mathrm{Zn}$. Os somatórios de todas as amostras estão disponíveis em Anexos. As Figuras de 17 a 19 mostram, representativamente, o teor disponível de $\mathrm{Cu}, \mathrm{Pb}$ e $\mathrm{Zn}$, em $\mathrm{mg} \mathrm{kg}^{-1}$, junto às estações amostrais ao longo do Sistema Cananéia-Iguape.

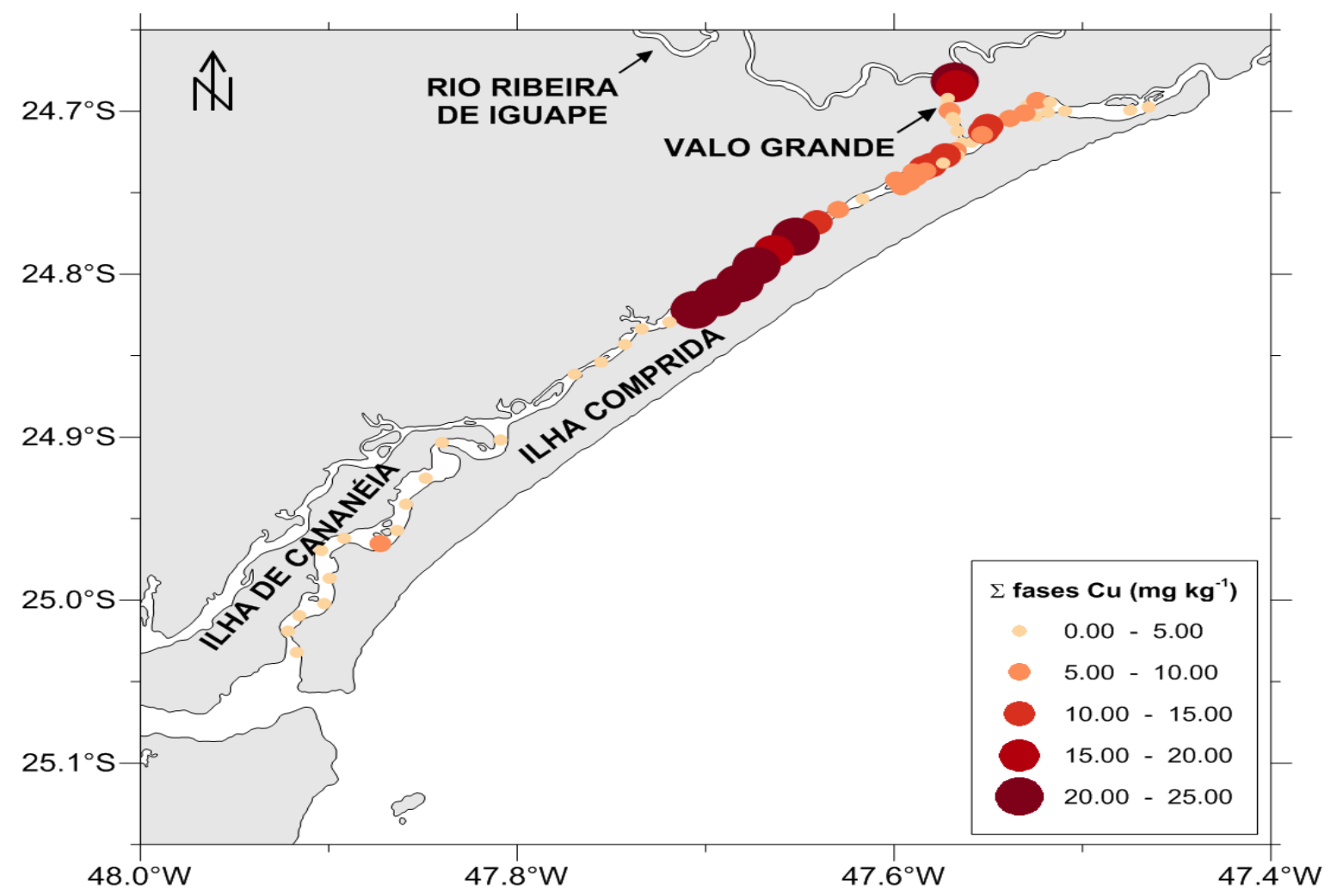

Figura 17. Teor disponível de $\mathrm{Cu}$, em $\mathrm{mg} \mathrm{kg}^{-1}$, nas estações amostrais ao longo do Sistema Cananéia-Iguape. 


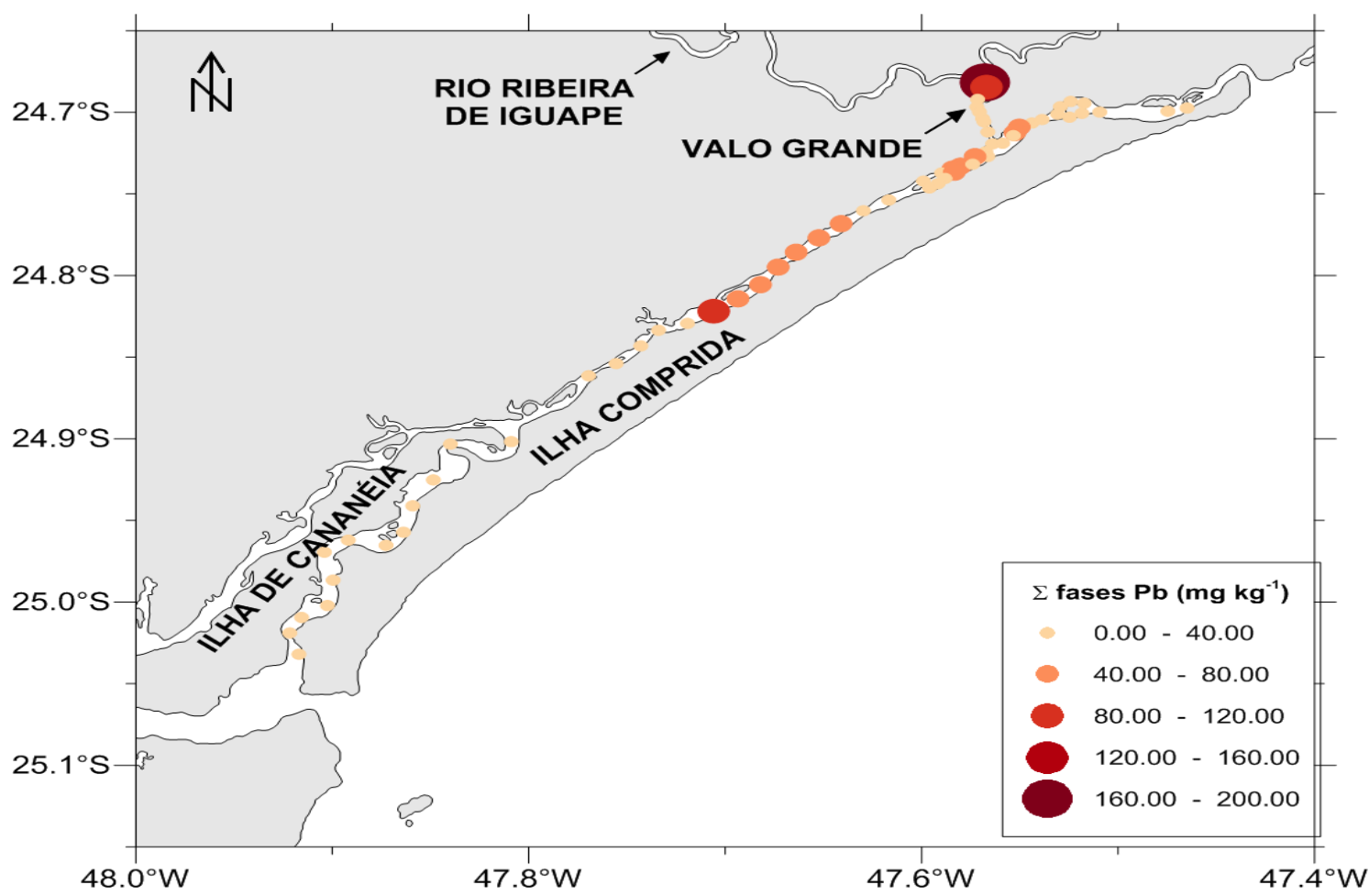

Figura 18. Teor disponível de $\mathrm{Pb}$, em $\mathrm{mg} \mathrm{kg}^{-1}$, nas estações amostrais ao longo do Sistema Cananéia-Iguape.

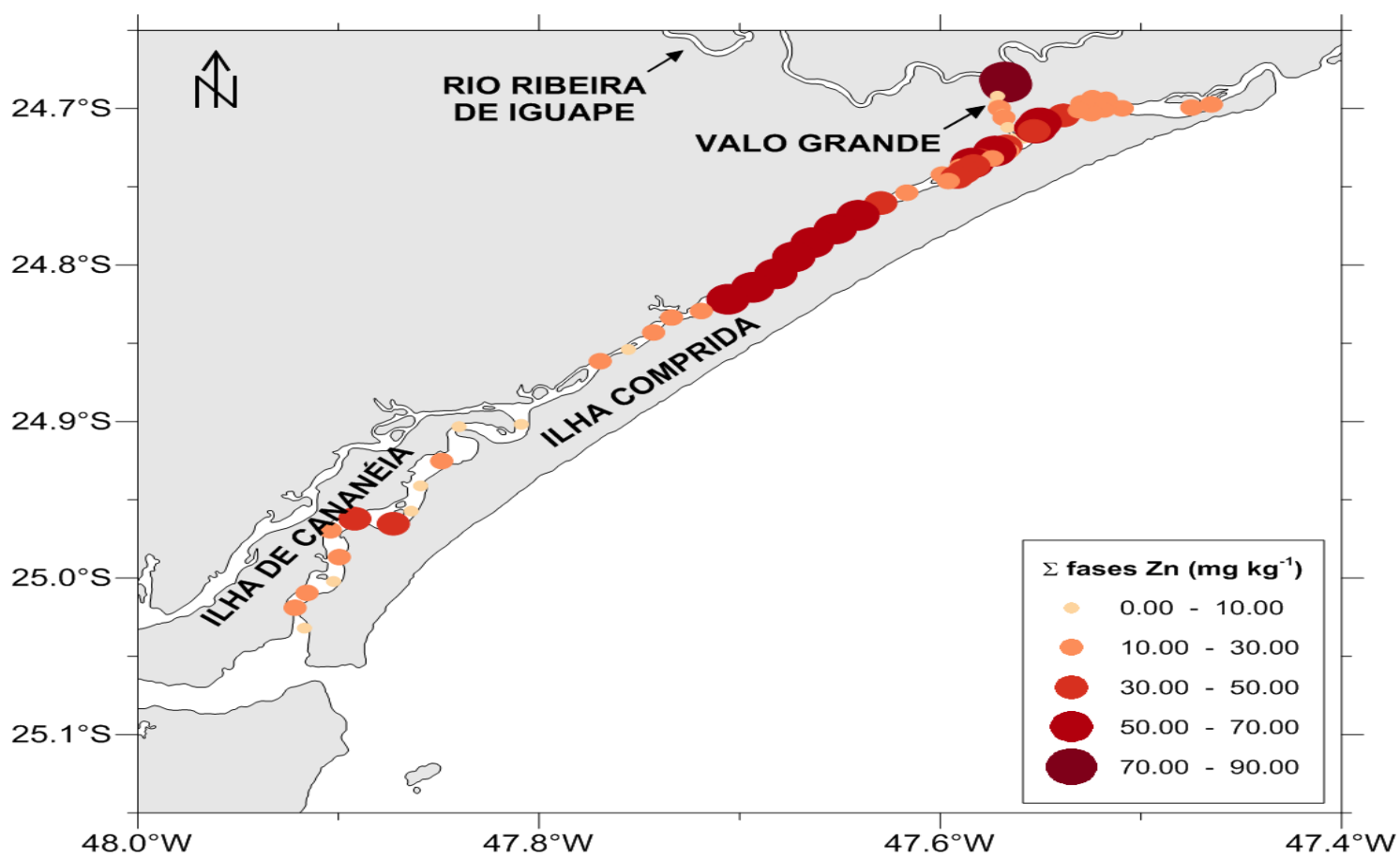

Figura 19. Teor disponível de $\mathrm{Zn}$, em $\mathrm{mg} \mathrm{kg}^{-1}$, nas estações amostrais ao longo do Sistema Cananéia-Iguape. 
A fim de facilitar a análise do teor disponível de $\mathrm{Cu}, \mathrm{Pb}$ e $\mathrm{Zn}$ e das condições oceanográficas que, possivelmente, contribuíram para o acúmulo de metais ao longo do Sistema Cananéia-Iguape, a Figura 20 mostra a área de estudo subdividida nas regiões: Iguape-Valo Grande, Mar Pequeno e Mar de Cananéia. Em relação ao $\mathrm{Cu}$, observou-se que dentre as três regiões, Mar Pequeno apresentou o conjunto de estações amostrais com maior teor disponível. Essas estações estão localizadas, principalmente, nas proximidades da Pedra do Tombo em direção à foz do Valo Grande, representadas graficamente na Figura 20, basicamente, pela concentração de 20 a $25 \mathrm{mg} \mathrm{kg}^{-1}$. A amostra P45, apresentou o teor mais elevado, 24,33 $\mathrm{mg} \mathrm{kg}^{-1}$. Na região Iguape-Valo Grande, as mais elevadas concentrações foram determinadas nas estações amostrais P1 e P2 (Figura 2), próximas ao ponto de interligação entre o canal do Valo Grande e o rio Ribeira de Iguape. Nas proximidades da cidade de Iguape e em direção à Barra de Icapara, também foi observado ligeiro incremento no teor disponível de $\mathrm{Cu}$. Na região do Mar de Cananéia encontra-se o conjunto de estações amostrais com menor teor disponível de $\mathrm{Cu}$, como mostra a Figura 20.

$\mathrm{O} \mathrm{Pb}$ apresentou comportamento similar ao $\mathrm{Cu}$. O conjunto de amostras com maior teor disponível desse elemento está na região do Mar Pequeno, em estações localizadas no início do canal e, principalmente, na região da Pedra do Tombo, representadas graficamente na Figura 20, basicamente, pela concentração de 40 a $80 \mathrm{mg} \mathrm{kg}^{-1}$. A amostra P46, apresentou o teor mais elevado, $82,18 \mathrm{mg} \mathrm{kg}^{-1}$. Na região Iguape-Valo Grande as estações amostrais P1 e P2 (Figura 2), apresentaram elevado teor disponível de Pb, principalmente em P1 (191,58 $\left.\mathrm{mg} \mathrm{kg}^{-1}\right)$, caracterizando-se em 
uma situação pontual. Nessa região observou-se também, incremento na concentração de $\mathrm{Pb}$ próximo à cidade de Iguape e em direção à Barra de Icapara. Na região do Mar de Cananéia está o conjunto de estações amostrais com menor teor disponível de $\mathrm{Pb}$; contudo houve incremento na concentração desse elemento nas estações de P57 a P60 (Figura 2).

O Zn, por sua vez, também apresentou comportamento similar aos outros elementos. A região do Mar Pequeno comportou o conjunto de estações com maior teor disponível. Essas estações estão localizadas no início do canal e, principalmente, na região da Pedra do Tombo, representadas graficamente na Figura 20, basicamente, pela concentração de 50 a $70 \mathrm{mg} \mathrm{kg}^{-1}$. A amostra P46, apresentou o teor mais elevado, $66,15 \mathrm{mg} \mathrm{kg}^{-1}$. Na região Iguape-Valo Grande as estações amostrais P1 e P2 (Figura 2), apresentaram as mais elevadas concentrações de $\mathrm{Zn}$, caracterizando uma situação pontual também para esse elemento. Nessa região também foi observado incremento na concentração de Zn próximo à cidade de Iguape e em direção à Barra de Icapara. Na região do Mar de Cananéia está o conjunto de amostras com menor teor disponível de $\mathrm{Zn}$; contudo, como ocorreu para o $\mathrm{Pb}$, houve incremento na concentração desse elemento nas estações amostrais de P57 a P60 e, ainda, na P63 (Figura 2).

O comportamento dos elementos estudados neste trabalho foi bastante similar e o conjunto de estações amostrais com teor disponível mais elevado está concentrado na região do Mar Pequeno, no início do canal e, principalmente, na região da Pedra do Tombo, que de acordo com TESSLER, SUGUIO e ROBILOTTA (1987), corresponde ao ponto de encontro de 
correntes de marés de sentidos opostos, provenientes das barras de Icapara e de Cananéia. Esse fenômeno permite a deposição de finos, especificamente os sedimentos finos carreados em suspensão a partir do rio Ribeira de Iguape, através do Valo Grande (TESSLER e SOUZA, 1998), favorecendo o acúmulo de metais. Os dados de granulometria dessa região corroboram essa hipótese, visto que indicaram estações amostrais com percentuais de lama acima de 40\% no início do canal e nas proximidades da Pedra do Tombo. A correlação entre a concentração de metais e o tamanho das partículas, também permite melhor compreensão da predominância de menor teor de $\mathrm{Cu}, \mathrm{Pb}$ e $\mathrm{Zn}$ na maior parte das estações das regiões Iguape-Valo Grande e Mar de Cananéia, considerando-se que na maioria das estações os percentuais de lama não ultrapassaram $20 \%$. 

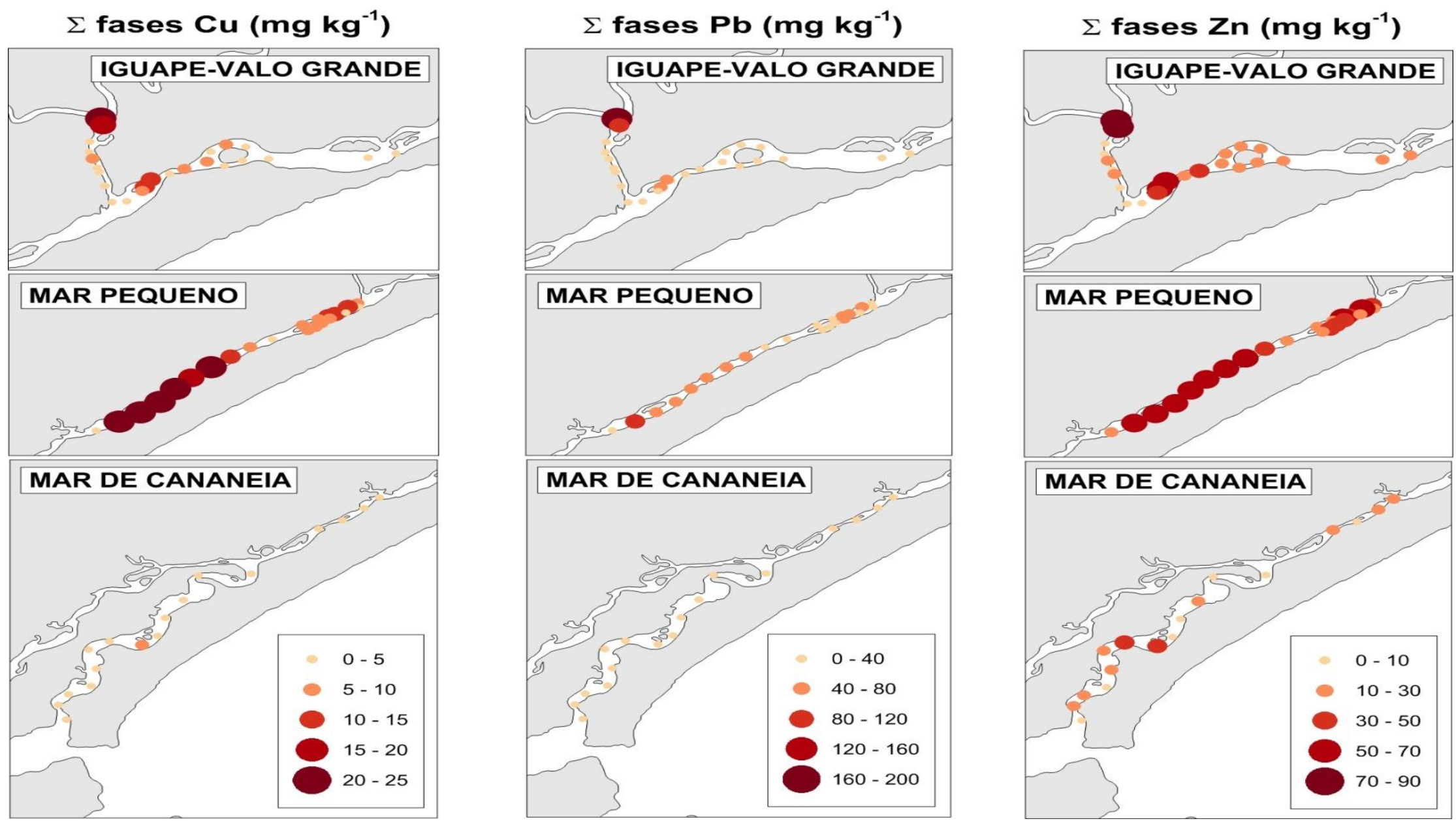

Figura 20. Teor disponível de $\mathrm{Cu}, \mathrm{Pb}$ e $\mathrm{Zn}$, em mg kg-1, juntos às estações amostrais nas regiões Iguape-Valo Grande, Mar Pequeno e Mar de Cananéia. 


\subsection{Análise química ambiental}

\subsubsection{Grau de contaminação dos sedimentos}

A fim de avaliar o grau de contaminação dos sedimentos, o teor disponível de $\mathrm{Cu}, \mathrm{Pb}$ e $\mathrm{Zn}$ nas amostras foi comparado aos limites ISQG e PEL (CCME, 2001), a valores regionais considerando-se teores de base de testemunho (MAHIQUES et al., 2013) e, ainda, aos valores de background desses elementos com base na composição média dos folhelhos (TUREKIAN e WEDEPOHL, 1961), conforme explanações constantes no Capítulo 4. Esses valores, que a partir de agora serão tratados como valores de comparação, foram indicados na Tabela 6.

As Figuras de 21 a 23 mostram o cruzamento entre o teor disponível de $\mathrm{Cu}, \mathrm{Pb}$ e $\mathrm{Zn}$ e seus respectivos valores de comparação. A ausência da indicação do teor em determinadas amostras significa que, nas três frações móveis, a concentração do elemento foi inferior ao seu LQ. Em relação ao Cu, na maioria das amostras (89\%) o teor disponível foi inferior ao ISQG. Apenas na estação P1 (Figura 2), localizada próxima ao ponto de interligação entre o canal do Valo Grande e o rio Ribeira de Iguape, e em um reduzido grupo de estações próximas à região da Pedra do Tombo, P41 a P46 (Figura 2), o teor disponível desse elemento foi ligeiramente superior ao ISQG, porém bem inferior ao PEL. O teor máximo disponível de $\mathrm{Cu}, 24,33 \mathrm{mg} \mathrm{kg}^{-1}$, foi inferior aos valores regional e de background.

Quanto ao $\mathrm{Pb}$, aproximadamente um terço das estações amostrais apresentou teor disponível superior ao ISQG; a maioria dessas estações está 
localizada no canal do Mar Pequeno. Apenas na estação P1 (Figura 2) o teor foi superior ao PEL, caracterizando uma situação pontual. Em aproximadamente $50 \%$ das estações o teor disponível de $\mathrm{Pb}$ foi superior aos valores regional e de background.

Em relação ao Zn, o teor máximo disponível nas estações amostrais, $83,52 \mathrm{mg} \mathrm{kg}^{-1}$, foi inferior aos valores ISQG, regional e de background. 


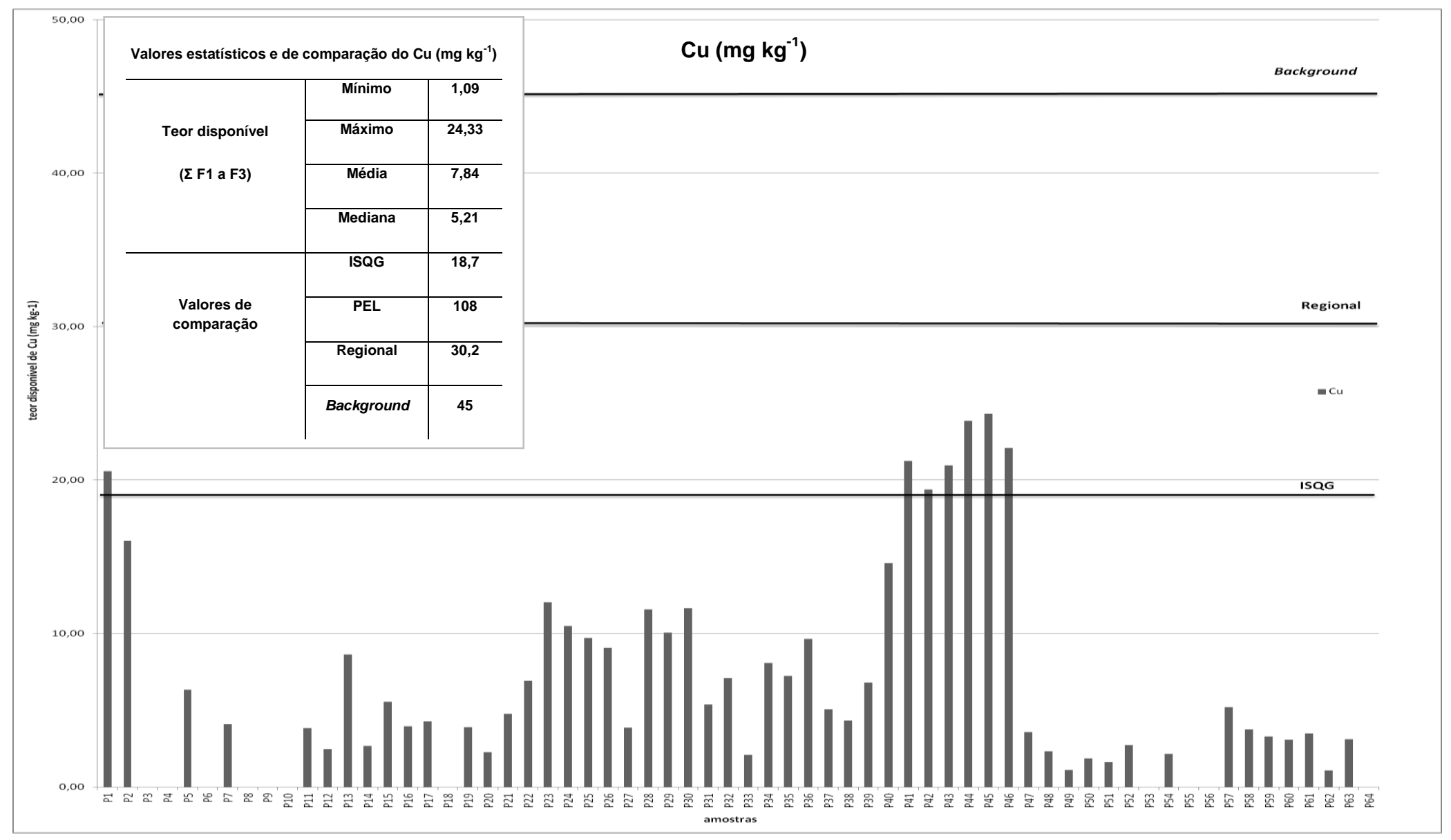

ISQG/PEL(CCME, 2001); Regional (MAHIQUES et al., 2013); Background (TUREKIAN e WEDEPOHL, 1961)

Figura 21. Teor disponível e valores de comparação do $\mathrm{Cu}$, em mg kg${ }^{-1}$, em amostras superficiais ao longo do Sistema CananéiaIguape. 


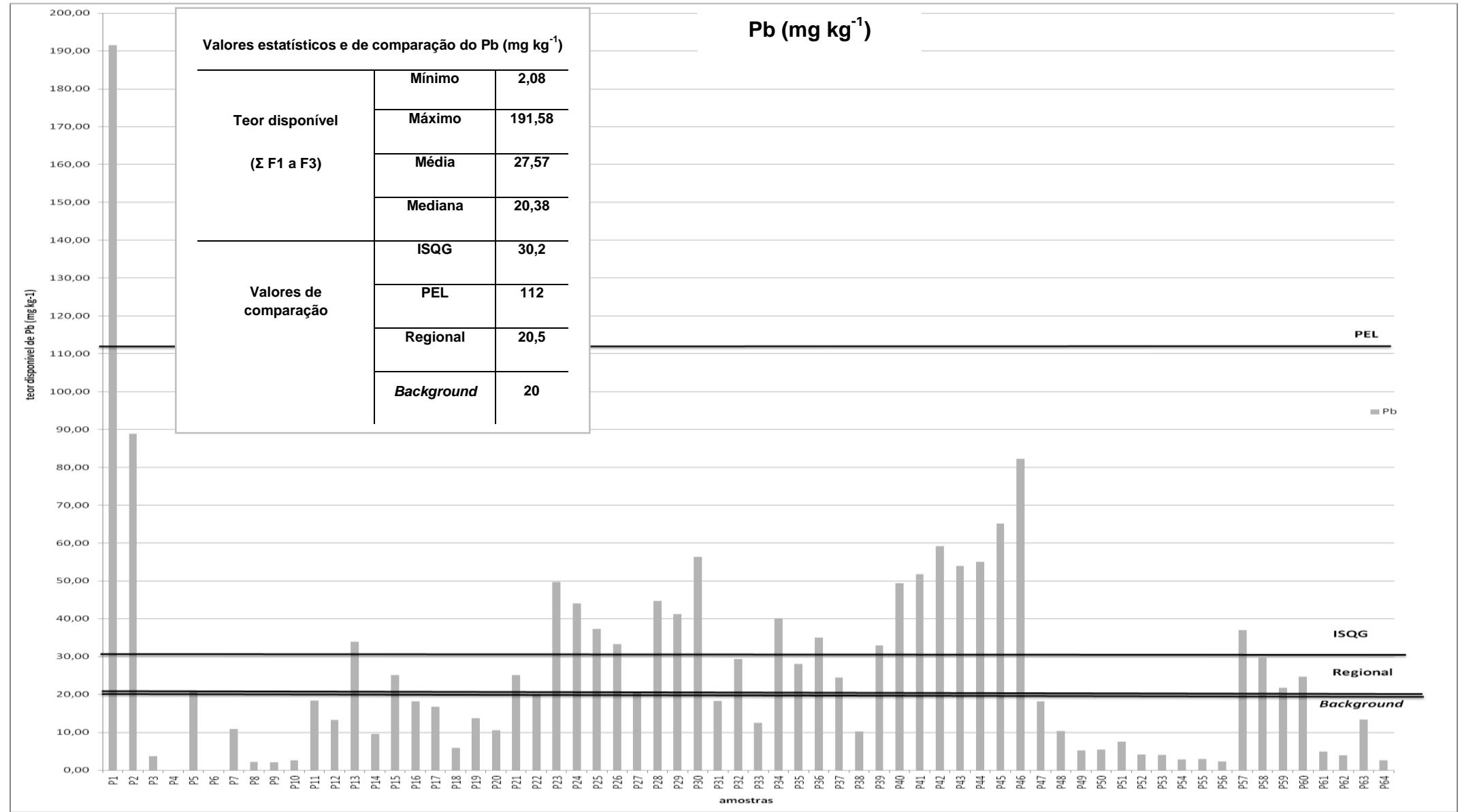

ISQG/PEL(CCME, 2001); Regional (MAHIQUES et al., 2013); Background (TUREKIAN e WEDEPOHL, 1961)

Figura 22. Teor disponível e valores de comparação do $\mathrm{Pb}$, em mg kg${ }^{-1}$, em amostras superficiais ao longo do Sistema CananéiaIguape. 


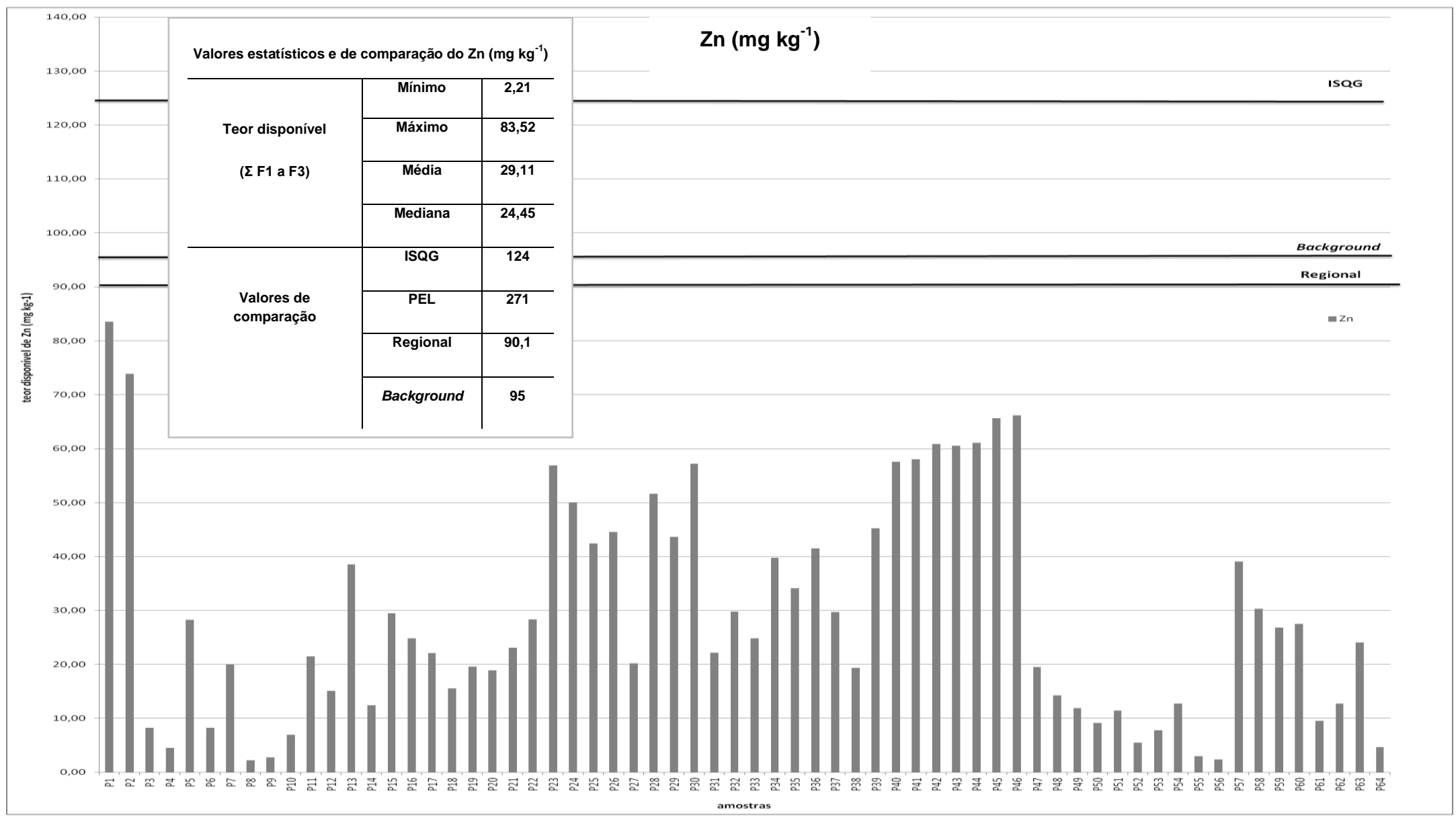

ISQG/PEL(CCME, 2001); Regional (MAHIQUES et al., 2013); Background (TUREKIAN e WEDEPOHL, 1961)

Figura 23. Teor disponível e valores de comparação do $\mathrm{Zn}$, em $\mathrm{mg} \mathrm{kg}^{-1}$, em amostras superficiais ao longo do Sistema CananéiaIguape. 


\subsubsection{Análise do potencial de mobilidade}

A análise do potencial de mobilidade permite estimar o percentual do metal nas frações móveis, em relação ao teor total. Para avaliar o potencial de mobilidade do $\mathrm{Cu}, \mathrm{Pb}$ e $\mathrm{Zn}$ no Sistema Cananéia-Iguape, foram comparados o teor disponível ( $\Sigma$ F1 a F3) e o teor pseudo-total desses elementos nas estações amostrais. O teor pseudo-total foi obtido por digestão com base no método ISO 11466, conforme descrito no Capítulo 4. Na digestão pseudo-total os elementos associados às estruturas silicáticas, geralmente, não são dissolvidos. Portanto, é possível que o teor disponível de um elemento, estimado a partir do somatório dos teores das frações móveis, seja igual ou até superior ao seu teor parcial. Nestes casos, este trabalho considerou que $100 \%$ do metal presente no sedimento está associado às frações móveis. O conteúdo não extraído na digestão pseudo-total não é relevante em termos de disponibilidade ambiental, em razão da baixa probabilidade de remobilização.

Considerando-se o percentual médio de $\mathrm{Cu}, \mathrm{Pb}$ e $\mathrm{Zn}$ em frações móveis, estima-se a seguinte ordem de mobilidade, do mais para o menos disponível: $\mathrm{Pb}(92 \%)>\mathrm{Zn}(59 \%)>\mathrm{Cu}(55 \%)$. A Figura 24 mostra os gráficos de potencial de mobilidade da área de estudo subdividida nas regiões IguapeValo Grande, Mar Pequeno e Mar de Cananéia, na qual é possível observar o elevado potencial de mobilidade do $\mathrm{Pb}$, principalmente, na região do Mar Pequeno. 


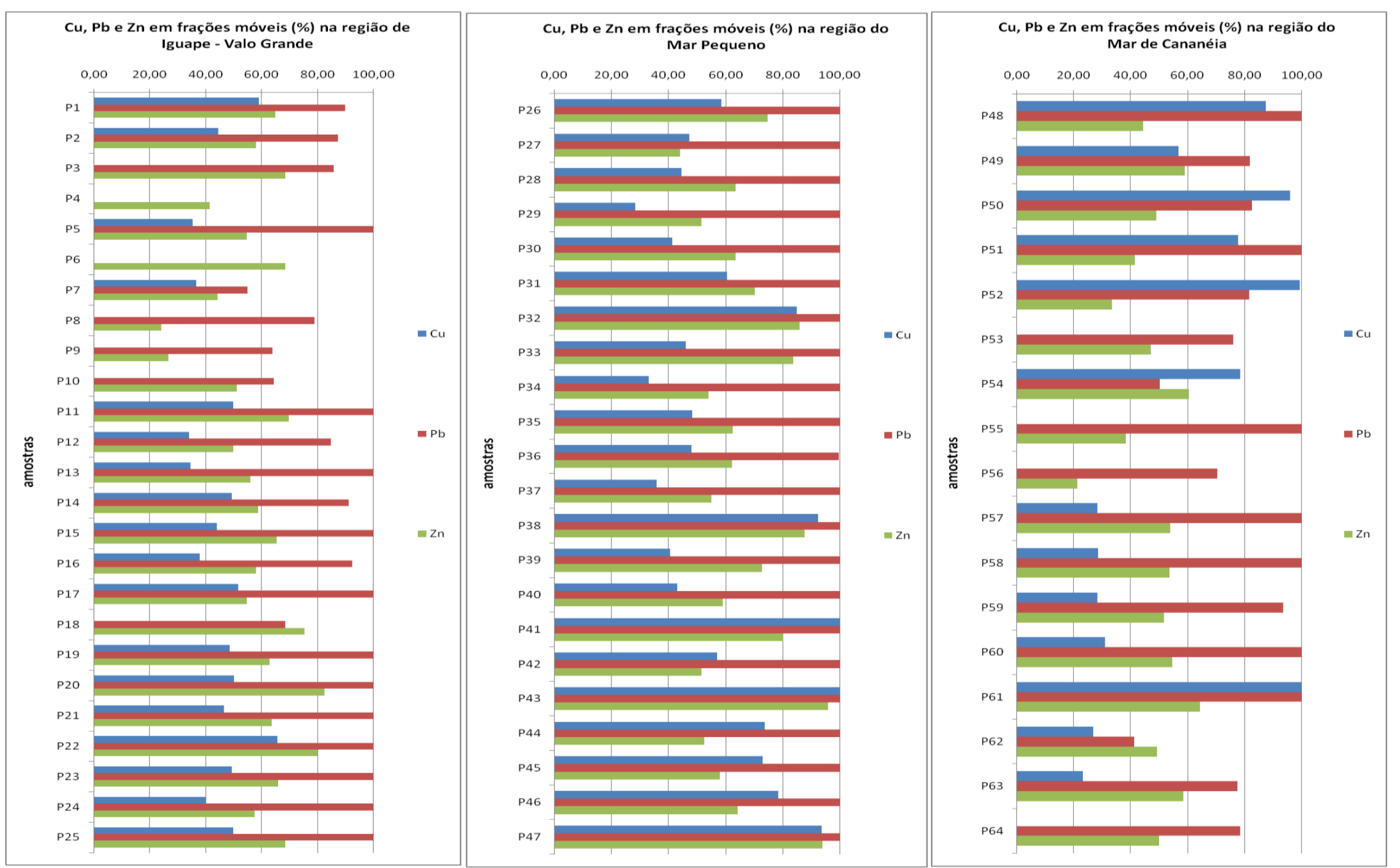

Figura 24. Potencial de mobilidade do $\mathrm{Cu}, \mathrm{Pb}$ e $\mathrm{Zn}$ nas regiões Iguape-Valo Grande, Mar Pequeno e Mar de Cananéia. 


\subsubsection{Risk Assessment Code (RAC)}

Para análise do risco ambiental foi utilizada a metodologia Risk Assessment Code (RAC), conforme descrito no Capítulo 4. Neste trabalho, o RAC foi determinado considerando-se o percentual do elemento na fração solúvel em ácido (F1), em relação ao seu teor pseudo-total (método ISO 11466). Se inferior a 1\% não há risco para o sistema aquático; entre 1 e $10 \%$ apresenta baixo risco; entre 11 e $30 \%$ médio risco; entre 31 e $50 \%$ alto risco; superior a 50\% altíssimo risco (PERIN et al., 1985 apud JAIN, 2004).

As Figuras de 25 a 27 mostram, graficamente, os resultados dessa análise nas regiões Iguape-Valo Grande, Mar Pequeno e Mar de Cananéia. Na região Iguape-Valo Grande o $\mathrm{Cu}$ apresentou predomínio de nenhum e médio risco de remobilização, o $\mathrm{Pb}$, de nenhum risco e o $\mathrm{Zn}$, de médio risco. $\mathrm{Na}$ região do Mar Pequeno o Cu apresentou predomínio de baixo e médio risco, o $\mathrm{Pb}$, de nenhum e médio risco e o $\mathrm{Zn}$, de médio risco. Observou-se que nessas duas regiões, de forma pontual, o $\mathrm{Zn}$ mostrou alto risco de remobilização em uma das estações. Na região do Mar de Cananéia o Cu apresentou nenhum risco de remobilização em todas as estações, o $\mathrm{Pb}$ mostrou predomínio de nenhum risco e o $\mathrm{Zn}$, de baixo e médio risco. Em síntese, verificou-se que $\mathrm{Cu}$, $\mathrm{Pb}$ e $\mathrm{Zn}$ apresentaram, respectivamente, risco médio de remobilização em, aproximadamente, $30 \%, 27 \%$ e $73 \%$ das estações amostrais do Sistema Cananéia-Iguape; o $\mathrm{Zn}$ também apresentou risco alto em 3\% das estações, conforme mencionado acima.

Contudo, considerando-se que o RAC baseia-se no percentual do teor do metal presente na $\mathrm{F} 1$, é importante ressaltar que os valores máximos 
determinados para $\mathrm{Cu}\left(4,11 \mathrm{mg} \mathrm{kg}^{-1}\right), \mathrm{Pb}\left(9,00 \mathrm{mg} \mathrm{kg}^{-1}\right)$ e $\mathrm{Zn}\left(30,82 \mathrm{mg} \mathrm{kg}^{-1}\right)$ nessa fração foram inferiores aos valores de comparação (CCME, 2001; MAHIQUES et al., 2013; TUREKIAN e WEDEPOHL, 1961), indicados na Tabela 6. Portanto, ainda que alterações ambientais no Sistema CananéiaIguape favorecessem a remobilização desses metais, em razão do baixo grau de contaminação química nessa fração, estima-se que a probabilidade de efeitos adversos à biota seria baixa.

A Figura 28 apresenta os resultados do Risk Assessment Code (RAC) para $\mathrm{Cu}, \mathrm{Pb}$ e $\mathrm{Zn}$ em todo o Sistema Cananéia-Iguape. 


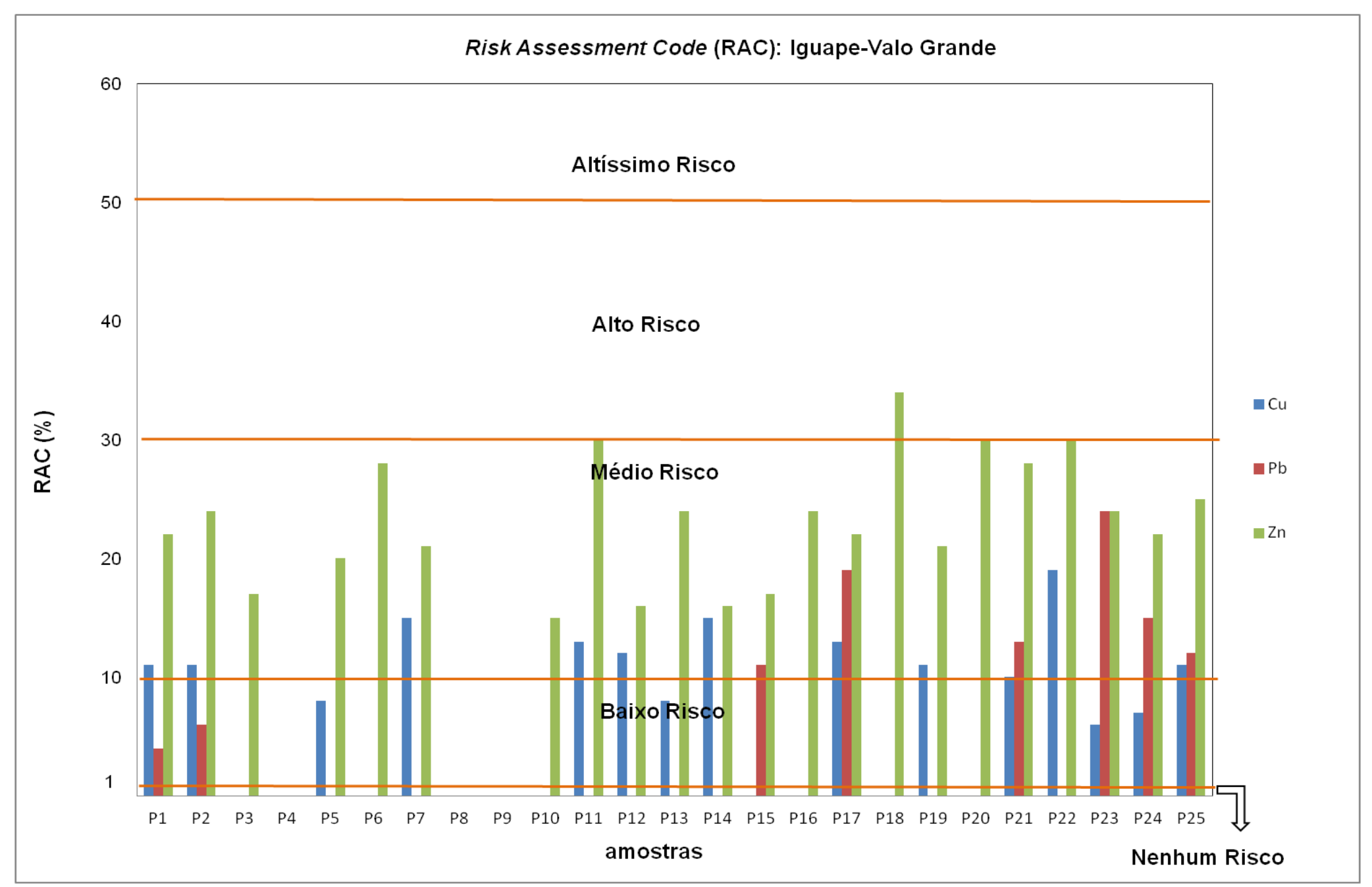

Figura 25. Risk Assessment Code (RAC) para $\mathrm{Cu}, \mathrm{Pb}$ e $\mathrm{Zn}$ na região Iguape-Valo Grande. 


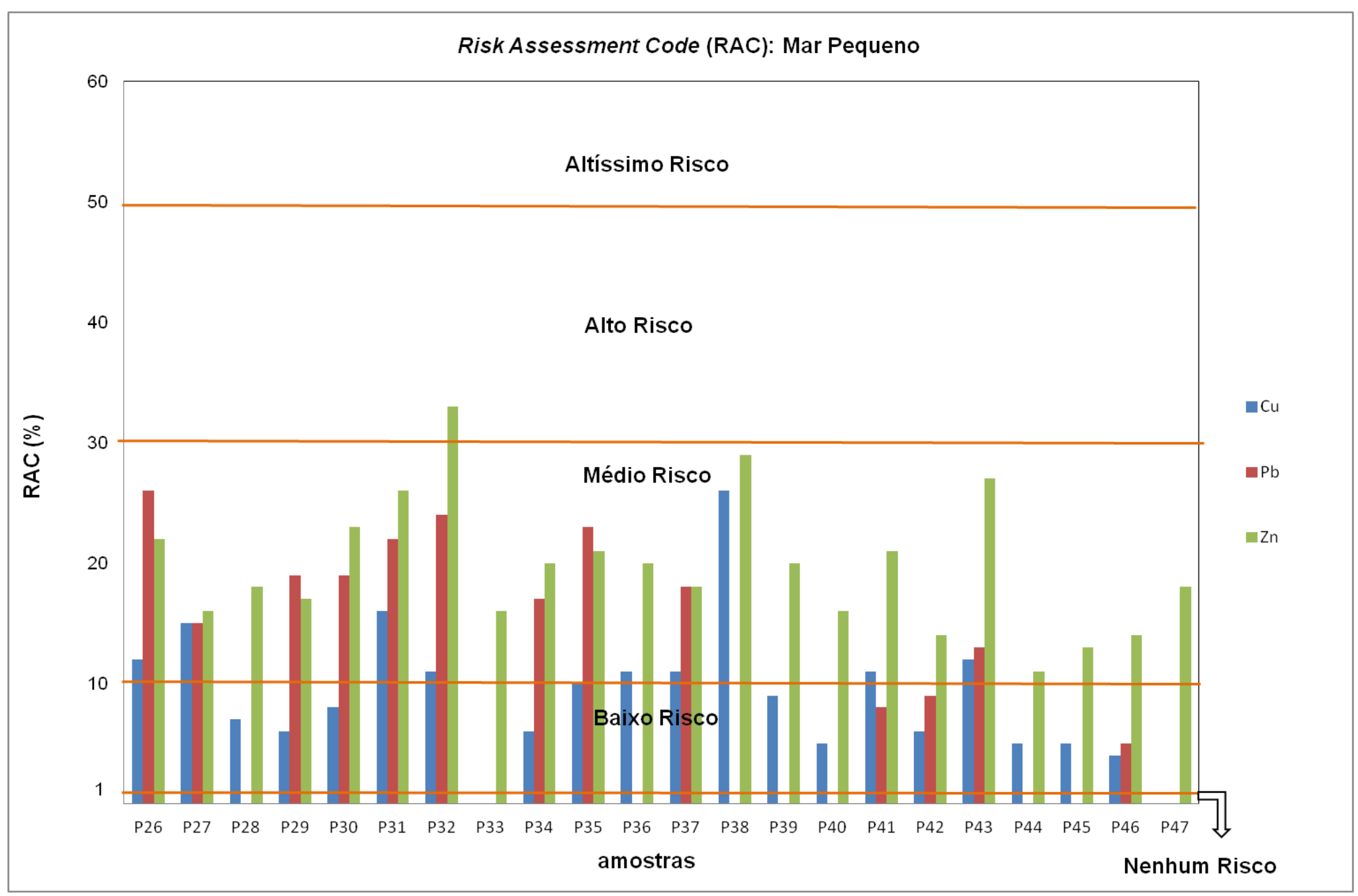

Figura 26. Risk Assessment Code (RAC) para $\mathrm{Cu}, \mathrm{Pb}$ e $\mathrm{Zn}$ na região do Mar Pequeno. 


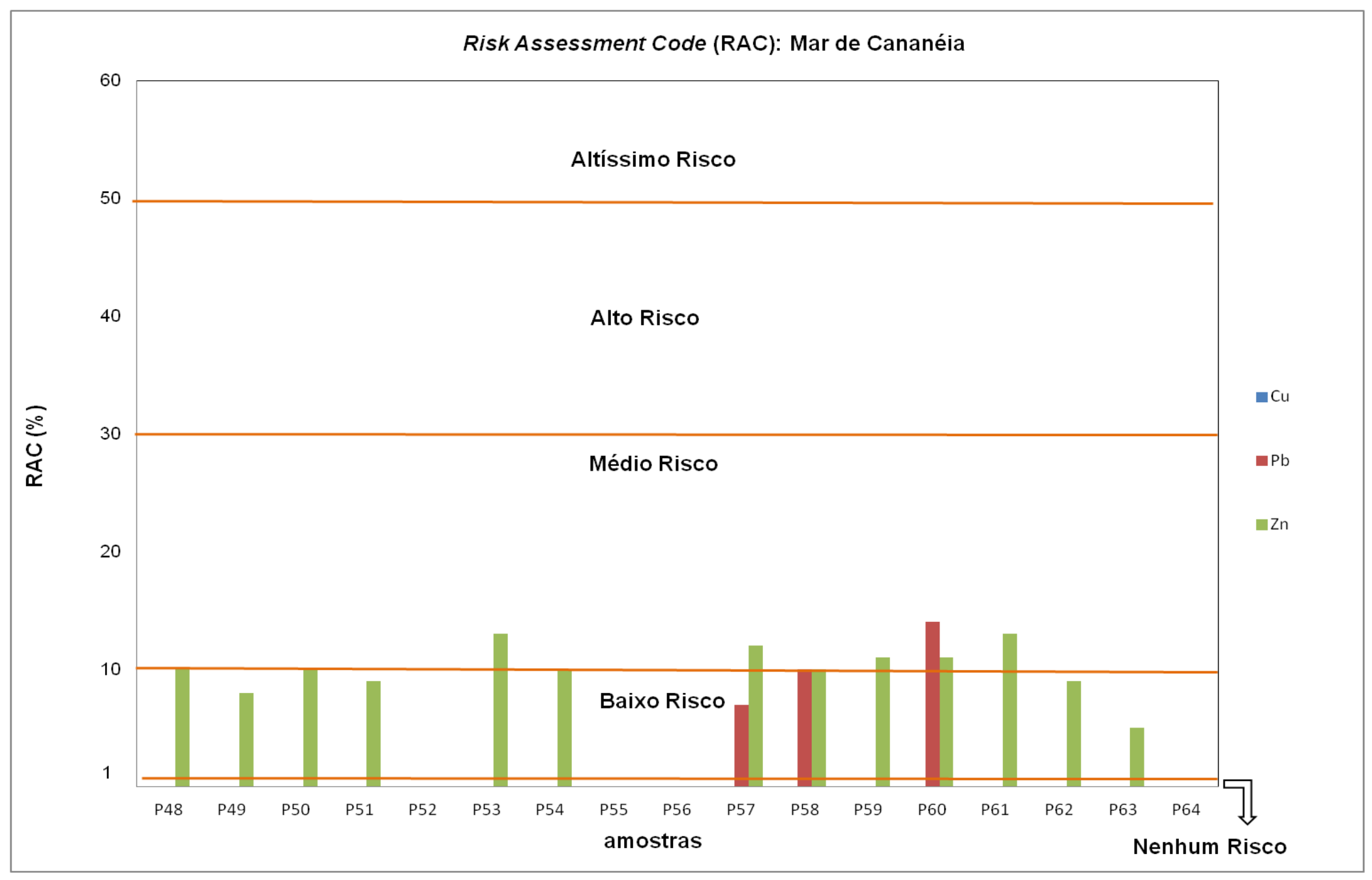

Figura 27. Risk Assessment Code (RAC) para $\mathrm{Cu}, \mathrm{Pb}$ e $\mathrm{Zn}$ na região do Mar de Cananéia. 


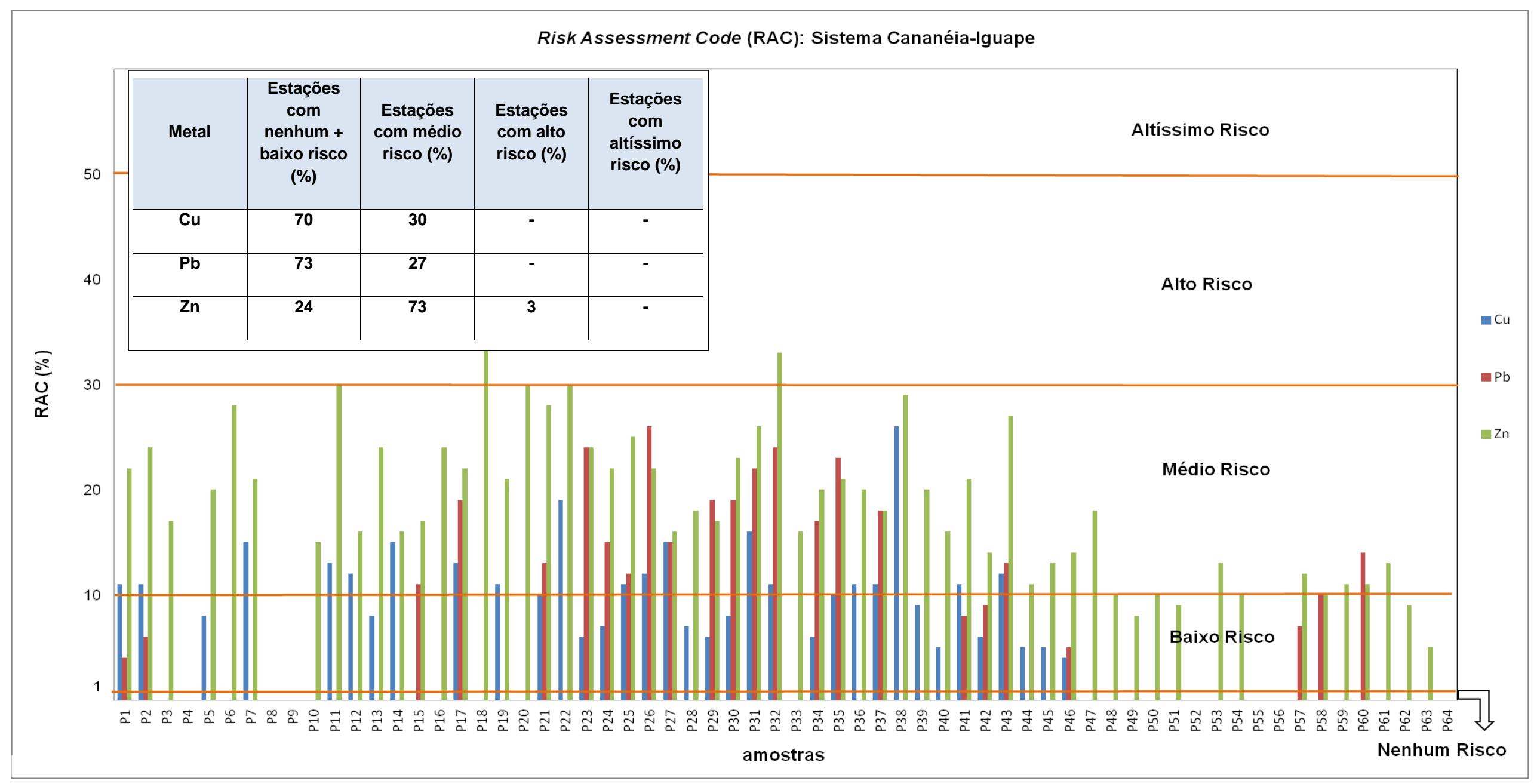

Figura 28. Risk Assessment Code (RAC) para $\mathrm{Cu}, \mathrm{Pb}$ e $\mathrm{Zn}$ no Sistema Cananéia-Iguape. 


\subsubsection{Comparação do teor disponível de $\mathrm{Cu}, \mathrm{Pb}$ e $\mathrm{Zn}$ entre o Sistema Cananéia-Iguape e outras regiões afetadas por atividades de mineração}

A fim de complementar a análise química ambiental, o teor disponível de metais no Sistema Cananéia-lguape foi comparado ao determinado em outras localidades afetadas por atividades de exploração mineral. Essas regiões estão indicadas na Tabela 8 . Foram selecionadas regiões expostas a despejos líquidos e sólidos contendo metais tóxicos oriundos de mineração, incluindo bacias de deposição de rejeitos, além de uma região que recebe efluentes de atividades de fundição de metais não ferrosos. Nesses estudos foram aplicadas metodologias de extração sequencial com base nos protocolos BCR e de TESSIER, para determinar o teor de $\mathrm{Cu}, \mathrm{Pb}$ e $\mathrm{Zn}$ nas frações móveis. Para fins de comparação dos resultados, este trabalho considerou como teor disponível nessas regiões a soma do teor das frações móveis. Quando necessário, o teor dessas frações foi estimado a partir do seu percentual em relação à concentração total, conforme indicado na Tabela 8.

Em relação ao $\mathrm{Cu}$ e ao $\mathrm{Zn}$, verificou-se que o teor disponível destes elementos no Sistema Cananéia-Iguape foi inferior ao estimado nas localidades comparadas (Tabela 8). Dentre as regiões selecionadas, o teor disponível médio de $\mathrm{Cu}$ no estuário Guadiana na Península Ibérica $\left(30,1 \mathrm{mg} \mathrm{kg}^{-1}\right)$, estimado a partir do estudo de DELGADO et al. (2011), é o valor que mais se aproxima ao do Sistema Cananéia-Iguape $\left(7,8 \mathrm{mg} \mathrm{kg}^{-1}\right)$, embora seja quase quatro vezes maior que este e, ainda, superior ao teor máximo desse elemento no Sistema $\left(24,3 \mathrm{mg} \mathrm{kg}^{-1}\right)$. A partir do estudo de WANG et al. (2010), estimou- 
se o teor disponível médio de $\mathrm{Cu}\left(89 \mathrm{mg} \mathrm{kg}^{-1}\right)$ no testemunho HLD3, com localização mais próxima ao estuário Wuli na baía Jinzhou (China), verificandose que este valor também foi superior ao teor disponível médio e máximo de Cu no Sistema Cananéia-Iguape.

Para o Zn, verificou-se que o teor médio disponível desse elemento no estuário Guadiana (132,7 mg kg$\left.{ }^{-1}\right)$, estimado a partir do estudo de DELGADO et al. (2011), também é o valor que mais se aproxima ao do Sistema CananéiaIguape $\left(29,1 \mathrm{mg} \mathrm{kg}^{-1}\right)$, ainda que quase cinco vezes maior que este, além de superior ao teor máximo disponível desse elemento no Sistema $\left(83,5 \mathrm{mg} \mathrm{kg}^{-1}\right)$.

Quanto ao $\mathrm{Pb}$, dentre as regiões selecionadas, o teor disponível médio desse elemento no Sistema Cananéia-Iguape $\left(27,6 \mathrm{mg} \mathrm{kg}^{-1}\right)$, foi ligeiramente superior ao do estuário Guadiana $\left(24,1 \mathrm{mg} \mathrm{kg}^{-1}\right)$, estimado a partir do estudo de DELGADO et al. (2011). O teor disponível máximo de $\mathrm{Pb}\left(191,6 \mathrm{mg} \mathrm{kg}^{-1}\right)$ no Sistema Cananéia-Iguape também excedeu o teor máximo do rio São Pedro em Sonora no México (54 $\mathrm{mg} \mathrm{kg}^{-1}$ ), estimado a partir do estudo de GÓMESÁLVAREZ et al. (2011). Na baía Jinzhou, o teor disponível médio de Pb no testemunho HLD3 $\left(192,4 \mathrm{mg} \mathrm{kg}^{-1}\right)$, estimado a partir do estudo de WANG et al. (2010), foi superior ao do Sistema Cananéia-Iguape.

A partir de estudos no rio São Pedro (México) (GÓMES-ÁLVAREZ et al., 2011), estuário Afon Goch (Reino Unido) (WHITELEY e PEARCE, 2003) e Zawar (Rajasthan-Índia) (ANJU e BANERJEE, 2010), foram estimados teor disponível de $\mathrm{Cu}$ e $\mathrm{Zn}$ altíssimo nessas duas primeiras localidades e, de $\mathrm{Pb}$ e Zn, em Zawar (Tabela 8), tornando inviável a comparação ao Sistema Cananéia-Iguape. 
Tabela 8. Comparação do teor disponível de $\mathrm{Cu}, \mathrm{Pb}$ e $\mathrm{Zn}$ entre o Sistema Cananéia-Iguape e outras regiões afetadas por atividades de exploração mineral e afins

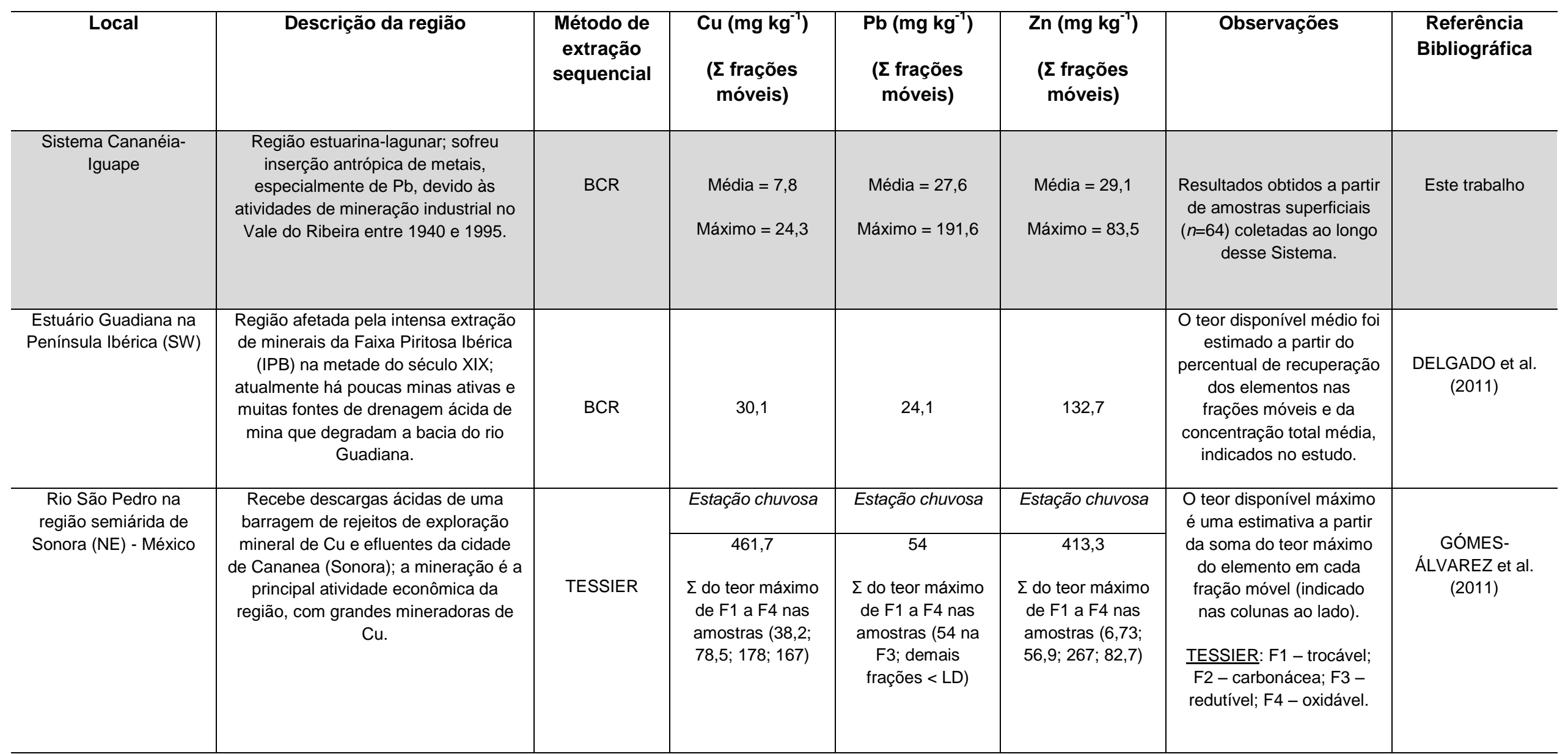




\begin{tabular}{|c|c|c|c|c|c|c|c|}
\hline & & & Estação seca & Estação seca & Estação seca & & \\
\hline & & & $\begin{array}{c}502 \\
\Sigma \text { do teor máximo } \\
\text { de F1 a F4 nas } \\
\text { amostras (1620; } \\
\text { 502; 330; 1050) }\end{array}$ & $\begin{array}{c}41,6 \\
\Sigma \text { do teor máximo } \\
\text { de F1 a F4 nas } \\
\text { amostras ( } 9,85 \text { na } \\
\text { F1 e } 31,7 \text { na F3; } \\
\text { F2 e F4 < LD) }\end{array}$ & $\begin{array}{c}1067,4 \\
\Sigma \text { do teor máximo } \\
\text { de F1 a F4 nas } \\
\text { amostras }(66,5 ; \\
327 ; 575 ; 98,9)\end{array}$ & & \\
\hline $\begin{array}{l}\text { Estuário Afon Goch, } \\
\text { baía Dulas em } \\
\text { Anglesey, North Wales } \\
\text { - Reino Unido }\end{array}$ & $\begin{array}{l}\text { Impactado por extração em grande } \\
\text { escala de minério de Cu; recebe } \\
\text { águas ricas em metais de mina } \\
\text { abandonada em Parys Mountain. }\end{array}$ & TESSIER & $\begin{array}{l}980,9 \text { (L2) a } \\
1747,6 \text { (L3) }\end{array}$ & ND & $\begin{array}{c}1073,4(\mathrm{~L} 2) \mathrm{a} \\
2850,5(\mathrm{~L} 5)\end{array}$ & $\begin{array}{l}\text { O estudo utilizou amostras de } \\
\text { nove testemunhos, identificadas } \\
\text { pela sua profundidade, em cm } \\
\text { (Och- } 0 \text { a } 1 \text {; L1-1 a } 6 ; \text {; } 2-6 \text { a } 11 \text {; } \\
\text { L3-11 a 16; L4- } 16 \text { a 33; L5- 33 } \\
\text { a 46). O teor disponível médio } \\
\text { foi estimado a partir da soma do } \\
\text { teor médio nas frações móveis } \\
\text { das amostras ( } \Sigma \text { F1 a F4). }\end{array}$ & $\begin{array}{c}\text { WHITELEY } \\
\text { e PEARCE } \\
\text { (2003) }\end{array}$ \\
\hline $\begin{array}{l}\text { Baía Jinzhou na China } \\
\text { (NO) }\end{array}$ & $\begin{array}{l}\text { Afetada por atividades de fundição de } \\
\mathrm{Pb}-\mathrm{Zn} \text { ao longo da margem sudoeste } \\
\text { do rio Wuli; recebe águas residuais } \\
\text { contendo metais tóxicos e resíduos } \\
\text { sólidos desde } 1937 .\end{array}$ & TESSIER & 89 (HLD3) & 192,4 (HLD3) & ND & $\begin{array}{l}\text { Foram utilizados dados do } \\
\text { testemunho HLD3 (localização } \\
\text { mais próxima ao estuário Wuli). } \\
\text { O teor médio disponível foi } \\
\text { estimado a partir do percentual } \\
\text { de recuperação das frações } \\
\text { móveis ( } \Sigma \text { F1 a F4) em relação à } \\
\text { concentração total média, } \\
\text { indicados no estudo. }\end{array}$ & $\begin{array}{l}\text { WANG et al } \\
(2010)\end{array}$ \\
\hline $\begin{array}{l}\text { Zawar, comunidade de } \\
\text { mineração de Pb-Zn, } \\
\text { em Rajasthan - Índia }\end{array}$ & $\begin{array}{c}\text { Bacias para deposição de rejeitos de } \\
\text { mineração; old tailing dam - utilizada } \\
\text { antes de 1980; new tailing dam - } \\
\text { atual. }\end{array}$ & BCR & ND & $\begin{array}{l}\text { Old: } 1227,6 \\
\text { New: } 933,4\end{array}$ & $\begin{array}{l}\text { Old: } 3680,9 \\
\text { New: } 1404,6\end{array}$ & $\begin{array}{l}\text { O teor médio disponível foi } \\
\text { estimado a partir do percentual } \\
\text { de recuperação das frações } \\
\text { móveis em relação à } \\
\text { concentração total média, } \\
\text { indicados no estudo. }\end{array}$ & $\begin{array}{l}\text { ANJU e } \\
\text { BANERJEE } \\
(2010)\end{array}$ \\
\hline
\end{tabular}

ND - não determinado 


\subsection{Análises estatísticas}

\subsubsection{Coeficiente de correlação de Pearson}

O grau de associação entre as variáveis foi medido pelo coeficiente de correlação de Pearson ( $r$ ).

5.5.1.1 Teor disponível ( $\Sigma$ F1 a F3) e parcial de $\mathrm{Cu}$, Pb e $\mathrm{Zn}$ (método ISO 11466)

Observou-se forte correlação entre os teores disponível e parcial para os três elementos. O valor de $r$ para o $\mathrm{Cu}, \mathrm{Pb}$ e $\mathrm{Zn}$ foi, respectivamente, 0,86 $(p<0,05) ; 0,98(p<0,05)$ e $0,96(p<0,05)$. As Figuras de 29 a 31 apresentam os gráficos de dispersão do $\mathrm{Cu}, \mathrm{Pb}$ e $\mathrm{Zn}$, respectivamente.

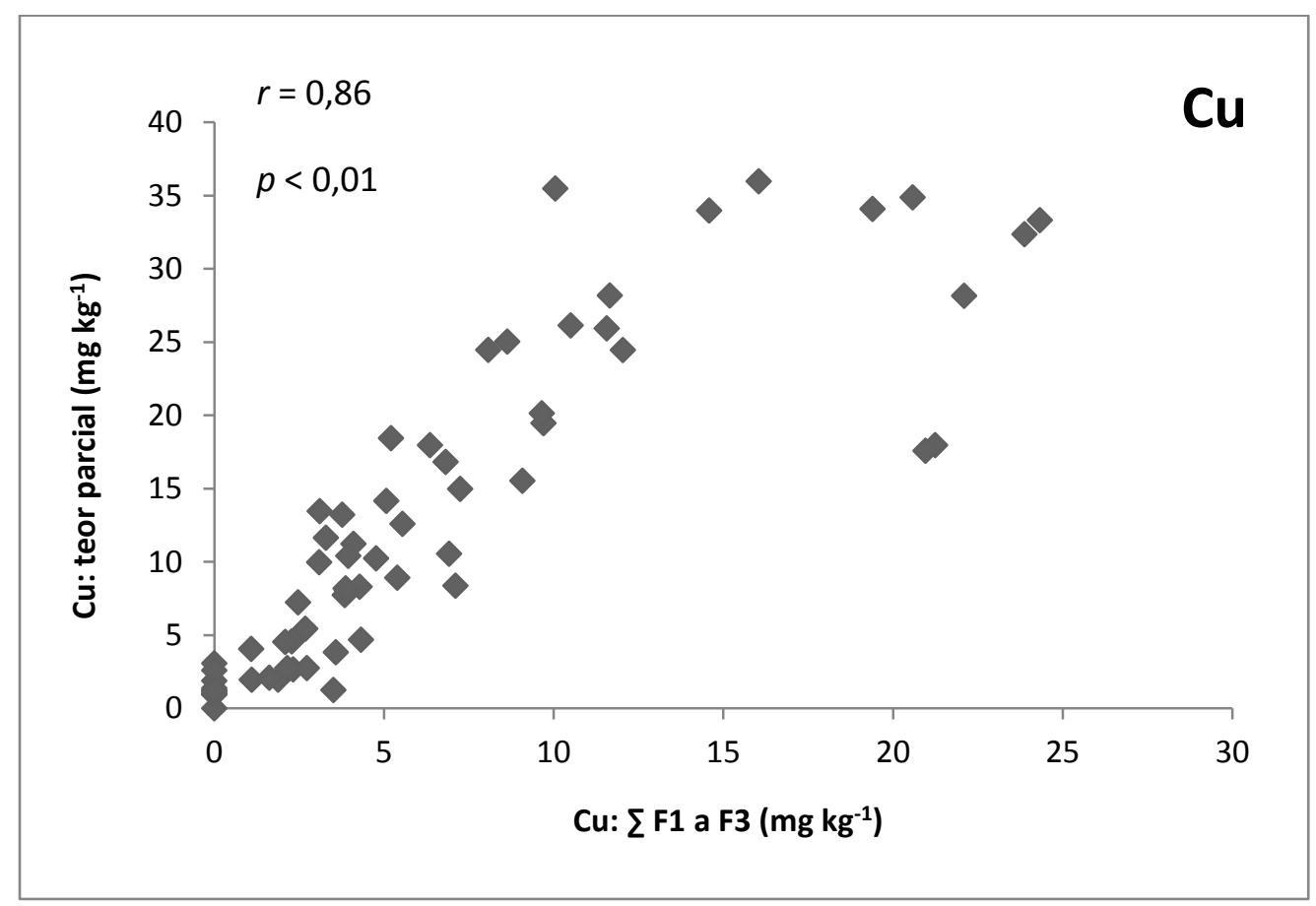

Figura 29. Gráfico de dispersão entre teor disponível e teor parcial de Cu. 


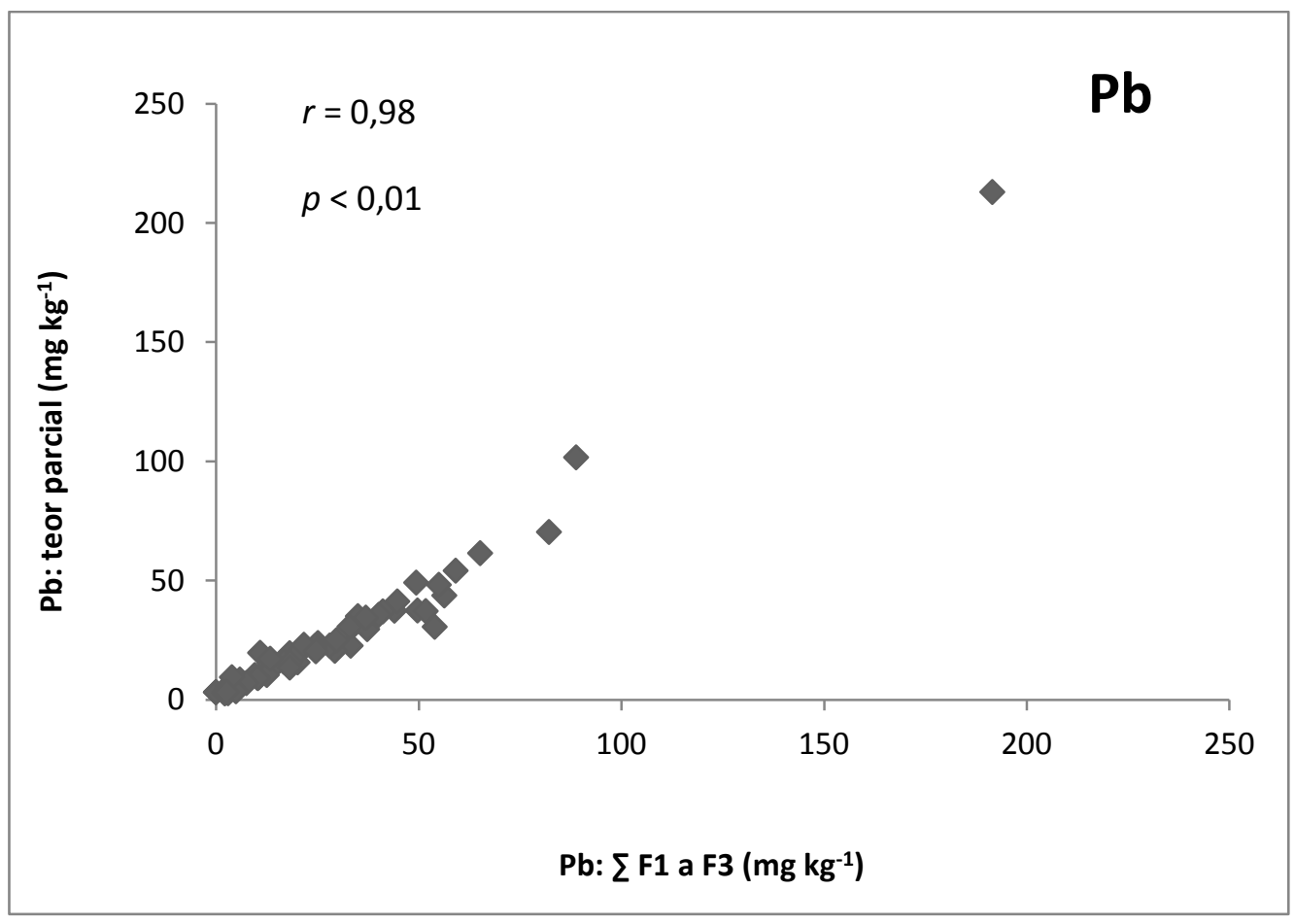

Figura 30. Gráfico de dispersão entre teor disponível e teor parcial de Pb.

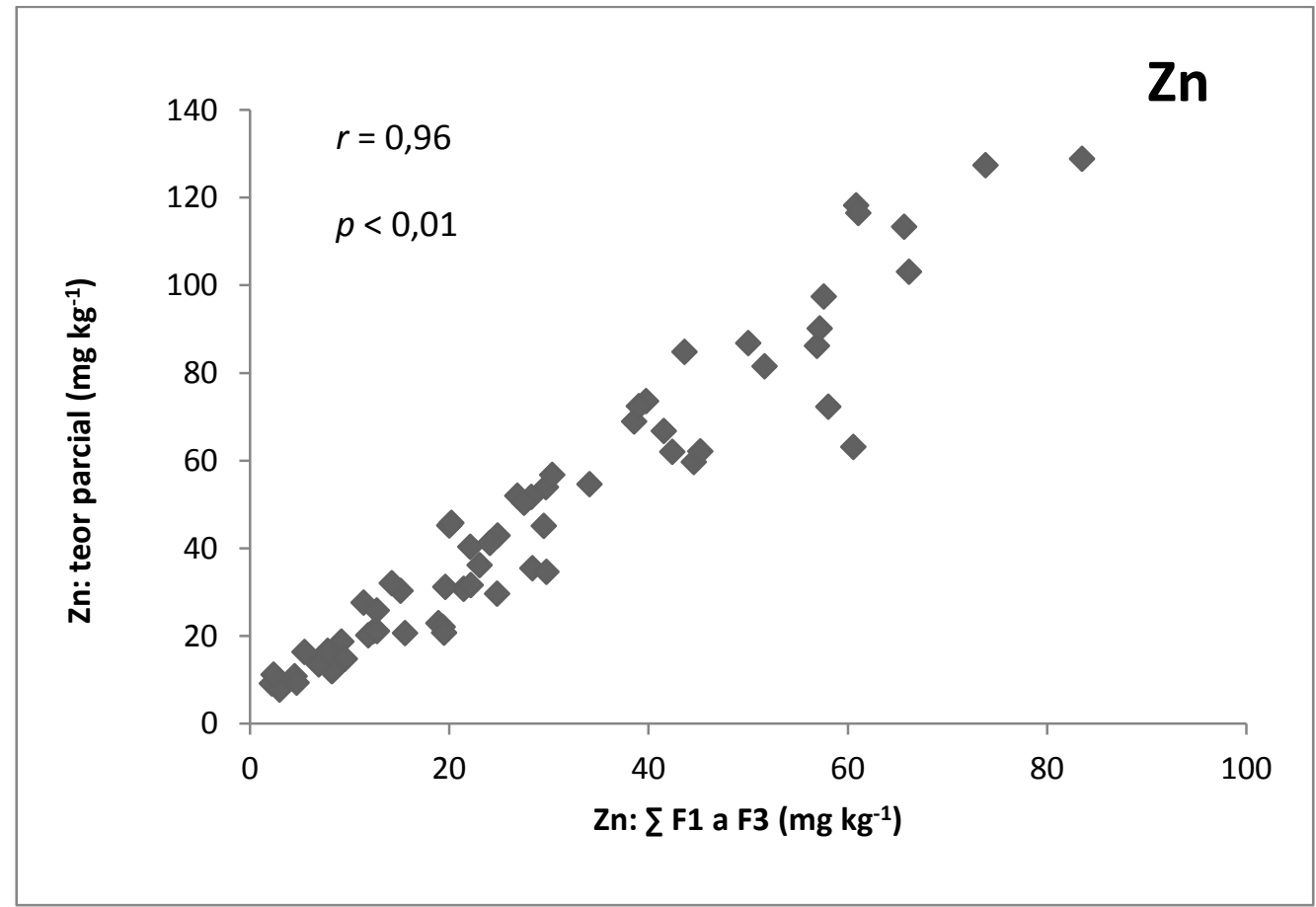

Figura 31. Gráfico de dispersão entre teor disponível e teor parcial de Zn. 


\subsubsection{Teor parcial de $\mathrm{Cu}, \mathrm{Pb}$ e Zn (métodos ISO 11466 e US EPA 3050B)}

Para os três elementos observou-se forte correlação entre os resultados de teor parcial obtidos pelos métodos de digestão ISO 11466 e US EPA 3050B. O valor de $r$ para o $\mathrm{Cu}, \mathrm{Pb}$ e $\mathrm{Zn}$ foi, respectivamente, 0,90 $(p<0,05) ; 0,97(p<0,05)$ e $0,90(p<0,05)$. As Figuras de 32 a 34 apresentam os gráficos de dispersão do $\mathrm{Cu}, \mathrm{Pb}$ e $\mathrm{Zn}$, respectivamente.

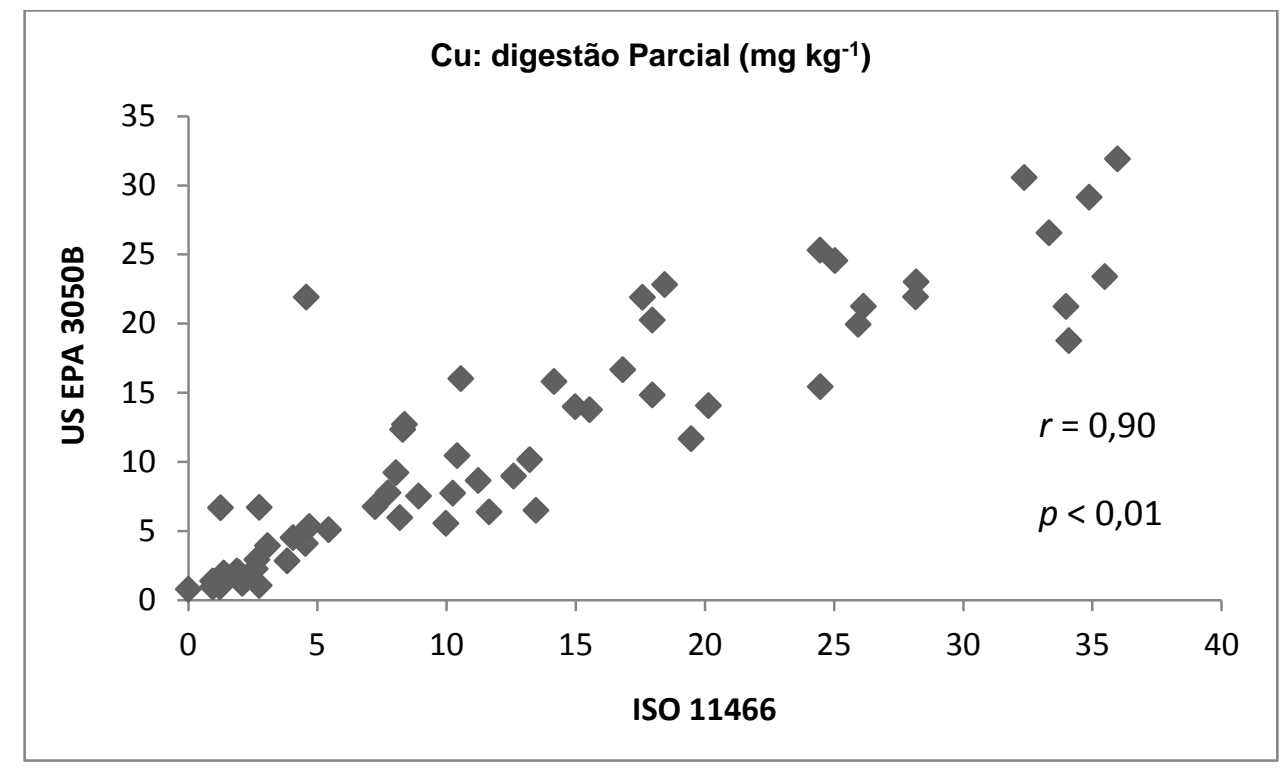

Figura 32. Gráfico de dispersão do teor parcial de Cu obtido pelos métodos de digestão ISO 11466 e US EPA 3050B. 


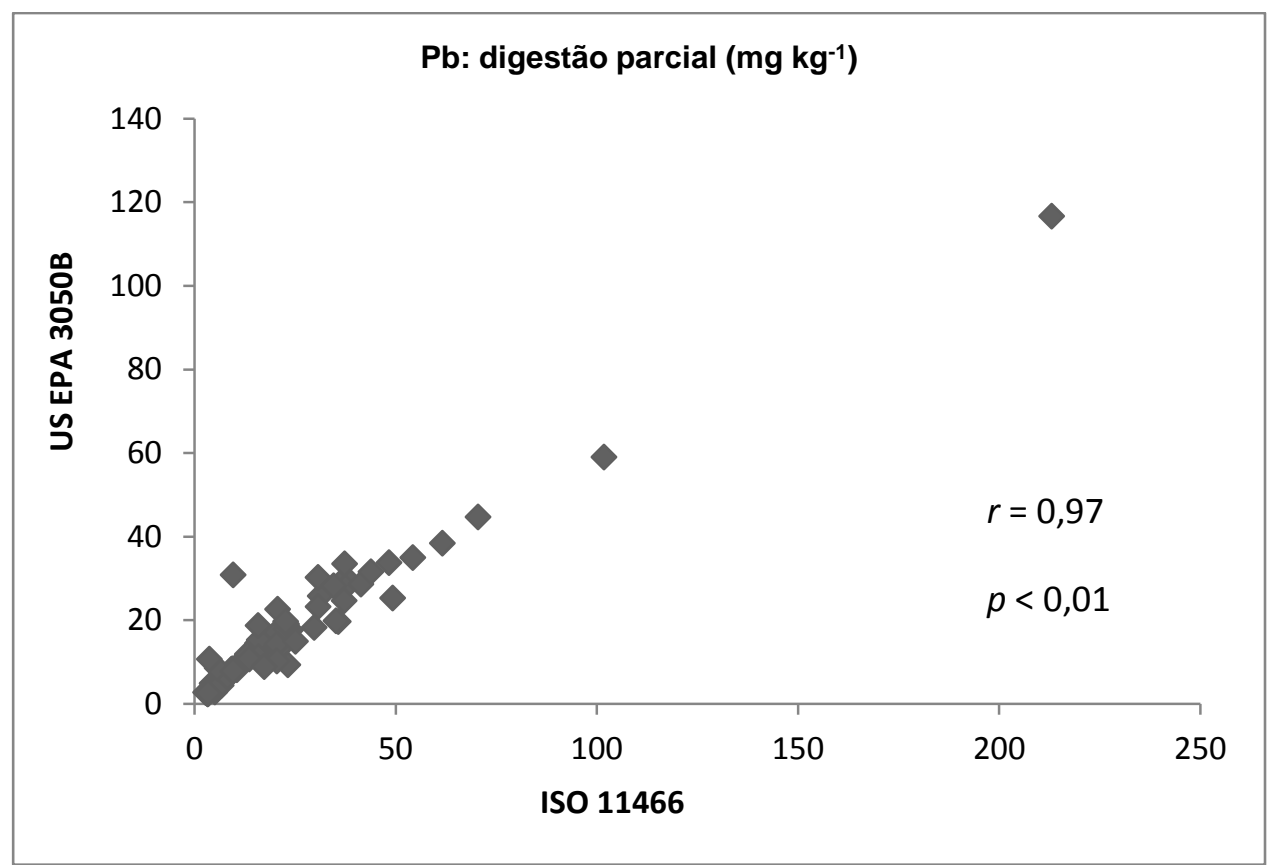

Figura 33. Gráfico de dispersão do teor parcial de $\mathrm{Pb}$ obtido pelos métodos de digestão ISO 11466 e US EPA 3050B.

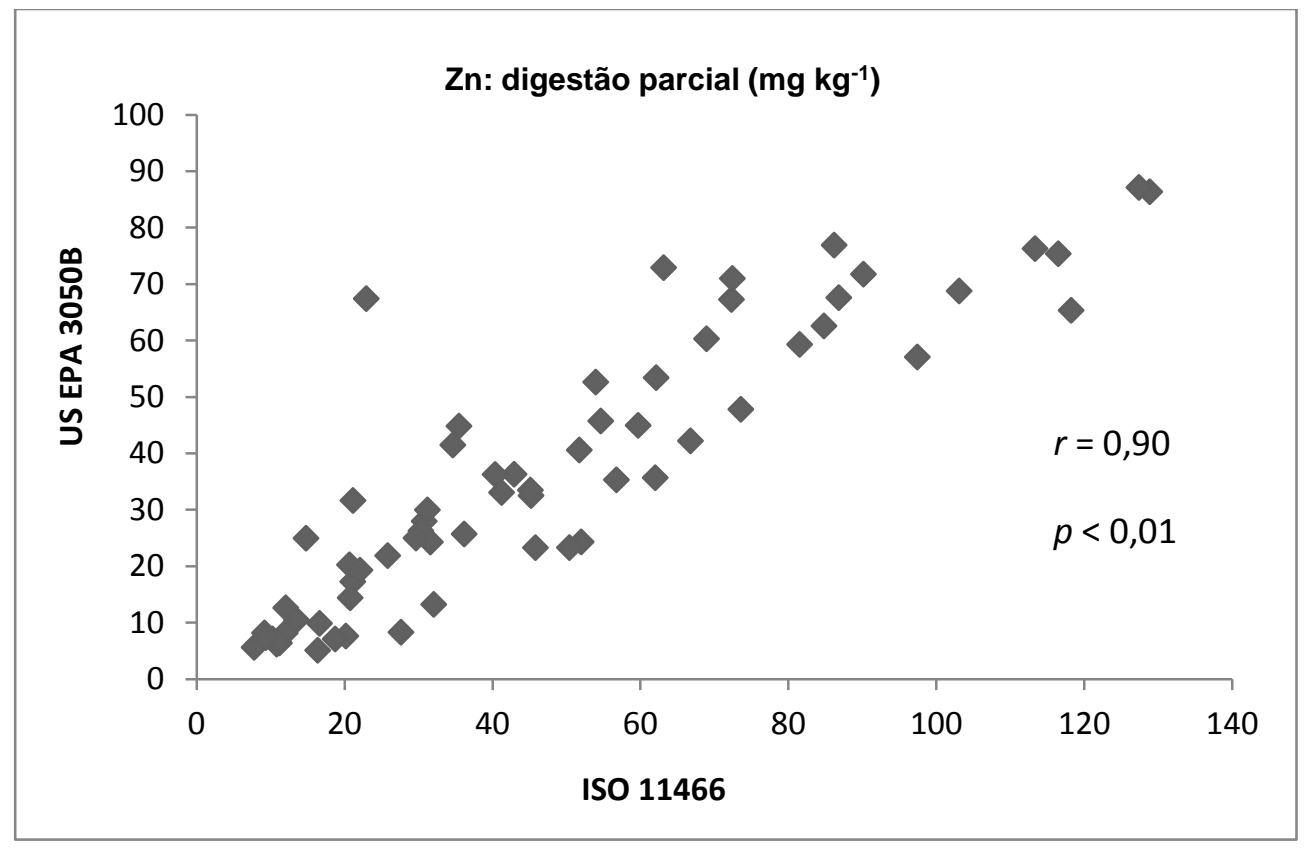

Figura 34. Gráfico de dispersão do teor parcial de Zn obtido pelos métodos de digestão ISO 11466 e US EPA 3050B. 


\subsubsection{Matriz de correlação}

A Tabela 9 apresenta a matriz de correlação entre o teor de $\mathrm{Cu}, \mathrm{Pb}$ e Zn nas frações móveis (F1, F2 e F3), COT e lama. Observou-se que $p$ foi inferior ao nível de significância ( $\alpha$ ) estabelecido $(0,05)$, indicando correlação entre todos os dados. Os valores de $p$ sugerem similaridade no comportamento dos metais e correlação positiva com os dados granulométricos e COT.

Entre os metais observou-se forte correlação, principalmente nas frações F2 e F3. Metais e sedimentos finos, em geral, apresentaram correlação moderada em todas as frações, também com melhores resultados em F2 e F3, possivelmente em razão do mecanismo de associação entre os metais e os componentes do sedimento nessas duas frações. É importante lembrar que em $\mathrm{F} 1$ os metais estão fracamente ligados ao sedimento e podem ser facilmente liberados em caso de alteração das condições ambientais.

A correlação entre os metais e COT variou de fraca a moderada, em geral, com melhores resultados na F3, provavelmente, devido à associação dos metais à matéria orgânica nessa fração. O coeficiente de correlação entre os resultados de COT e de sedimentos finos mostrou correlação positiva moderada. 
Tabela 9. Matriz de correlação entre os resultados de metais, lama e COT das amostras superficiais do Sistema Cananéia-Iguape.

\begin{tabular}{|c|c|c|c|c|c|c|c|c|c|c|c|}
\hline & F1_Cu & F2_Cu & F3_Cu & F1_Pb & F2_Pb & F3_Pb & F1_Zn & F2_Zn & F3_Zn & Lama & COT \\
\hline F1_Cu & & $1,05 \mathrm{E}-15$ & 2,37E-06 & $2,44 \mathrm{E}-08$ & $3,20 \mathrm{E}-13$ & 2,83E-09 & $1,32 \mathrm{E}-24$ & $1,09 \mathrm{E}-11$ & 3,30E-09 & 0,002612 & 0,013093 \\
\hline F2_Cu & 0,80527 & & $8,04 \mathrm{E}-21$ & 1,68E-05 & $7,65 \mathrm{E}-15$ & $3,69 \mathrm{E}-20$ & $2,92 \mathrm{E}-18$ & $1,58 \mathrm{E}-18$ & $3,34 \mathrm{E}-25$ & 1,73E-05 & 0,001971 \\
\hline F3_Cu & 0,55114 & 0,87119 & & 0,0016912 & $1,88 \mathrm{E}-10$ & 1,37E-22 & 2,68E-09 & $1,51 \mathrm{E}-16$ & $1,22 E-29$ & 5,66E-06 & 1,19E-05 \\
\hline F1_Pb & 0,63 & 0,5099 & 0,38482 & & 1,44E-07 & 1,24E-05 & $3,05 E-11$ & 3,33E-07 & 5,85E-05 & 0,001193 & 0,031306 \\
\hline F2_Pb & 0,76022 & 0,7908 & 0,69493 & 0,60181 & & $6,73 \mathrm{E}-24$ & $4,60 \mathrm{E}-17$ & $8,27 \mathrm{E}-18$ & $6,45 \mathrm{E}-13$ & 6,47E-05 & 0,002569 \\
\hline F3_Pb & 0,66075 & 0,86424 & 0,888 & 0,5167 & 0,89891 & & $2,63 \mathrm{E}-15$ & $6,51 \mathrm{E}-25$ & $3,79 E-24$ & 1,58E-06 & 1,94E-05 \\
\hline F1_Zn & 0,90434 & 0,8419 & 0,66145 & 0,71554 & 0,82578 & 0,7987 & & $1,81 \mathrm{E}-19$ & $2,34 \mathrm{E}-13$ & 8,24E-05 & 0,000521 \\
\hline F2_Zn & 0,72643 & 0,84527 & 0,81826 & 0,58752 & 0,83602 & 0,9066 & 0,85654 & & $1,20 \mathrm{E}-19$ & 3,19E-08 & 1,96E-07 \\
\hline F3_Zn & 0,65864 & 0,90868 & 0,93516 & 0,48052 & 0,75392 & 0,90086 & 0,76297 & 0,85859 & & 2,76E-06 & 0,000171 \\
\hline Lama & 0,3701 & 0,50929 & 0,53345 & 0,39617 & 0,47804 & 0,55894 & 0,47198 & 0,6259 & 0,5481 & & 0,000171 \\
\hline COT & 0,30862 & 0,37971 & 0,51754 & 0,26946 & 0,37067 & 0,50666 & 0,4216 & 0,59667 & 0,45301 & 0,45299 & \\
\hline
\end{tabular}

$p$ inferior a $a$ 


\subsubsection{Análise de Agrupamento}

Para a análise de agrupamento aplicou-se o método Cluster (método hierárquico de agrupamento de Ward), utilizando-se os dados padronizados do teor disponível de $\mathrm{Cu}, \mathrm{Pb}$ e $\mathrm{Zn}$, dos percentuais de lama e de COT. A Figura 35 apresenta o dendrograma obtido através do método aglomerativo, no qual as amostras dividem-se, basicamente, em três grupos, que foram identificados como A, B e C. Os grupos são diferenciados, principalmente, pelo teor de metal disponível, seguido da granulometria e COT.

Os grupos A e B apresentaram comportamento opostos quanto ao acúmulo de metais, presença de lama e COT. O grupo A é composto por um conjunto de amostras cuja concentração disponível variou de 1,1 a 5,4 mg kg-1 para $\mathrm{Cu}$, de 2,1 a 25,2 $\mathrm{mg} \mathrm{kg}^{-1}$ para $\mathrm{Pb}$ e de 2,2 a 24,9 $\mathrm{mg} \mathrm{kg}^{-1}$ para $\mathrm{Zn}$; no grupo B a concentração variou de 10,0 a 24,3 $\mathrm{mg} \mathrm{kg}^{-1}$ para Cu, de 41,2 a 191,6 $\mathrm{mg} \mathrm{kg}^{-1}$ para $\mathrm{Pb}$ e de 43,6 a $83,5 \mathrm{mg} \mathrm{kg}^{-1}$ para $\mathrm{Zn}$. Esses valores mostraram que, em geral, o teor de metais é consideravelmente maior no grupo B. Quanto aos sedimentos finos e COT, esses dois grupos permaneceram com a mesma tendência apresentada pelos os metais; se comparados, os maiores percentuais estão no grupo B.

O grupo A é formado por estações amostrais das três regiões: IguapeValo Grande, Mar de Cananéia e Mar Pequeno. Entretanto, aproximadamente 84\% das estações estão localizadas nas duas primeiras regiões. Conforme dados apresentados anteriormente, a região Iguape-Valo Grande mostrou predomínio de baixo teor disponível de $\mathrm{Cu}, \mathrm{Pb}$ e $\mathrm{Zn}$, com exceção da área de interligação entre o Canal do Valo Grande e o rio Ribeira de Iguape, bem como 
nas imediações da cidade de Iguape e em direção à Barra de Icapara. Comportamento similar ao dos metais ocorreu com COT e sedimentos finos nessa região, onde há predomínio de areia fina e muito fina. Por sua vez, a região do Mar de Cananéia também apresentou predomínio de baixo teor disponível de metais, além de reduzidos percentuais de COT e sedimentos compostos, principalmente, por areia fina. A partir desses dados, considerouse que a predominância de amostras dessas duas regiões no grupo A é coerente com as respectivas características desse grupo.

O grupo B, é constituído por estações amostrais que, de modo geral, apresentaram as mais elevadas concentrações de metais no Sistema Cananéia-Iguape. Uma característica importante nesse grupo é a sua formação apenas por amostras das regiões Iguape-Valo Grande e do Mar Pequeno, tendo sido excluída a região do Mar de Cananéia, onde as estações geralmente apresentaram baixo teor disponível de $\mathrm{Cu}, \mathrm{Pb}$ e $\mathrm{Zn}$. As características da região Iguape-Valo Grande foram apresentadas no grupo anterior; quanto às características do Mar Pequeno, que é responsável por $75 \%$ do total de estações que compõe o grupo $B$, trata-se da região que comporta o conjunto de estações amostrais com maior teor disponível de Cu, $\mathrm{Pb}$ e $\mathrm{Zn}$, além do maior percentual médio de COT e lama. Conforme discutido anteriormente, o fenômeno conhecido como tombo das águas favorece a ocorrência de sedimentos finos nessa região, os quais costumam apresentar correlação positiva com COT e maior acúmulo de metais. Portanto, a predominância de amostras dessa região no grupo B também é coerente com as características desse grupo. 
O grupo $\mathrm{C}$, em geral, apresentou concentrações de $\mathrm{Cu}, \mathrm{Pb}$ e $\mathrm{Zn}$ intermediárias entre os grupos A e B. Os teores variaram de 3,1 a $11,6 \mathrm{mg} \mathrm{kg}^{-1}$ para $\mathrm{Cu}$, de 4 a $44,8 \mathrm{mg} \mathrm{kg}^{-1}$ para $\mathrm{Pb}$ e de 7,8 a $51,7 \mathrm{mg} \mathrm{kg}^{-1}$ para $\mathrm{Zn}$. Esse grupo é constituído por amostras das três regiões na seguinte proporção: Iguape-Valo Grande, 33\%, Mar Pequeno, 38\% e Mar de Cananéia, 29\%. Diante dessas proporções e das características de cada região, apresentadas anteriormente, considerou-se que o grupo $\mathrm{C}$ ocupa uma posição intermediária entre os demais. Em relação aos sedimentos finos e, principalmente, em relação ao COT, verificou-se que no grupo $\mathrm{C}$ o percentual médio ficou próximo ao determinado no grupo B. Uma possível explicação seria a extensa área de manguezais da região, que favorece o acúmulo de matéria orgânica. De acordo com CUNHA-LIGNON (2001), os manguezais de Cananéia-Iguape dominam praticamente todas as margens do Sistema, compreendendo uma área de aproximadamente $72 \mathrm{~km}^{2}$. 


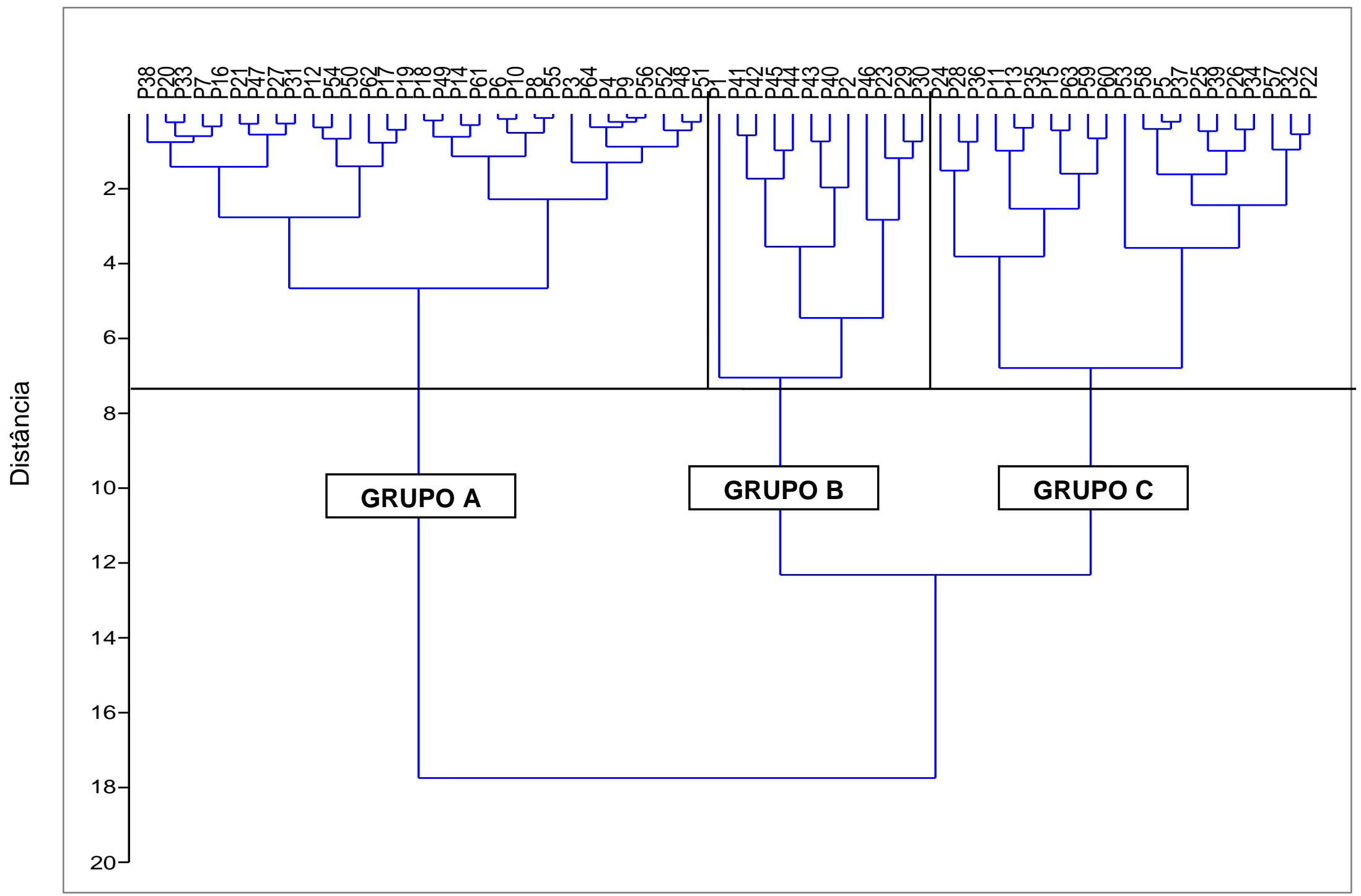

Figura 35. Dendrograma com os agrupamentos entre teor disponível de $\mathrm{Cu}, \mathrm{Pb}$ e $\mathrm{Zn}$, lama e COT em amostras superficiais do Sistema Cananéia-Iguape. 


\subsection{Histórico da inserção antrópica de $\mathrm{Cu}, \mathrm{Pb}$ e $\mathrm{Zn}$ no Sistema Cananéia-Iguape durante o período de atividades de mineração no Vale do Ribeira}

\subsubsection{Extração sequencial: teor disponível de $\mathrm{Cu}, \mathrm{Pb}$ e $\mathrm{Zn}$}

Amostras de cinco testemunhos (CAN 02, 04, 05, 07 e 10) coletados ao longo do Sistema Cananéia-Iguape (Figura 2, Tabela 3), foram submetidas ao procedimento de extração sequencial, conforme descrito no Capítulo 4. A partir do somatório do teor das frações móveis ( $\Sigma$ F1 a F3) estimou-se o teor disponível de metais nessas amostras de sedimento, assim como efetuado para as amostras de sedimento superficial. O teor de $\mathrm{Cu}, \mathrm{Pb}$ e $\mathrm{Zn}$ em cada fração móvel, bem como, a estimativa do teor disponível desses elementos foram indicados nas Figuras de 36 a 38. A ausência da indicação do teor em uma ou mais frações significa que a concentração foi inferior ao $L Q$ do elemento. Os resultados de $\mathrm{Cu}, \mathrm{Pb}$ e $\mathrm{Zn}$ nessas amostras estão disponíveis em Anexos.

O Cu mostrou-se associado, principalmente, aos óxidos de Fe e Mn, à matéria orgânica e aos sulfetos. Nos testemunhos CAN 02, 04 e 07 verificou-se maior associação do elemento à F2, já em CAN 10, o Cu apresentou-se associado, principalmente, à F3. Em CAN 05 a preferência de associação se alterou com o aumento da profundidade; até $10 \mathrm{~cm}$ o Cu mostrou-se associado, principalmente, aos óxidos de $\mathrm{Fe}$ e $\mathrm{Mn}$ e, de 22 a $50 \mathrm{~cm}$, à matéria orgânica e aos sulfetos. A associação do Cu à F1, considerada a fração mais lábil, não foi predominante em nenhum dos testemunhos. O teor máximo de Cu nas frações F1, F2 e F3 foi, respectivamente, $2,45 \mathrm{mg} \mathrm{kg}^{-1}$ (CAN 04); $11,61 \mathrm{mg} \mathrm{kg}^{-1}$ 
(CAN 04) e 10,85 $\mathrm{mg} \mathrm{kg}^{-1}$ (CAN 05). O teor máximo disponível de Cu foi 18,74 $\mathrm{mg} \mathrm{kg}^{-1}$ (CAN 05).

$\mathrm{O} \mathrm{Pb}$ apresentou forte associação à $\mathrm{F} 2$ em todos os testemunhos, mostrando que esse elemento encontra-se, predominantemente, associado aos óxidos de $\mathrm{Fe}$ e $\mathrm{Mn}$. A preferência de associação do $\mathrm{Pb}$ à $\mathrm{F} 2$ também foi observada nas amostras de sedimento superficial. $\mathrm{O}$ teor máximo de $\mathrm{Pb}$ nas frações F1, F2 e F3 foi, respectivamente, $21,21 \mathrm{mg} \mathrm{kg}^{-1}$ (CAN 04); 152,25 $\mathrm{mg} \mathrm{kg}^{-1}$ (CAN 04) e 12,34 $\mathrm{mg} \mathrm{kg}^{-1}$ (CAN 05). O teor máximo disponível de Pb foi $177,55 \mathrm{mg} \mathrm{kg}^{-1}$ (CAN 04).

Dentre os elementos estudados neste trabalho, o $\mathrm{Zn}$ foi o único que apresentou associação com as três frações em todas as amostras e, portanto, o elemento com maior ocorrência na F1. O teor máximo de Zn nas frações F1, F2 e F3 foi, respectivamente, 63,40 $\mathrm{mg} \mathrm{kg}^{-1}$ (CAN 04); $49,96 \mathrm{mg} \mathrm{kg}^{-1}$ (CAN 04) e 14,99 $\mathrm{mg} \mathrm{kg}^{-1}$ (CAN 05). O teor máximo disponível de Zn foi 123,03 $\mathrm{mg} \mathrm{kg}^{-1}$ (CAN 04). 

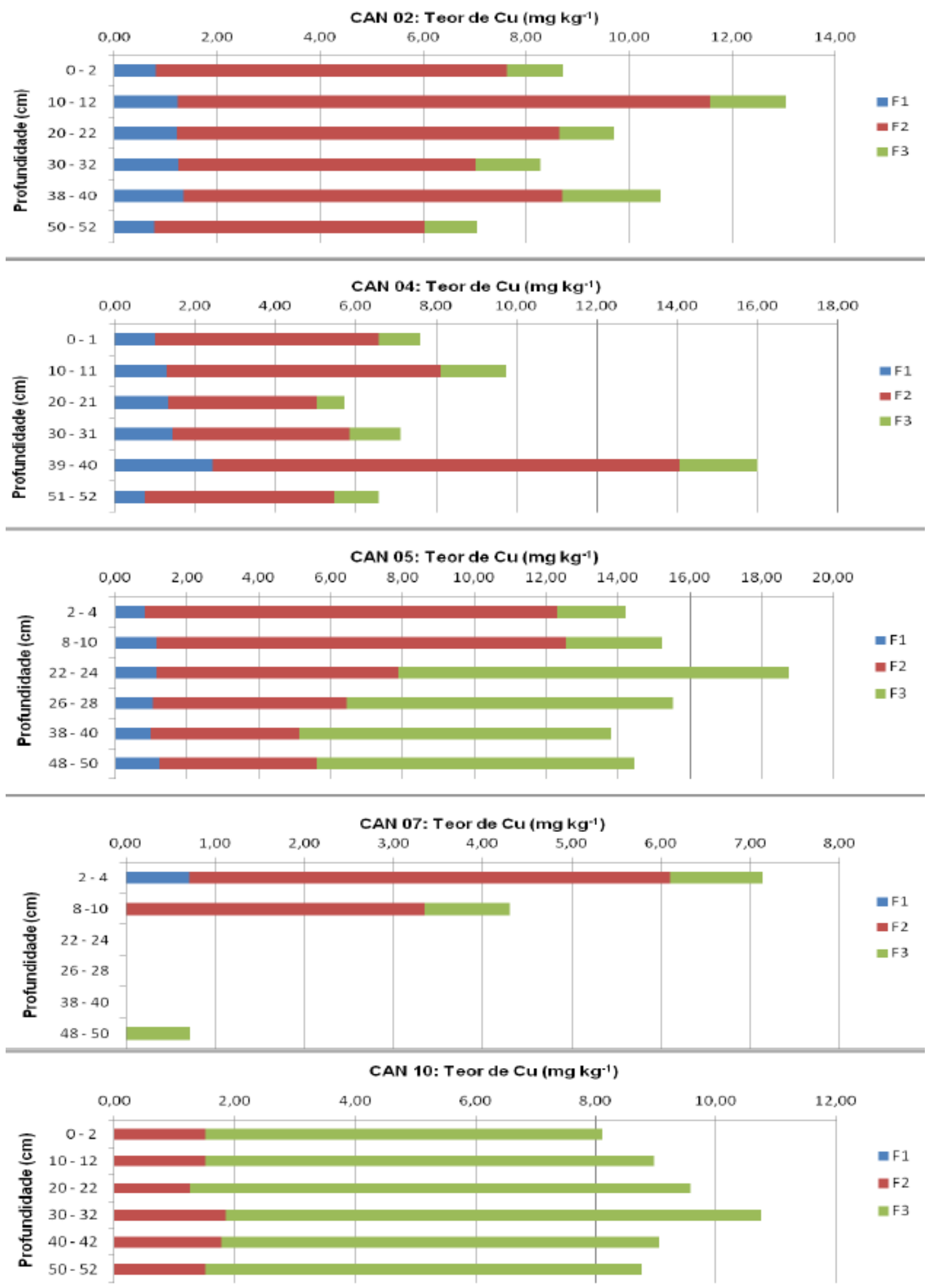

Figura 36. Teor de $\mathrm{Cu}$, em $\mathrm{mg} \mathrm{kg}^{-1}$, associado às frações móveis nas amostras de sedimento dos testemunhos CAN 02, 04, 05, 07 e 10, coletados ao longo do Sistema Cananéia-Iguape. 

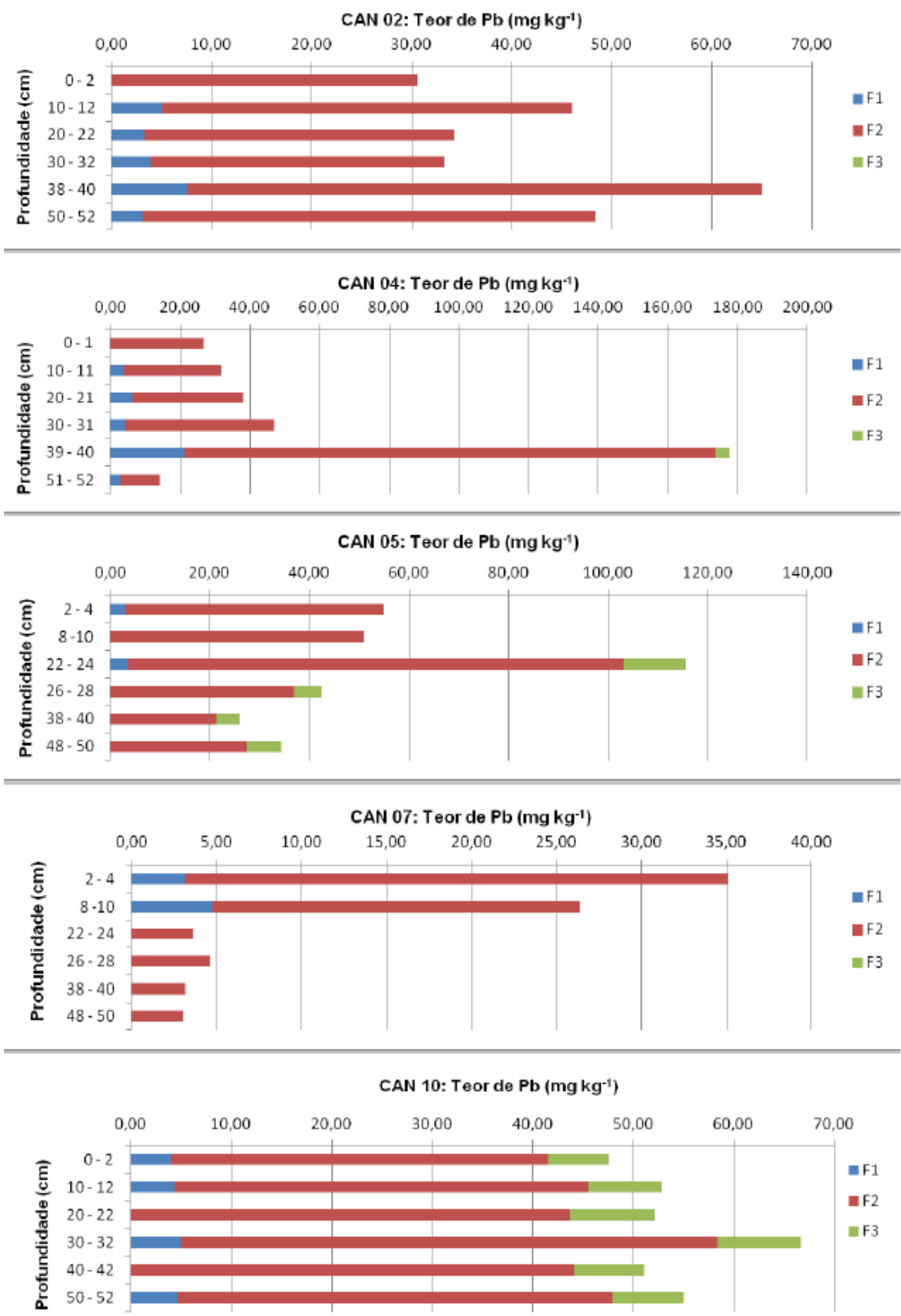

Figura 37. Teor de $\mathrm{Pb}$, em $\mathrm{mg} \mathrm{kg}^{-1}$, associado às frações móveis nas amostras de sedimento dos testemunhos CAN 02, 04, 05, 07 e 10, coletados ao longo do Sistema Cananéia-Iguape. 

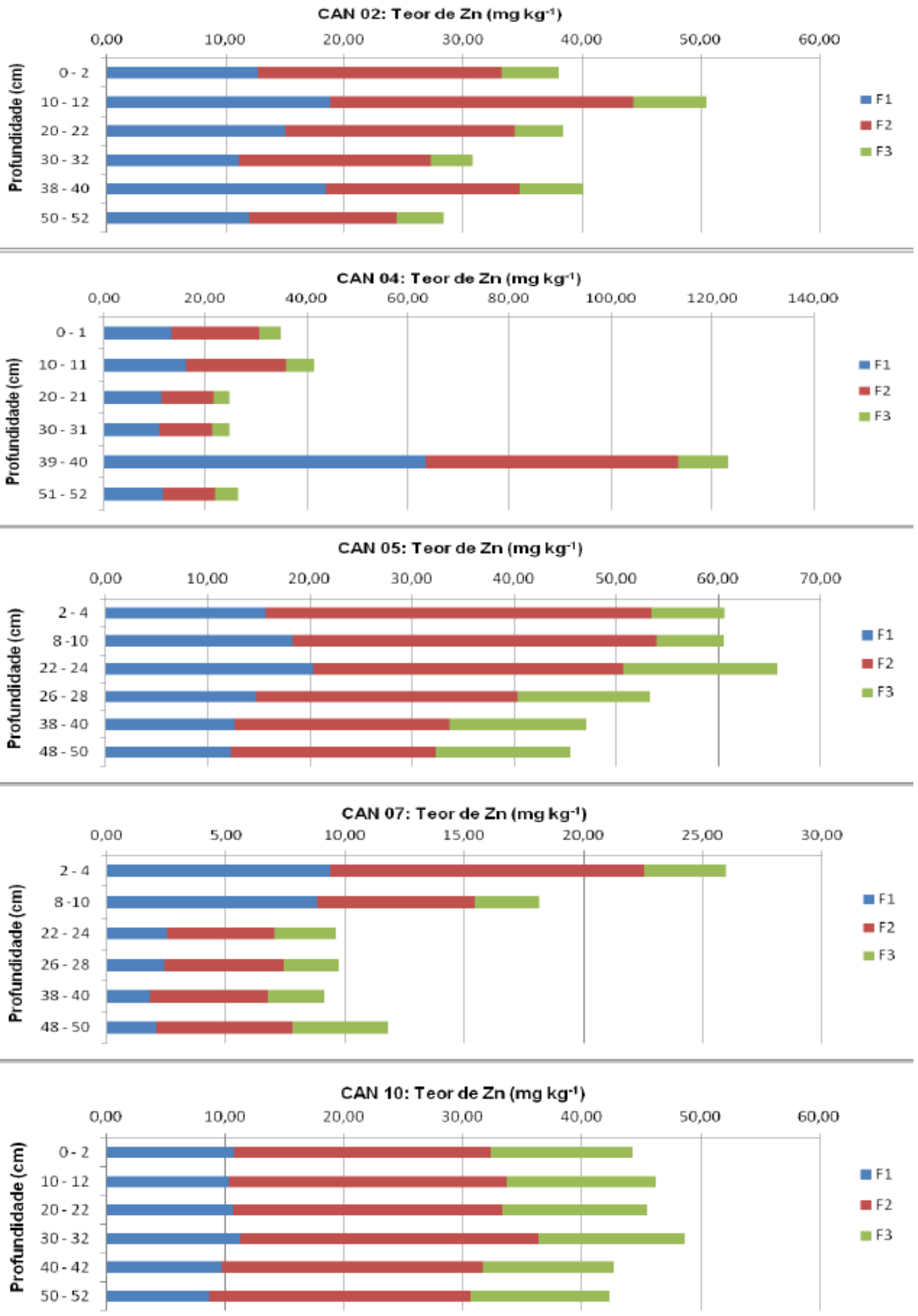

Figura 38. Teor de $\mathrm{Zn}$, em mg kg${ }^{-1}$, associado às frações móveis nas amostras de sedimento dos testemunhos CAN 02, 04, 05, 07 e 10, coletados ao longo do Sistema Cananéia-Iguape. 


\subsubsection{Grau de contaminação dos sedimentos}

A fim de avaliar o grau de contaminação das amostras dos testemunhos, os teores disponíveis de $\mathrm{Cu}, \mathrm{Pb}$ e $\mathrm{Zn}$ também foram comparados aos valores ISQG e PEL (CCME, 2001), aos valores regionais (MAHIQUES et al., 2013) e aos valores de background (TUREKIAN e WEDEPOHL, 1961); todos indicados na Tabela 6. As Figuras de 39 a 41 mostram o cruzamento entre teor disponível e valores de comparação do $\mathrm{Cu}, \mathrm{Pb}$ e $\mathrm{Zn}$. A ausência da indicação do teor significa que as três frações foram inferiores ao $L Q$ do elemento. Em relação ao Cu observou-se que o teor disponível nas amostras foi inferior aos valores de background e regional; apenas uma amostra do testemunho CAN 05 apresentou teor desse elemento no limite do ISQG.

Quanto ao Pb, apenas duas amostras, CAN 04 (39-40) e CAN 05 (2224), apresentaram teor disponível superior ao PEL. Entretanto, na maioria das amostras dos testemunhos verificou-se teor disponível de $\mathrm{Pb}$ superior aos valores de comparação; em aproximadamente $73 \%$ das amostras o teor foi superior ao ISQG e, em $83 \%$, superior ao valor regional e ao de background. 0 Zn apresentou teor disponível inferior ao ISQG em todas as amostras e, em apenas uma delas (CAN 04 (39-40)), o teor foi superior ao valor regional e ao de background.

De modo geral, os elementos mostraram comportamento similar ao observado nas amostras de sedimento superficial. O Cu e o Zn apresentaram teor disponível baixo em relação aos valores de comparação. Entretanto, o Pb continua sendo um elemento preocupante na região, com teor disponível 
superior aos seus valores de comparação na maior parte das amostras dos testemunhos.

Os testemunhos CAN 02, 04 e 05 foram coletados, respectivamente, a uma distância de 2 km, 200 m e 7,5 km da foz do canal do Valo Grande. Além da proximidade geográfica com 0 referido canal, as características granulométricas desses testemunhos analisadas por MAHIQUES et al. (2013) e comentadas a seguir, evidenciaram condições satisfatórias para o acúmulo de metais, principalmente, em CAN 05:

- CAN 02, da sua base até $110 \mathrm{~cm}$, apresenta teor de lama tão alto quanto $80 \%$ e, dessa profundidade até o topo do testemunho, há uma oscilação de valores variando de 20 a $60 \%$.

- CAN04, da sua base até $40 \mathrm{~cm}$ apresenta um "engrossamento" ascendente em que o teor de silte + argila diminui de 70 a $20 \%$, seguido de um "afinamento" ascendente em que os valores aumentam até $60 \%$.

- CAN 05 apresenta a base composta essencialmente por sedimentos arenosos com teor de silte + argila não superior a $20 \%$, porém de $130 \mathrm{~cm}$ até o topo é marcado por sedimentação lamosa com teor de silte + argila variando de 70 a $80 \%$.

O acúmulo de sedimentos finos em CAN 05 pode ter sido favorecido pela sua localização, relativamente próxima à região de encontro das correntes de maré no canal do Mar Pequeno. 
Dentre os testemunhos, CAN 07 apresentou um conjunto de amostras com menor teor disponível de $\mathrm{Cu}, \mathrm{Pb}$ e $\mathrm{Zn}$. Uma possível explicação seria a sua localização a $20 \mathrm{~km}$ da foz do canal do Valo Grande e a sua composição granulométrica. Segundo o estudo de MAHIQUES et al. (2013), CAN 07 é caracterizado pelo predomínio de areia na composição, com uma tendência geral de "afinamento" ascendente e dois picos com maior teor de silte + argila, um deles a $80 \mathrm{~cm} \mathrm{e,} \mathrm{o} \mathrm{outro,} \mathrm{no} \mathrm{topo} \mathrm{do} \mathrm{testemunho.} \mathrm{Essas} \mathrm{características}$ mostraram-se coerentes com os resultados de metais obtidos neste trabalho para esse testemunho, como pode ser observado nos gráficos de CAN 07 (Figuras de 36 a 38).

Embora seja o testemunho mais distante da foz do canal do Valo Grande, CAN 10 mostrou a inserção antrópica de $\mathrm{Pb}$. Esse cenário pode ter sido favorecido pela sua localização, próxima a região de um tombo das águas secundário. Evidências da possível existência de outro tombo das águas na região do Mar de Cubatão, ainda que com resposta menos efetiva quanto à detectada para o fenômeno do Mar Pequeno, foram relatadas em TESSLER e SOUZA (1998) e em referências ali citadas. 


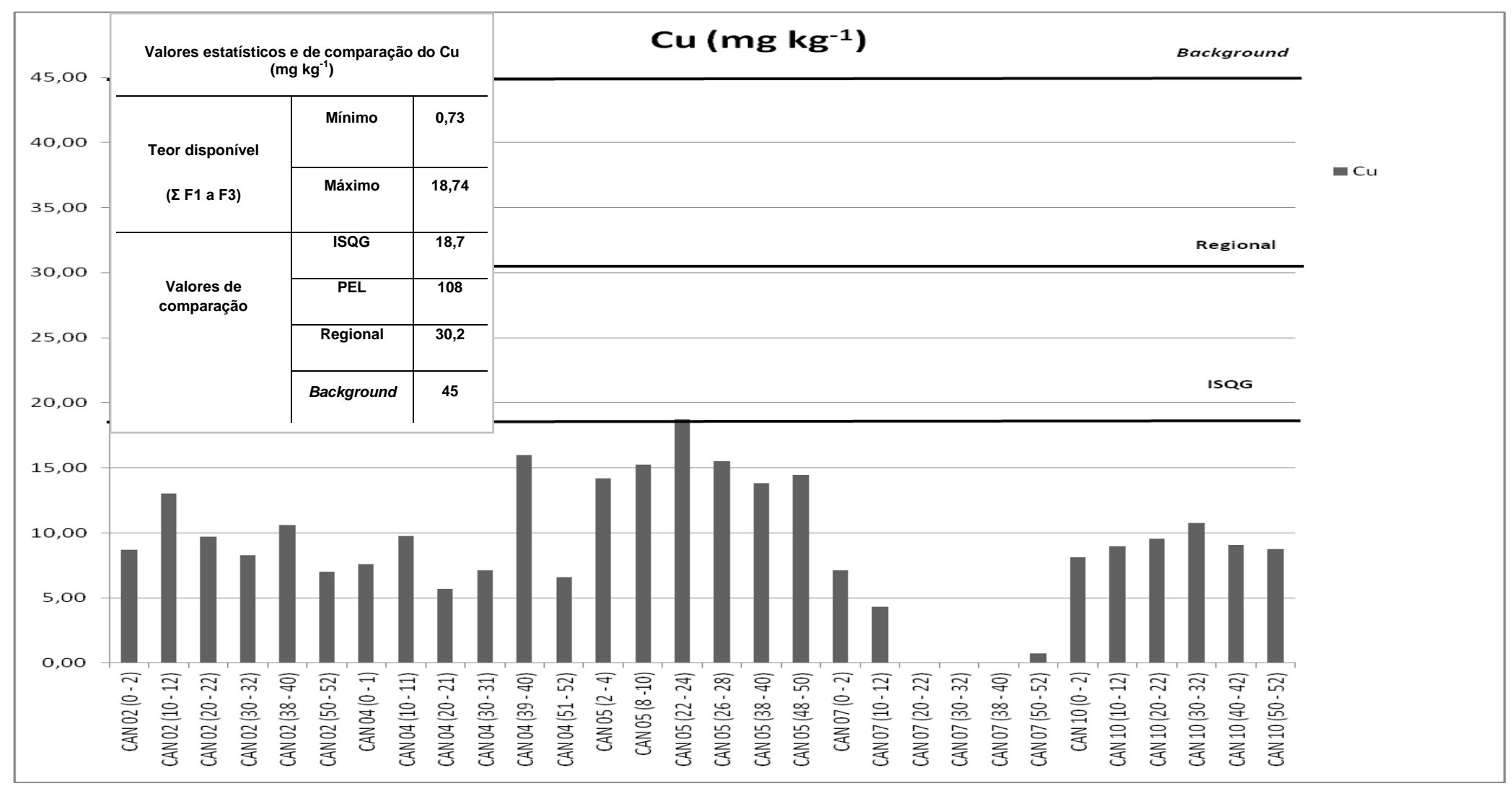

ISQG/PEL (CCME, 2001); Regional (MAHIQUES et al., 2013); Background (TUREKIAN e WEDEPOHL, 1961)

Figura 39. Teor disponível e valores de comparação do $\mathrm{Cu}$, em $\mathrm{mg} \mathrm{kg}^{-1}$, em amostras de testemunhos coletados ao longo do Sistema Cananéia-Iguape. 


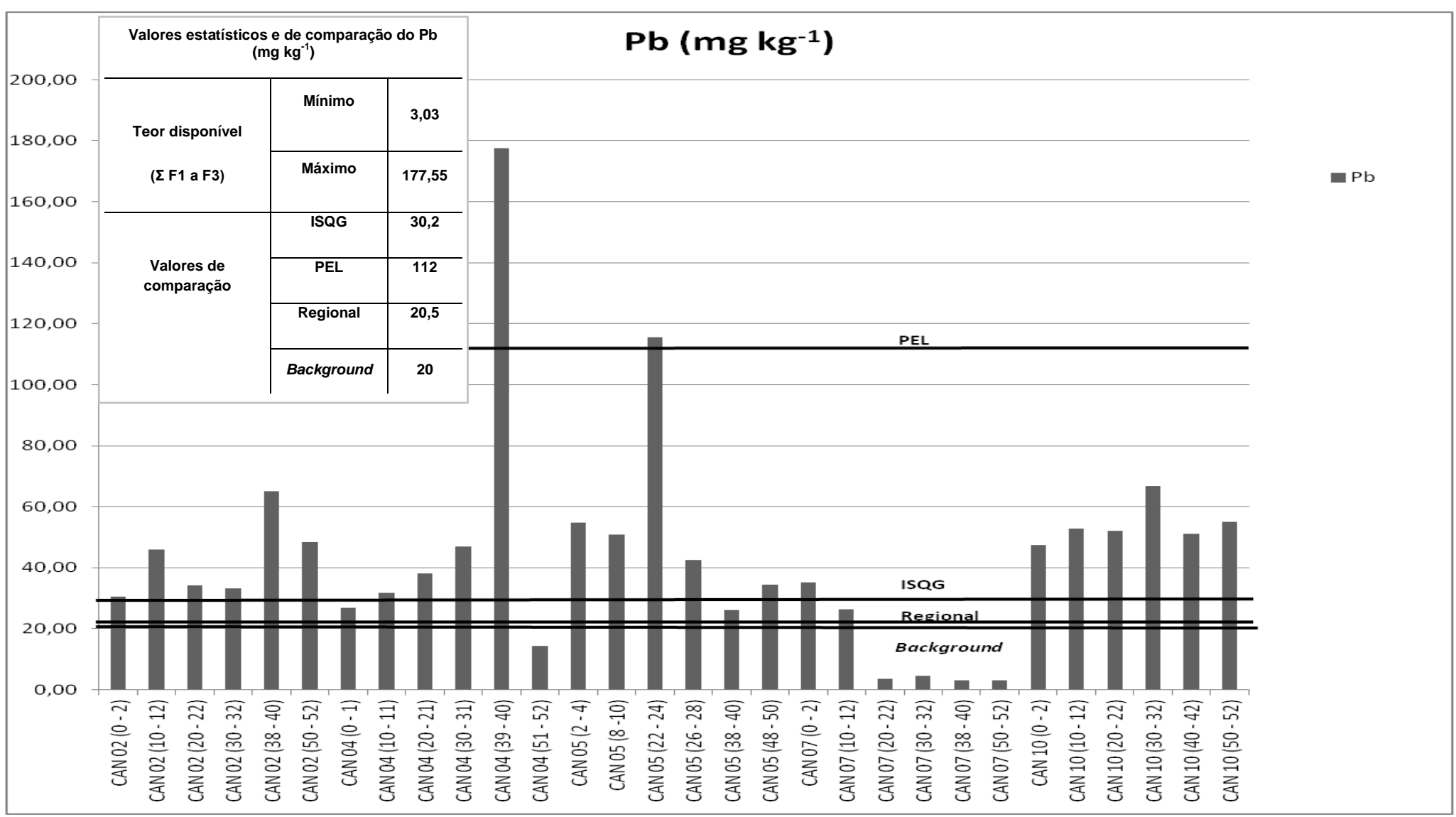

ISQG/PEL (CCME, 2001); Regional (MAHIQUES et al., 2013); Background (TUREKIAN e WEDEPOHL, 1961)

Figura 40. Teor disponível e valores de comparação do $\mathrm{Pb}, \mathrm{em} \mathrm{mg} \mathrm{kg}^{-1}$, em amostras de testemunhos coletados ao longo do Sistema Cananéia-Iguape. 


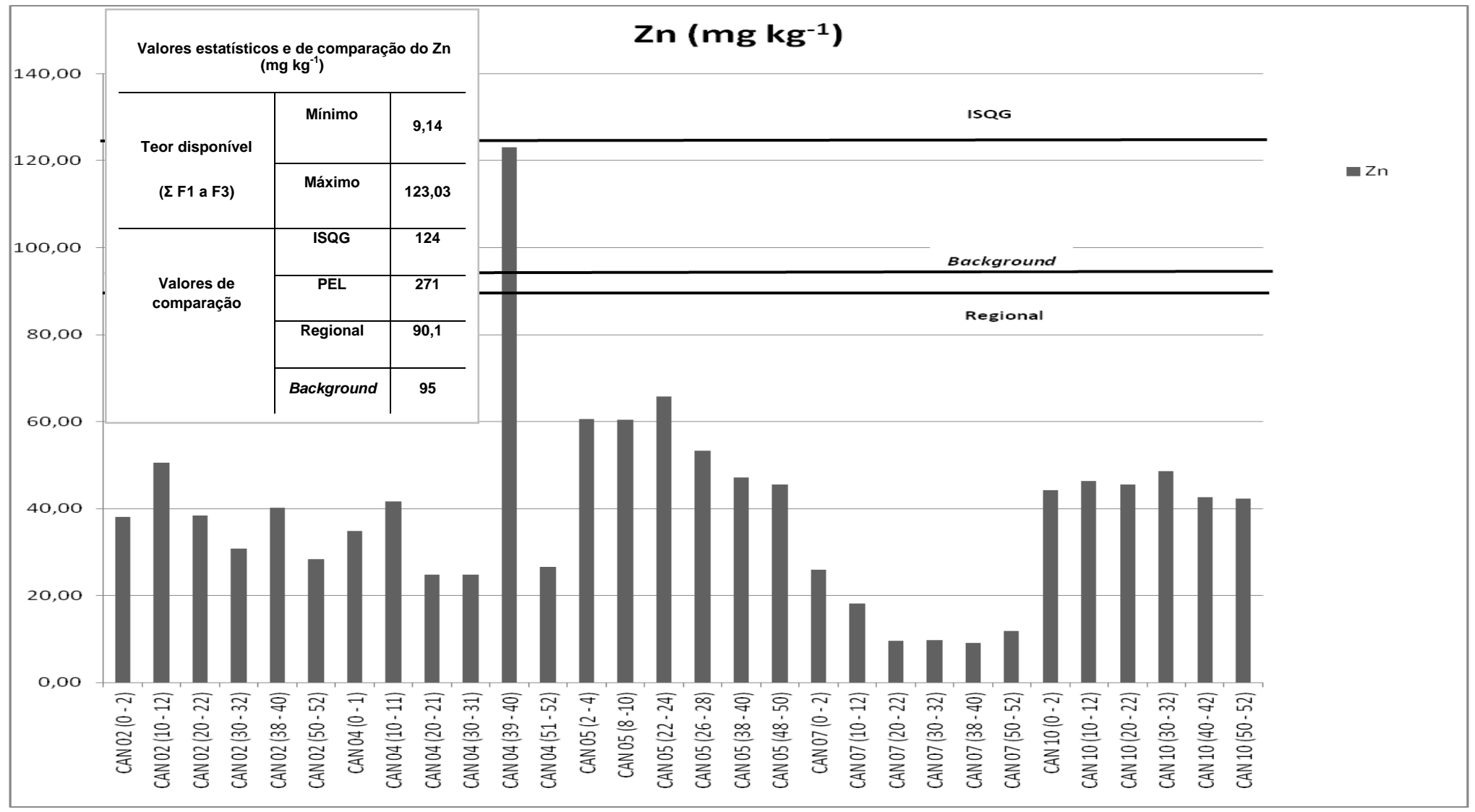

ISQG/PEL (CCME, 2001); Regional (MAHIQUES et al., 2013); Background (TUREKIAN e WEDEPOHL, 1961)

Figura 41. Teor disponível e valores de comparação do $\mathrm{Zn}$, em mg kg-1, em amostras de testemunhos coletados ao longo do Sistema Cananéia-Iguape. 


\subsubsection{Geocronologia da camada superior sedimentar dos testemunhos}

Conforme explanação no Capítulo 4, utilizando-se as taxas de sedimentação dos testemunhos (Tabela 7), foram estimadas as idades das amostras da camada superior $(0$ a $50 \mathrm{~cm})$. O período de deposição dessas amostras variou entre 1926 e 2008. As Figuras de 42 a 46 mostram o teor disponível de $\mathrm{Cu}, \mathrm{Pb}$ e $\mathrm{Zn}$ nas amostras e suas respectivas idades.

Embora o $\mathrm{Cu}$ tenha apresentado baixo teor disponível em todas as amostras, em CAN 04 é possível observar um incremento na sua concentração no ano de 1953; o teor máximo disponível de $\mathrm{Cu}\left(18,74 \mathrm{mg} \mathrm{kg}^{-1}\right)$ foi determinado em CAN 05 no ano de 1993. O Zn apresentou comportamento similar ao $\mathrm{Cu}$; em CAN 04 houve um pico na concentração desse elemento (123,03 $\mathrm{mg} \mathrm{kg}^{-1}$ ) em 1953, sendo este o teor máximo disponível de Zn.

$\mathrm{O} \mathrm{Pb}$, ao contrário do $\mathrm{Cu}$ e do $\mathrm{Zn}$, durante o período de atividades de mineração industrial, apresentou teor disponível superior aos seus valores de comparação na maioria das amostras. Entretanto, pode-se destacar o incremento na concentração desse elemento nos testemunhos CAN 02 em 1970 e, em CAN 10, em 1958. Além disso, em CAN 04 e 05 existe um pico no teor disponível de Pb em 1953 (177,55 mg kg-1) e em 1993 (115,53 mg kg-1), respectivamente. Conforme mencionado acima, em 1953 também foram observados incrementos na concentração do $\mathrm{Cu}$ e do Zn e, em 1993, foi determinado o teor máximo de $\mathrm{Cu}$.

Verificou-se também, que nas amostras com período de deposição estimado em 2006 (CAN 05) e em 2008 (CAN 02, 04, 07 e 10), após a 
decorrência de mais de uma década do encerramento das atividades da mineradora Plumbum, o teor disponível de $\mathrm{Pb}$ foi, quase sempre, superior aos seus valores de comparação. Uma possível explicação seria os resíduos do beneficiamento de $\mathrm{Pb}$ depositados no solo, que foram removidos apenas em 2007 (GUIMARÃES e SíGOLO, 2008), além das instalações e das minas abandonadas por muitos anos (PARANÁ, 2008), conforme histórico apresentado no Capítulo 1. Essa situação foi observada até mesmo no testemunho CAN 07, que apresentou o conjunto de amostras com menor teor disponível de metais (Figura 45). Entretanto, conforme visto anteriormente, durante a análise da composição granulométrica, MAHIQUES et al. (2013) observaram um pico com maior teor de silte + argila (em torno de $40 \%$ ) no topo desse testemunho, fato que pode ter favorecido o acúmulo dos metais.

Em relação ao $\mathrm{Pb}$, foi possível reconhecer a inserção antrópica nos testemunhos, considerando que o teor desse elemento na maioria das amostras foi superior aos seus valores de comparação e que a deposição destas contempla o período de intensa atividade de mineração industrial, indicada como a única fonte desse metal na região. 


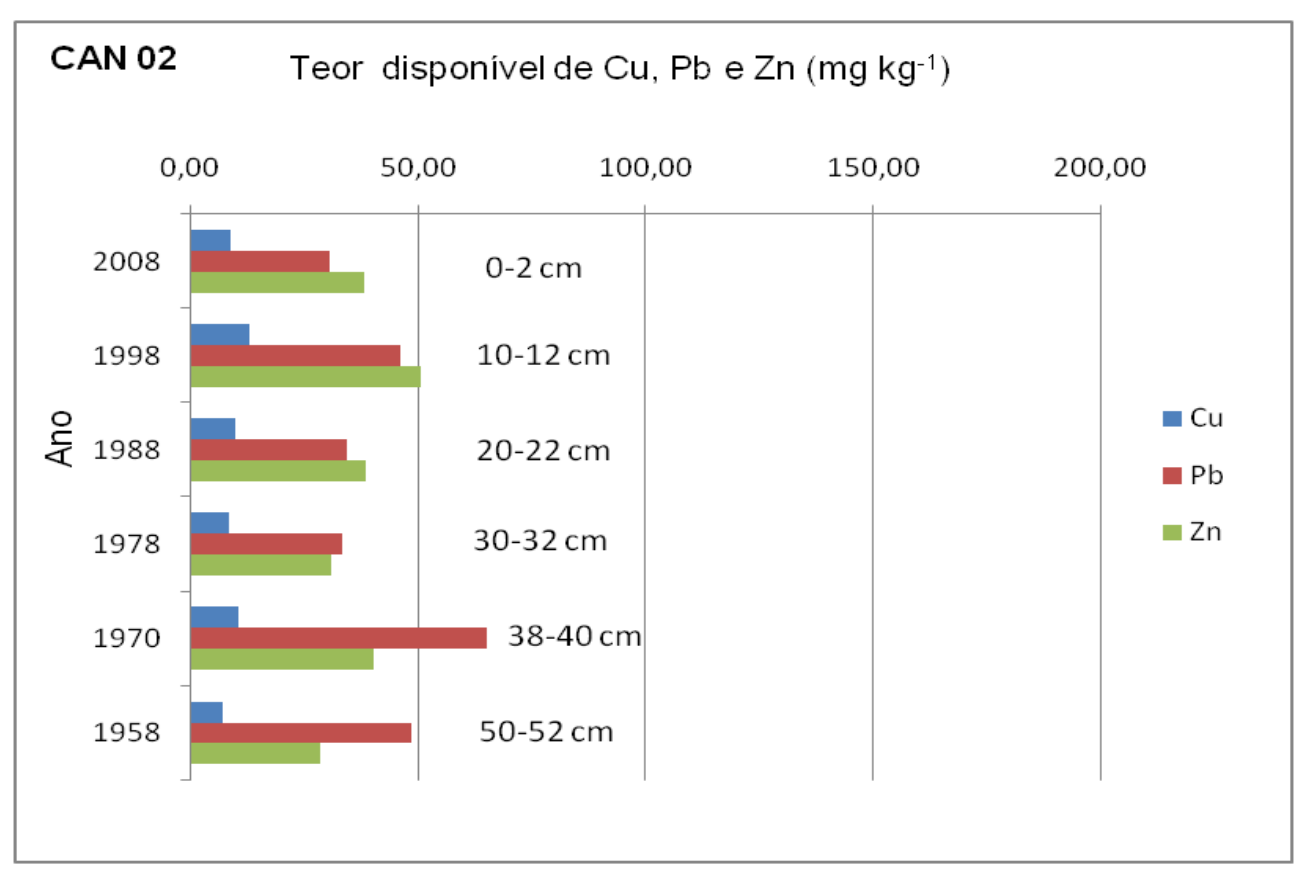

Figura 42. Idade (ano) e teor disponível de $\mathrm{Cu}, \mathrm{Pb}$ e $\mathrm{Zn}$, em $\mathrm{mg} \mathrm{kg}^{-1}$, das amostras do testemunho CAN 02.

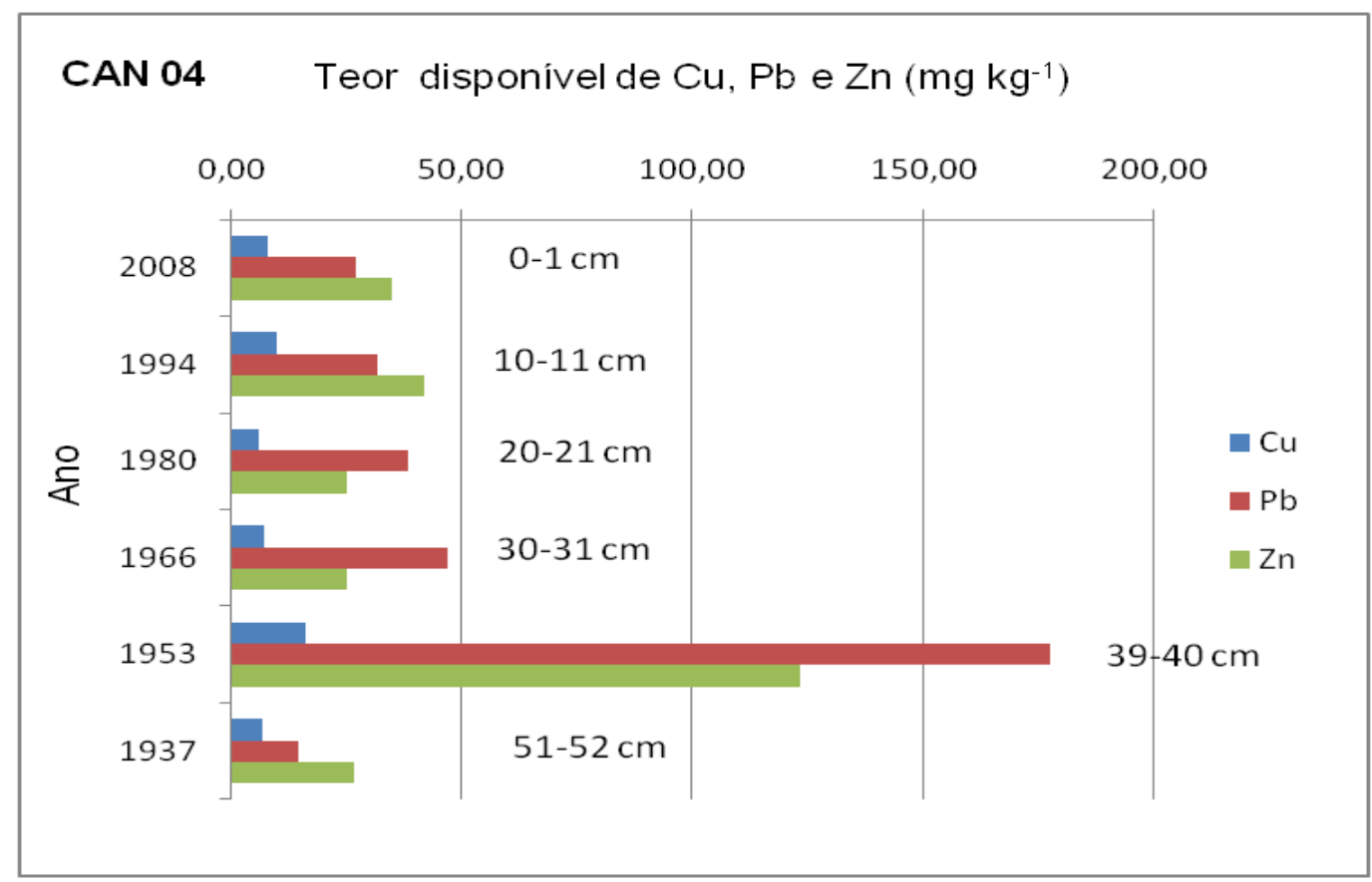

Figura 43. Idade (ano) e teor disponível de $\mathrm{Cu}, \mathrm{Pb}$ e $\mathrm{Zn}$, em $\mathrm{mg} \mathrm{kg}^{-1}$, das amostras do testemunho CAN 04. 


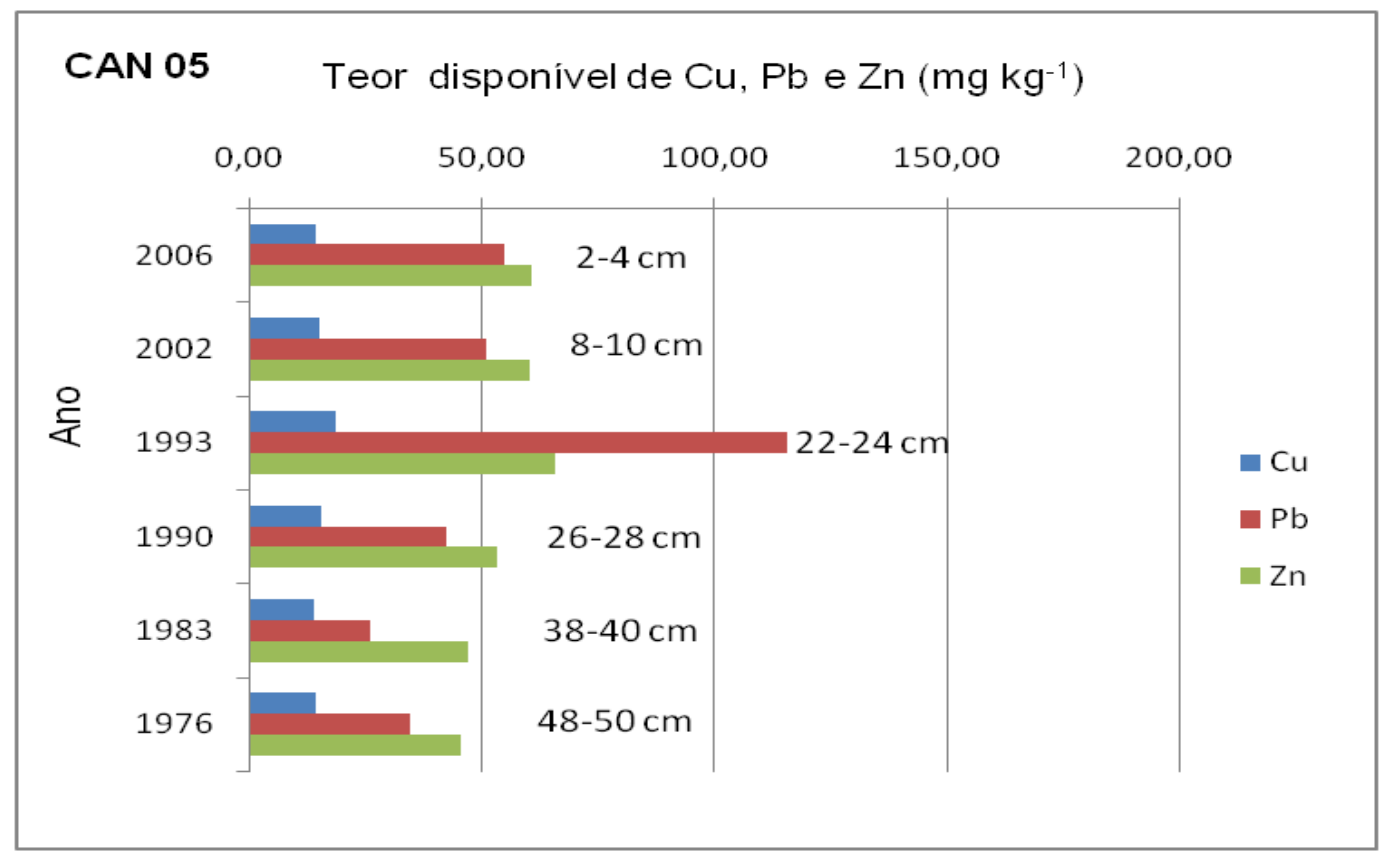

Figura 44. Idade (ano) e teor disponível de $\mathrm{Cu}, \mathrm{Pb}$ e $\mathrm{Zn}$, em $\mathrm{mg} \mathrm{kg}^{-1}$, das amostras do testemunho CAN 05.

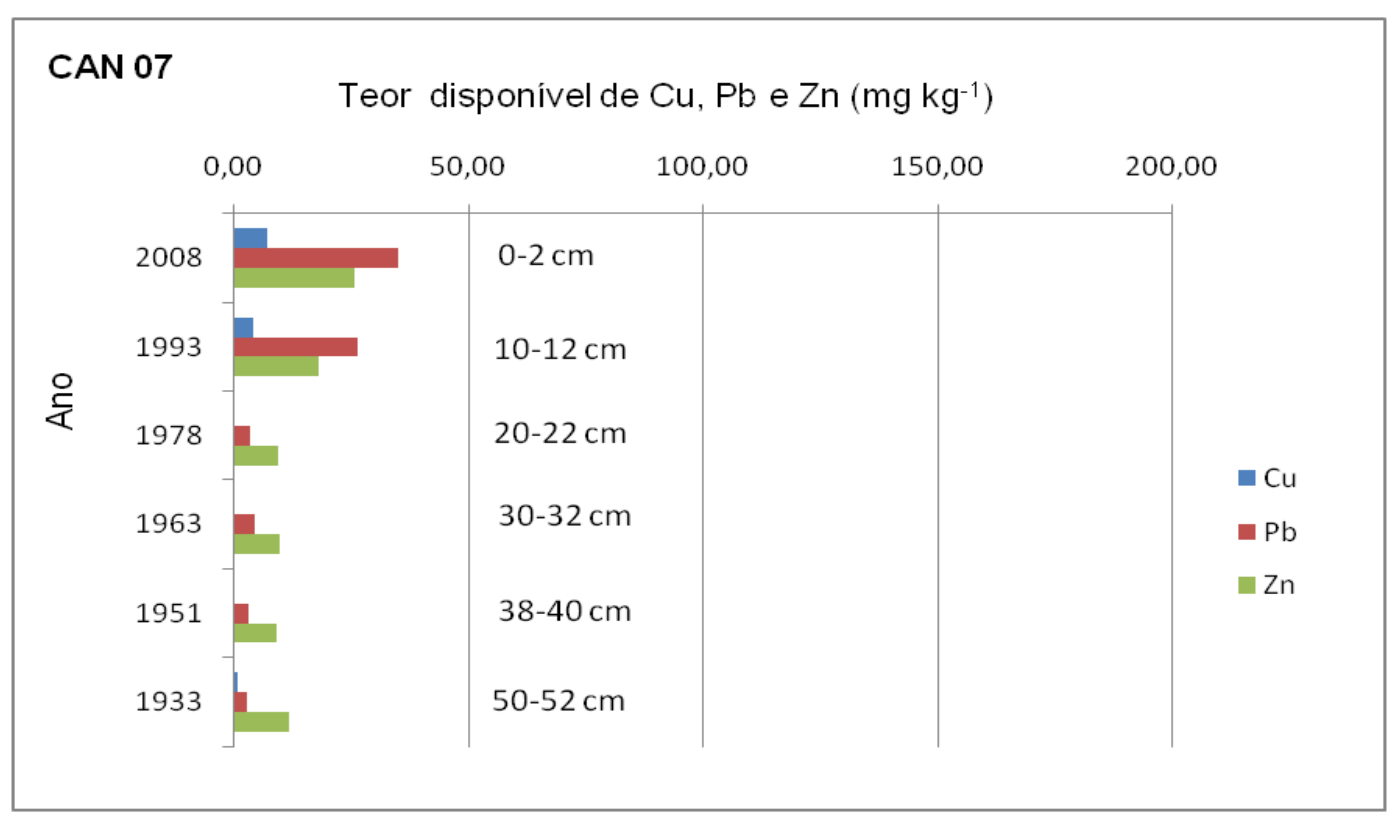

Figura 45. Idade (ano) e teor disponível de $\mathrm{Cu}, \mathrm{Pb}$ e $\mathrm{Zn}$, em $\mathrm{mg} \mathrm{kg}^{-1}$, das amostras do testemunho CAN 07. 


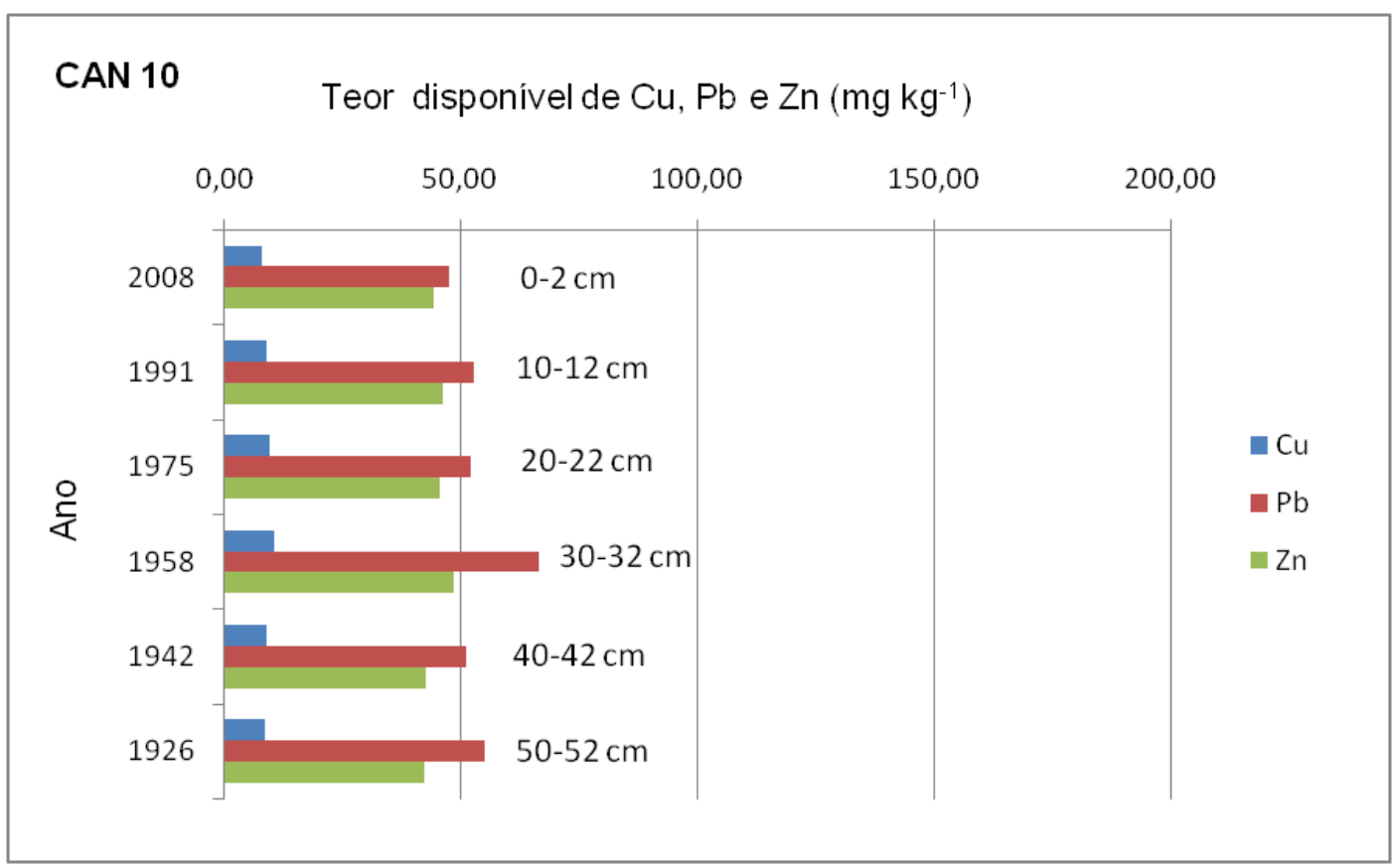

Figura 46. Idade (ano) e teor disponível de $\mathrm{Cu}, \mathrm{Pb}$ e $\mathrm{Zn}$, em $\mathrm{mg} \mathrm{kg}^{-1}$, das amostras do testemunho CAN 10. 


\section{CONCLUSÕES}

Os resultados de extração sequencial em amostras de sedimento superficial mostraram que o teor disponível ( $\Sigma$ F1 a F3) de Cu no Sistema Cananéia-Iguape foi inferior aos valores de background e regional, em todas as estações amostrais, bem como, ao limite ISQG na sua maioria. O Zn apresentou teor disponível inferior aos valores de comparação em todas as estações. Ao contrário desses elementos, o teor disponível de $\mathrm{Pb}$ foi superior ao ISQG em, aproximadamente, $33 \%$ das estações, e aos valores de background e regional em, aproximadamente, $50 \%$ destas. O Pb encontra-se associado principalmente à fração redutível (F2), na qual o elemento está ligado aos óxidos de Fe e Mn. Entretanto, esse metal poderá ser remobilizado em condições redutoras e alterações no potencial redox (Eh), que conduzam à dissolução desses óxidos. Estima-se que em caso de remobilização do Cu e do $\mathrm{Zn}$, esses elementos, possivelmente, não representariam perigo às comunidades aquáticas, devido à baixa concentração nas frações móveis. Entretanto, o teor disponível de $\mathrm{Pb}$ em parte das estações amostrais, sugere atenção quanto à sua biodisponibilidade, considerando-se importante o seu monitoramento no Sistema Cananéia-Iguape.

A região desse Sistema que comporta o conjunto de estações amostrais com maior teor disponível de metais é o canal do Mar Pequeno, principalmente, nas proximidades da Pedra do Tombo. Esse fato, provavelmente, ocorre devido ao fenômeno tombo das águas, provocado pelo encontro de ondas de maré, que favorece a deposição de sedimentos finos, oriundos do rio Ribeira de Iguape através do canal do Valo Grande. 
Analisando-se os percentuais médios de $\mathrm{Cu}, \mathrm{Pb}$ e $\mathrm{Zn}$ em frações móveis, em relação ao teor pseudo-total, considera-se a seguinte ordem de mobilidade desses elementos, do mais para o menos disponível: $\mathrm{Pb}>\mathrm{Zn}>$ Cu. Os resultados do RAC, com base no percentual de metal associado à fração solúvel em ácido (F1), mostraram que $\mathrm{Cu}, \mathrm{Pb}$ e $\mathrm{Zn}$ apresentaram risco médio de remobilização em, respectivamente, 30\%, 27\% e 73\% das estações amostrais do Sistema Cananéia-Iguape; o $\mathrm{Zn}$ foi o único elemento que apresentou risco alto, porém, em apenas 3\% das estações. É importante ressaltar que o teor máximo determinado para esses elementos na $F 1$, principalmente para $\circ \mathrm{Zn}\left(30,82 \mathrm{mg} \mathrm{kg}^{-1}\right)$, foi inferior aos seus respectivos valores de comparação e, portanto, ainda que remobilizados, estima-se baixa probabilidade de efeitos adversos à biota.

A análise estatística mostrou correlação positiva entre o acúmulo de metais, composição granulométrica e percentual de COT nas amostras de sedimento superficial. O método de agrupamento basicamente separou as amostras em três grupos, diferenciando-os, principalmente, pelo teor de metal disponível. As características de cada grupo foram coerentes com as das regiões de origem das estações amostrais (Iguape-Valo Grande, Mar Pequeno e Mar de Cananéia), considerando suas devidas proporções na formação do conjunto.

Comparando-se o teor disponível médio de $\mathrm{Cu}, \mathrm{Pb}$ e $\mathrm{Zn}$ no Sistema Cananéia-Iguape ao estimado em outras regiões impactadas por atividades de exploração mineral e afins, verificou-se que $\mathrm{Cu}$ e $\mathrm{Zn}$ estão em menor concentração no Sistema, enquanto o teor médio de $\mathrm{Pb}$ ficou próximo ao 
estimado para o estuário Guadiana na Península Ibérica e inferior ao teor médio de outras localidades.

Os resultados de extração sequencial de $\mathrm{Cu}, \mathrm{Pb}$ e $\mathrm{Zn}$ nas amostras de sedimentos dos testemunhos também mostraram a forte associação do $\mathrm{Pb}$ aos óxidos de Fe e Mn. Os elementos apresentaram comportamento similar ao observado nas amostras de sedimento superficial; $\mathrm{Cu}$ e $\mathrm{Zn}$ com baixo teor disponível em relação aos valores de comparação, e o Pb, com teor superior a esses valores na maioria das amostras. A partir dos dados de geoquímica e de geocronologia desses testemunhos, foi possível reconhecer a inserção antrópica de $\mathrm{Pb}$ no Sistema Cananéia-Iguape durante o período de atividades de mineração, considerada como única fonte desse metal na região.

Existem diversos estudos relacionados à contaminação de metais no Sistema Cananéia-Iguape. Contudo, as informações, geralmente, estão baseadas em resultados de metais totais ou parciais. Este trabalho apresentou o estudo da disponibilidade de $\mathrm{Cu}, \mathrm{Pb}$ e $\mathrm{Zn}$, fornecendo informações importantes sobre o comportamento e a mobilidade desses elementos na região. Esses dados serão contribuições relevantes para outros estudos ambientais nessa localidade. 


\section{REFERÊNCIAS BIBLIOGRÁFICAS}

ABD EL-AZIM, H.; EL-MOSELHY, KH. M. 2005. Determination and partitioning of metals in sediments along the Suez Canal by sequential extraction. J. Marine Syst., v.56, p. 363-374.

ABOLLINO, O.; MALANDRINO, M.; GIACOMINO, A.; MENTASTI, E. 2011. The role of chemometrics in single and sequential extraction assays: A review Part I. Extraction procedures, uni- and bivariate techniques and multivariate variable reduction techniques for pattern recognition. Anal. Chim. Acta, v.688, p.104-121.

ANJOS, J. A. S. A. 2003. Avaliação da eficiência de uma zona alagadiça (wetland) no controle da poluição por metais: O caso da Plumbum em Santo Amaro da Purificação/BA. Tese de Doutorado. Escola Politécnica da Universidade de São Paulo, Departamento de Engenharia de Minas e de Petróleo, 328 p.

ANJU, M.; BANERJEE, D. K. 2010. Comparison of two sequential extraction procedures for heavy metal partitioning in mine tailings. Chemosphere, v.78, p. 1393-1402.

ARAIN, M. B.; KAZI, T. G.; JAMALI, M. K.; BAIG, J. A.; AFRIDI, H. I.; JALBANI, N.; SARFRAZ, R. A. 2009. Comparison of Different Extraction Approaches for Heavy Metal Partitioning in Sediment Samples. Pedosphere, v.19 (4), p.476485. 
BAIRD, C. 2002. Química Ambiental; trad. Maria Angeles Lobo Recio e Luiz Carlos Marques Carrera. $2^{\mathrm{a}}$ edição. Porto Alegre: Bookman. 622 p.

BARCELLOS, R. L.; BERBEL, G. B. B.; BRAGA, E. S.; FURTADO, V. V. 2005. Distribuição e características do fósforo sedimentar no Sistema Estuarino Lagunar de Cananéia-lguape, estado de São Paulo, Brasil. Geochim. Brasil, v.19 (1), p. 22-36.

BARCELloS, L. R.; CAMARGO, P. B.; GALVÃO, A.; WeBER, R. R. 2009. Sedimentary organic matter in cores of the Cananéia-Iguape LagoonalEstuarine System, São Paulo State, Brazil. J. Coastal Res., SI 56, p.1335-1339. BÁSCONES, I. S. 2003. Determinación de metales pesados en suelos de Medina del Campo (Valladolid): contenidos extraíbeles, níveles fondo y de referencia. Tese de Doutorado da Universidad de Valladolid (España), Facultad de Ciencias, Departamento de Química Analítica, 275 p.

BÉRGAMO, A. L. 2000. Características da hidrografia, circulação e transporte de sal: Barra de Cananéia, sul do mar de Cananéia e Baía do Trapandé. Dissertação de Mestrado. Universidade de São Paulo, Instituto Oceanográfico, $254 \mathrm{p}$.

BERNARDES, M. E. C.; MIRANDA, L. B. 2001. Circulação estacionária e estratificação de sal em canais estuarinos: simulação com modelos analíticos. Rev. bras. Oceanogr., v.49 (1/2), p.115-132. 
BOURGOIN, B. P.; RISKB, M. J.; AITKEN, A. E. 1991. Factors controlling lead availability to the deposit-feeding bivalve Macoma balthica in sulphide-rich oxic sediments. Estuar. Coast. Shelf S., v.32, p.625-63

BRADL, H. B. 2005. Sources and Origins of Heavy Metals. In: (ed.) Heavy metals in the environment. ELSEVIER Academic Press, v.6, p.1-27.

CALMANO, W.; FÖRSTNER, U. 1983. Chemical extraction of heavy metals in polluted river sediments in central Europe. Sci. Total Environ., v.28, p.77-90.

CALMANO, W.; HONG, J.; FÖRSTNER, U. 1993. Binding and mobilization of heavy metals in contaminated sediments affected by $\mathrm{pH}$ and redox potential. Wat. Sci. Tech, v. 28, n. 8-9, p. 223-235.

CALMANO, W.; AHLF, W.; FÖRSTNER, U. 1996. Sediment quality assessment: chemical and biological approaches. In: CALMANO, W.; FÖRSTNER, U. (eds.). Sediments and toxic substances. Berlin, New York: Springer, p. 1-35.

CALMANO, W.; FÖRSTNER, U. 2004. Dredged material. In: Twardowska, I.; Allen, H.E.; Kettrup, A.A.F.; Lacy, W.J. (eds). Solid Waste: Assessment, monitoring and remediation. ELSEVIER B.V., p. 297-318.

CCME - CANADIAN COUNCIL OF MINISTERS OF THE ENVIRONMENT. 1999. Canadian sediment quality guidelines for the protection of aquatic life: Protocol for the Derivation of Canadian Sediment Quality Guidelines for the Protection of Aquatic Life (Canadian Council of Ministers of the Environment 1995 - CCME EPC-98E), $35 \mathrm{p}$. 
CCME - CANADIAN COUNCIL OF MINISTERS OF THE ENVIRONMENT. 2001. Canadian sediment quality guidelines for the protection of aquatic life: Summary tables. Updated. In: Canadian environmental quality guidelines, 1999, Canadian Council of Ministers of the Environment. Winnipeg.

CETESB - COMPANHIA DE TECNOLOGIA E SANEAMENTO AMBIENTAL. 2001. Qualidade das águas interiores do estado de São Paulo (2000). Série Relatórios, 227 p. Disponível em: < http://www.cetesb.sp.gov.br/tecnologiaambiental/laboratorios/61-publicacoes-e-relatorios---relatorios-de-qualidade>. Acesso em: 10/11/2012.

CETESB - COMPANHIA DE TECNOLOGIA E SANEAMENTO AMBIENTAL. 2002. Qualidade das águas interiores do estado de São Paulo (2001). Série Relatórios. 240 p. Disponível em: < http://www.cetesb.sp.gov.br/tecnologiaambiental/laboratorios/61-publicacoes-e-relatorios---relatorios-de-qualidade>. Acesso em: 10/11/2012.

CETESB - COMPANHIA DE TECNOLOGIA E SANEAMENTO AMBIENTAL. 2008. Qualidade das águas interiores do estado de São Paulo (2007). Série Relatórios. 540 p. Disponível em: < http://www.cetesb.sp.gov.br/tecnologiaambiental/laboratorios/61-publicacoes-e-relatorios---relatorios-de-qualidade>. Acesso em: 10/11/2012.

CETESB - COMPANHIA AMBIENTAL DO ESTADO DE SÃO PAULO. 2012. Qualidade das águas superficiais no estado de São Paulo 2011. Série Relatórios. 342 p. Disponível em: < http://www.cetesb.sp.gov.br/agua/aguassuperficiais/35-publicacoes-/-relatorios>. Acesso em: 05/01/2014. 
CETESB - COMPANHIA AMBIENTAL DO ESTADO DE SÃO PAULO. 2013. Qualidade das águas superficiais no estado de São Paulo 2012. Série Relatórios. 354 p. Disponível em: < http://www.cetesb.sp.gov.br/agua/aguassuperficiais/35-publicacoes-/-relatorios>. Acesso em: 05/01/2014.

CORSI, A. C. 1999. Estudo da dispersão de metais pesados em água e sedimentos de corrente a partir de mineralizações de chumbo - zinco - prata: O exemplo das jazidas de Canoas, Perau e Barrinha (Vale do Ribeira - PR). Dissertação de Mestrado. Universidade Estadual Paulista (Campus Rio Claro), Instituto de Geociências e Ciências Exatas, 139 p.

COTTA, J. A. O.; REZENDE, M. O. O.; PIOVANI, M. R. 2006. Avaliação do teor de metais em sedimento do Rio Betari no parque estadual turístico do Alto Ribeira - Petar, São Paulo, Brasil. Quim. Nova, v.29, n.1, p. 40-45.

CUNHA-LIGNON, M. 2001. Dinâmica do Manguezal no Sistema de CananéiaIguape, estado de São Paulo - Brasil. Dissertação de Mestrado. Universidade de São Paulo, Instituto Oceanográfico, 72 p.

CUONG, D. T; OBBARD, J. P. 2006. Metal speciation in coastal marine sediments from Singapore using a modified BCR-sequential extraction procedure. Appl. Geochem., v.21, p.1335-1346.

DAVUTLUOGLU, O. I.; SECKIN, G.; ERSU, C. B.; YILMAZ, T.; SARI, B. 2011. Heavy metal content and distribution in surface sediments of the Seyhan River, Turkey. J. Environ. Manage., v.92, p.2250-2259. 
DELGADO, J.; BARBA-BRIOSO, C.; NIETO, J. M.; BOSKI, T. 2011. Speciation and ecological risk of toxic elements in estuarine sediments affected by multiple anthropogenic contributions (Guadiana saltmarshes, SW Iberian Peninsula): I. Surficial sediments. Sci. Total Environ., v.409, p. 3666-3679.

DI GIULIO, G. M, PEREIRA, N. M., FIGUEIREDO, B. R. 2008. O papel da mídia na construção social do risco: o caso Adrianópolis, no Vale do Ribeira. Hist. Cienc. Saúde-Man., v.15, n.2, p. 293-311.

DYMOTT, T. C. 1995. Application of ICP-OES techniques in environmental QC. In: SUBRAMANIAN, G. Quality assurance in environmental monitoring. Federal Republic of Germany: VCH, p. 95-132.

FIGUEIREDO, B. R.; CAPITANI, E. M.; GITAHY, L. M. C. 2004. Exposição humana à contaminação por chumbo e arsênio no Vale do Ribeira (SP-PR). In: Segundo Encontro da ANPPAS, Indaiatuba.

FIGUEIREDO FILHO, D. B.; SILVA JÚNIOR, J. A. 2009. Desvendando os mistérios do coeficiente de correlação de Pearson (r). Revista Política Hoje, v.18, n. 1, p. 115-146.

FOLK, R. L.; WARD, W. C. 1957. Brazos river bar: A study in the significance of grain size parameters. J. Sediment Petrol. v. 27, n. 1, p. 3-26.

FÖRSTNER, U. 1979. Sources and sediment associations of heavy metals in polluted coastal regions. In: L.H. Ahrens (ed.) Origin and distribution of the elements. Physics and Chemistry of the Earth, Pergamon Press: Oxford, v.11, p. 849-866. 
FÖRSTNER, U. 1981. Metal transfer between solid and aqueous phases. In: FÖRSTNER, U.; WITTMANN, G.T. Metal pollution in the aquatic environment. Berlin: Springer - Verlag, p. 197-270.

FÖRSTNER, U. 2004. Traceability of sediment analysis. TrAC - Trend. Anal. Chem., v. 23, n.3, p. 217-236.

FROELICH, P. N.; KLINKHAMME, G. P.; BENDER, M. L.; LUEDTK, N. A.; HEATH, G. R.; CULLEN, D.; DAUPHIN, P. 1979. Early oxidation of organic matter in pelagic sediments of the eastern equatorial Atlantic: suboxic diagenesis. Geochim. Cosmochim. Ac., v.43, p. 1075-1090.

GARRISON, T. 2010. Fundamentos de oceanografia. Trad. da 4ª edição norteamericana. 4ª edição. São Paulo: Cengage Learning, 426 p.

GAUDETTE, H. E; FLIGHT, W. R. 1974. An inexpensive titration method for the determination of organic carbon in recent sediments. J. Sediment. Petrol., v.44, n.1, p. 249-253.

GEOBRÁS. 1966. Complexo Valo Grande, Mar Pequeno e Rio Ribeira de Iguape. Relatório Técnico. DAEE: São Paulo, v.1.

GHREFAT, H; YUSUF, N. 2006. Assessing Mn, Fe, Cu, Zn, and Cd pollution in bottom sediments of Wadi Al-Arab Dam, Jordan. Chemosphere, v. 65, p. 21142121.

GLEYZES, C.; TELLIER, S.; ASTRUC, M. 2002. Fractionation studies of trace elements in contaminated soils and sediments: a review of sequential extraction procedures. Trend. Anal. Chem., v. 21, n. 6+7, p. 451-467. 
GÓMEZ-ÁLVAREZ, A.; VALENZUELA-GARCíA, J. L.; MEZA-FIGUEROA, D.; LA O-VILLANUEVA, M.; RAMÍREZ-HERNÁNDEZ, J.; ALMENDARIZ-TAPIA, J.; PÉREZ-SEGURA, E. 2011. Impact of mining activities on sediments in a semiarid environment: San Pedro River, Sonora, Mexico. Appl. Geochem., v.26, p. 2101-2112.

GONZÁLEZ, G. P. 2005. Disponibilidad de metales tóxicos en sitios contaminado: Aplicaciones y limitaciones de la fraccionación en la determinación de gradientes de polución. Tese de Doutorado. Universitat Autònoma de Barcelona (España), Departamento de Química, Unitat de Química Analítica, 386 p.

GUIMARÃES, V; SíGOLO, J. B. 2008. Associação de resíduos da metalurgia com sedimentos em suspensão - Rio Ribeira de Iguape. Geo. USP. Sér. Cient. São Paulo, v.8, n.2, p. 1-10.

HOROWITZ, A. J. 1985. A primer on trace metal-sediment chemistry. U.S. Geological Survey Water Supply Paper 2277, Washington, DC, 67 p. Disponível em: $<$ http://pubs.usgs.gov/wsp/2277/report.pdf $>$. Acesso em: 08/11/2012.

HORVÁTH, M.; BOKOVÁ, V.; HELTAI, G.; FLÓRIÁN, K.; FEKETE, I. 2010. Study of application of BCR sequential extraction procedure for fractionation of heavy metal content of soils, sediments, and gravitation dusts. Toxicol. Environ. Chem., v. 92, n.3, p.429-441.

ICMBio - INSTITUTO CHICO MENDES DE CONSERVAÇÃO DA BIODIVERSIDADE. MINISTÉRIO DO MEIO AMBIENTE. 2008. Estação Ecológica dos Tupiniquins. Brasília, 403 p. 
INMETRO - INSTITUTO NACIONAL DE METROLOGIA, NORMALIZAÇÃO E QUALIDADE INDUSTRIAL. 2007. Orientação sobre validação de métodos de ensaios químicos. Documento de caráter orientativo (DOQ-CGCRE-008).

ISHIKAWA, D. N.; NOALE, R. Z.; OHE, T. H. K.; SOUZA, E. B. R.; SCARMÍNIO, I. S.; BARRETO, W. J.; BARRETO, S. R. G. 2009. Avaliação do risco ambiental em sedimento dos lagos do Riacho Cambé, em Londrina, pela distribuição de metais. Quim. Nova, v.32, n.7, p.1744-1749.

JAIN, C. K. 2004. Metal fractionation study on bed sediments of River Yamuna, India. Water Res., v.38, p.569-578.

KELDERMAN, P.; OSMAN, A. A. 2007. Effect of redox potential on heavy metal binding forms in polluted canal sediments in Delft (The Netherlands). Water Res., v.41, p.4251-4261.

KUMPERA, B. 2007. Contribuição ao processo sedimentar atual no Canal do Ararapira, Sistema estuarino-lagunar de Cananéia-lguape. Dissertação de Mestrado. Universidade de São Paulo, Instituto Oceanográfico, 118 p.

LIMA, M. C.; GIANCOMELLI, M. B. O.; STÜPP, V.; ROBERGE, F. D.; BARREIRA, P. B. 2001. Especiação de cobre e chumbo em sedimento do rio Tubarão (sc) pelo método TESSIER. Quim. Nova, v.24, n.6, p.734-742.

LÓPEZ JULIÁN, P. L.; MANDADO COLLADO, J. M. 2002. Extracciones químicas secuenciales de metales pesados. Aplicación en ciencias geológicas. Estudios Geol., v.58: p.133-144.

MAHIQUES, M. M.; BURONE, L.; FIGUEIRA, R. C. L.; OLIVEIRA, A. A.; 
LAVENÉRE, W.; CAPELLARI, B; ROGACHESKI, C. E.; BARROSO, C. P.; SANTOS, L. A. S.; CORDERO, L. M.; CUSSIOLI, M. C. 2009. Anthropogenic influences in a lagoonal environment: A multiproxy approach at the Valo Grande mouth, Cananéia-Iguape System (SE Brazil). Braz. J. Oceanogr., v.57(4), p.325-337.

MAHIQUES, M. M.; FIGUEIRA, R. C. L.; SALAROLI, A. B.; ALVES, D. P. V.; GONÇALVES, C. 2013. 150 years of anthropogenic metal input in a Biosphere Reserve: The case study of the Cananéia-Iguape coastal system, Southeastern Brazil. Environ. Earth Sci., v.68, p.1073-1087.

MALUF, J. C. C. 2009. Estudos dos metais traço (zinco, cádmio e chumbo) em duas regiões do complexo Estuarino-Lagunar de Cananéia-Iguape (SP) sob diferentes pressões antrópicas. Dissertação de Mestrado. Universidade de São Paulo, Instituto Oceanográfico, $125 \mathrm{p}$.

MARIN, B.; VALLADON, M.; POLVE, M.; MONACO, A. 1997. Reproducibility testing of a sequential extraction scheme for the determination of trace metal speciation in a marine reference sediment by inductively coupled plasma-mass spectrometry. Anal. Chim. Acta, v.342, p. 91-112.

MARTINS, C. C. 2005. Marcadores Orgânicos Geoquímicos em testemunhos de sedimento do Sistema Estuarino de Santos e São Vicente (SP): um registro histórico da introdução de hidrocarbonetos no ambiente marinho. Tese de Doutorado. Universidade de São Paulo, Instituto Oceanográfico, 215 p.

MELLADO, J. M. R.; GALVÍN, R. M. 1999. Fisicoquímica de águas. Madrid Espanã: Ed. Díaz de Santos S.A, 467 p. 
MIYAO, S .Y.; NISHIHARA, L.; SARTI, C. C. 1986. Características físicas e químicas do Sistema Estuarino-Lagunar de Cananéia-Iguape. Bolm. Inst. Oceanogr., São Paulo, v.34, p.23-36,

MIYAO, S. Y.; HARARI, J. 1989. Estudo preliminar da maré e das correntes de maré da região estuarina de Cananéia $\left(25^{\circ} 5-48^{\circ} \mathrm{W}\right)$. Bolm. Inst. Oceanogr., São Paulo, v.37(2): p.107-123.

MORAES, P. R. 1997. Transporte de chumbo e metais associados no rio Ribeira de Iguape, São Paulo, Brasil. Dissertação de Mestrado. Universidade Estadual de Campinas, Instituto de Geociências, 94 p.

MORILLO, J.; USERO, J.; GRACIA, I. 2004. Heavy metal distribution in marine sediments from the southwest coast of Spain. Chemosphere, v.55, p.431-442.

NAJI, A.; ISMAIL, A.; ISMAIL, A. R. 2010. Chemical speciation and contamination assessment of $\mathrm{Zn}$ and $\mathrm{Cd}$ by sequential extraction in surface sediment of Klang River, Malaysia. Microchem. J., v.95, p. 285-292.

OTERO, X. L.; FERREIRA, T. O.; HUERTA-DÍAZ, M. A.; PARTITI, C. S. M.; SOUZA Jr., V.; VIDAL-TORRADO, P.; MACÍAS, F. 2009. Geochemistry of iron and manganese in soils and sediments of a mangrove system, Island of Pai Matos (Cananeia - SP, Brazil). Geoderma, v.148, p.318-335.

PARANÁ - Ministério da Saúde do Brasil, Secretaria de Estado da Saúde do Paraná, Secretaria Municipal da Saúde de Adrianópolis. 2008. Avaliação de Risco à Saúde Humana por Exposição aos Resíduos da PLUMBUM no Município de Adrianópolis - PR, 196 p. Disponível em: < 
http://portal.saude.gov.br/portal/arquivos/pdf/avaliacao risco adrianopolis para na 08.pdf $>$. Acesso em: 10/11/2012.

PASSOS, E. A.; ALVES, J. C.; SANTOS, I. S.; ALVES, J. P. H; GARCIA, C. A. B.; COSTA, A. C. S. 2010. Assessment of trace metals contamination in estuarine sediments using a sequential extraction technique and principal component analysis. Microchem. J., v. 96, p. 50-57.

PEREIRA, J. C.; GUIMARÃES-SILVA, A. K.; NALINI JÚNIOR, H. A.; PACHECO-SILVA, E.; LENA, J. C. 2007. Distribuição, fracionamento e mobilidade de elementos traço em sedimentos superficiais. Quim. Nova, v. 30, n.5, p. $1249-1255$.

PEREIRA, L. C. 2009. Especiação química de cobre em ambientes aquáticos próximos ao município do Rio Grande - RS. Dissertação de Mestrado. Universidade Federal do Rio Grande, Departamento de Engenharia Oceânica, $68 \mathrm{p}$.

PONZI, V. R. A. 2004. Sedimentação Marinha. In: BAPTISTA NETO, J. A.; PONZI, V. R. A.; SICHEL, S. E. (Org.). Introdução à Geologia Marinha. Rio de Janeiro: Interciência, p. 219-242.

POSSOLI, S. 1984. Técnicas de análise multivariada para avaliação das condições de saúde dos municípios do Rio Grande do Sul, Brasil. Rev. Saúde Publ., v.18, p. 288-300.

PUEYO, M., RAURET, G., LÜCK, D., YLI-HALLA, M., MUNTAU, H., QUEVAUVILLER, Ph., LÓPEZ-SÁNCHEZ, F. J. 2001. Certification of the 
extractable contents of $\mathrm{Cd}, \mathrm{Cr}, \mathrm{Cu}, \mathrm{Ni}, \mathrm{Pb}$ and $\mathrm{Zn}$ in a freshwater sediment following a collaboratively tested and optimised three-step sequential extraction procedure. J. Environ. Monit., v.3, p. 243-250.

QUEVAUVILLER, Ph. 1998. Operationally defined extraction procedures for soil and sediment analysis I. Standardization. Trend. Anal. Chem., v. 17, n. 5, p. 289-298.

RAO, C. R. M.; SAHUQUILLO A.; LOPEZ SANCHEZ J. F. 2008. A review of the different methods applied in environmental geochemistry for single and sequential extraction of trace elements in soils and related materials. Water Air Soil Poll., v.189, p. 291-333.

RAURET, G. 1998. Extraction procedures for the determination of heavy metals in contaminated soil and sediment, Talanta, v.46, p. 449-455.

RAURET, G.; LÓPEZ-SÁNCHEZ, J. F.; SAHUQUILLO, A.; RUBIO, R.; DAVIDSON, C.; URE, A.; QUEVAUVILLER, Ph. 1999. Improvement of the BCR three step sequential extraction procedure prior to the certification of new sediment and soil reference materials. J. Environ. Monit., v.1, p. 57-61.

ROCHA, J. C.; ROSA, A. H. 2003. Substâncias Húmicas Aquáticas: Interações com espécies metálicas. São Paulo: Ed. UNESP, 120 p.

RODRIGUES, L. C. V. 2008. Estudo da disponibilidade química de chumbo e arsênio em sedimentos de corrente e colunas de sedimentos no Vale do Ribeira - SP. Tese de Doutorado. Universidade Federal Fluminense, Centro de Estudos Gerais, Instituto de Química, 133 p. 
RYBICKA, H. E.; CALMANO, W.; BREEGER, A. 1995. Heavy metals sorption/desorption on competing clay minerals; an experimental study. Appl. Clay Sci., v.9, p. 369-381.

SAHUQUILLO, A.; LÓPEZ-SÁNCHEZ, J. F.; RUBIO, R.; RAURET, G.; THOMAS, R. P.; DAVIDSON, C. M.; URE, A. M. 1999. Use of a certified reference material for extractable trace metals to assess sources of uncertainty in the BCR three-stage sequential extraction procedure. Anal. Chim. Acta, v.382, p. 317-327.

SAKAN, S. M., DORDEVíc, D. S., MANOJLOVíc, D. D., PREDRAG, P. S. 2009. Assessment of heavy metal pollutants accumulation in the Tisza river sediments. J. Environ. Manage., v.90, p. 3382-3390.

SALOMONS, W. 1995. Environmental impact of metals derived from mining activities: Processes, predictions, prevention. J. Geochem. Explor., v.52, p. 523.

SCHNITZER, M. 1978. Humic Substances: Chemistry and Reactions. In: SCHNITZER, M.; KHUAN, S.U. (Eds). Soil Organic Matter. ELSEVIER Science Publishers B.V., p. 1-64.

SILVA, R. H. P. 1997. Geoquímica e impacto ambiental do arsênio no Vale do Ribeira (SP-PR). Dissertação de Mestrado. Universidade Estadual de Campinas, Instituto de Geociências, 100 p. 
SINGH, K. P.; MOHAN, D.; SINGH, V. K.; MALIK, A. 2005. Studies on distribution and fractionation of heavy metals in Gomti river sediments - A tributary of the Ganges, India. J. Hydrol., v. 312, p.14-27.

TESSIER, A.; CAMPBELL, P. G. C.; BISSON, M. 1979. Sequential extraction procedure for the speciation of particulate trace metals. Anal. Chem., v.51, n.7, p. $844-851$.

TESSLER, M. G. 1982. Sedimentação atual na região lagunar de CananéiaIguape, Estado de São Paulo. Dissertação de Mestrado. Universidade de São Paulo, Instituto de Geociências, 2 v.

TESSLER, M. G., SUGUIO, K., ROBILOTTA, P. R. 1987. Teores de alguns elementos traço metálicos em sedimentos pelíticos da superfície de fundo da região Lagunar Cananéia-Iguape. In: Simpósio Sobre Ecossistemas da Costa Sul e Sudeste Brasileira, Cananéia, v.2, São Paulo, p. 255-263.

TESSLER, M. G.; SOUZA, L. A. P. 1998. Dinâmica sedimentar e feições sedimentares identificadas na superfície de fundo do Sistema CananéiaIguape, SP. Rev. bras. Oceanogr., v.46(1), p. 69-83.

TESSLER, M. G. 2001. Taxas de sedimentação holocênica na plataforma continental sul do estado de São Paulo. Tese de livre-docência. Universidade de São Paulo, Instituto Oceanográfico, 155 p.

TRIBOVILLARD, N.; ALGEO, T. J.; LYONS, T.; RIBOULLEAU, A. 2006. Trace metals as paleoredox and paleoproductivity proxies: An update. Chem. Geol., v. 232, p. $12-32$. 
TUREKIAN, K. K.; WEDEPOHL, K. H. 1961. Distribution of the elements in some major units of the Earth's crust. Geo. Soc. Am. Bull. v. 72, n. 2, p. 175192.

US CFR - CODE OF FEDERAL REGULATIONS. 2011. Environmental Protection Agency, D-Water programs, Guidelines establishing test procedures for the analyses of pollutants, Appendix B to Part 136 - Definition and procedure for the determination of method detection limit. Revision 1.11. In: Title 40: Protection of Environment, p. 317-319.

US EPA - UNITED STATES ENVIRONMENTAL PROTECTION AGENCY. 1996. Method 3050B. Acid digestion of sediments, sludges and soil. Revision 2.

US EPA - UNITED STATES ENVIRONMENTAL PROTECTION AGENCY. 2000. Methods for measuring the toxicity and bioaccumulation of sedimentassociated contaminants with freshwater invertebrates. $2^{\text {nd }}$ Edition.

WANG, Shaofeng.; JIA, Y.; WANG Shuying; WANG, X.; WANG, H.; ZHAO, Z.; LIU, B. 2010. Fractionation of heavy metals in shallow marine sediments from Jinzhou Bay, China. J. Environ. Sc., v.22(1), p. 23-31.

WENTWORTH, C. K. 1922. A scale of grade and class terms for clastic sediments. J. Geol., v. 30, n. 5, p. 377-392.

WHITELEY, J. D.; PEARCE, N. J. G. 2003. Metal distribution during diagenesis in the contaminated sediments of Dulas Bay, Anglesey, N. Wales, UK. Appl. Geochem., v.18, p. 901-913. 
WROBEL, Katarzina.; WROBEL, Kazimierz.; CARUSO, J. A. 2007. Metal analysis. In: SCOTT, R. A.; LUKEHART, C. M. (Eds). Applications de Physical Methods to Inorganic and Bioinorganic Chemistry. England: WILEY, p. 205-226.

YAN, C.; LI, Q.; ZHANG, X.; LI, G; 2010. Mobility and ecological risk assessment of heavy metals in surface sediments of Xiamen Bay and its adjacent areas, China. Environ. Earth Sci., v.60, p. 1469-1479.

ZAKIR, H. M.; SHIKAZONO, N. 2011. Environmental mobility and geochemical partitioning of $\mathrm{Fe}, \mathrm{Mn}, \mathrm{Co}, \mathrm{Ni}$ and $\mathrm{Mo}$ in sediments of an urban river. J. Environ. Chem. Ecotoxicol., v.3(5), p. 116-126.

ŽEMBERYOVÁ, M.; BARTEKOVÁ, J.; HAGAROVÁ, I. 2006. The utilization of modified BCR three-step sequential extraction procedure for the fractionation of $\mathrm{Cd}, \mathrm{Cr}, \mathrm{Cu}, \mathrm{Ni}, \mathrm{Pb}$ and $\mathrm{Zn}$ in soil reference materials of different origins. Talanta, v.70, p. 973-978.

ZOUMIS, T., SCHMIDT, A., GRIGOROVA, L., CALMANO, W. 2001. Contaminants in sediments: remobilisation and demobilisation. Sci. Total Environ., v.266, p. 195-202. 
ANEXOS 
TABELAS 
Tabela 1. Coordenadas e profundidades aproximadas das amostras de sedimento superficial coletadas ao longo do Sistema CananéiaIguape

\begin{tabular}{|c|c|c|c|c|c|}
\hline \multirow[t]{2}{*}{ Amostras } & \multicolumn{2}{|c|}{ Latitude ( $\left.{ }^{\circ} \mathrm{S}\right)$} & \multicolumn{2}{|c|}{ Longitude $\left({ }^{\circ} \mathrm{W}\right)$} & \multirow{2}{*}{$\begin{array}{l}\text { Profundidade } \\
\text { (m) }\end{array}$} \\
\hline & graus & minutos & graus & minutos & \\
\hline $\mathrm{P} 1$ & 47 & 34,068 & 24 & 40,900 & ND \\
\hline P2 & 47 & 34,019 & 24 & 41,074 & ND \\
\hline P3 & 47 & 34,291 & 24 & 41,526 & ND \\
\hline P4 & 47 & 34,312 & 24 & 41,804 & ND \\
\hline P5 & 47 & 34,235 & 24 & 41,985 & ND \\
\hline P6 & 47 & 34,138 & 24 & 42,229 & 6,4 \\
\hline P7 & 47 & 34,096 & 24 & 42,347 & 4,0 \\
\hline P8 & 47 & 33,977 & 24 & 42,722 & 3,7 \\
\hline P9 & 47 & 33,832 & 24 & 43,161 & 3,7 \\
\hline P10 & 47 & 33,523 & 24 & 43,139 & 2,1 \\
\hline $\mathrm{P} 11$ & 47 & 32,934 & 24 & 42,577 & 10,1 \\
\hline $\mathrm{P} 12$ & 47 & 32,630 & 24 & 42,395 & 11,0 \\
\hline P13 & 47 & 32,318 & 24 & 42,263 & 13,0 \\
\hline P14 & 47 & 31,766 & 24 & 41,797 & 4,9 \\
\hline P15 & 47 & 31,447 & 24 & 41,603 & 7,0 \\
\hline P16 & 47 & 31,034 & 24 & 41,665 & 7,0 \\
\hline P17 & 47 & 30,559 & 24 & 41,992 & 8,5 \\
\hline P18 & 47 & 28,479 & 24 & 41,960 & 4,6 \\
\hline P19 & 47 & 27,893 & 24 & 41,843 & 5,5 \\
\hline P20 & 47 & 31,104 & 24 & 42,037 & ND \\
\hline P21 & 47 & 31,482 & 24 & 42,180 & ND \\
\hline P22 & 47 & 31,846 & 24 & 42,066 & ND \\
\hline P23 & 47 & 33,018 & 24 & 42,547 & ND \\
\hline P24 & 47 & 33,146 & 24 & 42,747 & ND \\
\hline P25 & 47 & 33,198 & 24 & 42,858 & ND \\
\hline P26 & 47 & 34,038 & 24 & 43,451 & ND \\
\hline P27 & 47 & 33,976 & 24 & 43,624 & ND \\
\hline P28 & 47 & 34,368 & 24 & 43,631 & ND \\
\hline P29 & 47 & 34,815 & 24 & 43,980 & ND \\
\hline P30 & 47 & 35,050 & 24 & 44,088 & ND \\
\hline P31 & 47 & 35,392 & 24 & 44,232 & ND \\
\hline P32 & 47 & 35,943 & 24 & 44,531 & ND \\
\hline P33 & 47 & 34,439 & 24 & 43,908 & ND \\
\hline
\end{tabular}


Continuação da Tabela 1

\begin{tabular}{|c|c|c|c|c|c|}
\hline P34 & 47 & 35,001 & 24 & 44,202 & ND \\
\hline P35 & 47 & 35,285 & 24 & 44,430 & ND \\
\hline P36 & 47 & 35,499 & 24 & 44,625 & ND \\
\hline P37 & 47 & 35,761 & 24 & 44,779 & ND \\
\hline P38 & 47 & 37,002 & 24 & 45,225 & 3,4 \\
\hline P39 & 47 & 37,778 & 24 & 45,620 & 1,5 \\
\hline $\mathrm{P} 40$ & 47 & 38,459 & 24 & 46,093 & 4,0 \\
\hline P41 & 47 & 39,138 & 24 & 46,614 & 4,0 \\
\hline P42 & 47 & 39,831 & 24 & 47,141 & 1,5 \\
\hline P43 & 47 & 40,382 & 24 & 47,689 & 4,3 \\
\hline P44 & 47 & 40,921 & 24 & 48,335 & 4,3 \\
\hline P45 & 47 & 41,609 & 24 & 48,855 & 6,1 \\
\hline P46 & 47 & 42,350 & 24 & 49,311 & 4,3 \\
\hline P47 & 47 & 43,150 & 24 & 49,762 & 7,6 \\
\hline P48 & 47 & 44,035 & 24 & 50,012 & 10,4 \\
\hline P49 & 47 & 44,576 & 24 & 50,586 & 7,3 \\
\hline P50 & 47 & 45,330 & 24 & 51,236 & 7,3 \\
\hline P51 & 47 & 46,171 & 24 & 51,685 & 7,9 \\
\hline P52 & 47 & 48,533 & 24 & 54,105 & 7,9 \\
\hline P53 & 47 & 50,392 & 24 & 54,196 & 16,8 \\
\hline P54 & 47 & 50,912 & 24 & 55,512 & 7,6 \\
\hline P55 & 47 & 51,542 & 24 & 56,464 & 4,0 \\
\hline P56 & 47 & 51,824 & 24 & 57,433 & 6,1 \\
\hline P57 & 47 & 52,358 & 24 & 57,917 & 6,4 \\
\hline P58 & 47 & 53,511 & 24 & 57,724 & 11,0 \\
\hline P59 & 47 & 54,241 & 24 & 58,168 & 12,8 \\
\hline P60 & 47 & 53,973 & 24 & 59,195 & 6,4 \\
\hline P61 & 47 & 54,146 & 25 & 0,129 & 7,0 \\
\hline P62 & 47 & 54,938 & 25 & 0,566 & 6,4 \\
\hline P63 & 47 & 55,297 & 25 & 1,138 & 11,9 \\
\hline P64 & 47 & 55,018 & 25 & 1,919 & 7,3 \\
\hline
\end{tabular}

ND - Não determinado 
Tabela 2. Dados granulométricos das amostras de sedimento superficial coletadas ao longo do Sistema Cananéia-Iguape

\begin{tabular}{|c|c|c|c|c|c|c|}
\hline Amostras & $\begin{array}{c}\text { Areia } \\
(\%)\end{array}$ & $\begin{array}{c}\text { Silte } \\
(\%)\end{array}$ & $\begin{array}{c}\text { Argila } \\
(\%)\end{array}$ & $\begin{array}{l}\text { Diâmetro } \\
\text { médio }(\phi)\end{array}$ & $\begin{array}{c}\text { Desvio-padrão } \\
(\phi)\end{array}$ & $\begin{array}{c}\text { Classificação } \\
\text { textural }\end{array}$ \\
\hline P1 & 39,91 & 51,83 & 8,25 & 4,81 & 1,88 & silte grosso \\
\hline P2 & 59,46 & 36,04 & 4,50 & 3,72 & 2,18 & areia muito fina \\
\hline P3 & 71,91 & 21,56 & 6,52 & 3,99 & 1,90 & areia muito fina \\
\hline P4 & 100,00 & 0,00 & 0,00 & 1,97 & 0,43 & areia media \\
\hline P5 & 66,75 & 28,56 & 4,69 & 3,72 & 1,99 & areia muito fina \\
\hline P6 & 100,00 & 0,00 & 0,00 & 2,24 & 0,53 & areia fina \\
\hline P7 & 87,97 & 10,87 & 1,16 & 2,76 & 1,10 & areia fina \\
\hline P8 & 100,00 & 0,00 & 0,00 & 2,02 & 0,44 & areia fina \\
\hline P9 & 100,00 & 0,00 & 0,00 & 2,01 & 0,64 & areia fina \\
\hline P10 & 100,00 & 0,00 & 0,00 & 2,42 & 0,49 & areia fina \\
\hline P11 & 80,02 & 17,93 & 2,05 & 3,30 & 1,41 & areia muito fina \\
\hline P12 & 71,17 & 25,03 & 3,80 & 3,73 & 1,70 & areia muito fina \\
\hline P13 & 70,65 & 26,46 & 2,89 & 3,31 & 1,92 & areia muito fina \\
\hline P14 & 95,74 & 4,05 & 0,21 & 1,98 & 0,89 & areia media \\
\hline P15 & 57,12 & 37,96 & 4,92 & 3,90 & 2,09 & areia muito fina \\
\hline P16 & 82,56 & 13,02 & 4,43 & 3,21 & 1,71 & areia muito fina \\
\hline P17 & 73,38 & 22,98 & 3,65 & 3,75 & 1,61 & areia muito fina \\
\hline P18 & 96,79 & 3,21 & 0,00 & 2,86 & 0,61 & areia fina \\
\hline P19 & 84,17 & 11,41 & 4,41 & 3,20 & 1,20 & areia muito fina \\
\hline P20 & 94,83 & 4,72 & 0,45 & 2,56 & 1,10 & areia fina \\
\hline P21 & 94,73 & 5,08 & 0,19 & 1,96 & 1,10 & areia media \\
\hline P22 & 36,14 & 52,06 & 11,80 & 5,12 & 2,07 & silte médio \\
\hline P23 & 26,42 & 56,94 & 16,64 & 5,62 & 2,12 & silte médio \\
\hline P24 & 94,49 & 4,95 & 0,56 & 2,56 & 1,12 & areia fina \\
\hline P25 & 51,91 & 41,95 & 6,14 & 4,23 & 2,19 & silte grosso \\
\hline P26 & 71,91 & 25,52 & 2,57 & 3,31 & 1,85 & areia muito fina \\
\hline P27 & 95,13 & 4,50 & 0,37 & 2,16 & 1,37 & areia fina \\
\hline P28 & 66,42 & 30,46 & 3,12 & 3,51 & 1,98 & areia muito fina \\
\hline P29 & 25,50 & 61,43 & 13,06 & 5,49 & 1,96 & silte médio \\
\hline P30 & 31,57 & 56,55 & 11,88 & 5,18 & 2,02 & silte médio \\
\hline
\end{tabular}




\begin{tabular}{|c|c|c|c|c|c|c|}
\hline P31 & 100,00 & 0,00 & 0,00 & 2,64 & 0,49 & areia fina \\
\hline P32 & 54,30 & 38,80 & 6,89 & 4,18 & 2,08 & silte grosso \\
\hline P33 & 92,24 & 7,03 & 0,73 & 2,74 & 0,89 & areia fina \\
\hline P34 & 73,20 & 23,65 & 3,15 & 3,62 & 1,56 & areia muito fina \\
\hline P35 & 76,24 & 21,91 & 1,85 & 3,44 & 1,28 & areia muito fina \\
\hline P36 & 53,02 & 41,20 & 5,78 & 4,24 & 2,03 & silte grosso \\
\hline P37 & 62,69 & 33,51 & 3,80 & 3,63 & 2,03 & areia muito fina \\
\hline P38 & 92,60 & 6,61 & 0,79 & 2,59 & 0,96 & areia fina \\
\hline P39 & 62,54 & 33,48 & 3,98 & 3,80 & 1,92 & areia muito fina \\
\hline $\mathrm{P} 40$ & 87,36 & 10,98 & 1,66 & 2,60 & 1,36 & areia fina \\
\hline P41 & 57,53 & 37,62 & 4,85 & 3,81 & 2,20 & areia muito fina \\
\hline $\mathrm{P} 42$ & 39,23 & 50,88 & 9,89 & 4,83 & 2,34 & silte grosso \\
\hline P43 & 83,02 & 14,74 & 2,24 & 3,19 & 1,27 & areia muito fina \\
\hline P44 & 6,75 & 65,36 & 27,89 & 6,62 & 1,69 & silte fino \\
\hline $\mathrm{P} 45$ & 40,35 & 52,07 & 7,58 & 4,73 & 2,10 & silte grosso \\
\hline P46 & 27,35 & 60,72 & 11,92 & 5,36 & 1,95 & silte médio \\
\hline P47 & 98,35 & 1,65 & 0,00 & 2,08 & 0,95 & areia fina \\
\hline P48 & 95,04 & 4,05 & 0,91 & 2,30 & 0,73 & areia fina \\
\hline P49 & 96,72 & 2,76 & 0,52 & 2,46 & 0,51 & areia fina \\
\hline P50 & 53,02 & 41,20 & 5,78 & 4,24 & 2,03 & silte grosso \\
\hline P51 & 100,00 & 0,00 & 0,00 & 2,67 & 0,44 & areia fina \\
\hline P52 & 100,00 & 0,00 & 0,00 & 2,56 & 0,48 & areia fina \\
\hline P53 & 9,49 & 69,37 & 21,13 & 6,32 & 1,76 & silte fino \\
\hline P54 & 67,70 & 29,72 & 2,58 & 3,63 & 1,63 & areia muito fina \\
\hline P55 & 96,36 & 3,44 & 0,20 & 2,30 & 0,53 & areia fina \\
\hline P56 & 100,00 & 0,00 & 0,00 & 2,57 & 0,54 & areia fina \\
\hline P57 & 28,83 & 54,88 & 16,28 & 5,46 & 2,29 & silte médio \\
\hline P58 & 64,02 & 29,65 & 6,33 & 3,89 & 2,11 & areia muito fina \\
\hline P59 & 45,28 & 50,38 & 4,34 & 4,32 & 1,85 & silte grosso \\
\hline P60 & 24,14 & 63,14 & 12,71 & 5,48 & 1,96 & silte médio \\
\hline P61 & 87,96 & 10,45 & 1,59 & 2,77 & 1,31 & areia fina \\
\hline P62 & 81,84 & 16,71 & 1,45 & 3,22 & 1,23 & areia muito fina \\
\hline P63 & 56,04 & 38,40 & 5,55 & 3,88 & 2,30 & areia muito fina \\
\hline P64 & 92,28 & 6,27 & 1,44 & 2,49 & 0,94 & areia fina \\
\hline
\end{tabular}


Tabela 3. Percentual de COT das amostras de sedimento superficial coletadas ao longo do Sistema Cananéia-Iguape

\begin{tabular}{|c|c|}
\hline Amostras & COT (\%) \\
\hline $\mathrm{P} 1$ & 1,55 \\
\hline P2 & 0,53 \\
\hline P3 & 0,43 \\
\hline P4 & 0,50 \\
\hline P5 & 1,10 \\
\hline P6 & 0,72 \\
\hline P7 & 0,96 \\
\hline P8 & 0,93 \\
\hline P9 & 0,41 \\
\hline P10 & 0,61 \\
\hline P11 & 2,18 \\
\hline P12 & 1,02 \\
\hline P13 & 2,09 \\
\hline P14 & 1,01 \\
\hline P15 & 2,62 \\
\hline P16 & 0,79 \\
\hline P17 & 1,19 \\
\hline P18 & 0,91 \\
\hline P19 & 1,47 \\
\hline P20 & 0,83 \\
\hline P21 & 1,05 \\
\hline P22 & 0,81 \\
\hline P23 & 2,42 \\
\hline P24 & 2,31 \\
\hline P25 & 1,11 \\
\hline P26 & 1,55 \\
\hline P27 & 1,40 \\
\hline P28 & 2,71 \\
\hline P29 & 1,85 \\
\hline P30 & 1,49 \\
\hline P31 & 1,28 \\
\hline
\end{tabular}


Continuação da Tabela 3

\begin{tabular}{|c|c|}
\hline P32 & 0,85 \\
\hline P33 & 0,85 \\
\hline P34 & 1,23 \\
\hline P35 & 1,87 \\
\hline P36 & 3,16 \\
\hline P37 & 1,05 \\
\hline P38 & 0,55 \\
\hline P39 & 0,99 \\
\hline P40 & 1,58 \\
\hline P41 & 1,30 \\
\hline P42 & 1,33 \\
\hline P43 & 1,39 \\
\hline P44 & 1,68 \\
\hline P45 & 1,87 \\
\hline P46 & 3,40 \\
\hline P47 & 1,07 \\
\hline P48 & 0,34 \\
\hline P49 & 0,92 \\
\hline P50 & 1,20 \\
\hline P51 & 0,26 \\
\hline P52 & 0,45 \\
\hline P53 & 0,59 \\
\hline P54 & 1,24 \\
\hline P55 & 0,96 \\
\hline P56 & 0,31 \\
\hline P57 & 0,98 \\
\hline P58 & 1,19 \\
\hline P59 & 1,75 \\
\hline P60 & 2,06 \\
\hline P61 & 1,13 \\
\hline P62 & 1,55 \\
\hline P63 & 2,72 \\
\hline P64 & 0,34 \\
\hline
\end{tabular}


Tabela 4. Teor parcial de $\mathrm{Cu}, \mathrm{Pb}$ e $\mathrm{Zn}\left(\mathrm{mg} \mathrm{kg}^{-1}\right)$ das amostras de sedimento superficial coletadas ao longo do Sistema Cananéia-Iguape (método ISO 11466)

\begin{tabular}{|c|c|c|c|}
\hline Amostras & $\mathrm{Cu}\left(\mathrm{mg} \mathrm{kg}^{-1}\right)$ & $\mathrm{Pb}\left(\mathrm{mg} \mathrm{kg}^{-1}\right)$ & $\mathrm{Zn}\left(\mathrm{mg} \mathrm{kg}^{-1}\right)$ \\
\hline $\mathrm{P} 1$ & 34,8754 & 213,0340 & 128,8950 \\
\hline P2 & 35,9732 & 101,7670 & 127,4310 \\
\hline P3 & 1,8787 & 4,3777 & 12,0634 \\
\hline P4 & $<L Q$ & 3,3312 & 10,8428 \\
\hline P5 & 17,9628 & 20,3814 & 51,7571 \\
\hline P6 & 0,9966 & 3,2829 & 12,0025 \\
\hline P7 & 11,2238 & 19,8159 & 45,2346 \\
\hline P8 & 0,9415 & 2,7838 & 9,1901 \\
\hline P9 & 1,2209 & 3,2495 & 10,2753 \\
\hline P10 & 1,3706 & 4,0924 & 13,5339 \\
\hline P11 & 7,7323 & 15,6519 & 30,7866 \\
\hline P12 & 7,2321 & 15,5972 & 30,3389 \\
\hline P13 & 25,0322 & 31,2490 & 68,9653 \\
\hline P14 & 5,4313 & 10,5117 & 21,1327 \\
\hline P15 & 12,5915 & 21,5096 & 45,1445 \\
\hline P16 & 10,4051 & 19,6718 & 42,9476 \\
\hline P17 & 8,2995 & 16,0851 & 40,3771 \\
\hline P18 & 3,0671 & 8,6185 & 20,6830 \\
\hline P19 & 8,0380 & 13,1225 & 31,2212 \\
\hline P20 & 4,5683 & 9,6051 & 22,9523 \\
\hline P21 & 10,2369 & 23,9090 & 36,1896 \\
\hline P22 & 10,5500 & 15,8053 & 35,4879 \\
\hline P23 & 24,4572 & 37,5670 & 86,2182 \\
\hline P24 & 26,1371 & 37,4802 & 86,8452 \\
\hline P25 & 19,4656 & 29,7433 & 62,0317 \\
\hline P26 & 15,5333 & 22,7932 & 59,7165 \\
\hline P27 & 8,1868 & 20,4993 & 45,8322 \\
\hline P28 & 25,9347 & 41,3661 & 81,5512 \\
\hline P29 & 35,4818 & 37,1991 & 84,8418 \\
\hline P30 & 28,1774 & 43,8560 & 90,1825 \\
\hline
\end{tabular}




\section{Continuação da Tabela 4}

\begin{tabular}{|c|c|c|c|}
\hline P31 & 8,9140 & 15,8782 & 31,6283 \\
\hline P32 & 8,3691 & 20,6548 & 34,6551 \\
\hline P33 & 4,5328 & 10,5164 & 29,6777 \\
\hline P34 & 24,4667 & 35,7287 & 73,6046 \\
\hline P35 & 14,9771 & 22,8819 & 54,6598 \\
\hline P36 & 20,1357 & 35,1847 & 66,7954 \\
\hline P37 & 14,1583 & 22,6540 & 53,9816 \\
\hline P38 & 4,6836 & 9,4282 & 22,1017 \\
\hline P39 & 16,8190 & 30,7235 & 62,1537 \\
\hline $\mathrm{P} 40$ & 33,9804 & 49,2530 & 97,4650 \\
\hline P41 & 17,9628 & 37,3124 & 72,3327 \\
\hline P42 & 34,0870 & 54,2572 & 118,2660 \\
\hline P43 & 17,5799 & 30,7091 & 63,1612 \\
\hline P44 & 32,3614 & 48,3356 & 116,5210 \\
\hline P45 & 33,3210 & 61,6047 & 113,3850 \\
\hline P46 & 28,1568 & 70,4776 & 103,1230 \\
\hline P47 & 3,8259 & 13,6201 & 20,7742 \\
\hline $\mathrm{P} 48$ & 2,6568 & 9,2046 & 32,0755 \\
\hline P49 & 1,9487 & 6,4092 & 20,1901 \\
\hline P50 & 1,9592 & 6,6375 & 18,7457 \\
\hline P51 & 2,0893 & 7,1107 & 27,6464 \\
\hline P52 & 2,7467 & 5,0593 & 16,3816 \\
\hline P53 & 2,5891 & 5,3197 & 16,6376 \\
\hline P54 & 2,7467 & 5,6306 & 21,1558 \\
\hline P55 & 1,0845 & 2,8590 & 7,7874 \\
\hline P56 & 0,9472 & 3,2954 & 11,2111 \\
\hline P57 & 18,4409 & 34,5760 & 72,4555 \\
\hline P58 & 13,2157 & 25,0980 & 56,7802 \\
\hline P59 & 11,6430 & 23,2038 & 52,0147 \\
\hline P60 & 9,9705 & 20,4710 & 50,4225 \\
\hline P61 & 1,2489 & 3,6961 & 14,8076 \\
\hline P62 & 4,0555 & 9,5930 & 25,8468 \\
\hline P63 & 13,4584 & 17,3241 & 41,2549 \\
\hline P64 & 1,2191 & 3,3913 & 9,3798 \\
\hline
\end{tabular}

LQ = Limite de Quantificação 
Tabela 5. Teor parcial de $\mathrm{Cu}, \mathrm{Pb}$ e $\mathrm{Zn}\left(\mathrm{mg} \mathrm{kg}^{-1}\right)$ das amostras de sedimento superficial coletadas ao longo do Sistema Cananéia-Iguape (método US EPA 3050B)

\begin{tabular}{|c|c|c|c|}
\hline Amostras & $\mathrm{Cu}\left(\mathrm{mg} \mathrm{kg}{ }^{-1}\right)$ & $\mathrm{Pb}\left(\mathrm{mg} \mathrm{kg}^{-1}\right)$ & $\mathrm{Zn}\left(\mathrm{mg} \mathrm{kg}^{-1}\right)$ \\
\hline $\mathrm{P} 1$ & 29,1396 & 116,7090 & 86,3556 \\
\hline P2 & 31,9066 & 59,0795 & 87,1211 \\
\hline P3 & 2,0896 & 4,9488 & 12,6155 \\
\hline P4 & 0,7759 & 2,4266 & 6,1856 \\
\hline P5 & 14,8331 & 15,4522 & 40,5832 \\
\hline P6 & 1,3262 & 2,8972 & 8,1524 \\
\hline P7 & 8,6398 & 14,0951 & 32,5041 \\
\hline P8 & 1,3697 & 2,8059 & 8,1597 \\
\hline P9 & 0,9521 & 2,4464 & 7,0954 \\
\hline P10 & 1,9471 & 3,5150 & 10,4528 \\
\hline P11 & 7,7533 & 14,5201 & 27,9614 \\
\hline P12 & 6,7549 & 12,2751 & 26,2474 \\
\hline P13 & 24,5531 & 25,8380 & 60,2945 \\
\hline P14 & 5,0828 & 9,0486 & 17,2550 \\
\hline P15 & 8,9621 & 13,6633 & 33,4687 \\
\hline P16 & 10,4424 & 16,4859 & 36,2924 \\
\hline P17 & 12,3354 & 15,3166 & 36,2485 \\
\hline P18 & 3,9279 & 7,4379 & 20,2294 \\
\hline P19 & 9,2095 & 11,9077 & 29,9639 \\
\hline P20 & 21,9101 & 30,9026 & 67,4070 \\
\hline P21 & 7,7264 & 17,7061 & 25,6944 \\
\hline P22 & 16,0141 & 18,7775 & 44,8214 \\
\hline P23 & 25,3074 & 30,2256 & 76,8973 \\
\hline P24 & 21,2413 & 27,9072 & 67,5859 \\
\hline P25 & 11,6650 & 18,3285 & 35,6711 \\
\hline P26 & 13,7607 & 17,9351 & 44,9488 \\
\hline P27 & 5,9555 & 14,2733 & 23,2776 \\
\hline P28 & 19,9382 & 28,6898 & 59,2919 \\
\hline P29 & 23,3941 & 24,7323 & 62,5764 \\
\hline P30 & 23,0098 & 31,6392 & 71,7471 \\
\hline
\end{tabular}




\section{Continuação da Tabela 5}

\begin{tabular}{|c|c|c|c|}
\hline P31 & 7,5156 & 11,3108 & 24,2731 \\
\hline P32 & 12,6997 & 22,6851 & 41,4736 \\
\hline P33 & 4,0863 & 8,1992 & 24,9759 \\
\hline P34 & 15,4309 & 19,7358 & 47,7966 \\
\hline P35 & 13,9815 & 19,1343 & 45,7242 \\
\hline P36 & 14,0595 & 19,9175 & 42,2064 \\
\hline P37 & 15,8048 & 19,7564 & 52,6225 \\
\hline P38 & 5,3112 & 8,4176 & 19,2860 \\
\hline P39 & 16,6624 & 23,2908 & 53,3995 \\
\hline $\mathrm{P} 40$ & 21,2310 & 25,3542 & 57,0651 \\
\hline P41 & 20,2499 & 33,5441 & 67,2631 \\
\hline P42 & 18,7615 & 35,0414 & 65,3381 \\
\hline P43 & 21,8979 & 30,2941 & 72,8996 \\
\hline P44 & 30,5621 & 33,8228 & 75,3727 \\
\hline P45 & 26,5594 & 38,4781 & 76,2752 \\
\hline P46 & 21,9283 & 44,7475 & 68,7733 \\
\hline P47 & 2,8288 & 10,7837 & 14,3900 \\
\hline P48 & 2,9149 & 8,3153 & 13,2208 \\
\hline P49 & 1,9985 & 5,7280 & 7,6068 \\
\hline P50 & 1,6971 & 4,4732 & 7,0897 \\
\hline P51 & 1,1980 & 5,4714 & 8,2872 \\
\hline P52 & 1,0488 & 2,8824 & 5,0817 \\
\hline P53 & 2,2487 & 3,5247 & 9,8560 \\
\hline P54 & 6,6957 & 8,6357 & 31,6397 \\
\hline P55 & 1,3095 & 2,7416 & 5,6065 \\
\hline P56 & 0,9419 & 2,7070 & 6,3828 \\
\hline P57 & 22,8153 & 28,2887 & 70,9852 \\
\hline P58 & 10,1516 & 15,0021 & 35,2987 \\
\hline P59 & 6,3724 & 9,3916 & 24,2966 \\
\hline P60 & 5,5430 & 10,2989 & 23,2863 \\
\hline P61 & 6,6721 & 10,7471 & 24,9455 \\
\hline P62 & 4,5108 & 7,8462 & 21,8633 \\
\hline P63 & 6,4837 & 8,9449 & 33,0572 \\
\hline P64 & 1,2496 & 2,6016 & 7,3397 \\
\hline
\end{tabular}

LQ = Limite de Quantificação 
Tabela 6. Teor de $\mathrm{Cu}\left(\mathrm{mg} \mathrm{kg}^{-1}\right)$ nas frações móveis ou disponíveis das amostras de sedimento superficial coletadas ao longo do Sistema Cananéia-Iguape

\begin{tabular}{|c|c|c|c|c|}
\hline Amostras & F1 & F2 & F3 & $\Sigma$ F1 a F3 \\
\hline P1 & 3,9493 & 7,0645 & 9,5670 & 20,5808 \\
\hline P2 & 4,1061 & 7,1724 & 4,7655 & 16,0440 \\
\hline P3 & $<L Q$ & $<L Q$ & $<L Q$ & $<L Q$ \\
\hline P4 & $<L Q$ & $<\mathrm{LQ}$ & $<\mathrm{LQ}$ & $<L Q$ \\
\hline P5 & 1,3575 & 3,0398 & 1,9592 & 6,3565 \\
\hline P6 & $<L Q$ & $<L Q$ & $<L Q$ & $<L Q$ \\
\hline P7 & 1,7083 & 1,0580 & 1,3357 & 4,1020 \\
\hline P8 & $<\mathrm{LQ}$ & $<\mathrm{LQ}$ & $<\mathrm{LQ}$ & $<L Q$ \\
\hline P9 & $<L Q$ & $<L Q$ & $<\mathrm{LQ}$ & $<L Q$ \\
\hline P10 & $<\mathrm{LQ}$ & $<L Q$ & $<L Q$ & $<L Q$ \\
\hline $\mathrm{P} 11$ & 1,0185 & 1,6656 & 1,1613 & 3,8454 \\
\hline P12 & 0,8523 & 1,6162 & $<L Q$ & 2,4685 \\
\hline P13 & 1,9214 & 3,8651 & 2,8469 & 8,6334 \\
\hline P14 & 0,7963 & 0,9345 & 0,9512 & 2,6820 \\
\hline P15 & $<L Q$ & 1,6086 & 3,9379 & 5,5465 \\
\hline P16 & $<\mathrm{LQ}$ & 1,5031 & 2,4460 & 3,9491 \\
\hline P17 & 1,1026 & 1,7086 & 1,4727 & 4,2839 \\
\hline P18 & $<L Q$ & $<L Q$ & $<L Q$ & $<L Q$ \\
\hline P19 & 0,8524 & 1,6432 & 1,4118 & 3,9074 \\
\hline P20 & $<\mathrm{LQ}$ & 0,9502 & 1,3331 & 2,2833 \\
\hline P21 & 1,0651 & 1,8143 & 1,8888 & 4,7682 \\
\hline P22 & 2,0005 & 2,5843 & 2,3343 & 6,9191 \\
\hline P23 & 1,4510 & 3,1717 & 7,4179 & 12,0406 \\
\hline P24 & 1,8522 & 3,2319 & 5,4193 & 10,5034 \\
\hline P25 & 2,0788 & 3,2382 & 4,3839 & 9,7009 \\
\hline P26 & 1,8966 & 2,6188 & 4,5653 & 9,0807 \\
\hline P27 & 1,2477 & 1,1338 & 1,4894 & 3,8709 \\
\hline P28 & 1,6896 & 3,6255 & 6,2493 & 11,5644 \\
\hline P29 & 2,1116 & 3,7822 & 4,1558 & 10,0496 \\
\hline P30 & 2,3377 & 4,1683 & 5,1499 & 11,6559 \\
\hline P31 & 1,3982 & 1,6155 & 2,3789 & 5,3926 \\
\hline P32 & 0,9102 & 2,7818 & 3,4159 & 7,1079 \\
\hline
\end{tabular}


Continuação da Tabela 6

\begin{tabular}{|c|c|c|c|c|}
\hline P33 & $<L Q$ & 1,0063 & 1,0853 & 2,0916 \\
\hline P34 & 1,5716 & 3,0009 & 3,5018 & 8,0743 \\
\hline P35 & 1,5367 & 2,6066 & 3,1023 & 7,2456 \\
\hline P36 & 2,2643 & 3,1375 & 4,2493 & 9,6511 \\
\hline P37 & 1,5169 & 1,9391 & 1,6136 & 5,0696 \\
\hline P38 & 1,2244 & 1,2905 & 1,8087 & 4,3236 \\
\hline P39 & 1,4881 & 2,7413 & 2,5882 & 6,8176 \\
\hline $\mathrm{P} 40$ & 1,7518 & 4,0349 & 8,7962 & 14,5829 \\
\hline P41 & 1,9036 & 8,1480 & 11,1923 & 21,2439 \\
\hline P42 & 2,1241 & 6,7986 & 10,4749 & 19,3976 \\
\hline P43 & 2,0288 & 6,5469 & 12,3827 & 20,9584 \\
\hline P44 & 1,7707 & 7,3740 & 14,7306 & 23,8753 \\
\hline $\mathrm{P} 45$ & 1,5763 & 7,3296 & 15,4224 & 24,3283 \\
\hline P46 & 1,0287 & 5,2106 & 15,8578 & 22,0971 \\
\hline P47 & $<L Q$ & 1,5549 & 2,0264 & 3,5813 \\
\hline P48 & $<L Q$ & 0,9247 & 1,3986 & 2,3233 \\
\hline P49 & $<L Q$ & $<L Q$ & 1,1034 & 1,1034 \\
\hline P50 & $<\mathrm{LQ}$ & 0,7738 & 1,1062 & 1,8800 \\
\hline P51 & $<\mathrm{LQ}$ & 0,7546 & 0,8674 & 1,6220 \\
\hline P52 & $<L Q$ & 1,9378 & 0,7899 & 2,7277 \\
\hline P53 & $<L Q$ & $<L Q$ & $<L Q$ & $<L Q$ \\
\hline P54 & $<L Q$ & $<\mathrm{LQ}$ & 2,1501 & 2,1501 \\
\hline P55 & $<L Q$ & $<\mathrm{LQ}$ & $<L Q$ & $<\mathrm{LQ}$ \\
\hline P56 & $<L Q$ & $<L Q$ & $<L Q$ & $<L Q$ \\
\hline P57 & $<L Q$ & 1,1835 & 4,0246 & 5,2081 \\
\hline P58 & $<L Q$ & 1,3125 & 2,4574 & 3,7699 \\
\hline P59 & $<\mathrm{LQ}$ & 1,0668 & 2,2222 & 3,2890 \\
\hline P60 & $<L Q$ & 1,0589 & 2,0329 & 3,0918 \\
\hline P61 & $<L Q$ & $<L Q$ & 3,5097 & 3,5097 \\
\hline P62 & $<\mathrm{LQ}$ & $<\mathrm{LQ}$ & 1,0880 & 1,0880 \\
\hline P63 & $<L Q$ & 0,7373 & 2,3699 & 3,1072 \\
\hline P64 & $<L Q$ & $<L Q$ & $<L Q$ & $<\mathrm{LQ}$ \\
\hline
\end{tabular}

LQ = Limite de Quantificação 
Tabela 7. Teor de $\mathrm{Pb}\left(\mathrm{mg} \mathrm{kg}^{-1}\right)$ nas frações móveis ou disponíveis das amostras de sedimento superficial coletadas ao longo do Sistema Cananéia-Iguape

\begin{tabular}{|c|c|c|c|c|}
\hline Amostras & F1 & F2 & F3 & $\Sigma$ F1 a F3 \\
\hline P1 & 9,0024 & 165,5140 & 17,0592 & 191,5756 \\
\hline $\mathrm{P} 2$ & 6,5980 & 74,4371 & 7,8414 & 88,8765 \\
\hline P3 & $<L Q$ & 3,7508 & $<L Q$ & 3,7508 \\
\hline P4 & $<L Q$ & $<\mathrm{LQ}$ & $<L Q$ & $<\mathrm{LQ}$ \\
\hline P5 & $<\mathrm{LQ}$ & 18,2657 & 2,5516 & 20,8173 \\
\hline P6 & $<L Q$ & $<L Q$ & $<L Q$ & $<\mathrm{LQ}$ \\
\hline P7 & $<\mathrm{LQ}$ & 10,8940 & $<L Q$ & 10,8940 \\
\hline P8 & $<L Q$ & 2,1959 & $<L Q$ & 2,1959 \\
\hline P9 & $<\mathrm{LQ}$ & 2,0774 & $<L Q$ & 2,0774 \\
\hline P10 & $<\mathrm{LQ}$ & 2,6330 & $<\mathrm{LQ}$ & 2,6330 \\
\hline $\mathrm{P} 11$ & $<L Q$ & 16,0143 & 2,3773 & 18,3916 \\
\hline P12 & $<L Q$ & 13,2350 & $<L Q$ & 13,2350 \\
\hline P13 & $<\mathrm{LQ}$ & 29,9396 & 3,9781 & 33,9177 \\
\hline P14 & $<\mathrm{LQ}$ & 7,5379 & 2,0397 & 9,5776 \\
\hline P15 & 2,3302 & 17,8523 & 4,9211 & 25,1036 \\
\hline P16 & $<L Q$ & 14,3162 & 3,8746 & 18,1908 \\
\hline P17 & 3,0373 & 13,7153 & $<\mathrm{LQ}$ & 16,7526 \\
\hline P18 & $<L Q$ & 5,9105 & $<L Q$ & 5,9105 \\
\hline P19 & $<L Q$ & 11,6281 & 2,0636 & 13,6917 \\
\hline P20 & $<\mathrm{LQ}$ & 8,4468 & 2,1530 & 10,5998 \\
\hline P21 & 3,0290 & 19,4185 & 2,7226 & 25,1701 \\
\hline P22 & $<L Q$ & 17,3059 & 2,8471 & 20,1530 \\
\hline P23 & 8,9486 & 33,7901 & 6,9997 & 49,7384 \\
\hline P24 & 5,4608 & 34,0004 & 4,5881 & 44,0493 \\
\hline P25 & 3,5340 & 28,6222 & 5,1720 & 37,3282 \\
\hline P26 & 5,8140 & 22,8253 & 4,6167 & 33,2560 \\
\hline P27 & 3,1295 & 15,2229 & 2,2559 & 20,6083 \\
\hline P28 & $<L Q$ & 38,5037 & 6,2504 & 44,7541 \\
\hline P29 & 7,1548 & 30,0871 & 3,9480 & 41,1899 \\
\hline P30 & 8,2121 & 42,6453 & 5,4969 & 56,3543 \\
\hline P31 & 3,5526 & 12,5801 & 2,1514 & 18,2841 \\
\hline P32 & 5,0225 & 20,7453 & 3,5810 & 29,3488 \\
\hline
\end{tabular}




\section{Continuação da Tabela 7}

\begin{tabular}{|c|c|c|c|c|}
\hline P33 & $<L Q$ & 10,2996 & 2,2505 & 12,5501 \\
\hline P34 & 6,2411 & 29,3275 & 4,5898 & 40,1584 \\
\hline P35 & 5,2434 & 19,9427 & 2,8910 & 28,0771 \\
\hline P36 & $<\mathrm{LQ}$ & 30,6637 & 4,3677 & 35,0314 \\
\hline P37 & 4,1311 & 18,2401 & 2,0736 & 24,4447 \\
\hline P38 & $<L Q$ & 10,1775 & $<L Q$ & 10,1775 \\
\hline P39 & $<\mathrm{LQ}$ & 29,1168 & 3,8121 & 32,9289 \\
\hline P40 & $<L Q$ & 40,9912 & 8,4329 & 49,4241 \\
\hline $\mathrm{P} 41$ & 3,0228 & 41,0752 & 7,6699 & 51,7679 \\
\hline P42 & 4,7043 & 47,3139 & 7,1383 & 59,1565 \\
\hline P43 & 4,0058 & 42,3461 & 7,6326 & 53,9845 \\
\hline P44 & $<\mathrm{LQ}$ & 44,7765 & 10,2280 & 55,0045 \\
\hline P45 & $<L Q$ & 52,5138 & 12,6843 & 65,1981 \\
\hline P46 & 3,3762 & 65,9821 & 12,8259 & 82,1842 \\
\hline $\mathrm{P} 47$ & $<\mathrm{LQ}$ & 14,9991 & 3,2186 & 18,2177 \\
\hline P48 & $<L Q$ & 7,8102 & 2,5215 & 10,3317 \\
\hline P49 & $<\mathrm{LQ}$ & 5,2373 & $<L Q$ & 5,2373 \\
\hline P50 & $<L Q$ & 5,4685 & $<L Q$ & 5,4685 \\
\hline P51 & $<\mathrm{LQ}$ & 7,5167 & $<\mathrm{LQ}$ & 7,5167 \\
\hline P52 & $<L Q$ & 4,1203 & $<L Q$ & 4,1203 \\
\hline P53 & $<\mathrm{LQ}$ & 4,0392 & $<L Q$ & 4,0392 \\
\hline P54 & $<\mathrm{LQ}$ & 2,8279 & $<L Q$ & 2,8279 \\
\hline P55 & $<\mathrm{LQ}$ & 2,9896 & $<L Q$ & 2,9896 \\
\hline P56 & $<L Q$ & 2,3210 & $<L Q$ & 2,3210 \\
\hline P57 & 2,3827 & 28,8111 & 5,7926 & 36,9864 \\
\hline P58 & 2,5664 & 23,4834 & 3,6949 & 29,7447 \\
\hline P59 & $<\mathrm{LQ}$ & 18,2892 & 3,4142 & 21,7034 \\
\hline P60 & 2,8653 & 18,7150 & 3,0664 & 24,6467 \\
\hline P61 & $<\mathrm{LQ}$ & 4,9373 & $<L Q$ & 4,9373 \\
\hline P62 & $<\mathrm{LQ}$ & 3,9388 & $<L Q$ & 3,9388 \\
\hline P63 & $<L Q$ & 11,2237 & 2,1649 & 13,3886 \\
\hline P64 & $<L Q$ & 2,6606 & $<L Q$ & 2,6606 \\
\hline
\end{tabular}

\section{LQ = Limite de Quantificação}


Tabela 8. Teor de $\mathrm{Zn}\left(\mathrm{mg} \mathrm{kg}^{-1}\right)$ nas frações móveis ou disponíveis das amostras de sedimento superficial coletadas ao longo do Sistema Cananéia-Iguape

\begin{tabular}{|c|c|c|c|c|}
\hline Amostras & F1 & F2 & F3 & $\Sigma$ F1 a F3 \\
\hline $\mathrm{P} 1$ & 28,6657 & 32,8054 & 22,0505 & 83,5216 \\
\hline P2 & 30,8156 & 24,1227 & 18,8946 & 73,8329 \\
\hline P3 & 2,0647 & 1,8417 & 4,3501 & 8,2565 \\
\hline $\mathrm{P} 4$ & $<L Q$ & 1,4894 & 2,9959 & 4,4853 \\
\hline P5 & 10,5773 & 9,6196 & 8,0482 & 28,2451 \\
\hline $\mathrm{P} 6$ & 3,3646 & 1,5693 & 3,2801 & 8,2140 \\
\hline P7 & 9,4021 & 4,4107 & 6,1937 & 20,0065 \\
\hline P8 & $<L Q$ & $<L Q$ & 2,2053 & 2,2053 \\
\hline P9 & $<L Q$ & $<L Q$ & 2,7479 & 2,7479 \\
\hline P10 & 2,0545 & 1,9001 & 2,9580 & 6,9126 \\
\hline $\mathrm{P} 11$ & 9,1831 & 6,9069 & 5,3599 & 21,4499 \\
\hline P12 & 4,8085 & 6,3512 & 3,9589 & 15,1186 \\
\hline P13 & 16,7393 & 13,3451 & 8,4780 & 38,5624 \\
\hline P14 & 3,4811 & 3,0233 & 5,8938 & 12,3982 \\
\hline P15 & 7,8814 & 11,7015 & 9,9152 & 29,4981 \\
\hline P16 & 10,3216 & 6,3651 & 8,1755 & 24,8622 \\
\hline P17 & 8,8161 & 6,4284 & 6,8711 & 22,1156 \\
\hline P18 & 6,9968 & 3,7317 & 4,8408 & 15,5693 \\
\hline P19 & 6,4468 & 6,0701 & 7,0931 & 19,6100 \\
\hline P20 & 6,9688 & 4,5415 & 7,4094 & 18,9197 \\
\hline P21 & 9,9686 & 6,4940 & 6,5915 & 23,0540 \\
\hline P22 & 10,6438 & 9,2837 & 8,4246 & 28,3521 \\
\hline P23 & 20,3528 & 19,0681 & 17,4941 & 56,9150 \\
\hline P24 & 18,9784 & 18,4157 & 12,6222 & 50,0163 \\
\hline P25 & 15,7732 & 13,9219 & 12,7007 & 42,3958 \\
\hline P26 & 12,8499 & 12,4543 & 19,2490 & 44,5532 \\
\hline P27 & 7,1045 & 6,3474 & 6,7709 & 20,2228 \\
\hline P28 & 14,8877 & 23,6023 & 13,1651 & 51,6551 \\
\hline P29 & 14,4125 & 18,9477 & 10,2594 & 43,6196 \\
\hline P30 & 21,1261 & 23,9852 & 12,0792 & 57,1905 \\
\hline P31 & 8,2829 & 6,2361 & 7,6449 & 22,1639 \\
\hline P32 & 11,4704 & 10,0052 & 8,2857 & 29,7613 \\
\hline P33 & 4,8026 & 12,9678 & 7,0376 & 24,8080 \\
\hline
\end{tabular}


Continuação da Tabela 8

\begin{tabular}{|c|c|c|c|c|}
\hline P34 & 14,5044 & 16,0866 & 9,1692 & 39,7602 \\
\hline P35 & 11,2594 & 14,2844 & 8,5433 & 34,0871 \\
\hline P36 & 13,1992 & 18,2727 & 10,0690 & 41,5409 \\
\hline P37 & 9,4593 & 12,7819 & 7,4687 & 29,7099 \\
\hline P38 & 6,4338 & 5,7295 & 7,1911 & 19,3544 \\
\hline P39 & 12,1326 & 17,9365 & 15,1385 & 45,2076 \\
\hline $\mathrm{P} 40$ & 15,9415 & 26,4107 & 15,2447 & 57,5969 \\
\hline P41 & 15,5319 & 19,8673 & 22,6535 & 58,0527 \\
\hline P42 & 16,3038 & 22,0375 & 22,5019 & 60,8432 \\
\hline P43 & 16,9597 & 19,7699 & 23,8345 & 60,5641 \\
\hline P44 & 13,0584 & 22,7864 & 25,2196 & 61,0644 \\
\hline P45 & 15,0497 & 23,6097 & 27,0057 & 65,6651 \\
\hline P46 & 14,9238 & 28,7200 & 22,5095 & 66,1533 \\
\hline P47 & 3,6416 & 6,8940 & 8,9534 & 19,4890 \\
\hline P48 & 3,2907 & 4,2024 & 6,7446 & 14,2377 \\
\hline P49 & 1,7142 & 2,2689 & 7,8955 & 11,8786 \\
\hline P50 & 1,8040 & 2,1826 & 5,1952 & 9,1818 \\
\hline P51 & 2,6134 & 2,3076 & 6,4913 & 11,4123 \\
\hline P52 & $<L Q$ & 1,7427 & 3,7370 & 5,4797 \\
\hline P53 & 2,1769 & 2,0788 & 3,5504 & 7,8061 \\
\hline P54 & 2,1879 & 5,2173 & 5,3481 & 12,7533 \\
\hline P55 & $<\mathrm{LQ}$ & $<L Q$ & 2,9739 & 2,9739 \\
\hline P56 & $<L Q$ & $<L Q$ & 2,3783 & 2,3783 \\
\hline P57 & 8,5274 & 18,8227 & 11,6881 & 39,0382 \\
\hline P58 & 5,8635 & 15,1979 & 9,2842 & 30,3456 \\
\hline P59 & 5,4967 & 12,6453 & 8,6975 & 26,8395 \\
\hline P60 & 5,5169 & 13,2992 & 8,6973 & 27,5134 \\
\hline P61 & 1,9556 & 3,0400 & 4,5335 & 9,5291 \\
\hline P62 & 2,3787 & 5,8797 & 4,4741 & 12,7324 \\
\hline P63 & 2,1981 & 12,1067 & 9,7803 & 24,0851 \\
\hline P64 & $<\mathrm{LQ}$ & 1,9668 & 2,7206 & 4,6874 \\
\hline
\end{tabular}

\section{LQ = Limite de Quantificação}


Tabela 9. Teor de $\mathrm{Cu}\left(\mathrm{mg} \mathrm{kg}^{-1}\right)$ nas frações móveis ou disponíveis das amostras dos testemunhos coletados ao longo do Sistema Cananéia-Iguape

\begin{tabular}{|c|c|c|c|c|}
\hline CAN $02(\mathrm{~cm})$ & F1 & F2 & F3 & $\Sigma$ F1 a F3 \\
\hline $0-2$ & 0,8019 & 6,8256 & 1,0857 & 8,7131 \\
\hline $10-12$ & 1,2344 & 10,3402 & 1,4764 & 13,0510 \\
\hline $20-22$ & 1,2017 & 7,4437 & 1,0567 & 9,7022 \\
\hline $30-32$ & 1,2465 & 5,7780 & 1,2561 & 8,2806 \\
\hline $38-40$ & 1,3460 & 7,3538 & 1,8983 & 10,5981 \\
\hline $50-52$ & 0,7777 & 5,2626 & 0,9985 & 7,0387 \\
\hline CAN $04(\mathrm{~cm})$ & F1 & F2 & F3 & $\Sigma$ F1 a F3 \\
\hline $0-1$ & 0,9858 & 5,5830 & 1,0386 & 7,6074 \\
\hline $10-11$ & 1,2895 & 6,8144 & 1,6366 & 9,7405 \\
\hline $20-21$ & 1,3362 & 3,6764 & 0,6909 & 5,7034 \\
\hline $30-31$ & 1,4450 & 4,3897 & 1,2689 & 7,1036 \\
\hline $39-40$ & 2,4466 & 11,6090 & 1,9412 & 15,9968 \\
\hline $51-52$ & 0,7575 & 4,7088 & 1,1032 & 6,5695 \\
\hline CAN $05(\mathrm{~cm})$ & F1 & F2 & F3 & $\Sigma$ F1 a F3 \\
\hline $2-4$ & 0,8306 & 11,4830 & 1,8878 & 14,2014 \\
\hline $8-10$ & 1,1567 & 11,3934 & 2,6859 & 15,2360 \\
\hline $22-24$ & 1,1553 & 6,7364 & 10,8495 & 18,7412 \\
\hline $26-28$ & 1,0445 & 5,4072 & 9,0621 & 15,5138 \\
\hline $38-40$ & 1,0006 & 4,1332 & 8,6639 & 13,7977 \\
\hline $48-50$ & 1,2325 & 4,3912 & 8,8108 & 14,4345 \\
\hline CAN $07(\mathrm{~cm})$ & F1 & F2 & F3 & $\Sigma$ F1 a F3 \\
\hline $0-2$ & 0,7122 & 5,3841 & 1,0400 & 7,1363 \\
\hline $10-12$ & $<\mathrm{LQ}$ & 3,3574 & 0,9474 & 4,3048 \\
\hline $20-22$ & $<\mathrm{LQ}$ & $<\mathrm{LQ}$ & $<\mathrm{LQ}$ & $<\mathrm{LQ}$ \\
\hline $30-32$ & $<\mathrm{LQ}$ & $<\mathrm{LQ}$ & $<\mathrm{LQ}$ & $<\mathrm{LQ}$ \\
\hline $38-40$ & $<\mathrm{LQ}$ & $<\mathrm{LQ}$ & $<\mathrm{LQ}$ & $<\mathrm{LQ}$ \\
\hline $50-52$ & $<\mathrm{LQ}$ & $<\mathrm{LQ}$ & 0,7258 & 0,7258 \\
\hline CAN $10(\mathrm{~cm})$ & F1 & F2 & F3 & $\Sigma$ F1 a F3 \\
\hline $0-2$ & $<L Q$ & 1,5065 & 6,6081 & 8,1146 \\
\hline $10-12$ & $<L Q$ & 1,5072 & 7,4632 & 8,9704 \\
\hline $20-22$ & $<L Q$ & 1,2460 & 8,3275 & 9,5735 \\
\hline $30-32$ & $<L Q$ & 1,8574 & 8,8953 & 10,7527 \\
\hline $40-42$ & $<\mathrm{LQ}$ & 1,7754 & 7,2841 & 9,0595 \\
\hline $50-52$ & $<L Q$ & 1,5038 & 7,2586 & 8,7624 \\
\hline
\end{tabular}


Tabela 10. Teor de $\mathrm{Pb}\left(\mathrm{mg} \mathrm{kg}^{-1}\right)$ nas frações móveis ou disponíveis das amostras dos testemunhos coletados ao longo do Sistema Cananéia-Iguape

\begin{tabular}{|c|c|c|c|c|}
\hline CAN $02(\mathrm{~cm})$ & F1 & F2 & F3 & $\Sigma$ F1 a F3 \\
\hline $0-2$ & $<L Q$ & 30,5201 & $<L Q$ & 30,5201 \\
\hline $10-12$ & 5,0566 & 41,0108 & $<L Q$ & 46,0674 \\
\hline $20-22$ & 3,2950 & 30,9881 & $<L Q$ & 34,2831 \\
\hline $30-32$ & 3,9479 & 29,2952 & $<L Q$ & 33,2431 \\
\hline $38-40$ & 7,4987 & 57,5393 & $<L Q$ & 65,0380 \\
\hline $50-52$ & 3,0771 & 45,3125 & $<L Q$ & 48,3896 \\
\hline CAN $04(\mathrm{~cm})$ & F1 & F2 & F3 & $\Sigma$ F1 a F3 \\
\hline $0-1$ & $<L Q$ & 26,7633 & $<L Q$ & 26,7633 \\
\hline $10-11$ & 3,7363 & 27,9648 & $<L Q$ & 31,7011 \\
\hline $20-21$ & 6,3168 & 31,7889 & $<L Q$ & 38,1057 \\
\hline $30-31$ & 4,3408 & 42,5767 & $<L Q$ & 46,9175 \\
\hline $39-40$ & 21,2132 & 152,2530 & 4,0825 & 177,5487 \\
\hline $51-52$ & 2,8008 & 11,4845 & $<L Q$ & 14,2853 \\
\hline CAN $05(\mathrm{~cm})$ & F1 & F2 & F3 & $\Sigma$ F1 a F3 \\
\hline $2-4$ & 3,0588 & 51,8224 & $<L Q$ & 54,8812 \\
\hline $8-10$ & $<L Q$ & 50,9439 & $<L Q$ & 50,9439 \\
\hline $22-24$ & 3,5514 & 99,6434 & 12,3370 & 115,5318 \\
\hline $26-28$ & $<\mathrm{LQ}$ & 36,9628 & 5,5628 & 42,5256 \\
\hline $38-40$ & $<\mathrm{LQ}$ & 21,3173 & 4,7158 & 26,0331 \\
\hline $48-50$ & $<\mathrm{LQ}$ & 27,3568 & 7,0776 & 34,4344 \\
\hline CAN 07 (cm) & F1 & F2 & F3 & $\Sigma$ F1 a F3 \\
\hline $0-2$ & 3,1463 & 31,9352 & $<L Q$ & 35,0815 \\
\hline $10-12$ & 4,7343 & 21,6111 & $<L Q$ & 26,3454 \\
\hline $20-22$ & $<L Q$ & 3,5862 & $<L Q$ & 3,5862 \\
\hline $30-32$ & $<\mathrm{LQ}$ & 4,5666 & $<L Q$ & 4,5666 \\
\hline $38-40$ & $<L Q$ & 3,1674 & $<L Q$ & 3,1674 \\
\hline $50-52$ & $<\mathrm{LQ}$ & 3,0344 & $<L Q$ & 3,0344 \\
\hline CAN $10(\mathrm{~cm})$ & F1 & F2 & F3 & $\Sigma$ F1 a F3 \\
\hline $0-2$ & 4,0537 & 37,4217 & 6,0437 & 47,5192 \\
\hline $10-12$ & 4,3819 & 41,1541 & 7,2785 & 52,8144 \\
\hline $20-22$ & $<L Q$ & 43,7688 & 8,2851 & 52,0539 \\
\hline $30-32$ & 4,9864 & 53,3555 & 8,3211 & 66,6629 \\
\hline $40-42$ & $<\mathrm{LQ}$ & 44,1057 & 6,9865 & 51,0922 \\
\hline $50-52$ & 4,6543 & 43,2118 & 7,1194 & 54,9855 \\
\hline
\end{tabular}


Tabela 11. Teor de $\mathrm{Zn}\left(\mathrm{mg} \mathrm{kg}^{-1}\right)$ nas frações móveis ou disponíveis das amostras dos testemunhos coletados ao longo do Sistema Cananéia-Iguape

\begin{tabular}{|c|c|c|c|c|}
\hline CAN $02(\mathrm{~cm})$ & F1 & F2 & F3 & $\Sigma$ F1 a F3 \\
\hline $0-2$ & 12,7058 & 20,5618 & 4,8089 & 38,0765 \\
\hline $10-12$ & 18,8322 & 25,4277 & 6,2190 & 50,4789 \\
\hline $20-22$ & 15,0018 & 19,3490 & 4,0721 & 38,4229 \\
\hline $30-32$ & 11,1733 & 16,0988 & 3,5135 & 30,7856 \\
\hline $38-40$ & 18,4525 & 16,3018 & 5,3972 & 40,1515 \\
\hline $50-52$ & 12,0043 & 12,4435 & 3,9357 & 28,3835 \\
\hline CAN $04(\mathrm{~cm})$ & F1 & F2 & F3 & $\Sigma$ F1 a F3 \\
\hline $0-1$ & 13,3551 & 17,1771 & 4,3479 & 34,8801 \\
\hline $10-11$ & 16,2861 & 19,6627 & 5,6263 & 41,5751 \\
\hline $20-21$ & 11,3020 & 10,2592 & 3,3077 & 24,8689 \\
\hline $30-31$ & 10,7459 & 10,5330 & 3,5731 & 24,8520 \\
\hline $39-40$ & 63,3969 & 49,9612 & 9,6759 & 123,0340 \\
\hline $51-52$ & 11,6588 & 10,3421 & 4,5495 & 26,5504 \\
\hline CAN $05(\mathrm{~cm})$ & F1 & F2 & F3 & $\Sigma$ F1 a F3 \\
\hline $2-4$ & 15,6366 & 37,8264 & 7,0608 & 60,5238 \\
\hline $8-10$ & 18,3119 & 35,6630 & 6,4900 & 60,4649 \\
\hline $22-24$ & 20,3738 & 30,3356 & 14,9929 & 65,7023 \\
\hline $26-28$ & 14,7345 & 25,5381 & 13,0373 & 53,3099 \\
\hline $38-40$ & 12,6003 & 21,0631 & 13,4021 & 47,0655 \\
\hline $48-50$ & 12,2541 & 20,0963 & 13,1313 & 45,4817 \\
\hline CAN $07(\mathrm{~cm})$ & F1 & F2 & F3 & $\Sigma$ F1 a F3 \\
\hline $0-2$ & 9,3474 & 13,1998 & 3,4062 & 25,9534 \\
\hline $10-12$ & 8,8084 & 6,6439 & 2,6934 & 18,1457 \\
\hline $20-22$ & 2,5249 & 4,4859 & 2,5751 & 9,5859 \\
\hline $30-32$ & 2,3999 & 5,0073 & 2,3314 & 9,7387 \\
\hline $38-40$ & 1,8008 & 4,9663 & 2,3732 & 9,1403 \\
\hline $50-52$ & 2,0460 & 5,7266 & 4,0027 & 11,7753 \\
\hline CAN $10(\mathrm{~cm})$ & F1 & F2 & F3 & $\Sigma$ F1 a F3 \\
\hline $0-2$ & 10,7260 & 21,6159 & 11,9070 & 44,2489 \\
\hline $10-12$ & 10,2740 & 23,4440 & 12,5397 & 46,2577 \\
\hline $20-22$ & 10,6414 & 22,6649 & 12,1756 & 45,4819 \\
\hline $30-32$ & 11,2512 & 25,1110 & 12,2905 & 48,6527 \\
\hline $40-42$ & 9,6193 & 22,0855 & 10,9298 & 42,6346 \\
\hline $50-52$ & 8,6385 & 21,9967 & 11,6689 & 42,3041 \\
\hline
\end{tabular}


FIGURAS 


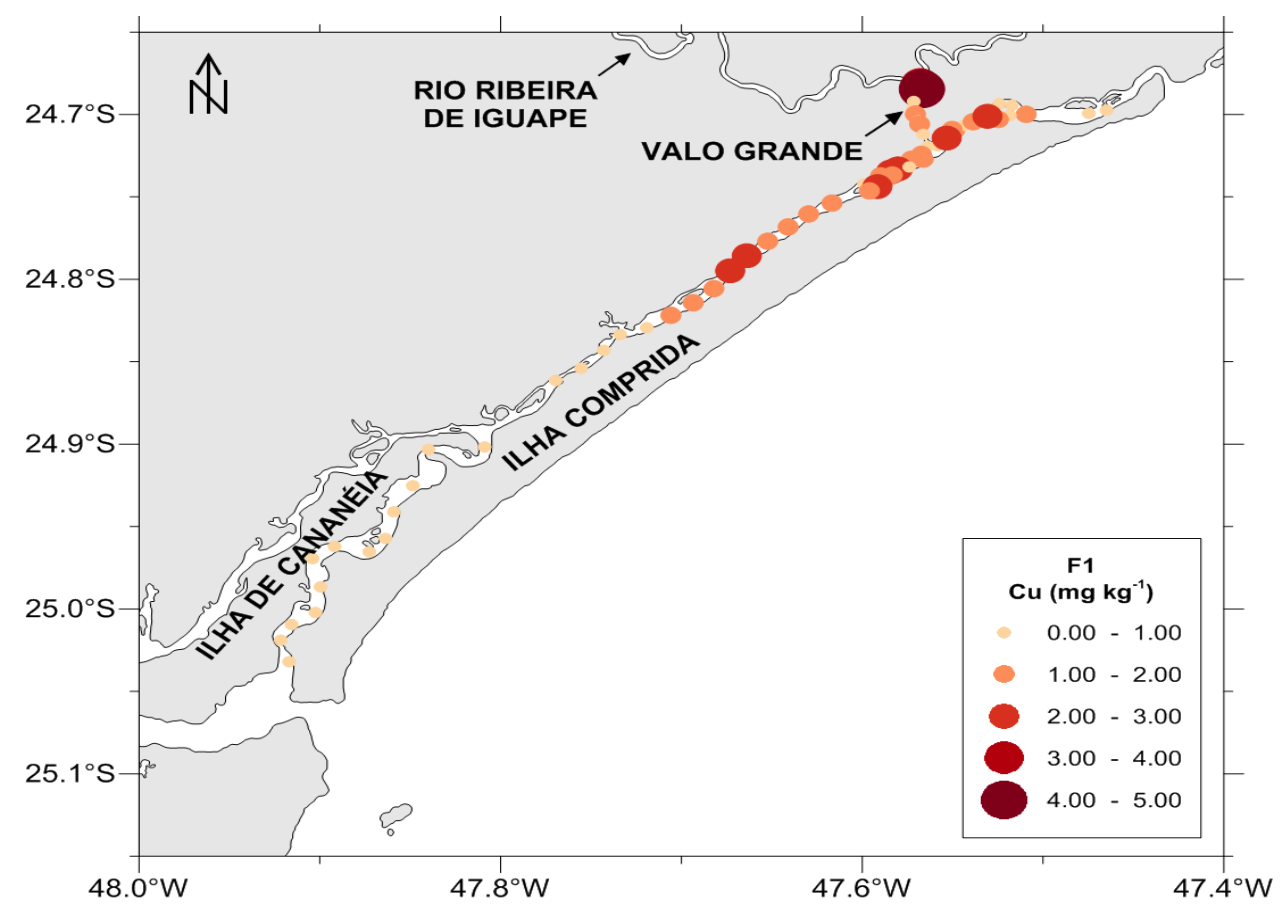

Figura 1. Teor de $\mathrm{Cu}\left(\mathrm{mg} \mathrm{kg}^{-1}\right)$ na fração solúvel em ácido (F1) nas amostras superficiais coletadas ao longo do Sistema Cananéia-Iguape.

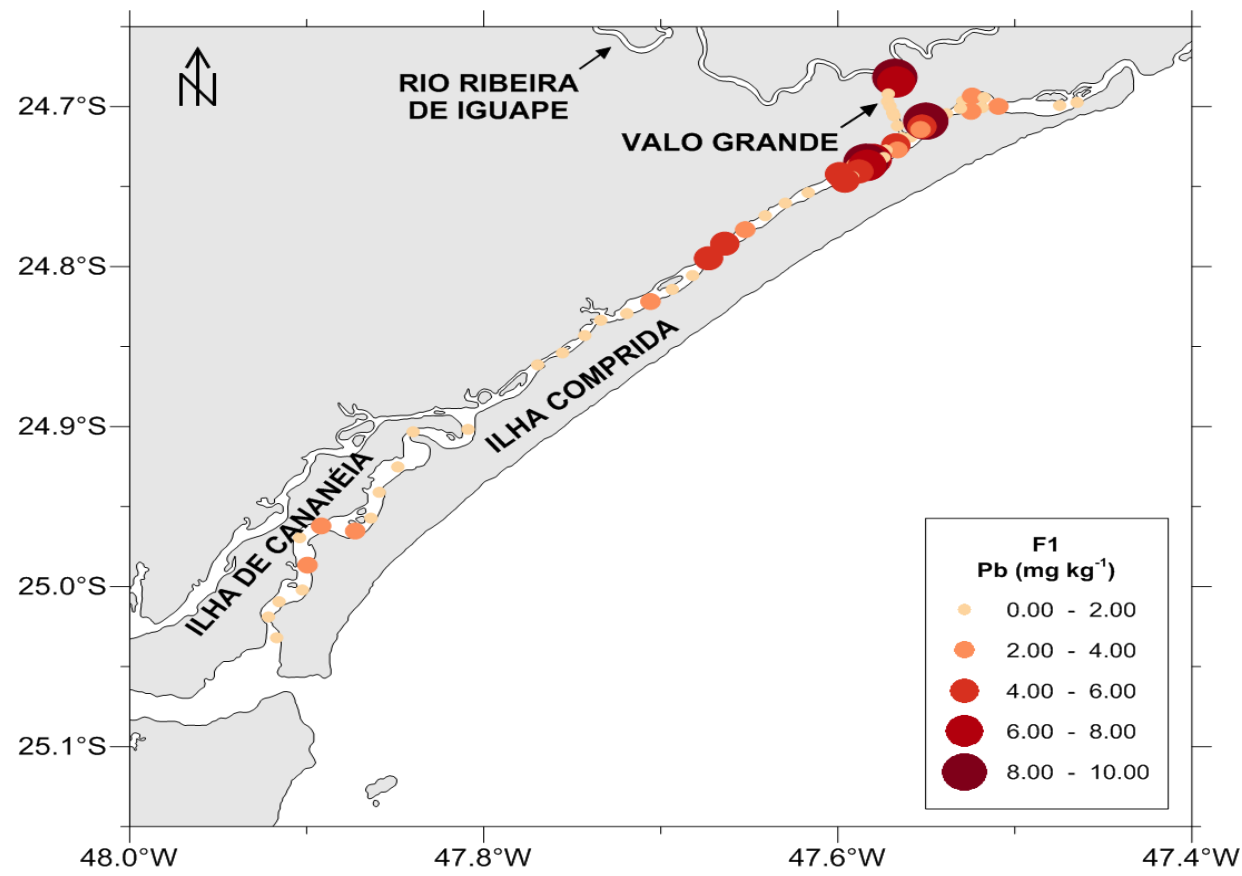

Figura 2. Teor de $\mathrm{Pb}\left(\mathrm{mg} \mathrm{kg}^{-1}\right)$ na fração solúvel em ácido (F1) nas amostras superficiais coletadas ao longo do Sistema Cananéia-Iguape. 


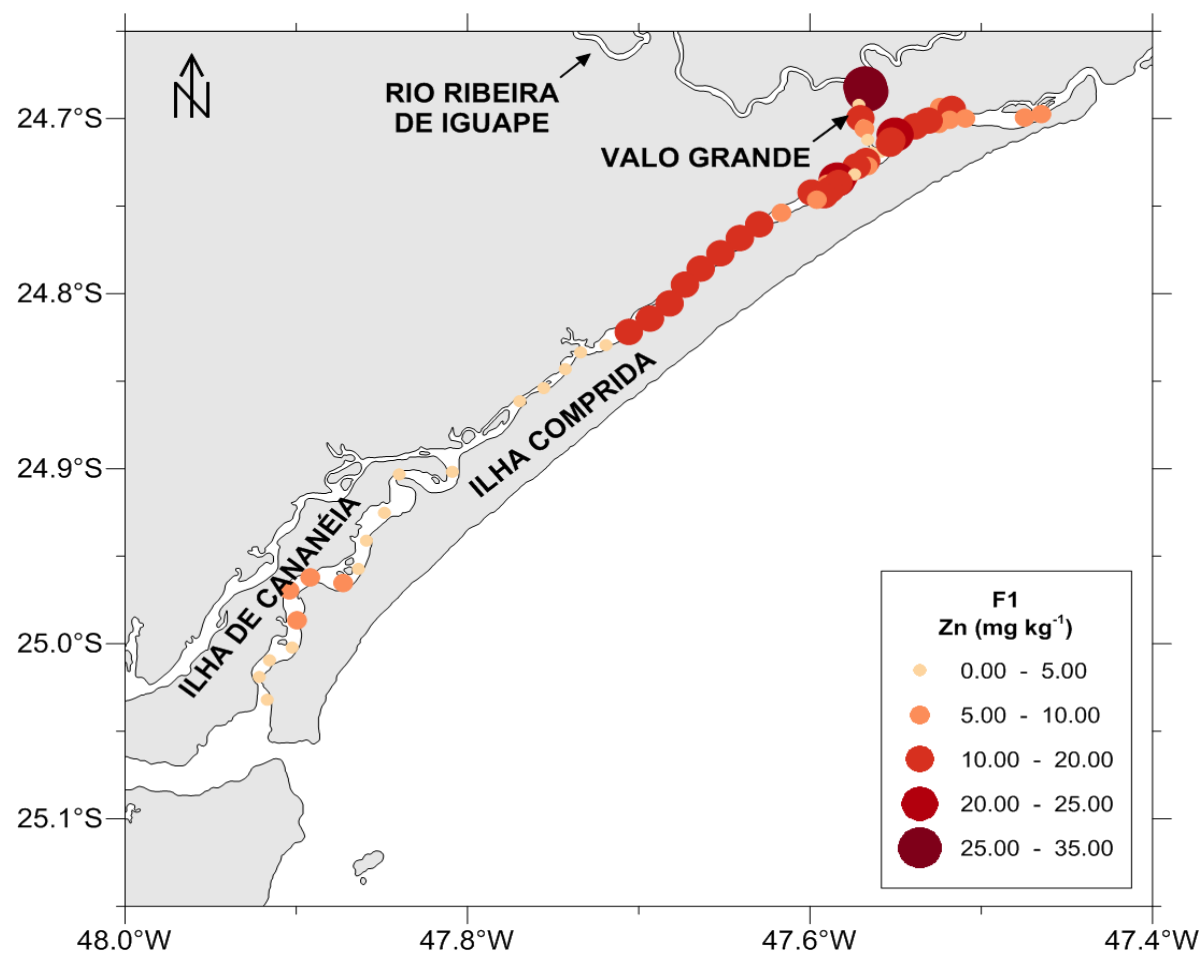

Figura 3. Teor de $\mathrm{Zn}\left(\mathrm{mg} \mathrm{kg}^{-1}\right)$ na fração solúvel em ácido (F1) nas amostras superficiais coletadas ao longo do Sistema Cananéia-Iguape.

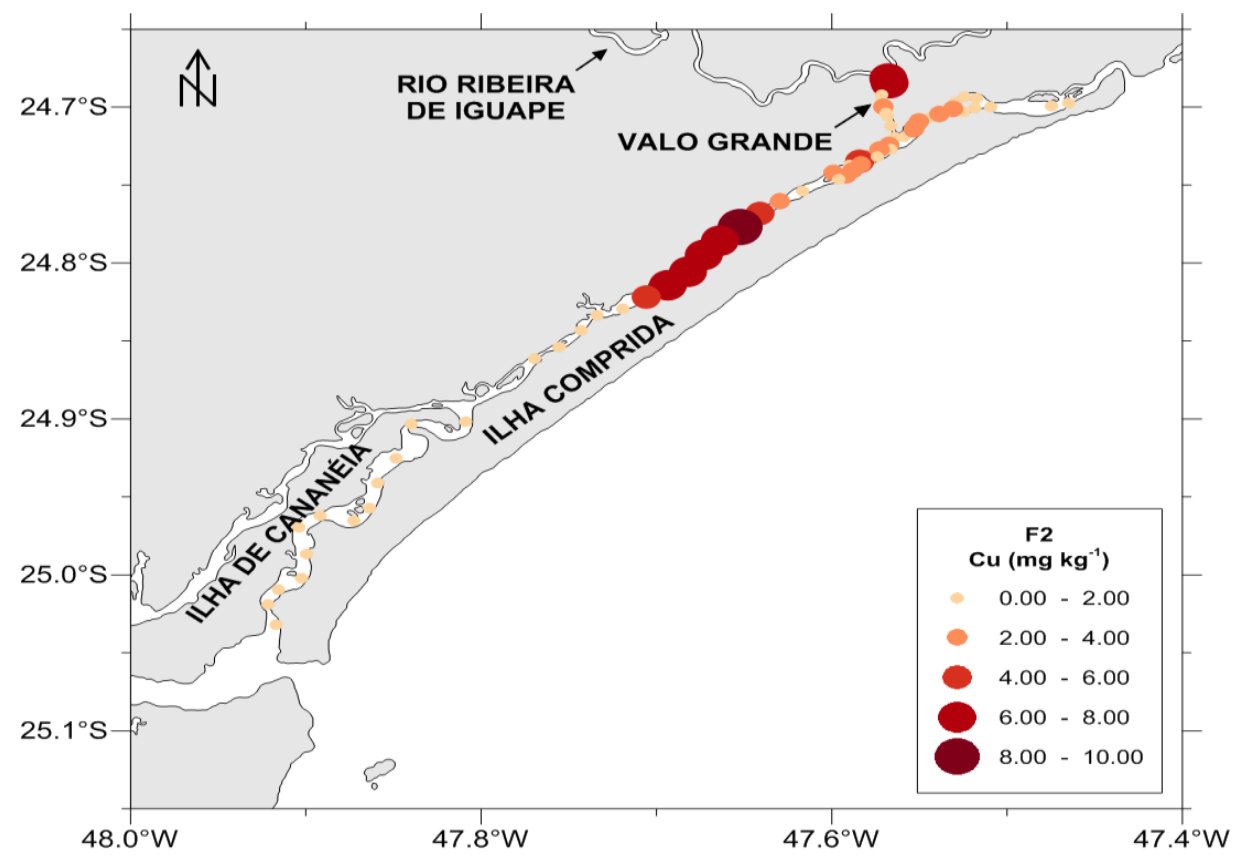

Figura 4. Teor de $\mathrm{Cu}\left(\mathrm{mg} \mathrm{kg}^{-1}\right)$ na fração redutível (F2) nas amostras superficiais coletadas ao longo do Sistema Cananéia-Iguape. 


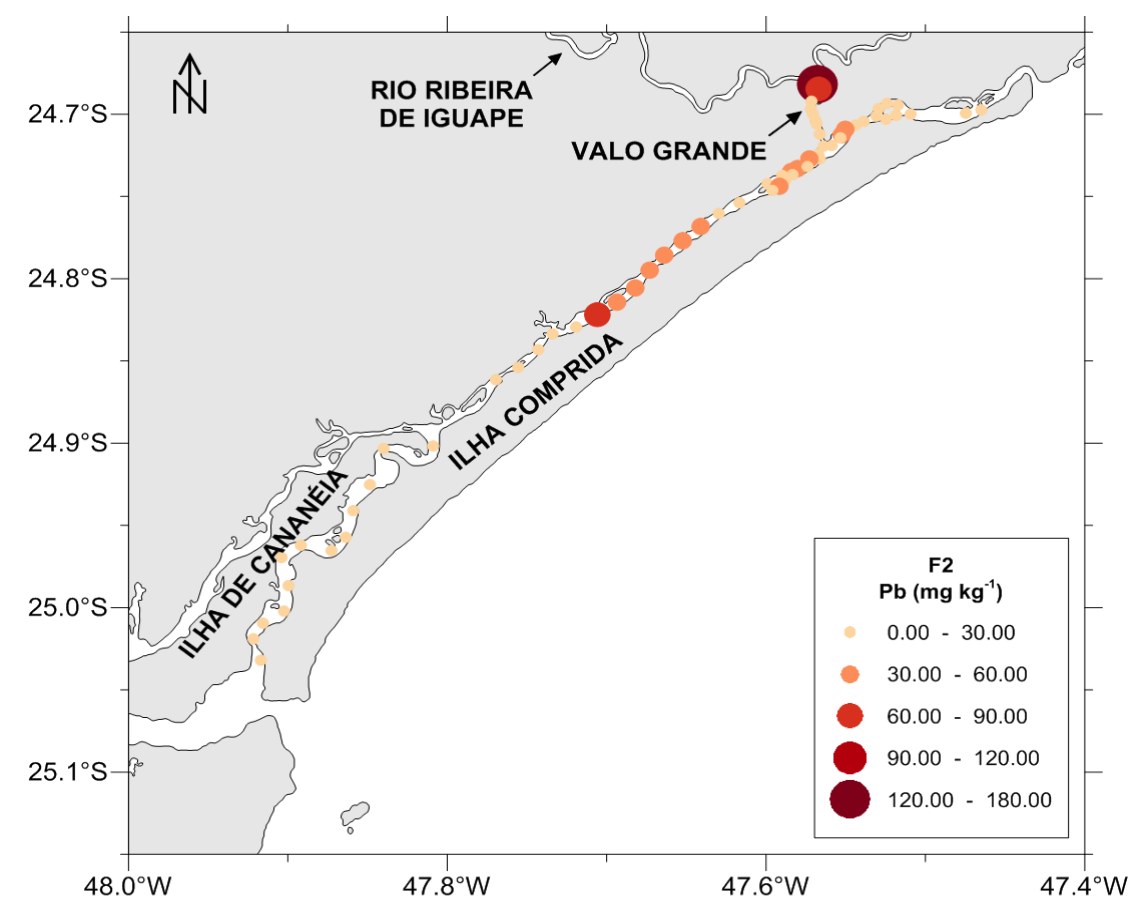

Figura 5. Teor de $\mathrm{Pb}\left(\mathrm{mg} \mathrm{kg}^{-1}\right)$ na fração redutível (F2) nas amostras superficiais coletadas ao longo do Sistema Cananéia-Iguape.

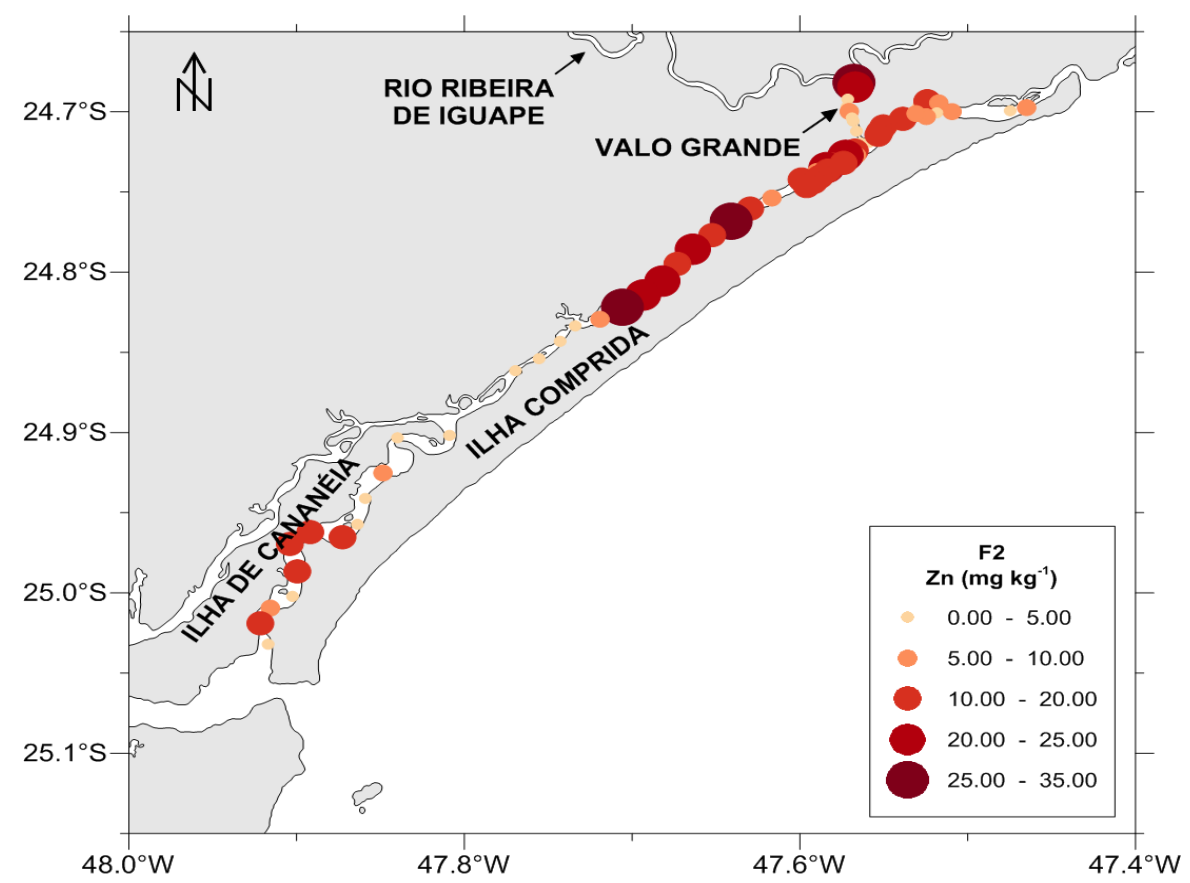

Figura 6. Teor de $\mathrm{Zn}\left(\mathrm{mg} \mathrm{kg}^{-1}\right)$ na fração redutível (F2) nas amostras superficiais coletadas ao longo do Sistema Cananéia-Iguape. 


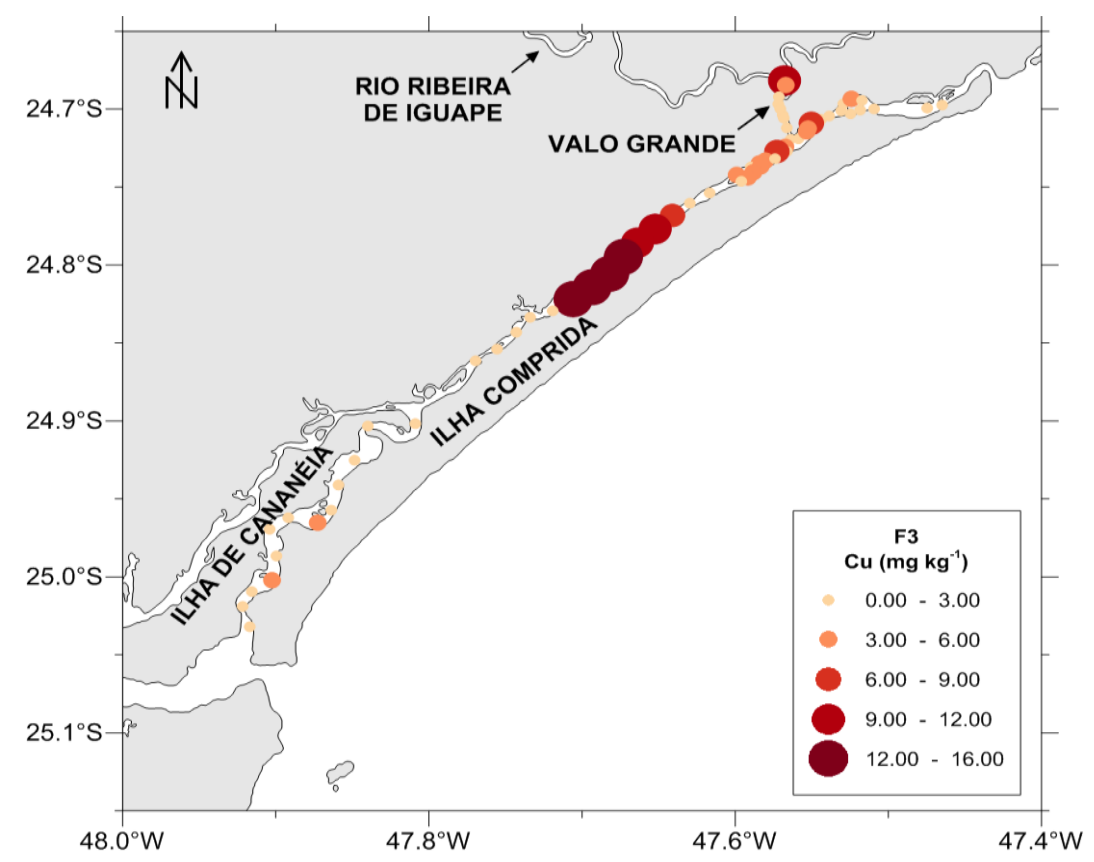

Figura 7. Teor de $\mathrm{Cu}\left(\mathrm{mg} \mathrm{kg}^{-1}\right)$ na fração oxidável (F3) nas amostras superficiais coletadas ao longo do Sistema Cananéia-Iguape.

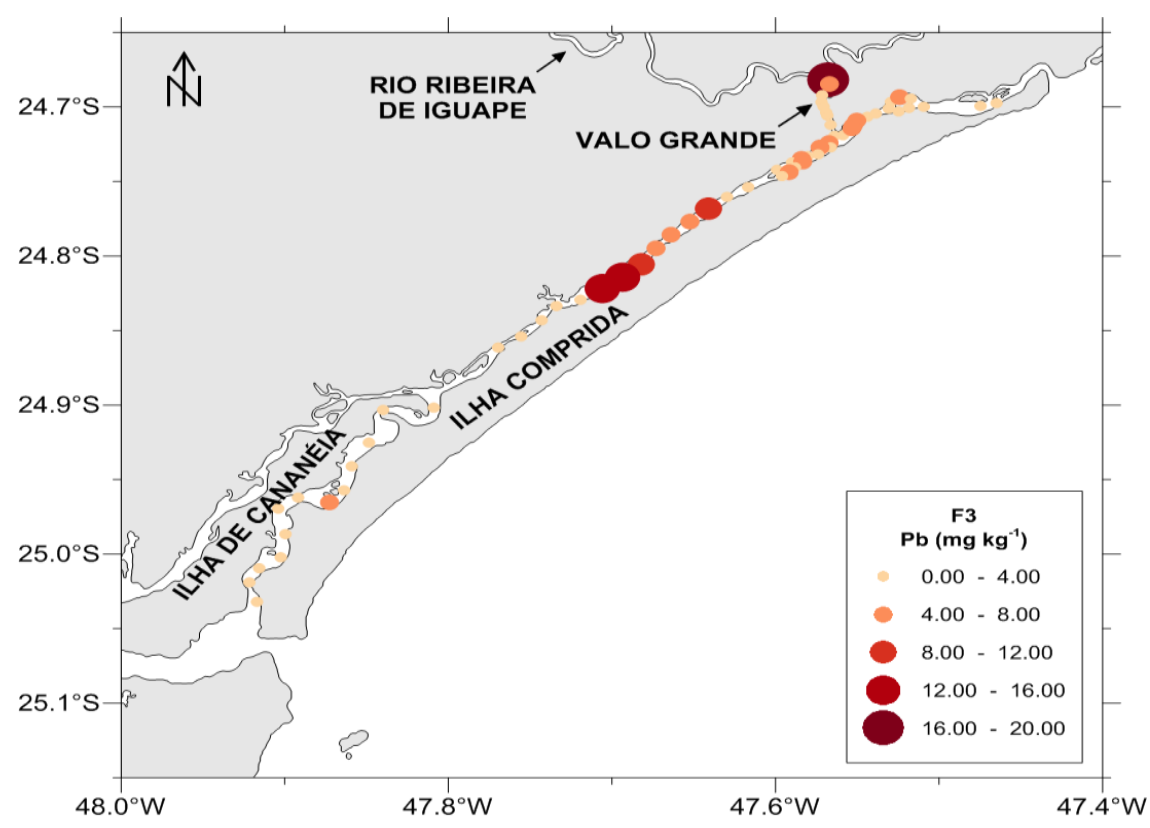

Figura 8. Teor de $\mathrm{Pb}\left(\mathrm{mg} \mathrm{kg}^{-1}\right)$ na fração oxidável (F3) nas amostras superficiais coletadas ao longo do Sistema Cananéia-lguape. 


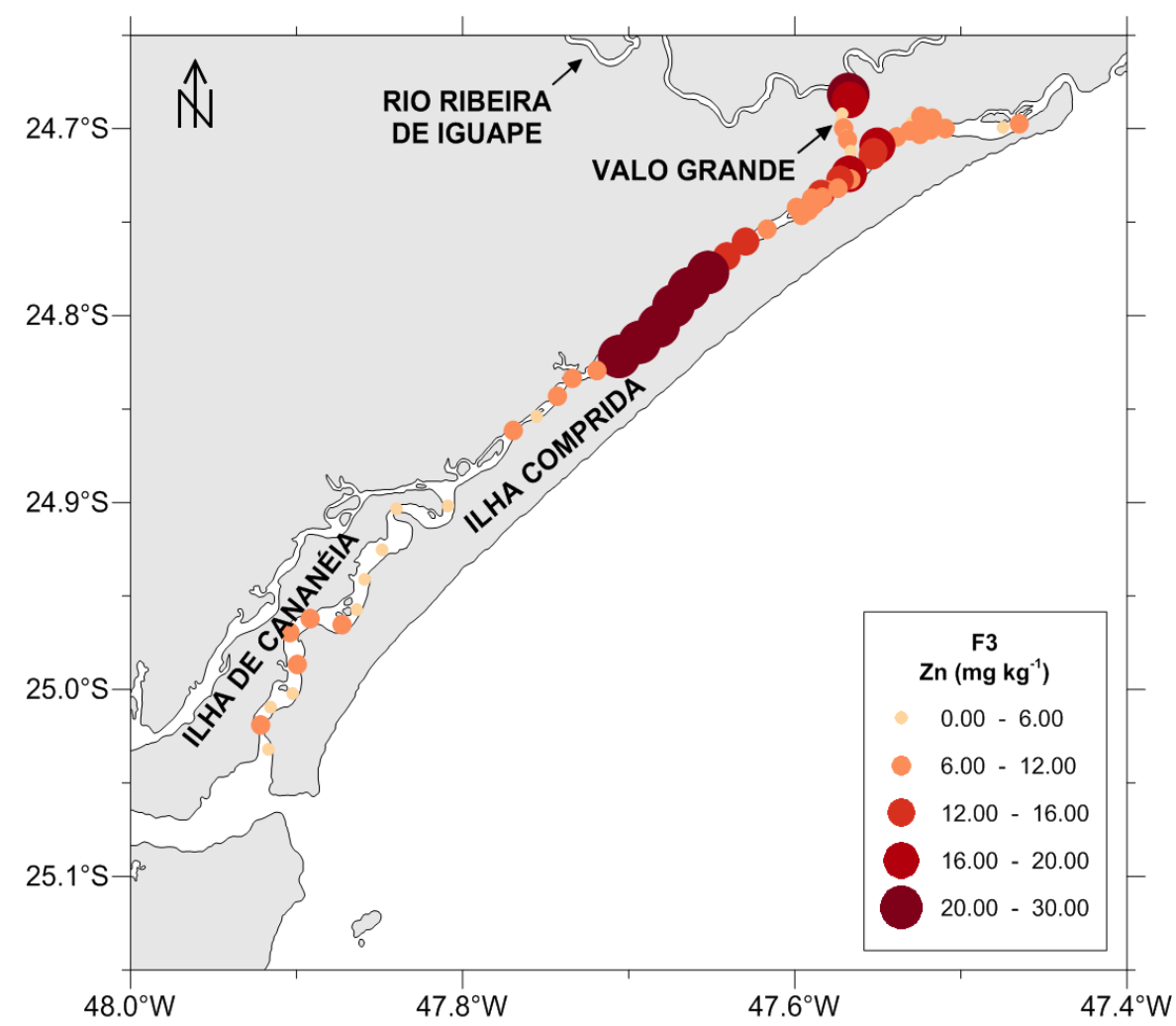

Figura 9. Teor de $\mathrm{Zn}\left(\mathrm{mg} \mathrm{kg}^{-1}\right)$ na fração oxidável (F3) nas amostras superficiais coletadas ao longo do Sistema Cananéia-Iguape. 